\title{
WestVirginiaUniversity
}

THE RESEARCH REPOSITORY @ WVU

Graduate Theses, Dissertations, and Problem Reports

2009

\section{Modeling issues for solid oxide fuel cells operating with coal syngas}

Francisco Elizalde-Blancas
West Virginia University

Follow this and additional works at: https://researchrepository.wvu.edu/etd

\section{Recommended Citation}

Elizalde-Blancas, Francisco, "Modeling issues for solid oxide fuel cells operating with coal syngas" (2009). Graduate Theses, Dissertations, and Problem Reports. 2896.

https://researchrepository.wvu.edu/etd/2896

This Dissertation is protected by copyright and/or related rights. It has been brought to you by the The Research Repository @ WVU with permission from the rights-holder(s). You are free to use this Dissertation in any way that is permitted by the copyright and related rights legislation that applies to your use. For other uses you must obtain permission from the rights-holder(s) directly, unless additional rights are indicated by a Creative Commons license in the record and/ or on the work itself. This Dissertation has been accepted for inclusion in WVU Graduate Theses, Dissertations, and Problem Reports collection by an authorized administrator of The Research Repository @ WVU.

For more information, please contact researchrepository@mail.wvu.edu. 


\title{
Modeling Issues for SOlid OXIDE Fuel CELlS OPERATING WITH COAL SYNGAS
}

\author{
Francisco Elizalde-Blancas
}

\author{
Dissertation submitted to the \\ College of Engineering and Mineral Resources \\ at West Virginia University \\ in partial fulfillment of the requirements \\ for the degree of \\ Doctor of Philosophy \\ in \\ Mechanical Engineering \\ Ismail Celik, Ph.D., Chair \\ Randall Gemmen, Ph.D. \\ Harry Finklea, Ph.D. \\ John Zondlo, Ph.D. \\ Nianqiang Wu, Ph.D.
}

Department of Mechanical and Aerospace Engineering

Morgantown, West Virginia

2009

Keywords: Fuel Cells, SOFC, Coal Syngas, Internal Reforming, Simultaneous Oxidation, Electrochemistry, Reaction Mechanism

Copyright 2009 Francisco Elizalde-Blancas 


\section{Abstract}

\section{MODELING ISSUES FOR SOLID OXIDE FUEL CELLS OPERATING WITH COAL SYNGAS}

\section{Francisco Elizalde-Blancas}

Fuel cells which directly convert the chemical energy into electricity are considered one of the most promising technologies to support energy needs in the near future. Solid Oxide Fuel Cells (SOFC) can run with alternative fuels such as synthesis coal gas due to their high operating temperature. Utilization of coal syngas in fuel cells would enable cleaner coal energy. A better understanding of the chemical and transport processes when running on syngas will allow researchers to find solutions to problems currently delaying the introduction of the technology into the market. A comprehensive modeling tool is developed for simulation of SOFCs operating on a wide range of fuel mixtures such as syngas, natural gas, etc. The new code takes into account the methane reforming and water gas shift reactions occurring on a common Ni-YSZ electrode using two alternative mechanisms namely, a global mechanism and a detailed surface mechanism. Simultaneous electrochemical oxidation of hydrogen and carbon monoxide at the anode-electrolyte active interface is accounted for using a new electrochemistry model. Model validation was performed by comparing the results with data published in the literature and available experimental data obtained at West Virginia University. Also, the associated numerical uncertainty was assessed and found that this was small in general, except for the ohmic heating. A parametric analysis considering the effect of temperature, fuel composition, and activation overpotential parameters for carbon monoxide oxidation was also performed. It was found that the increase of cell performance with temperature increase was caused by a decrease in all the overpotentials. The cell performance also increases when the concentration of the fuel in the anode stream increases. The operating temperature, as well as the composition of the fuel stream have a significant effect on the direction of the water gas shift reaction as well as on the current supported by hydrogen and carbon monoxide. However, when the ratio of hydrogen concentration to carbon monoxide concentration is kept constant, the splitting of the total current between these two fuels is not affected considerably. The cell showed one limiting current even when two fuels, hydrogen and carbon monoxide, are directly and simultaneously oxidized irrespective of the inlet composition. The new computational tool is applied to a more realistic case of planar SOFC with a surface of circa $100 \mathrm{~cm}^{2}$. 


\title{
Dedicated to
}

\section{My parents \\ "Because of them I am who I am"}

\author{
Dedicada a \\ Mis padres \\ "Por ellos soy lo que soy"
}




\section{ACKNOWLEDGMENTS}

I would like to deeply and sincerely thank my advisor Dr. Ismail Celik for the immense opportunity to work with him for the last four years of my life, for sharing his knowledge, experience and good judgment in research activities and for all the moral and financial support received during this great experience as a Doctoral student in a foreign country. Also I would like to thank Dr. Ever Barbero who played an important role in making my decision to enroll in the graduate program at West Virginia University. At the same time I want to thank all the faculty and staff who served and helped me during my doctoral studies at West Virginia University, particularly those from the Department of Mechanical and Aerospace Engineering. I am also grateful to Department of Energy Basic Energy Science (DOE BES), National Energy Technology Laboratoty (NETL), West Virginia ESPCoR program, West Virginia University and Carnegie Mellon Univeristy for funding this work.

Especially I want to express my gratefulness to my committee members: Dr. Randall Gemmen, Dr. Harry Finklea, Dr. John Zondlo and Dr. Nick Wu for their time, cooperation, contribution and valuable discussions. I would like to thank Dr. Chunchuan Xu for his collaboration by sharing the experimental data, very valued and important information used in my research. A remarkable mention is deserved by Dr. Raju Pakalapati for his technical support and guidance with his always useful and proper suggestions and equally important for his friendship offered unconditionally from the very beginning of my studies. I do not want to miss the chance to thank all the professors from whom I was educated during my doctoral studies.

Throughout the tough and long journey of my doctoral studies, I was fortunate to share

professional and personal experiences with the members of the CFD lab: Dr. Raju Pakalapati, Dr. Jaggu Nanduri, Dr. Ibrahim Yavuz, Cem, Ertan, Nihan, Fito, John, Don, and Jose from whom I received advice, support and unconditional friendship during hard, stressful and happy moments. I want to express my deep gratefulness to my friends Omar, Marlene, Eduardo, Charlotte, Julio, Hermann, Paty and Rachael who made me feel like at 
home and helped me to diminish the loneliness and sadness of being far away from my loved family.

Finally I want to express my incommensurable love to my family for their unconditional support and love that made me feel physically close to them even though I have been hundreds of miles away from home and also for being the motivation to reach this dream that became true. Without you, this would not have been possible. 


\section{CONTENTS}

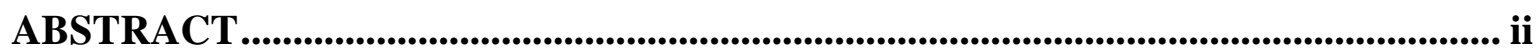

LIST OF FIGURES .................................................................................................................. ix

LIST OF TABLES .............................................................................................................

NOMENCLATURE..............................................................................................

Chapter 1 INTRODUCTION......................................................................................................1

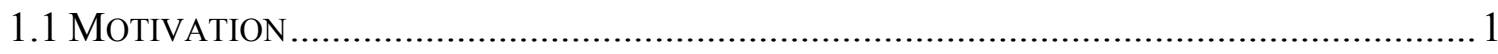

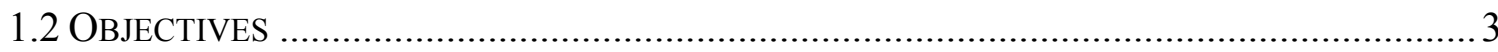

Chapter 2 LITERATURE REVIEW ......................................................................................4

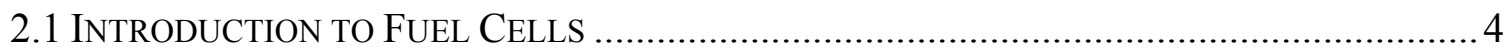

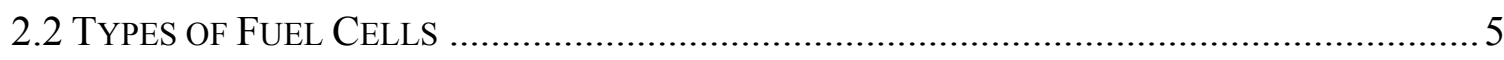

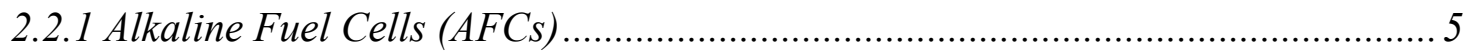

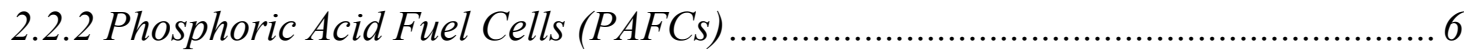

2.2.3 Proton Exchange Membrane Fuel Cells (PEMFCs) ......................................... 6

2.2.4 Direct Carbon Fuel Cells (DCFCs)................................................................. 7

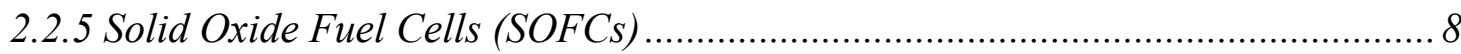

2.2.6 Molten Carbonate Fuel Cells (MCFCs) ............................................................ 9

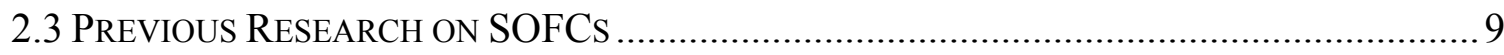

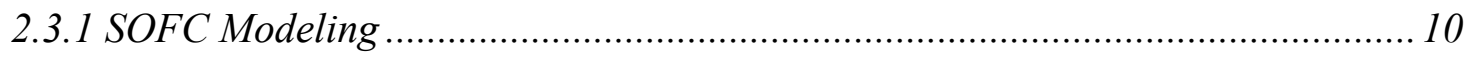

2.3.1.1 Zero-Dimensional Models ........................................................................... 11

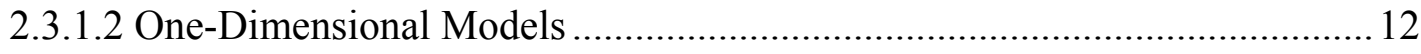

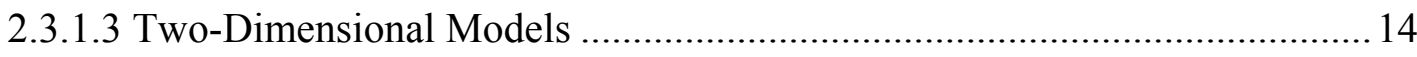

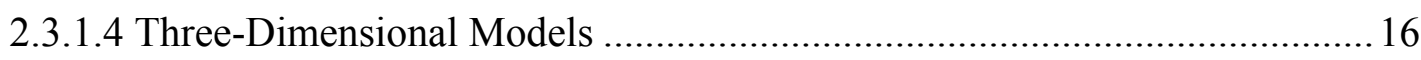

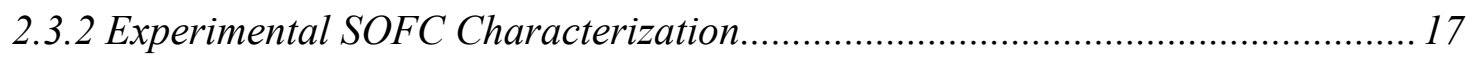

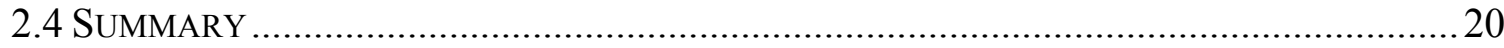

Chapter 3 COMPUTATIONAL MODEL .........................................................................21

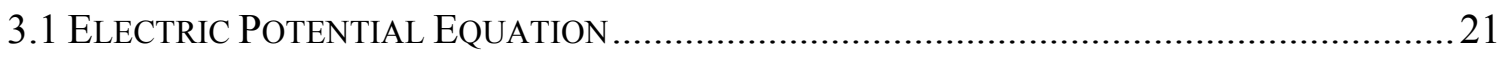

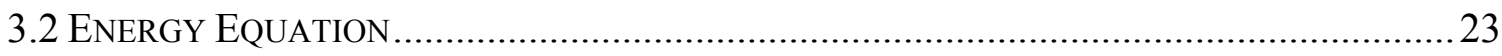




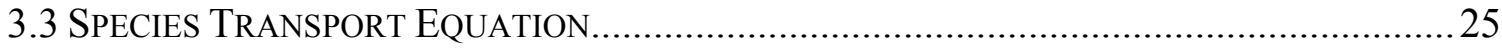

Chapter 4 COMPUTATIONAL SUB-MODELS.................................................................28

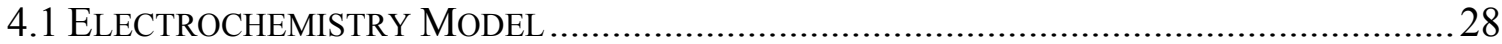

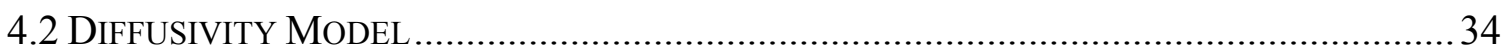

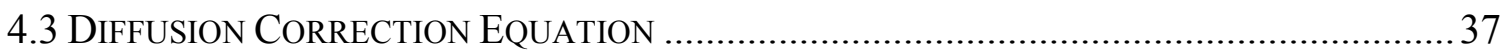

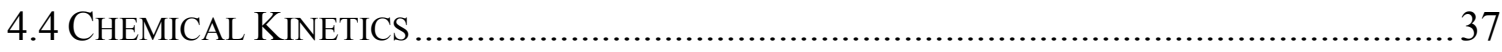

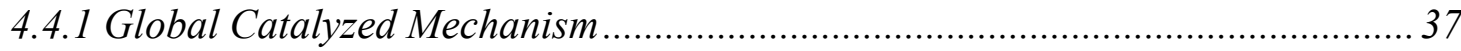

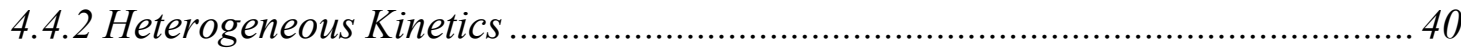

4.6 ELECTRICAL/ELECTRONIC CONDUCTIVITIES........................................................... 43

Chapter 5 VERIFICATION AND VALIDATION..............................................................45

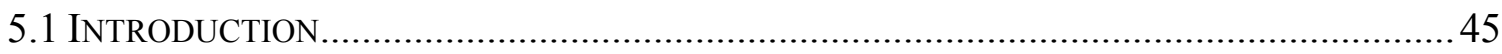

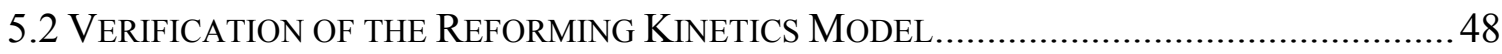

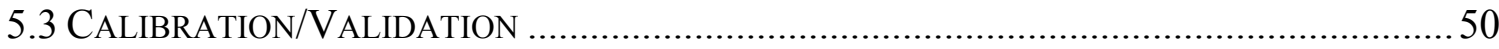

5.4 ANalysis of the Button Cell Operating on Simulated Clean Syngas ............55

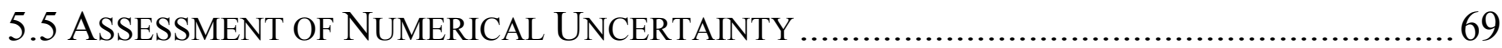

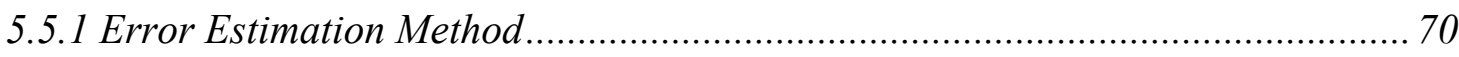

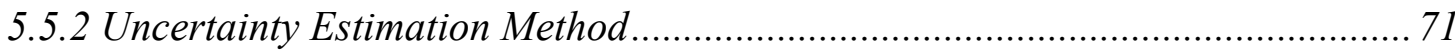

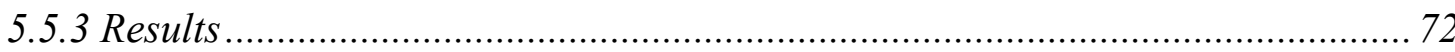

Chapter 6 PARAMETRIC ANALYSIS..........................................................................78

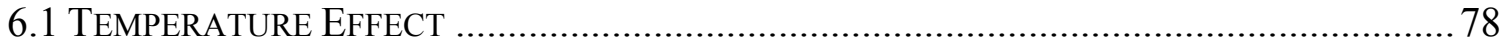

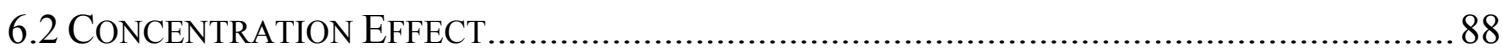

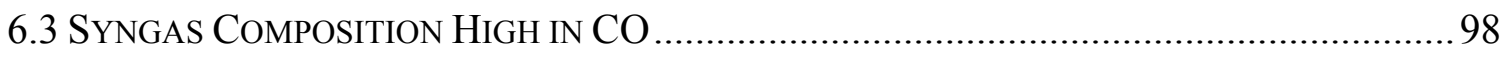

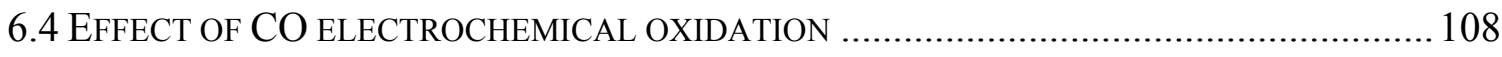

6.5 EFFect of Activation ENERgy IN THE EXChange CurRent of CO........................ 112

Chapter 7 PLANAR CELL OPERATING ON METHANE ..........................................119

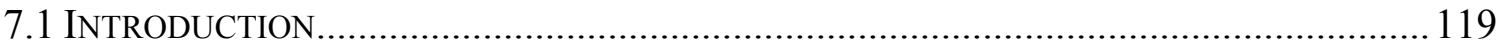

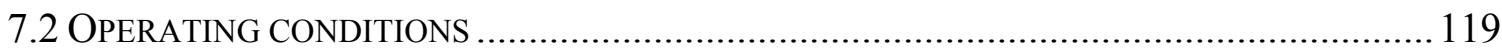

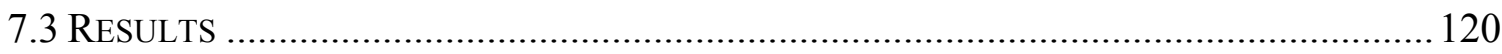


Chapter 8 CONCLUSIONS AND FUTURE WORK .....................................................131

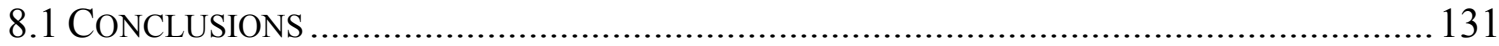

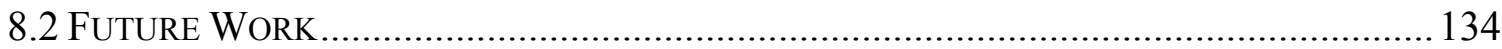

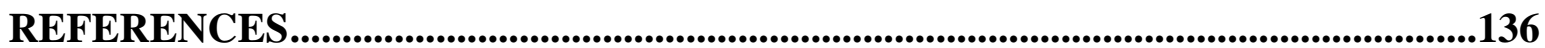

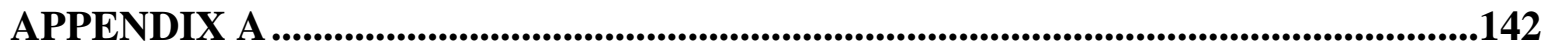




\section{LIST OF FIGURES}

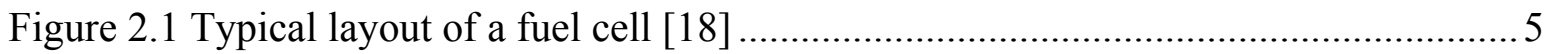

Figure 5.1 Sketch of the computational domain of the simulated button cell ................... 46

Figure 5.2 Nusselt and Sherwood dimensionless numbers used at the gas-electrode

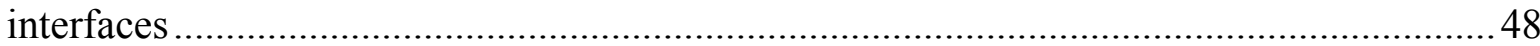

Figure 5.3 Comparison of the present model net production rates with those reported in literature

Figure 5.4 Experimentally obtained time variation of the cell voltage of a button cell running on coal syngas at $800^{\circ} \mathrm{C}$ and supporting a load of $0.5 \mathrm{~A} / \mathrm{cm}^{2}$ 50

Figure 5.5 Experimental error bars of a button cell running on coal syngas at $800^{\circ} \mathrm{C} \ldots \ldots . . .51$

Figure 5.6 Validation of the computational model through the V-I and power density curves; cell running on syngas at $800^{\circ} \mathrm{C}$ 52

Figure 5.7 Performance of a button cell running on wet hydrogen at $800^{\circ} \mathrm{C}$ 53

Figure 5.8 Mass fraction profile along the thickness of the anode for base case (a) $\mathrm{H}_{2}$, (b) $\mathrm{CO},(\mathrm{c}) \mathrm{H}_{2} \mathrm{O}$ and (d) $\mathrm{CO}_{2}$ of a button cell operating on clean syngas

Figure 5.9 Species concentrations at the electrode-electrolyte interfaces of a button cell for the base case, (a) mole fractions and (b) mass fractions 59

Figure 5.10 Oxygen mass fraction profiles along the thickness of the cathode of a button cell operating on syngas .60

Figure 5.11 Overpotentials of a cell operating on clean syngas 61

Figure 5.12 Net molar production rates inside the anode for (a) $\mathrm{H}_{2}$, (b) $\mathrm{CO}$, (c) $\mathrm{H}_{2} \mathrm{O}$ and (d) $\mathrm{CO}_{2}$ of a button cell operating on coal syngas 64 
Figure 5.13 Net molar production rate of methane inside the anode of a button cell operating on coal syngas...... 65

Figure 5.14 Predicted $\mathrm{H}_{2}$ and $\mathrm{CO}$ currents in a button cell operating on syngas (a) splitting of the total current and (b) ratio between $\mathrm{H}_{2}$ and $\mathrm{CO}$ current. .66

Figure 5.15 Variation of the (a) maximum change in cell temperature and (b) heat sources for a cell operating on clean syngas .68

Figure 5.16 Estimated error bars using AES method for (a) cell potential, (b) cell maximum temperature, (c) oxygen mass fraction at the cathode-electrolyte interface, (d) hydrogen activation overpotential, (e) entropic heat, and (f) ohmic heat. .76

Figure 6.1 Predicted performance of a button cell running on syngas at different operating temperatures. .79

Figure 6.2 Overpotentials of a button cell operating at different temperatures; (a) hydrogen activation, (b) oxygen activation, (c) ohmic and (d) concentration .81

Figure 6.3 Ratio between the current supported by $\mathrm{H}_{2}$ and $\mathrm{CO}$ at different operating temperatures .82

Figure 6.4 Overall heat generation from WGSR at different operating temperatures 83

Figure 6.5 Heat generation at different operating temperatures; (a) ohmic heat and (b) entropic heat .84

Figure 6.6 Cell temperature change $\left(\mathrm{T}_{\text {cell }}-\mathrm{T}_{\mathrm{op}}\right)$ at different operating temperatures. .85

Figure 6.7 Molar fractions at the anode-electrolyte interface for (a) hydrogen and (b) carbon monoxide .86

Figure 6.8 Mass fractions at the anode-electrolyte interface for (a) hydrogen and (b) carbon monoxide. .87 
Figure 6.9 Predicted performance of a button cell at different fuel compositions; $\mathrm{T}_{\mathrm{op}}=800^{\circ} \mathrm{C}$

.88

Figure 6.10 Overpotentials of a button cell operating at different fuel compositions; (a) CO activation, (b) oxygen activation, (c) concentration and (d) ohmic

Figure 6.11 Ratio of $\mathrm{H}_{2}$ current to $\mathrm{CO}$ current at different syngas compositions; $\mathrm{T}_{\mathrm{op}}=800^{\circ} \mathrm{C}$ 92

Figure 6.12 Overall heat generation from (a) WGSR and (b) MRR at different syngas compositions .93

Figure 6.13 Overall heat generation in a button cell operating at different fuel compositions; (a) entropic heat and (b) ohmic heat 95

Figure 6.14 Cell temperature change $\left(\mathrm{T}_{\text {cell- }}-\mathrm{T}_{\mathrm{op}}\right)$ at different syngas compositions 96

Figure 6.15 Mass fraction profiles along the thickness of the anode for a button cell operating on $30 \%$ pre-reformed methane (a) $\mathrm{H}_{2}$, (b) $\mathrm{CO}$, (c) $\mathrm{CH}_{4}$ and (d) $\mathrm{H}_{2} \mathrm{O}$ 98

Figure 6.16 Predicted V-I and power density curves for the button cell running on equilibrium and non-equlibrium syngas concentrations .99

Figure 6.17 Overpotentials of a button cell operating on equilibrium and non-equilibrium syngas compositions; (a) carbon monoxide activation, (b) oxygen activation, (c) concentration and (d) ohmic

Figure 6.18 Cell temperature change during cell operation on syngas at equilibrium and non-equilibrium concentrations 103

Figure 6.19 Overall heat sources in a button cell operating at equilibrium and nonequilibrium syngas composition; (a) WGSR, (b) MRR, (c) entropic and (d) ohmic 105

Figure 6.20 Ratio of the current supported by hydrogen to the current supported by carbon monoxide at equilibrium and non-equilibrium syngas composition 106 
Figure 6.21 Concentration of hydrogen and carbon monoxide at the anode-electrolyte interface of a button cell opearting at equilibrium and non-equilibrium syngas composition; (a) mole fractions and (b) mass fractions.

Figure 6.22 Carbon monoxide mass fraction profile along the thickness of the anode on a button cell operating at $800^{\circ} \mathrm{C}$ on syngas with high $\mathrm{CO}$ concentration 108

Figure 6.23 Predicted V-I and power density curves for the button cell operating on coal syngas with and without $\mathrm{CO}$ oxidation

Figure 6.24 Overall heat from the water gas shift reaction when carbon monoxide oxidation is neglected. 110

Figure 6.25 Carbon monoxide concentration at the center of the anode/electrolyte interface when electrochemical oxidation of $\mathrm{CO}$ is considered and neglected; (a) mole fraction and (b) mass fraction 111

Figure 6.26 Effect on cell performance of activation energy in carbon monoxide exchange current at different operating temperatures.

Figure 6.27 Change in carbon monoxide activation overpotential by considering activation energy in its exchange current 114

Figure 6.28 Change in heat generation rate from WGSR by considering activation energy in carbon monoxide exchange current

Figure 6.29 Change in cell temperature increase by considering activation energy in carbon monoxide exchange current 115

Figure 6.30 Change in the hydrogen current to carbon monoxide current ratio by considering activation energy in carbon monoxide exchange current 116

Figure 7.1 Sketch of the planar cell showing only three channels 120

Figure 7.2 Mass fraction contours at the anode-electrolyte interface for (a) hydrogen, (b) carbon monoxide and (c) methane. 
Figure 7.3 Mass fraction contours of oxygen at the cathode-electrolyte interface 122

Figure 7.4 Contours of activation overpotentials at the electrode-electrolyte interface for (a) hydrogen oxidation, (b) carbon monoxide oxidation and (c) oxygen reduction. 124

Figure 7.5 Hydrogen activation overpotential along the width of the cell at the middle of the cell 125

Figure 7.6 Temperatures contours at the anode electrolyte interface of a planar cell running on $30 \%$ pre-reformed methane at $1073 \mathrm{~K}\left(800^{\circ} \mathrm{C}\right)$ 126

Figure 7.7 Temperature of the cell components in a plane that passes through one of the center channels along the cell flow direction. 127

Figure 7.8 Temperature contours along the flow direction and thickness of the cell (a) in a plane through a center channel and (b) in a plane through the center rib 128

Figure 7.9 Current density $\left(\mathrm{A} / \mathrm{cm}^{2}\right)$ distributions at the anode-electrolyte interface supported by (a) hydrogen and (b) carbon monoxide. 129

Figure 7.10 Ratio of the hydrogen current to the carbon monoxide current at the anodeelectrolyte interface 130

Figure A. 1 Time variation along the thickness of the anode of (a) Ni coverage and (b) cell temperature 144

Figure A.2 Coverages of the main surface species along the thickness of the anode of a button cell operating on simulated clean syngas at $\mathrm{t}=1.0 \mathrm{~s}$. 145

Figure A.3 Two-dimensional distributions of surface coverages at $t=1.0$ s for (a) $\mathrm{Ni}$, (b) $\mathrm{H}$, (c) $\mathrm{CO}$ and (d) $\mathrm{O}$ 146

Figure A.4 Splitting of the total current between current supported by hydrogen and carbon monoxide using a detailed surface reaction mechanism 147 
Figure A.5 Predicted performance of a button cell operating on coal syngas at $800^{\circ} \mathrm{C}$ using a detailed surface reaction mechanism ................................................................... 148 


\section{LIST OF TABLES}

Table 4.1 Parameters used in the electrochemistry model........................................... 34

Table 4.2 Lennard-Jones potentials for species considered in this work [45] ................... 36

Table 4.3 Constants used for modeling of the temperature dependant electrical

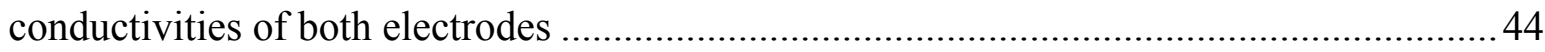

Table 5.1 Geometrical parameters of the button cell components [37] ...........................46

Table 5.2 Area specific resistance of each layer of the button cell at $800^{\circ} \mathrm{C} \ldots \ldots \ldots \ldots \ldots \ldots \ldots . . . . . . . .47$

Table 5.3 Fuel composition used for verification of the reforming model [21] ................49

Table 5.4 Composition of the clean syngas fuel stream ............................................... 55

Table 5.5 Number of computational cells used in the three grids to assess numerical

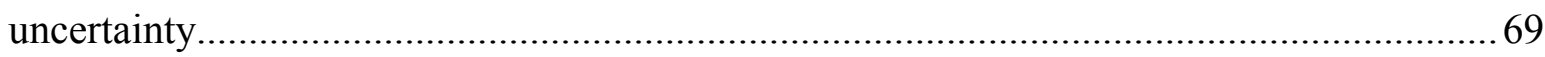

Table 5.6 Estimated numerical uncertainty of a button cell operating on wet hydrogen at

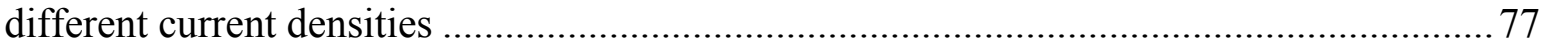

Table 6.1 Composition the clean syngas fuel stream with high CO concentration ............. 99

Table A.1 Heterogeneous reaction mechanism for methane reforming and water gas shift reactions on Ni-YSZ electrodes [26] 143 


\title{
NOMENCLATURE
}

\author{
$A \quad$ area $\left(\mathrm{m}^{2}\right)$ \\ C Concentration $\left(\mathrm{mol} \mathrm{m}{ }^{-3}\right)$ \\ $C_{p} \quad$ specific heat $\left(\mathrm{J} \mathrm{kg}^{-1} \mathrm{~K}^{-1}\right)$ \\ $C^{\text {ref }}$ reference concentration $\left(\mathrm{mol} \mathrm{m}{ }^{-3}\right)$ \\ $D^{e f f} \quad$ effective diffusivity $\left(\mathrm{m}^{2} \mathrm{sec}^{-1}\right)$ \\ $D^{\text {eff* }} \quad$ corrected effective diffusivity $\left(\mathrm{m}^{2} \mathrm{sec}^{-1}\right)$ \\ $D_{i, j} \quad$ binary diffusivity $\left(\mathrm{m}^{2} \mathrm{sec}^{-1}\right)$ \\ $D^{K} \quad$ Knudsen diffusivity $\left(\mathrm{m}^{2} \mathrm{sec}^{-1}\right)$ \\ $D_{m} \quad$ molecular diffusivity $\left(\mathrm{m}^{2} \mathrm{sec}^{-1}\right)$ \\ $e^{-} \quad$ electron \\ E Nernst potential (V) \\ $E_{a} \quad$ approximate error \\ $E_{a c t} \quad$ activation energy $\left(\mathrm{J} \mathrm{mol}^{-1}\right)$ \\ $E^{0} \quad$ standard state potential (V) \\ $E_{\text {cell }}^{\prime} \quad$ Nernst potential minus anode and cathode activation overpotentials (V)
}




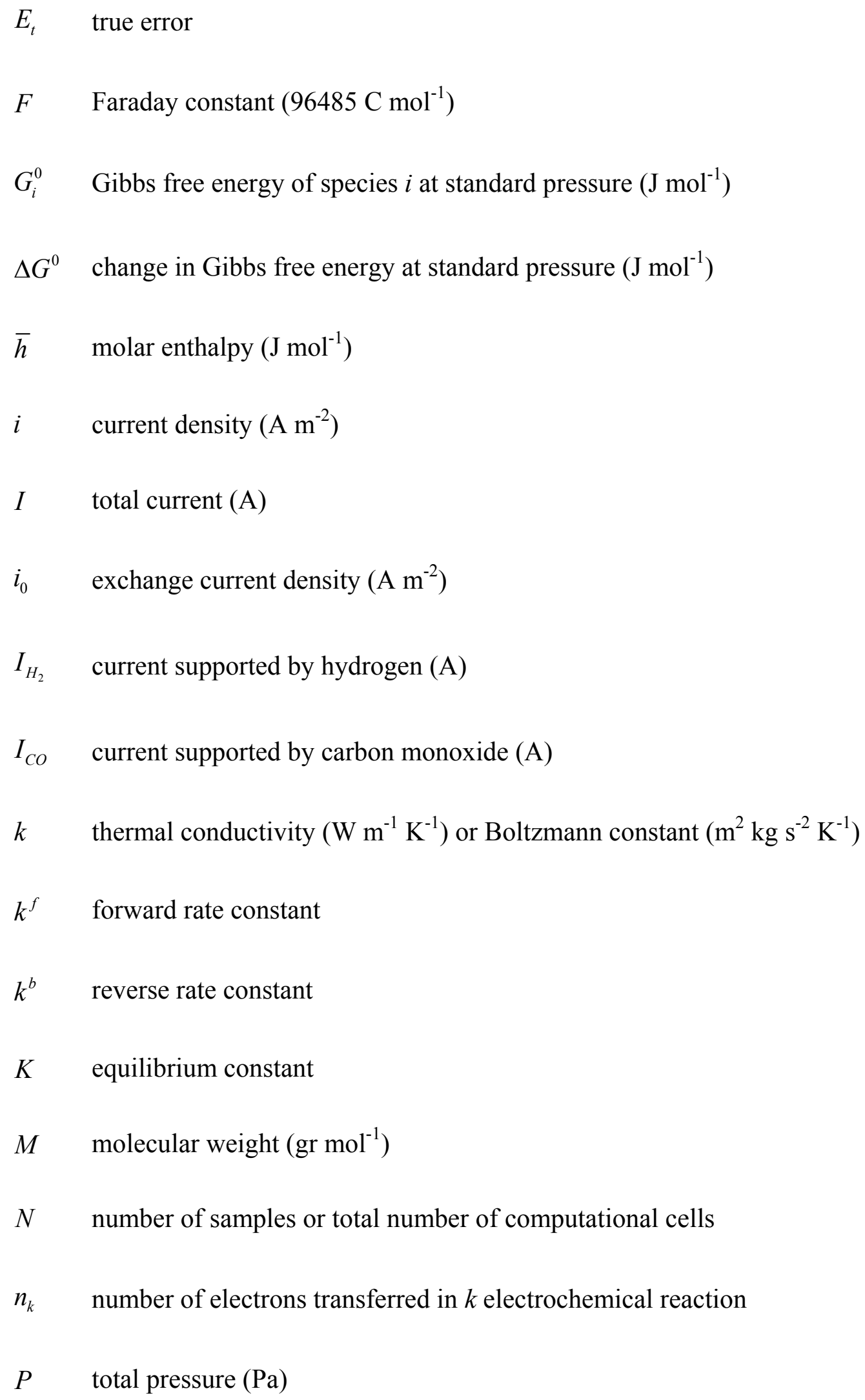


$P_{i} \quad$ partial pressure of species $i(\mathrm{~Pa})$

$q \quad$ net rate of progress (moles $\left.\mathrm{m}^{-3} \mathrm{sec}^{-1}\right)$

$\bar{r} \quad$ mean pore radius $(\mathrm{m})$

$R \quad$ universal gas constant $\left(8.314 \mathrm{~J} \mathrm{~mol}^{-1} \mathrm{~K}^{-1}\right)$

$R_{1} \quad$ production rate of the forward methane reforming reaction (moles $\mathrm{m}^{-3} \mathrm{sec}^{-1}$ )

$R_{2} \quad$ production rate of the reverse methane reforming reaction (moles $\mathrm{m}^{-3} \mathrm{sec}^{-1}$ )

$R_{3} \quad$ production rate of the forward water gas shift reaction (moles $\mathrm{m}^{-3} \mathrm{sec}^{-1}$ )

$R_{4} \quad$ production rate of the reverse water gas shift reaction (moles $\mathrm{m}^{-3} \mathrm{sec}^{-1}$ )

$T \quad$ temperature (K)

$T_{N} \quad$ dimensionless temperature

$V \quad$ volume $\left(\mathrm{m}^{3}\right)$

$V_{a} \quad$ potential jump at anode-electrolyte interface (V)

$V_{c} \quad$ potential jump at cathode-electrolyte interface (V)

$\dot{\omega} \quad$ net production rate (moles $\mathrm{m}^{-3} \mathrm{sec}^{-1}$ )

$x \quad \mathrm{x}$-coordinate $(\mathrm{m})$

$X \quad$ mass fraction

$[X] \quad$ surface molar concentration (moles $\mathrm{m}^{-2}$ )

$y \quad \mathrm{y}$-coordinate $(\mathrm{m})$ 
$Y \quad$ mole fraction

$z \quad$ z-coordinate $(\mathrm{m})$

Z $\quad$ site coverage

\section{Greek symbols}

$\alpha \quad$ transfer coefficient

$\beta \quad$ Specific area of catalyst $\left(\mathrm{m}^{-1}\right)$

$v \quad$ stoichiometric coefficient

$\varepsilon \quad$ porosity, characteristic Lennard-Jones energy $(\mathrm{J})$ or coverage parameter

$\eta_{k} \quad$ activation overpotential for electrochemical reaction $k(\mathrm{~V})$ or coverage parameter

$\eta_{\text {ohm }}$ ohmic overpotential (V)

$\gamma \quad$ sticking coefficient

$\phi \quad$ electric potential

$\Omega_{D} \quad$ collision integral

$\rho \quad$ density $\left(\mathrm{kg} \mathrm{m}^{-3}\right)$

$\sigma \quad$ electrical/ionic conductivity $\left(\Omega^{-1} \mathrm{~m}^{-1}\right)$, collision diameter $(\AA)$ or number of sites a molecule occupies

$\sigma_{m} \quad$ standard deviation of the mean

$\Gamma \quad$ Site density $\left(\right.$ moles $\left.\mathrm{m}^{-2}\right)$ 
$\tau \quad$ tortuosity

\author{
Subscripts \\ $a$ anode \\ c cathode \\ ext extrapolated \\ $f \quad$ fluid or fine grid \\ mix mixture \\ $m r \quad$ methane reforming reaction \\ $P \quad$ products \\ $R \quad$ reactants \\ ref reference or reforming reaction \\ $s \quad$ solid \\ tot total \\ wgs water gas shift reaction
}




\section{Chapter 1}

\section{INTRODUCTION}

\subsection{Motivation}

It is hard to imagine a world without energy supply. The necessity to provide enough energy to society is an important issue which has been foreseen to be a critical problem that can lead the world to its largest economic crisis ever seen by humanity, if this is not resolved soon. The dependence of the current, relatively inefficient, energy sources on fossil fuels can not be sustained for much longer; therefore alternative energy technologies such as solar, wind, geothermal, fuel cells, etc., have to be a subject of research and development in order to overcome this possible scenario.

Fuel cells are one of those emerging technologies in the energy field that are believed to play an important role in the future as one of the main sources of energy conversion and, at the same time, to help to relieve greenhouse gas emission since these electrochemical devices are eco-friendly and basically free of pollution. When they are not free of pollution, like Solid Oxide Fuel Cells (SOFCs) when operating on syngas $\left(\mathrm{CO}_{2}\right.$ emissions), system coupling with $\mathrm{CO}_{2}$ sequestration technology is an effective alternative.

Several types of fuel cells have been demonstrated to operate in the long term and, at the same time, to be candidates to resolve the energy conversion concerns, due to some proven advantages over well studied and researched combustion engines, such as higher efficiencies, high quality waste heat, etc. SOFCs seem to be the main player among these alternatives, since they can provide energy in the largest scale, besides the fuel flexibility offered exclusively by these devices. However, more research and development is necessary to solve cost and technical issues delaying their introduction into the market. 
As announced by the U.S. government in 2001, the Clean Coal Power Initiative is supporting the research and development of clean coal technologies such as fuel cells as a consequence of the abundant amount of coal in this Nation. Since then, more effort and attention has been put onto fuel cell technology, the goal being the development of a fuel cell running on alternative fuels such as coal syngas, biogas, methane, methanol, etc., which can provide stable and reliable operation at a reasonable affordable cost, the target being $\$ 400$ per kilowatt before 2010 [1].

In order to meet these specifications, research must be focused on developing anode materials tolerant to contaminants present in hydrocarbon fuels, designing electrodes and electrolytes that offer better electrical/electronic performance, improving gas clean up technologies, etc. Without question, the new proposed components have to be tested experimentally to establish their long term viability.

The motivation of this work is the necessity of a computational tool that can support the development, design and optimization of SOFCs operating on coal syngas. Numerical simulations will play an important role during the research and development stage since they offer cheaper and faster means to obtain information compared to experiments. Also, the information from numerical simulations is generally much more detailed than that from experiments. It is important to note that numerical calculations can not replace experimental work; in fact, experimental data is required to validate the computational models developed to represent the physics involved in the performance of these electrochemical devices. In other words, computational fluid dynamics (CFD) and experiments are complementary to each other.

The computational tool that is developed in the current study can be the platform for subsequent studies that require more detailed calculations such as the prediction of the performance degradation of a cell when trace elements are present in syngas. 


\subsection{Objectives}

The aim of the present work is to develop a multi-dimensional computational tool to simulate and assess the performance of solid oxide fuel cells operating on coal syngas. In order to model, in detail, the operation of a fuel cell running on syngas, several models have to be incorporated during the development of the already existing computational code DREAM-SOFC developed at WVU $[2,3]$. It is important to note that the previous version of this code was limited to the simulation of only $\mathrm{H}_{2}-\mathrm{H}_{2} \mathrm{O}$ mixtures in solid oxide fuel cells [4]. The modifications will considerably expand its capabilities, hence make it a comprehensive multi-dimensional model for SOFCs running on syngas fuel. A common practice in the literature is to simulate these electrochemical processes by assuming the ratio between current driven by hydrogen and carbon monoxide $[5,6]$ or simply neglecting carbon monoxide oxidation [7-15]. In this present work, however, the goal is to devise a more general model to predict the splitting of the total current into current produced by hydrogen oxidation and by carbon monoxide oxidation, that are both present in coal syngas. 


\section{Chapter 2}

\section{LITERATURE REVIEW}

\subsection{Introduction to Fuel Cells}

Fuel cells have been generating increasing interest in the energy research field for a couple of decades and trends show that more attention and efforts are and will be put into this promising technology. Although fuel cells can be thought of as a relatively new alternative for producing energy, its operation principle was demonstrated in 1839 by William Grove [16]. Nowadays, fuel cells are considered to be one of the main sources of future energy supply around the world because of several factors, some of them being: technology virtually free of pollution, the need to use alternative fuels other than fossil fuels that are used in conventional combustion engines, higher efficiencies than combustion engines, among others [17]. However, several problems have to be solved before fuel cells can be introduced in the market as a reliable and cost viable technology.

A fuel cell is a device that directly converts the chemical energy stored in the fuel into electricity. Typically a fuel cell is composed of two porous electrodes, anode and cathode, and an electrolyte as depicted in Figure 2.1. The anode and cathode electrodes are separated by the electrolyte which is impervious to gases but conducts oxygen ions. The anode electrode is where fuel is supplied, and the oxidant, commonly oxygen from air, is fed into the cathode electrode. The porous structure of the electrodes allows the gases to diffuse towards the electrode-electrolyte interface where electrochemical reactions take place. Fuel, usually hydrogen, is oxidized electrochemically at the anode-electrolyte interface and oxygen is reduced electrochemically at the cathode-electrolyte interface. The electrodes have high electric conductivities in order to transport electrons efficiently towards the collecting point to which the external load is connected. Other than to separate the fuel and air streams to avoid direct oxidation of the fuel the electrolyte is designed to allow the transport of ions through it, therefore it is required to have a high ionic conductivity. 


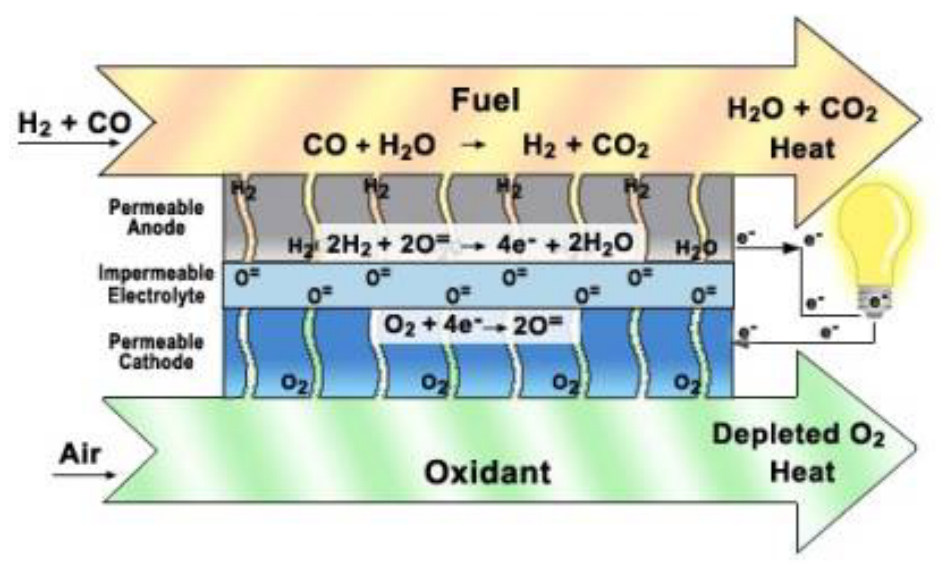

Figure 2.1 Typical layout of a fuel cell [18]

Although a battery has the same components as a fuel cell, the main difference between both devices is that a fuel cell can operate as long as the fuel and oxidant are supplied to the fuel cell into the anode and cathode side respectively. On the other hand a battery will stop working when the fuel is depleted.

\subsection{Types of Fuel Cells}

Fuel cells are usually classified according to the type of electrolyte used. Also fuel cells are classified as low, intermediate and high temperature fuel cells depending on the operating temperature. In this section a brief description of several types of fuel cells is presented.

\subsubsection{Alkaline Fuel Cells (AFCs)}

The operating temperature of AFCs is around $100^{\circ} \mathrm{C}$. The electrolyte in this type of fuel cells is an alkaline solution which can be mobile or static. When it is mobile it can also serve as a coolant. Usually AFCs have good cathode activity which is reflected in lower polarization losses. Also they have a fast start up and low cost. These cells are intolerant to $\mathrm{CO}_{2}$, offer low power density and the liquid electrolyte is corrosive. The electrolyte 
transports $\mathrm{OH}^{-}$ions as shown by the anode and cathode half cell reactions, Eqs. (2.2.1) and (2.2.2) respectively

$$
\begin{aligned}
& \mathrm{H}_{2}+2 \mathrm{OH}^{-} \rightarrow 2 \mathrm{H}_{2} \mathrm{O}+2 e^{-} \\
& \frac{1}{2} \mathrm{O}_{2}+\mathrm{H}_{2} \mathrm{O}+2 e^{-} \rightarrow 2 \mathrm{OH}^{-}
\end{aligned}
$$

\subsubsection{Phosphoric Acid Fuel Cells (PAFCs)}

Recognized as the most advanced fuel cells, PAFCs are the closest to commercialization. Typically the electrolyte is made of phosphoric acid $\left(\mathrm{H}_{3} \mathrm{PO}_{4}\right)$ which melts around $40^{\circ} \mathrm{C}$. The electrodes consist of a catalyst such as platinum and carbon bounded by polytetrafluoroethylene (PTFE). The operating temperature of PAFCs is around $200^{\circ} \mathrm{C}$. These cells could have an overall efficiency as high as $80 \%$. PAFCs are tolerant to $\mathrm{CO}_{2}$ but intolerant to $\mathrm{CO}$ in the fuel stream. Other disadvantages of these cells are the corrosive nature of its electrolyte and low ionic conductivity. Also PAFCs provide lower

power densities when compared to PEMFCs. Some of the applications are in electric utilities, on-site cogeneration and automobiles.

The electrochemical reactions occurring at anode-electrolyte interface and cathodeelectrolyte interface are respectively

$$
\begin{gathered}
\mathrm{H}_{2} \rightarrow 2 \mathrm{H}^{+}+2 e^{-} \\
\frac{1}{2} \mathrm{O}_{2}+2 \mathrm{H}^{+}+2 e^{-} \rightarrow \mathrm{H}_{2} \mathrm{O}
\end{gathered}
$$

\subsubsection{Proton Exchange Membrane Fuel Cells (PEMFCs)}

PEMFCs operate at around $80^{\circ} \mathrm{C}$. In the electrodes $\mathrm{Pt}$ is used as catalyst. The assembly of both electrodes and the electrolyte is referred as MEA which is usually expensive. Their 
relative simplicity, absence of corrosive electrolyte, low weight and volume, quick warmup and start-up time, and tolerance to $\mathrm{CO}_{2}$, are some of the advantages on PEM fuel cells. On the other hand the hydration of the electrolyte which is a very critical factor in the performance of these fuel cells can be considered as one of the main disadvantages along with the intolerance to CO in the fuel stream. Some of the applications of PEM fuel cells are in portable electronics, automobiles, combined heat and power systems, etc. Compared with other low temperature fuel cells, PEM fuel cells provide a wider range in power output going from a few to hundreds of thousand Watts.

Similar to PAFCs, the electrolyte in PEM fuel cells transports hydrogen ions as shown by the half cell reactions at anode and cathode-electrolyte interfaces (Eqs. (2.2.5) and $(2.2 .6))$

$$
\begin{gathered}
\mathrm{H}_{2} \rightarrow 2 \mathrm{H}^{+}+2 e^{-} \\
\frac{1}{2} \mathrm{O}_{2}+2 \mathrm{H}^{+}+2 e^{-} \rightarrow \mathrm{H}_{2} \mathrm{O}
\end{gathered}
$$

\subsubsection{Direct Carbon Fuel Cells (DCFCs)}

DCFCs use elemental carbon and oxygen to produce electrical energy and $\mathrm{CO}_{2}$. These fuel cells are the only ones that use fuel in solid phase. DCFCs also show the highest efficiency possible ( $80 \%$ ) because of the very low entropy change. The activation losses in DCFCs are close to zero. Although $\mathrm{CO}_{2}$ is a product in the overall reaction it can be easily sequestered. Some of the disadvantages of DCFCs are low reaction rates in the anode, refueling is complicated because of the solid phase of the fuel, impurities such as ashes in the fuel can pollute the electrolyte.

The electrochemical reactions taking place at the electrode-electrolyte interfaces are

$$
\mathrm{C}+2 \mathrm{CO}_{3}^{=} \rightarrow 3 \mathrm{CO}_{2}+4 e^{-}
$$




$$
\mathrm{O}_{2}+2 \mathrm{CO}_{2} \rightarrow 2 \mathrm{CO}_{3}^{=}
$$

at the anode and cathode respectively.

\subsubsection{Solid Oxide Fuel Cells (SOFCs)}

Although high operating temperature (above $700^{\circ} \mathrm{C}$ ) is considered a disadvantage for this type of cell, it brings some advantages such as: expensive catalysts are not required, internal reforming can be achieved, fuel flexibility, higher efficiencies when combined with turbine power systems, etc. On the other hand the high operating temperature restricts the cells to a long start-up time. The fuel flexibility allows SOFCs to use $\mathrm{CO}$ and gases from methane reforming.

Ceramic materials are mainly used in SOFCs. The anode is usually made of a Ni-YSZ (yttria-stabilized-zirconia $\mathrm{ZrO}_{2}-\mathrm{Y}_{2} \mathrm{O}_{3}$ ) cermet, the cathode made of $\mathrm{LaMnO}_{3}$ (lanthanum manganite) which is usually doped with $\mathrm{Sr}$ (strontium) and the electrolyte is made of YSZ.

The fuel, commonly hydrogen, is oxidized in the anode side as follows

$$
\mathrm{H}_{2}+\mathrm{O}^{=} \rightarrow \mathrm{H}_{2} \mathrm{O}+2 e^{-}
$$

If carbon monoxide is present in the fuel stream it can also be oxidized directly as

$$
\mathrm{CO}+\mathrm{O}^{=} \rightarrow \mathrm{CO}_{2}+2 e^{-}
$$

The oxygen reduction reaction occurring in the cathode side is given by

$$
\frac{1}{2} O_{2}+2 e^{-} \rightarrow O^{=}
$$

The main application of SOFCs is in stationary power plants. 


\subsubsection{Molten Carbonate Fuel Cells (MCFCs)}

Also considered a high temperature fuel cell, the MCFCs operate at around $800^{\circ} \mathrm{C}$ with a variety of fuels such as natural gas, coal gasified gas, biomass, etc. The electrolyte is made of molten mixture of alkali metals. The power generation efficiency of the MCFCs is about $50 \%$ based on LHV.

The electrochemical reactions occurring at the anode and cathode are respectively

$$
\begin{gathered}
\mathrm{H}_{2}+\mathrm{CO}_{3}^{=} \rightarrow \mathrm{H}_{2} \mathrm{O}+\mathrm{CO}_{2}+2 e^{-} \\
\frac{1}{2} \mathrm{O}_{2}+\mathrm{CO}_{2}+2 e^{-} \rightarrow \mathrm{CO}_{3}^{=}
\end{gathered}
$$

In general fuel cells present several advantages and disadvantages; some of the advantages are: fuel cells are more efficient than combustion engines and also they are more friendly with the environment since virtually no pollution is produced from these devices, their simplicity when compared with other technologies for energy generation since there are no moving parts which also brings into picture the low noise level. Currently the major disadvantages are the relatively short durability, the high cost due to the expensive materials used during manufacturing, the fuel storage and the fuel availability (mainly for hydrogen).

\subsection{Previous Research on SOFCs}

In the last decade much more attention has been focused on fuel cells because of their projected importance in the near future as one of the main technologies for energy supply. In recent years, one important goal in fuel cell research is to develop fuel cells that can run not only with hydrogen but with alternative fuels such as coal syngas and natural gas, among others. Solid Oxide Fuel Cells are important candidates to meet this requirement due to their fuel flexibility. Also, since the SOFCs operate at high temperature and their anode electrodes contain $\mathrm{Ni}$ which acts as a catalyst, it is possible to have internal reforming in SOFCs. Many studies have been conducted in order to understand, in more detail, the 
reforming kinetics in Ni-YSZ anodes of a SOFC as well as the transport processes inside porous electrodes and the electrochemical reactions. As in most research fields, experimental and numerical investigations have been performed which when combined can result in a better understanding of the physics involved in the performance of fuel cells. In what follows several numerical and experimental studies are summarized.

\subsubsection{SOFC Modeling}

Numerical modeling in general, can be classified according to the dimensionality or modeling level. The categories in this respect include lumped or zero-dimensional models, in which, only global performance parameters are solved for by the model. The next level of modeling is represented by one-dimensional models. These models usually consider the independent variable to be the coordinate normal to the surface of the cell (along the thickness of the cell) or sometimes the axial coordinate, although these types of models could be considered as pseudo two-dimensional models. Two-dimensional models solve the dependent variables in two directions, normal to the cell surface and in the axial direction. The dependent variables are solved in the three coordinates by three-dimensional models, which according to dimensionality are the most complete. The dimensionality of the numerical model depends on how much detailed information is desired to be obtained from the simulations. The larger the number of dimensions, more physics can be captured by the model and consequently, more expensive from the computational point of view.

Several differences among the models exist even among models with the same dimensionality. The main differences reside on the assumptions established in the models. Some of these assumptions can include steady-state operation of the cell neglecting the transient behavior, isothermal operation where the cell temperature is considered to be uniform, heat transfer by radiation not taken into account, one-dimensional or plug-flow in the channels, the transport mechanism of species inside the porous electrodes driven only by diffusion, among others. 
More differences among the models can be found in the used sub-models. One of these sub-models is the diffusion model which could be based on Fick's Model (FM), StefanMaxwell Model (SMM) or Dusty Gas Model (DGM). The electrochemistry model can consider simultaneous electrochemical oxidation of hydrogen and carbon monoxide or neglect direct oxidation of carbon monoxide, calculate the activation overpotentials solving the Butler-Volmer or Tafel equation, as well as the type of dependence of the exchange currents on temperature and/or concentration of the oxidized or reduced species involved in the half cell reactions. In case a kinetics model is considered, the type of mechanism employed to model methane reforming and water gas shift reactions as well as the rate expressions used to model these two reactions. The completeness of the computational model depends on how closely the physics involved in the performance of the cell is represented by that model.

\subsubsection{Zero-Dimensional Models}

A theoretical zero-dimensional model was developed by $\mathrm{Ni}$ et al. [19] to study the concentration overpotential of a reversible solid oxide fuel cell (RSOFC) which can perform as solid oxide steam electrolyzer (SOSE) to produce hydrogen or as a SOFC for power generation. The isothermal model applied to an electrolyte-supported cell showed that the higher concentration overpotential was observed in the cathode electrode when the RSOFC operates as a SOFC. Another isothermal zero-dimensional model was proposed by Patcharavorachot et al. [7]. In this study the fuel stream was based on a mixture from an external reformer fed with methane and steam; however, electrochemical oxidation of carbon monoxide was neglected. The model was used to predict the performance of a planar cell operating at $1073 \mathrm{~K}$ and, it was observed that the ohmic losses dominate the cell

performance when it is electrolyte-supported. It was also concluded that during operation at $1073 \mathrm{~K}$, the higher performance of the cell is observed when the cell is anode-supported. A similar observation was made by Chan et al. [20] who also concluded that a cathodesupported cell can not deliver a higher performance than an anode-supported cell even under high pressures on the cathode electrode. 


\subsubsection{One-Dimensional Models}

Several one-dimensional numerical models [5, 8-10, 21-23] were used to study SOFCs under different approaches. Lehnert et al. [21] analyzed the transport phenomena of gas species due to diffusion, permeation, electrochemistry and kinetics of the reforming reaction in a SOFC anode. The reaction rates for the reforming reaction and water gas shift reaction used in this study were obtained experimentally along with the structural properties such as the ratio 'porosity/tortuosity' and the mean pore radii of the anode needed in the diffusion model. Near the fuel-electrode interface, it was seen that the reforming rate for steam reforming was about 42 times higher than the electrochemical reaction rate when the cell supports $300 \mathrm{~mA} / \mathrm{cm}^{2}$ and operates at $1173 \mathrm{~K}$ and at $973 \mathrm{~K}$ it is only 7.2 times higher. Gemmen and Trembly [5] focused their study to investigate the detailed transport of coal syngas through a porous Ni-YSZ anode of an SOFC when operating in the pressure range of 1-15 atm. The electrochemical oxidation of $\mathrm{H}_{2}$ and $\mathrm{CO}$ was considered to occur simultaneously where a ratio of 4 between hydrogen and carbon monoxide oxidation was prescribed. It was found that operating the SOFC at a pressure up to $8 \mathrm{~atm}$, the methane reforming reaction proceeds forward producing hydrogen and that at higher pressures the same reaction proceeds in the reverse direction. An anode-supported planar cell considering only one fuel and air channel was studied at different temperatures, utilizations and flow configurations by Aguiar et al. [8], where the pressure drop along the channels was neglected and radiation between the positive electrode-electrolyte-negative electrode (PEN) and the interconnect was considered. In this study, it was concluded that the cathode activation overpotential is the major source of voltage loss. Also, the maximum temperature occurs near the inlet of the fuel stream in the counter-flow arrangement and a steeper temperature gradient is observed when compared with the co-flow case. Opposed to Aguiar et al. [8] who observed that the ohmic overpotential was the less dominant, it was found by Hussain et al. [9] in their anode-supported planar cell simulations that the ohmic overpotential is the largest source of potential loss. They also found that even at high currents, the anode concentration overpotential is significantly smaller (about four times) than the anode ohmic overpotential. In an isothermal study of an anode-supported cell, Ni et al. [10] compared the performance of a SOFC when it operates using proton conducting (SOFC-H) and oxygen ion conducting (SOFC-O) electrolytes. The cell was fed with pre- 
reformed mixture of methane and steam but only hydrogen electrochemical oxidation was taken into account in the model. The results predicted that the SOFC-O performs better than the SOFC-H which is in disagreement with previous studies where the overpotentials were not considered.

Nagel et al. [22] studied four different rates for the steam methane reforming reaction where the main differences were the reaction orders. The equilibrium of the reforming reaction was also considered. Besides, a sensitivity analysis which included the variation of the activation overpotential parameters such as activation energy and pre-exponential coefficient for the exchange current, variation of the diffusion overpotential parameters (porosity and tortuosity) and variation of the heat transfer coefficient was performed on an electrolyte-supported planar cell operating at $1073 \mathrm{~K}$. The activation energies used in the exchange current expressions were the only parameters that showed a strong effect on the cell performance quantified by the cell power. It was concluded that the impact of the fuel stream composition dominates those caused by the structural properties of the electrodes and the material properties of the cell components. This research group applied the same model to compare the performance of an electrolyte-supported planar cell and, cathodesupported tubular and triangular tube (delta8) cells [23]. The three different cells operating at $1073 \mathrm{~K}$ with a pre-reformed mixture of methane and steam were simulated and it was found that the performance of the delta8 cell was better than the planar cell and almost twice as much as that of the tubular cell.

Analysis of a cathode-supported tubular SOFC with internal reforming was carried out by Nagata et al. [24] with a one-dimensional numerical model where temperature and species concentrations were calculated only along the flow direction (one-dimensional). In this study, the effect of the catalyst density, the graded catalyst distribution, the internal reforming rate, the air and fuel inlet temperature were assessed by keeping the maximum cell temperature at $1300 \mathrm{~K}$. It was concluded that changing the operating conditions as described above, have a considerable effect on the temperature of the exhaust gases but a small effect on the SOFC efficiency. 


\subsubsection{Two-Dimensional Models}

Experimental and numerical investigations of steam reforming were performed by Lee et al. [25]. A transient two-dimensional model was developed where other than the heterogeneous steam methane reforming and water gas shift reactions, the direct steam reforming reaction to produce hydrogen and carbon dioxide was also considered. A new method for catalyst packing was proposed and studied. This new packing method (mixed packing) consisted of alternate active and inactive zones along the flow direction of the anode electrode. It was found that when heat is applied to the reactor, the production of hydrogen can be sometimes even better than that of uniform (continuous) packing.

In a few studies $[11,12,26]$, modeling of heterogeneous chemical kinetics with a detailed mechanism was performed. This mechanism was developed to describe the kinetics in a Ni-YSZ anode representing the methane steam reforming, water gas shift reaction and carbon deposition through the Bouduard reaction. The two-dimensional models used in these studies also share the following assumptions: isothermal performance and only direct oxidation of hydrogen was considered in their models neglecting carbon monoxide oxidation. Zhu et al. [11] used their model to simulate a planar anode-supported SOFC where the flow inside the channels was considered one-dimensional. A numerical and experimental study on a Ni-YSZ anode-supported SOFC was performed by Hecht et al. [26] where in both cases, the anode is sandwiched between the fuel channel and an 'electrolyte channel'. The electrolyte channel is meant to represent the anode-electrolyte interface by carrying the products of the electrochemical reactions (water vapor and carbon dioxide). In both channels plug flow was assumed. Hecht et al. [26] found that throughout the anode, $40 \%$ of the Nickel sites are covered and that the coverage of surface species is dominated by the following adsorbed species: $\mathrm{CO}, \mathrm{H}$ and $\mathrm{O}$. Also at the studied operating conditions, the reactions reached equilibrium at low current densities but, at low cell potentials, the kinetics were rate-limiting. Janardhanan and Deutschmann [12] modeled an anode-supported button cell running on wet methane. The electrodes' ohmic resistance was neglected in this model. It was reported that though the model predicts the surface carbon formation, it is not found to be accurate at high temperatures. Also the model predicted that 
at high currents the carbon formation decreased due to a higher water vapor concentration since it is produced at a higher rate at the TPB.

Nishino et al. [27] numerically modeled a tubular SOFC with internal reforming. The model is steady and two-dimensional with a co-flow arrangement. A novel electrochemistry model is used to consider simultaneous electrochemical oxidation of hydrogen and carbon monoxide. Effects of heat transfer by convection and radiation mechanisms are taken into account. In this study the inlet temperature and velocities of anode and cathode streams were varied as well as the catalyst distribution. It was found that uniformly and linearly reducing the catalyst distribution reduced the cell temperature as well as the temperature gradients. Also, when the cell operated at high current densities, the current density driven by hydrogen and carbon monoxide were basically in the same proportion.

In another study combining experimental and numerical efforts, Suwanwarangkul et al. [6] analyzed the performance of a SOFC running on syngas. The investigated cell was an electrolyte-supported button cell where the influence of nitrogen and carbon dioxide dilution on the cell performance was considered. Several syngas compositions and operating temperatures were tested experimentally and numerically with an isothermal twodimensional model. The model considered simultaneous electrochemical oxidation of hydrogen and carbon monoxide by assuming that the hydrogen oxidation reaction is 2.5 time faster than carbon monoxide oxidation reaction. In this model, the electrodes were not part of the domain since concentration and ohmic resistances inside the electrodes were neglected. It was found that the cell performance is lower when the fuel is diluted with carbon dioxide than when it is diluted with nitrogen. The cell performance is slightly lower when only carbon monoxide is oxidized compared to the case where hydrogen is only being oxidized. Arpino and Massarotti [28] developed their own code based on the finite element method, to simulate a planar cell operating on a $\mathrm{H}_{2}-\mathrm{H}_{2} \mathrm{O}-\mathrm{Ar}$ mixture. The code is based on a two-dimensional model and was used to study the effect of inlet fuel velocity. It was found that the activation losses increase as the fuel utilization decreases which could have been caused by the lack of concentration dependence of the exchange current used by the model. 


\subsubsection{Three-Dimensional Models}

Haberman and Young [13] developed a three-dimensional model to simulate the multicomponent reactive flows in the porous support of an integrated-planar SOFC (IP-SOFC). The computational domain considered in this study includes only the anode porous support of the IP-SOFC pioneered by Rolls-Royce [29]. A feature of the developed model is the ability to calculate the velocity boundary layers at the edges of the porous structure. The gas mixture fed to the cell in the numerical simulations was a 30\% reformed methane fuel; however, electrochemical oxidation of $\mathrm{CO}$ was neglected.

Steady-state numerical simulations of an anode supported cell were performed by Wang et al [30] where a commercial software was used. The fuel stream supplied to the cell was wet hydrogen. The ohmic polarization of the cell was ignored and constant exchange currents were used to calculate the activation overpotentials. One repeating cell unit of the planar cell (include only one channel on both sides of the PEN) was considered as the computational domain. Co-flow and counter-flow arrangements were studied as well as the effects of anode porosity and thickness, fuel and air inlet velocities and temperatures. The co-flow case showed more uniform temperature and current density as well as smaller temperature gradients. Similarly, Nikooyeh et al. [14] studied one repeating cell unit of an anode-supported SOFC but considering internal reforming, using a commercial software. The model did not consider concentration overpotentials and ohmic heating was attributed only to the anode. The effect of changing the inlet gas compositions in the fuel stream through recycling was studied in co-flow and counter-flow arrangements of the planar cell. It was observed that increasing the percentage of recycling, the temperature difference between the inlet and outlet decreases. Also the temperature gradients in the transverse direction are larger than in the in the flow direction.

Another study using a commercial tool to simulate a planar SOFC considering direct internal reforming was performed by Wang et al. [31]. The computational domain included one fuel and air channels and the flow arrangement was co-flow. It was seen that the maximum current density was located almost at the same position where hydrogen and 
carbon monoxide concentrations were higher and, the cathode overpotential was the biggest loss of potential. The hydrogen current to carbon monoxide current ratio varied from around 1.7 at the inlet to about 4.2 at the outlet. Finally, three-dimensional simulations of button cells were performed by Goldin et al. [15] using a commercial code. The computational domain included both electrodes, the electrolyte and the fuel and air compartments where the gas streams are supplied to the cell. The model considers convection inside the porous electrodes and ohmic overpotential only due to the electrolyte. A detailed surface reaction mechanism was used to model reforming and water gas shift reactions but carbon monoxide electrochemical oxidation was neglected. Hydrogen and oxygen exchange currents were used as calibration parameters to predict the performance of the button cell operating at different temperatures using wet hydrogen as fuel. In the numerical simulations it was observed that at high flow rates, the fuel concentration at the anode-electrolyte interface is almost the same as the inlet concentration which does not happen at low flow rates. Also, at high current densities, the cell temperature increases around $25^{\circ} \mathrm{C}$ when radiation is considered and about $40^{\circ} \mathrm{C}$ when radiation is not taken into account. When operating the button cell on a mixture of methane and carbon dioxide at $800^{\circ} \mathrm{C}$ with a low flow rate, the cell temperature increases around $13^{\circ} \mathrm{C}$ at high currents and, at low currents the cell cools down about $7^{\circ} \mathrm{C}$. In this study it was concluded that when high flow rates are used in the experiments, isothermal and uniform gas compositions conditions can be assumed.

\subsubsection{Experimental SOFC Characterization}

Matsuzaki and Yasuda [32] studied experimentally the electrochemical oxidation of hydrogen and carbon monoxide in a Ni-YSZ anode-YSZ electrolyte interface of a SOFC. The electrochemical characterization of the cell was performed by impedance spectroscopy and current polarization measurements. The study was carried out at $1023 \mathrm{~K}$ and $1273 \mathrm{~K}$ under constant oxygen partial pressure. Using $\mathrm{H}_{2}-\mathrm{H}_{2} \mathrm{O}$ and $\mathrm{CO}-\mathrm{CO}_{2}$ fuels and by fixing the activation overpotential, the hydrogen current to carbon monoxide current ratio was between 1.9-2.3 and 2.3-3.1 at $1023 \mathrm{~K}$ and $1073 \mathrm{~K}$, respectively. It was determined that at $1023 \mathrm{~K}$, the difference in the electrochemical rates of carbon monoxide and hydrogen is 
caused mainly by the difference in the mass transfer resistance of the active species At 1073 $\mathrm{K}$, the differences are attributed to mass transfer and charge transfer resistance.

The kinetics of the methane steam reforming reaction in a $\mathrm{Ni}-\mathrm{ZrO}_{2}$ anode was investigated experimentally by Dicks et al. [33] The study was performed on an electrolyte supported SOFC where the temperature range in which the reaction rates were studied was from $973 \mathrm{~K}$ to $1273 \mathrm{~K}$. Similarly, the concentration of the species present in the fuel stream $\left(\mathrm{CH}_{4}, \mathrm{H}_{2}\right.$ and $\left.\mathrm{H}_{2} \mathrm{O}\right)$ was varied to see their effect on the reaction rates. The experimental measurements were made emulating open circuit conditions and at reactant conditions close to equilibrium of the water gas shift reaction. The experimental results showed that the reaction rate was independent of the flow rate over a wide range and the inclusion of a diluent in the fuel stream did not greatly affect the reforming rate, therefore, mass transfer effects were not important. The order of the methane reforming reaction with respect to methane was found to be always close to one regardless of the temperature and partial pressures of hydrogen and steam.

Weber et al. [34] tested electrolyte supported planar single solid oxide fuel cells with conventional Ni-YSZ anodes. In this work the effect of the steam to carbon ratio on the performance of the cell was investigated. Fuel streams consisting of $\mathrm{CO}-\mathrm{H}_{2}$ and $\mathrm{CH}_{4}-\mathrm{H}_{2} \mathrm{O}$ mixtures were used and several compositions of these two mixtures were utilized for cell testing purposes. The SOFC characterization was done by direct current techniques and impedance spectroscopy. In fuel mixtures containing carbon monoxide and hydrogen, a decrease in cell performance was observed at carbon monoxides concentration larger than $90 \%$ as a consequence of significant increase of the anode polarization losses. The use of pure dry $\mathrm{CO}$ as fuel was possible but stable operation was not achieved where partial delamination and carbon deposition were apparent.

Sasaki et al. [35] studied the performance of a cathode-supported tubular SOFC operating on fuel mixtures consisting of carbon monoxide, hydrogen, water vapor and an inert gas. The hydrogen to carbon monoxide concentrations was varied as well as the type of carrier species (nitrogen, helium and argon). It was demonstrated in this study that the 
performance of the cell when running on fuels rich in carbon monoxide is comparable to the cell running on rich hydrogen fuel mixtures. Also, the inert gas affects the cell performance, however, the lighter the inert gas the better the performance. The dilution of carbon monoxide rich fuels with an inert species, significantly reduces the cell performance, whereas dilution of hydrogen rich fuels slightly reduces the performance. In fuel mixtures of hydrogen-carbon monoxide, the cell performance decreases by increasing the concentration of carbon monoxide.

The effect of fuel composition and the use of different diluents were investigated by Jiang and Virkar [36] in an anode-supported button SOFC operating at $1073 \mathrm{~K}$. The fuels considered in this study include hydrogen diluted with helium, nitrogen, water vapor or carbon dioxide; hydrogen-carbon monoxide and carbon monoxide-carbon dioxide mixtures. The experiments showed that the concentration overpotential for carbon monoxide-carbon dioxide fuel mixtures was larger than fuels composed of hydrogen-water vapor due to a lower diffusivity. It was also found that the performance of the cell running on hydrogencarbon monoxide is basically the same as the case when the cell operates on pure hydrogen. This happens when hydrogen is diluted with carbon monoxide up to around 55\%; in fact, a slight enhancement in the performance was observed when the mixture hydrogen-carbon monoxide contains $14 \%$ carbon monoxide. Finally, it was observed that the anodic concentration overpotential is lower when the fuel stream is diluted with an inert species with a low molecular weight, which is consistent with what Sasaki et al. [35] found in their investigation.

In a parametric study the effect of the electrolyte thickness, cathode interlayer thickness, anode support thickness and porosity on the performance of a button SOFC were analyzed by Zhao and Virkar [37]. The cells running on wet hydrogen were tested at several temperatures. The fabricated cell was made of an YSZ electrolyte, Ni-YSZ anode support and anode interlayer, LSM-YSZ cathode interlayer and LSM current collector. Operation of the cell at $1273 \mathrm{~K}$ with the optimized geometrical/structural parameters $(8 \mu \mathrm{m}$ electrolyte thickness, $0.5 \mathrm{~mm}$ anode support thickness, $20 \mu \mathrm{m}$ anode interlayer thickness, $20 \mu \mathrm{m}$ 
cathode interlayer thickness, $50 \mu \mathrm{m}$ cathode current collector thickness and 57\% anode porosity), increased the maximum power density around $50 \%$ with respect to the base case.

Experiments were performed by Sukeshini et al. [38] in order to study the electrochemical oxidation of dry and wet fuel streams containing only $\mathrm{H}_{2}, \mathrm{CO}$ and $\mathrm{H}_{2}-\mathrm{CO}$ mixtures. The experiments were conducted in single SOFCs consisting of patterned Ni-YSZ anodes, LSM/YSZ cathodes and YSZ electrolytes. In this study the width of the patterns in the anode electrode was varied from 10 to $100 \mu \mathrm{m}$ and the spacing between patterns was held constant, therefore providing essentially the same total Ni surface area. During the experiments, larger activation overpotentials and polarization resistances from carbon monoxide compared with hydrogen were not observed for mixtures containing both fuels down to $25 \%$ hydrogen. It was observed that decreasing the concentration of hydrogen and increasing the carbon monoxide concentration decreases the cell performance and, the presence of carbon monoxide in the fuel neither inhibits nor augments the electrochemical oxidation of hydrogen on Ni-YSZ anodes.

\subsection{Summary}

Many types of modeling approaches can be found in the literature. Most of these models are one or two-dimensional with simplifications and assumptions varying among them. Some models consider only hydrogen electrochemical oxidation, others consider hydrogen and carbon monoxide oxidation but the ratio of the currents produced from both fuels is prescribed. Only in a few studies this ratio is determined as part of the solution. Also most of the studies treat the reforming and water gas shift reaction as global reactions occurring in a single step. A few investigations consider detailed kinetics in a surface reaction mechanism of the steam reforming reaction and water gas shift reaction. A fully three-dimensional modeling study including; simultaneous electrochemical oxidation of hydrogen and carbon monoxide, where the splitting of the total current is obtained as part of the solution and surface chemistry through a detailed heterogeneous mechanism has not been found in literature. In the current study all these capabilities have been implemented using the in-house code DREAM-SOFC as the primary frame work. 


\section{Chapter 3 COMPUTATIONAL MODEL}

The governing equations for the simulation of button SOFCs are presented in this chapter. They are charge conservation, energy conservation and species conservation equations. The equations are three-dimensional and are written in Cartesian coordinates. The governing equations were discretized using the control volume technique [39]. In the porous electrodes, the convective terms are neglected leaving diffusion the main transport mechanism. For more information see [2] and [4].

\subsection{Electric Potential Equation}

The charge conservation equation is written as

$$
\frac{\partial}{\partial x}\left(\sigma \frac{\partial \phi}{\partial x}\right)+\frac{\partial}{\partial y}\left(\sigma \frac{\partial \phi}{\partial y}\right)+\frac{\partial}{\partial z}\left(\sigma \frac{\partial \phi}{\partial z}\right)=S_{\phi}
$$

where $\sigma$ represents the electrical/ionic conductivity and $\phi$ is the electric potential. The term on the right hand side of Eq. (3.1.1) is the potential source term which is applied at the anode-electrolyte and cathode-electrolyte interfaces. The discretized source terms $\left(S_{\phi} \Delta V\right)$ are applied as follows:

At the anode-electrolyte interface on the anode side the source term is

$$
S_{\phi} \Delta V=V_{a}\left(\frac{\sigma A}{\Delta y}\right)
$$

and on the electrolyte side it is defined by 


$$
S_{\phi} \Delta V=-V_{a}\left(\frac{\sigma A}{\Delta y}\right)
$$

where $A$ is the area normal to the interface, $V_{a}$ is the potential jump across the anodeelectrolyte interface given by

$$
V_{a}=\frac{1}{2} E_{\text {cell }}^{\prime}
$$

In Eq. (3.1.4) $E_{\text {cell }}^{\prime}$ is the Nernst potential minus the anode and cathode activation overpotentials.

At the cathode-electrolyte interface similar expressions apply. On the electrolyte side of the cathode-electrolyte interface the discretized source term is defined as

$$
S_{\phi} \Delta V=V_{c}\left(\frac{\sigma A}{\Delta y}\right)
$$

and on the cathode side

$$
S_{\phi} \Delta V=-V_{c}\left(\frac{\sigma A}{\Delta y}\right)
$$

where the potential jump is

$$
V_{c}=\frac{1}{2} E_{\text {cell }}^{\prime}
$$

The coefficient shown in Eqns. (3.1.4) and (3.1.7) is an empirically determined parameter; however it was observed that changing this parameter to 0.7 and 0.3 did not affect the steady-state solution. 
The electric potential is solved in the whole domain; therefore the electrical conductivity inside the electrodes is treated as a mixture property (gas and solid phase) and calculated as follows

$$
\sigma=\varepsilon \sigma_{f}+(1-\varepsilon) \sigma_{s}
$$

The subscripts $f$ and $s$ stand for fluid and solid phases.

\subsection{Energy Equation}

The energy conservation equation is given by

$$
\frac{\partial\left(\rho C_{P} T\right)}{\partial t}=\frac{\partial}{\partial x}\left(k \frac{\partial T}{\partial x}\right)+\frac{\partial}{\partial y}\left(k \frac{\partial T}{\partial y}\right)+\frac{\partial}{\partial z}\left(k \frac{\partial T}{\partial z}\right)+S_{T}
$$

where $S_{T}$ is the energy source term. The energy equation is solved in the whole domain, and similar to the electrical conductivity properties such as density, thermal conductivity and specific heat are calculated for mixture of fluid and solid phases in both electrodes. The density of the electrodes is given by

$$
\rho=\varepsilon \rho_{f}+(1-\varepsilon) \rho_{s}
$$

where the density of the fluid (i.e. a mixture of species) is calculated using the ideal gas model as

$$
\rho_{f}=\frac{P M_{m i x}}{R T}
$$

$M_{\text {mix }}$ being the molecular weight of the mixture. The specific heat is calculated as

$$
C_{P}=\frac{\varepsilon \rho_{f} C_{P f}+(1-\varepsilon) \rho_{s} C_{P s}}{\rho}
$$


and the specific heat of the gas mixture is given by

$$
C_{P f}=\sum X_{i} C_{P i}
$$

and $X_{i}$ representing the mass fraction. The thermal conductivity is given by

$$
k=\varepsilon k_{f}+(1-\varepsilon) k_{s}
$$

The source term is the sum of the ohmic heat, the net heat from surface reactions which are the endothermic methane reforming reaction and the exothermic water gas shift reaction and the entropy heat from the electrochemical oxidation of hydrogen and/or carbon monoxide. Mathematically the energy source term is given by

$$
S_{T}=S_{\Omega}+S_{\text {surf,reac }}+S_{\text {electrochem, reac }}
$$

where the ohmic heat is calculated as

$$
S_{\Omega}=\sigma\left[\left(\frac{\partial \phi}{\partial x}\right)^{2}+\left(\frac{\partial \phi}{\partial y}\right)^{2}+\left(\frac{\partial \phi}{\partial z}\right)^{2}\right]
$$

The energy source due to surface reactions is

$$
S_{\text {surf }, \text { reac }}=S_{r e f}+S_{w g s}
$$

The energy required by the methane reforming reaction is

$$
S_{\text {ref }}=\dot{\omega}_{\mathrm{CH}_{4}}\left(\bar{h}_{\mathrm{CO}}+3 \bar{h}_{\mathrm{H}_{2}}-\bar{h}_{\mathrm{CH}_{4}}-\bar{h}_{\mathrm{H}_{2} \mathrm{O}}\right)
$$

and the energy released by the water gas shift reaction given by 


$$
S_{w g s}=\dot{\omega}_{C O}\left(\bar{h}_{\mathrm{CO}_{2}}+\bar{h}_{\mathrm{H}_{2}}-\bar{h}_{\mathrm{CO}}-\bar{h}_{\mathrm{H}_{2} \mathrm{O}}\right)
$$

where $\dot{\omega}_{i}$ is the net production rate of species $i$ and $\bar{h}_{i}$ is the specific molar enthalpy of species $i$.

The discretized energy source due to electrochemical oxidation of hydrogen and/or carbon monoxide is given by

$$
s_{\text {electrochem, reac }}=-\frac{I_{\mathrm{H}_{2}}}{2 F} T\left(\bar{s}_{\mathrm{H}_{2} \mathrm{O}}-\bar{s}_{\mathrm{H}_{2}}-\frac{1}{2} \bar{s}_{\mathrm{O}_{2}}\right)-\frac{I_{\mathrm{CO}}}{2 F} T\left(\bar{s}_{\mathrm{CO}_{2}}-\bar{s}_{\mathrm{CO}}-\frac{1}{2} \bar{s}_{\mathrm{O}_{2}}\right)
$$

\subsection{Species Transport Equation}

The species conservation equation is solved in the anode and cathode electrodes where each electrode is treated as a different sub-domain. This equation governs the species conservation for each species present in the electrode. The species transport equation is given by

$$
\frac{\partial}{\partial t}\left(\varepsilon \rho X_{j}\right)=\nabla \cdot\left(\varepsilon \rho D^{e f f *} \nabla X_{j}\right)+\varepsilon S_{j}^{\text {surf, reac }}+\varepsilon S_{j}^{\text {"electrochem, reac }}
$$

where $\varepsilon$ represents the porosity of the electrode, $\rho$ is the density of the mixture of gases inside the electrode as defined in Eqn. (3.2.3), $D^{\text {eff* }}$ is the 'corrected' effective diffusivity and $X_{j}$ is the mass fraction of the species $j$. The last two terms on the right hand side represent the source terms. $S_{j}^{\text {surf,reac }}$ is the mass source of $j$ species from surface reactions, which in this study are the methane reforming and water gas shift reactions (see section 4.4) and $S_{j}^{\text {"electrochem,reac }}$ is the mass source term per unit volume due to the electrochemical reactions. 
The mass source term when using the global catalyzed mechanism described in the next chapter takes the form when it is treated explicitly given by

$$
S_{j}^{\text {surf }, \text { reac }}=\dot{\omega}_{j} M_{j}
$$

where $\dot{\omega}_{j}$ is the net production rate of the species $j$ in moles per unit time per unit volume from the surface reactions and $M_{j}$ is the molecular weight of that species. The net production rates of the species involved in the methane reforming reaction and the water gas shift reaction (see section 4.4 ) are given by

$$
\begin{gathered}
\dot{\omega}_{\mathrm{CH}_{4}}=-R_{1}+R_{2} \\
\dot{\omega}_{\mathrm{H}_{2}}=3 R_{1}-3 R_{2}+R_{3}-R_{4} \\
\dot{\omega}_{\mathrm{CO}}=R_{1}-R_{2}-R_{3}+R_{4} \\
\dot{\omega}_{\mathrm{CO}_{2}}=R_{3}-R_{4} \\
\dot{\omega}_{\mathrm{H}_{2} \mathrm{O}}=-R_{1}+R_{2}-R_{3}+R_{4}
\end{gathered}
$$

where the rates $R_{1}$ and $R_{3}$ are the production rates of forward methane reforming reaction and water gas reaction respectively. $R_{2}$ and $R_{4}$ are the production rates of the same reactions but in the backward direction. These four reaction rates are given by

$$
\begin{gathered}
R_{1}=k_{m r}^{f}\left[\mathrm{CH}_{4}\right]\left[\mathrm{H}_{2} \mathrm{O}\right] \\
R_{2}=k_{m r}^{b}[\mathrm{CO}]\left[\mathrm{H}_{2}\right]^{3} \\
R_{3}=k_{w g s}^{f}[\mathrm{CO}]\left[\mathrm{H}_{2} \mathrm{O}\right] \\
R_{4}=k_{w g s}^{b}\left[\mathrm{CO}_{2}\right]\left[\mathrm{H}_{2}\right]
\end{gathered}
$$


The expressions for the rate constants for methane reforming reaction and water gas shift reaction are given in the chemical kinetics section of a global catalyzed reaction mechanism in chapter 4 . When the reactions are treated as heterogeneous reactions, the net production rates are given in moles per unit area per unit time. A parameter called specific area of catalyst is needed to introduce the source term in Eq. (3.3.1). Therefore the source term from surface reactions in Eq. (3.3.1) becomes $\beta S_{j}^{\text {surf,reac }}$ instead of $\varepsilon S_{j}^{\text {surf,reac }}$. The parameter $\beta$ is the specific area of catalyst given in $\mathrm{m}^{-1}$. Also the net production rates $\dot{\omega}_{j}$ are given in moles per unit area per unit time.

The source terms from electrochemical reactions $S_{j}^{\text {melectrochem,reac }}$ are applied only at the electrode-electrolyte interface where the electrochemical reactions take place. In this study simultaneous electrochemical oxidation of hydrogen and carbon monoxide is considered, therefore at the anode-electrolyte interface the following mass source terms are considered

$$
\begin{gathered}
S_{\mathrm{H}_{2}}=-\frac{I_{\mathrm{H}_{2}} M_{\mathrm{H}_{2}}}{2 F} \\
S_{\mathrm{H}_{2} \mathrm{O}}=\frac{I_{\mathrm{H}_{2}} M_{\mathrm{H}_{2} \mathrm{O}}}{2 F} \\
S_{C O}=-\frac{I_{C O} M_{\mathrm{CO}}}{2 F} \\
S_{\mathrm{CO}_{2}}=\frac{I_{C O} M_{\mathrm{CO}_{2}}}{2 \mathrm{~F}}
\end{gathered}
$$

where $I_{H_{2}}$ and $I_{C O}$ are the currents produced from electrochemical oxidation of hydrogen and carbon monoxide respectively. At the cathode-electrolyte interface the mass source term is

$$
S_{O_{2}}=-\frac{I M_{O_{2}}}{4 F}
$$




\section{Chapter 4 COMPUTATIONAL SUB-MODELS}

For the closure of the governing equations for fuel cells, constituent models are required for electrochemistry, multi-component diffusion fluxes, chemical reaction kinetics, etc. These models are elucidated in this chapter.

\subsection{Electrochemistry Model}

The electrochemistry model employed in this study considers simultaneous electrochemical oxidation of hydrogen and carbon monoxide unlike some of the models in literature where either carbon monoxide oxidation is neglected $[11,12,40]$ or a fixed ratio is prescribed between the current driven from hydrogen and carbon monoxide $[5,6]$. In the present model the amount of current produced by $\mathrm{H}_{2}$ and $\mathrm{CO}$ is part of the solution and not prescribed a priori.

The main reason to consider electrochemical oxidation of both hydrogen and carbon monoxide on the anode side is that the fuel cell is fed with coal syngas through the fuel stream. Other possible scenario would be if the cell is fed with some methane since the model considers internal reforming reaction on Ni catalyst in the anode electrode.

The electrode reactions considered here are given by two anode oxidation reactions:

$$
\begin{aligned}
& \mathrm{H}_{2}+\mathrm{O}^{=} \rightarrow \mathrm{H}_{2} \mathrm{O}+2 e^{-} \\
& \mathrm{CO}+\mathrm{O}^{=} \rightarrow \mathrm{CO}_{2}+2 e^{-}
\end{aligned}
$$

and one reduction reaction at the cathode side 


$$
O_{2}+4 e^{-} \rightarrow 2 O^{=}
$$

Following two overall reactions can be established as a consequence of the two oxidation reactions (4.1.1) and (4.1.2)

$$
\begin{aligned}
& \mathrm{H}_{2}+\frac{1}{2} \mathrm{O}_{2} \rightarrow \mathrm{H}_{2} \mathrm{O} \\
& \mathrm{CO}+\frac{1}{2} \mathrm{O}_{2} \rightarrow \mathrm{CO}_{2}
\end{aligned}
$$

The Nernst potential for reactions (4.1.4) and (4.1.5) is given respectively by

$$
\begin{aligned}
& E_{\mathrm{H}_{2}}=E_{\mathrm{H}_{2}}^{0}-\frac{R T}{2 F} \ln \left[\frac{P_{\mathrm{H}_{2} \mathrm{O}}}{P_{\mathrm{H}_{2}} P_{\mathrm{O}_{2}}^{0.5}}\right] \\
& E_{\mathrm{CO}}=E_{\mathrm{CO}}^{0}-\frac{R T}{2 F} \ln \left[\frac{P_{\mathrm{CO}_{2}}}{P_{\mathrm{CO}} P_{\mathrm{O}_{2}}^{0.5}}\right]
\end{aligned}
$$

where $E_{\mathrm{H}_{2}}^{0}$ and $E_{\mathrm{CO}}^{0}$ are the standard state potentials for the reactions in Eqns. (4.1.4) and (4.1.5) respectively given by

$$
\begin{aligned}
& E_{H_{2}}^{0}=-\frac{\Delta G_{H_{2}}^{0}}{n_{H_{2}} F} \\
& E_{C O}^{0}=-\frac{\Delta G_{C O}^{0}}{n_{C O} F}
\end{aligned}
$$

In the above equations $\Delta G_{H_{2}}^{0}$ and $\Delta G_{C O}^{0}$ are the Gibbs free energies for reactions (4.1.4) and (4.1.5) at standard pressure and operating temperature. $n_{\mathrm{H}_{2}}$ and $n_{\mathrm{CO}}$ represent the number of electrons involved in hydrogen oxidation reaction (4.1.1) and in carbon 
monoxide oxidation reaction (4.1.2) respectively. $F$ is Faraday constant. Accordingly, the Gibbs free energies for reactions (4.1.4) and (4.1.5) are given respectively by

$$
\begin{gathered}
\Delta G_{\mathrm{H}_{2}}^{0}=G_{\mathrm{H}_{2} \mathrm{O}}^{0}-G_{\mathrm{H}_{2}}^{0}-\frac{1}{2} G_{\mathrm{O}_{2}}^{0} \\
\Delta G_{\mathrm{CO}}^{0}=G_{\mathrm{CO}_{2}}^{0}-G_{\mathrm{CO}}^{0}-\frac{1}{2} G_{O_{2}}^{0}
\end{gathered}
$$

The net potential difference across the cell $\left(E_{c}-E_{a}\right)$ due to the two electrochemical reactions occurring in parallel using the idea proposed by Achenbach [41] and adopted by Nishino et al. [27] and Wang et al. [31] is given by

$$
\begin{aligned}
& E_{H_{2}}-\eta_{H_{2}}-\eta_{O_{2}}=E_{c}-E_{a} \\
& E_{C O}-\eta_{C O}-\eta_{O_{2}}=E_{c}-E_{a}
\end{aligned}
$$

where $\eta_{\mathrm{H} 2}, \eta_{\mathrm{CO}}$ and $\eta_{\mathrm{O} 2}$ are the activation overpotentials for hydrogen, carbon monoxide and oxygen respectively. The calculation of these overpotentials is performed by using a simplified general current-overpotential equation which includes kinetics effects as a function of local concentrations. The general overpotential equation for electrochemical oxidation of species ' $k$ ' is written as

$$
i_{k}=i_{0, k}\left[\frac{C_{R}}{C_{R}^{r e f}} \exp \left(\frac{\alpha n_{k} F}{R T} \eta_{k}\right)-\frac{C_{P}}{C_{P}^{r e f}} \exp \left(-\frac{(1-\alpha) n_{k} F}{R T} \eta_{k}\right)\right]
$$

$i_{0, k}$ is the exchange current for electrochemical oxidation of species $k, C_{R}$ and $C_{P}$ are the local concentrations at the electrode-electrolyte interface of the reactant and product respectively, of the electrochemical oxidation reaction. $C_{R}^{r e f}$ and $C_{P}^{r e f}$ are the reference concentrations of the reduced and oxidized species, $\alpha$ is the transfer coefficient and $\eta_{k}$ is the activation overpotential. Rewriting the equation as 


$$
i_{k}=i_{0, k} \frac{C_{R}}{C_{R}^{r e f}}\left[\exp \left(\frac{\alpha n_{k} F}{R T} \eta_{k}\right)-\frac{C_{R}^{r e f}}{C_{R}} \frac{C_{P}}{C_{P}^{r e f}} \exp \left(-\frac{(1-\alpha) n_{k} F}{R T} \eta_{k}\right)\right]
$$

and realizing that the pre-exponential factor in the second term of the right hand side of Eq. (4.1.15) is close to one at relatively low currents and knowing that at high currents the second exponential term on the right hand side can be neglected, the equation can be reduced to

$$
i_{k}=i_{0, k}^{*}\left[\exp \left(\frac{\alpha n_{k} F}{R T} \eta_{k}\right)-\exp \left(-\frac{(1-\alpha) n_{k} F}{R T} \eta_{k}\right)\right]
$$

which is written in the form of the Butler-Volmer equation. For each participating species $k$ in the oxidation and reduction electrochemical reactions, i.e, $\mathrm{H}_{2}, \mathrm{CO}, \mathrm{O}_{2}$, an equation similar to Eq. (4.1.16) is used to calculate the activation overpotentials. In this equation $i_{0, k}^{*}$ is the exchange current given in terms of reactant concentration and temperature. The exchange current for hydrogen is given by

$$
i_{0, H_{2}}^{*}=c_{1}\left(\frac{Y_{H_{2}}}{Y_{H_{2}, r e f}}\right) \exp \left(-\frac{E_{a c t, H_{2}}}{R T}\right)
$$

where the reference concentration $Y_{H_{2}, \text { ref }}=0.333$ [38] and, the activation energy barrier is $91.661 \mathrm{~kJ} / \mathrm{mol}$ [38]. For carbon monoxide the expression used for the exchange current has the form

$$
i_{0, C O}^{*}=c_{2}\left(\frac{Y_{C O}}{Y_{C O, \text { ref }}}\right)
$$

The reference concentration for carbon monoxide is $Y_{C O, \text {,re }}=0.333$ [38]. Equations (4.1.17) and (4.1.18) were obtained by curve fitting to the experimental data reported in [38] in the 
temperature range of $750-850^{\circ} \mathrm{C}$. However, the constants $c_{1}$ and $c_{2}$ were used as free parameters to calibrate the model with the experiments, a similar approach was adopted by Janardhanan and Deutschman [12] and by Jiang and Virkar [36]. For the carbon monoxide exchange current, an equation dependent on temperature was not obtained since the experimental trend [38] of this parameter did not show the usual temperature dependence.

It is important to note that in Eqs. (4.1.12) and (4.1.13) the concentration overpotentials are not explicitly expressed since the partial pressures at the anode-electrolyte and cathodeelectrolyte interfaces are used in Eqs. (4.1.6) and (4.1.7) for the calculation of the Nernst potential. Similarly the ohmic overpotential is accounted for in the charge conservation equation.

The parameter $\alpha$ in Eqn. (4.1.16) is the transfer coefficient which in this study is assumed as 0.5 , as done in [12]. With this assumption, Eqn. (4.1.16) reduces to

$$
i_{k}=2 i_{0, k}^{*} \sinh \left(\frac{\alpha n_{k} F}{R T} \eta_{k}\right)
$$

where $n_{s}$ is the number of electrons transferred in the electrochemical reactions (4.1.1), (4.1.2) and (4.1.3). Therefore for the species participating in oxidation reactions, the relations between current density and activation overpotential are

$$
\begin{aligned}
& i_{\mathrm{H}_{2}}=2 i_{0, \mathrm{H}_{2}}^{*} \sinh \left(\frac{\alpha n_{\mathrm{H}_{2}} F}{R T} \eta_{\mathrm{H}_{2}}\right) \\
& i_{C O}=2 i_{0, C O}^{*} \sinh \left(\frac{\alpha n_{C O} F}{R T} \eta_{C O}\right)
\end{aligned}
$$

The current densities $i_{H 2}$ and $i_{C O}$ are the current densities driven by hydrogen and carbon monoxide respectively. $i_{O 2}=i_{t o t}$ is the total current density given by 


$$
i_{\text {tot }}=i_{H_{2}}+i_{C O}
$$

Eqns. (4.1.12) and (4.1.13) along with Eqns. (4.1.20), (4.1.21) and (4.1.22) form a set of equations to solve for hydrogen and carbon monoxide activation overpotentials as well as the current densities $i_{\mathrm{H}_{2}}$ and $i_{\mathrm{CO}}$.

The oxygen activation overpotential is simply calculated as

$$
\eta_{O_{2}}=\frac{R T}{\alpha n_{O_{2}} F} \operatorname{arcsinh}\left(\frac{i_{O_{2}}}{2 i_{0, O_{2}}^{*}}\right)
$$

where the oxygen exchange current density is given by

$$
i_{0, O_{2}}^{*}=\frac{c_{3}}{(T-279.1757)^{\frac{1}{2}}}\left(\frac{Y_{O_{2}}}{Y_{O_{2}, r e f}}\right) \exp \left(-\frac{E_{a c t, O_{2}}}{R T}\right)
$$

Equation (4.1.24) was obtained by curve fitting to the experimental data reported in [42] with a good agreement in the temperature range of $700-900^{\circ} \mathrm{C}$. The activation energy barrier in Eq. (4.1.24) is $120 \mathrm{~kJ} / \mathrm{mol}$.

Some of the constants and parameters used in the model previously described are summarized in Table 4.1. The model parameters $c_{1}, c_{2}$ and $c_{3}$ are reported in the next chapter, where the calibration of the present model is described. 
Table 4.1 Parameters used in the electrochemistry model

\begin{tabular}{c|c}
\hline Parameter & Value \\
\hline$n_{H 2}$ & 2 \\
$n_{C O}$ & 2 \\
$\alpha$ & $0.5[7,8,10,12,30]$ \\
$Y_{H 2, \text { ref }}$ & $0.333[38]$ \\
$Y_{C O, r e f}$ & $0.333[38]$ \\
$Y_{O 2, r e f}$ & $0.21[42]$ \\
$E_{a c t, H_{2}}$ & $91.661 \mathrm{~kJ} / \mathrm{mol}[38]$ \\
$E_{a c t, O_{2}}$ & $120 \mathrm{~kJ} / \mathrm{mol}[42]$ \\
\hline
\end{tabular}

\subsection{Diffusivity Model}

The transport mechanism considered in the porous electrodes is diffusion. The flux of species in the multi-component mixture is modeled using Fick's law along with an effective multi-component diffusivity similar to that done by Yakabe et al. [43]. The effective diffusivity of the $i^{\text {th }}$ species is given by

$$
D_{i}^{e f f}=\frac{\varepsilon}{\tau}\left(\frac{1-\alpha_{i, m} Y_{i}}{D_{i, m}}+\frac{1}{D_{i}^{K}}\right)^{-1}
$$

where $\varepsilon$ and $\tau$ are the porosity and tortuosity respectively. $Y_{i}$ is the mole fraction of species $i$ and $\alpha_{i, m}$ is a dimensionless parameter given by

$$
\alpha_{i, m}=1-\left(\frac{M_{i}}{M_{m}}\right)^{1 / 2}
$$


$M_{i}$ represents the molecular weight of the species $i$ and $M_{m}$ is the molecular weight of the mixture. The term $D_{i}^{k}$ shown in Eqn. (4.2.1) represents the Knudsen diffusivity which is defined as

$$
D_{i}^{K}=\frac{2}{3}\left(\frac{8 R T}{\pi M_{i}}\right)^{1 / 2} \bar{r}
$$

where $\bar{r}$ is the mean pore radius (1.07 $\mu \mathrm{m}[21]), R$ is the universal gas constant and $T$ is the temperature in $\mathrm{K}$.

$D_{i, m}$ from Eqn. (4.2.1) is the molecular diffusivity of species $i$ in the mixture. This multi-component molecular diffusivity $D_{i, m}$ is given by

$$
D_{i, m}=\frac{1-Y_{i}}{\sum_{j \neq i} \frac{Y_{j}}{D_{i, j}}}
$$

In the previous equation $Y_{i}$ is the mole fraction of the species $i$ and $D_{i, j}$ is the binary diffusion coefficient for species $i$ and $j$ which is calculated using the Chapman-Enskog theory [44] and given by

$$
D_{i, j}=0.001858 \frac{\left[T^{3}\left(M_{i}+M_{j}\right) / M_{i} M_{j}\right]^{1 / 2}}{p \sigma_{i, j}^{2} \Omega_{D}}
$$

The term $\sigma_{i, j}$ in Eqn. (4.2.5) is given by

$$
\sigma_{i, j}=\frac{\sigma_{i}+\sigma_{j}}{2}
$$

where $\sigma_{i}$ is the collision diameter of species $i$. The dimensionless parameter $\Omega_{D}$ is the collision integral calculated by 


$$
\Omega_{D}=\frac{A}{T_{N}^{B}}+\frac{C}{\exp \left(D T_{N}\right)}+\frac{E}{\exp \left(F T_{N}\right)}+\frac{G}{\exp \left(H T_{N}\right)}
$$

The coefficients A, B, C, D, E, F, G, H are 1.06036, 0.1561, 0.193, 0.47635, 1.03587, $1.52996,1.76474,3.89411$ respectively. The dimensionless temperature $T_{N}$ is given by

$$
T_{N}=\frac{k T}{\varepsilon_{i, j}}
$$

where $k$ is the Boltzmann constant. The term $\varepsilon_{i, k}$ is calculated as

$$
\varepsilon_{i, j}=\left(\varepsilon_{i} \varepsilon_{j}\right)^{1 / 2}
$$

$\varepsilon_{i}$ being the characteristic Lennard-Jones energy of species $i$.

It is important to note that from Eqn. (4.2.5) the binary diffusivity $D_{i, j}$ is given in $\left[\mathrm{cm}^{2} / \mathrm{s}\right.$ ] provided temperature $T$ in [K], pressure $p$ in [atm], molecular weights $M$ in [gr/mol] and the average collision diameter $\sigma_{i, k}$ in $[\AA]$.

In Table 4.2 the collision diameter and the characteristic Lennard Jones energy divided by the Boltzmann constant are shown for several species considered in this work.

Table 4.2 Lennard-Jones potentials for species considered in this work [45]

\begin{tabular}{c|ccccccccc}
\hline \multirow{2}{*}{ Potential parameters } & \multicolumn{8}{|c}{ Species } \\
\cline { 2 - 9 } & $\mathrm{H}_{2}$ & $\mathrm{CO}$ & $\mathrm{CH}_{4}$ & $\mathrm{H}_{2} \mathrm{O}$ & $\mathrm{CO}_{2}$ & $\mathrm{O}_{2}$ & $\mathrm{~N}_{2}$ & $\mathrm{OH}$ & $\mathrm{NO}$ \\
\hline$\varepsilon_{\mathrm{i}} / \kappa[\mathrm{K}]$ & 59.7 & 91.7 & 148.6 & 809.1 & 195.2 & 71.4 & 106.7 & 80.0 & 116.7 \\
$\sigma_{\mathrm{i}}[\AA]$ & 2.827 & 3.690 & 3.758 & 2.641 & 3.941 & 3.467 & 3.798 & 2.75 & 3.492 \\
\hline
\end{tabular}




\subsection{Diffusion Correction Equation}

The effective diffusivity presented in the previous section is used along with Fick's model when solving the species transport equation. Cayan et al. [46] compared the StefanMaxwell model with the Fick's model when solving the concentration distributions inside an anode electrode of a SOFC. In that study it was shown that these models do not compare well at high current densities. Therefore an empirical equation to correct the diffusion coefficient was proposed in such a way that the Fick's model compares with the StefanMaxwell model even at high currents. The objective of the correction to the effective diffusivity was to keep the simplicity of the Fick's model and avoid complex and computationally expensive calculations as is the case with the Stefan-Maxwell model. The empirical correction proposed by Cayan et al. [46] is

$$
D^{e f f *}=\left(1 \pm c \frac{i}{i_{r e f}}\right)^{n} D^{e f f}
$$

where $D^{e f f}$ is the effective diffusivity calculated as described in the previous section. The model parameter $c$ is a constant and $i_{\text {ref }}$ is intended to represent the properties of the cell. The power $n$ was found to be 2 .

\subsection{Chemical Kinetics}

The kinetics of the methane reforming reaction and the water gas shift reaction are considered in this work. Two alternative mechanisms were implemented to account for these reactions which are described in this section.

\subsubsection{Global Catalyzed Mechanism}

A global heterogeneous mechanism which considers the reversible methane reforming reaction

$$
\mathrm{CH}_{4}+\mathrm{H}_{2} \mathrm{O} \leftrightarrow \mathrm{CO}+3 \mathrm{H}_{2}
$$


and the reversible water gas shift reaction

$$
\mathrm{CO}+\mathrm{H}_{2} \mathrm{O} \leftrightarrow \mathrm{CO}_{2}+\mathrm{H}_{2}
$$

was implemented. The reaction rate constants used in this work to describe the reaction rates of these two global reactions (with assumed heterogeneous intermediate reactions) are those presented by Lehnert et al. [21] and fitted Arrhenius type curves by Haberman and Young [13]. Gemmen and Trembly [5] made some adjustments to these equations and the resulting expressions are used in this study. The forward rate constants for the methane steam reforming reaction and the water gas shift reaction are given respectively by

$$
\begin{aligned}
& k_{w g s, p}^{f}=0.0203 \exp \left(\frac{-103191}{R T}\right) \\
& k_{m r, p}^{f}=4651.09 \exp \left(\frac{-231266}{R T}\right)
\end{aligned}
$$

where $m r$ and wgs stand for methane reforming and water gas shift reaction respectively. It is important to note that forward rate constants are given in pressure basis $\left(\mathrm{mol} / \mathrm{m}^{3}-\mathrm{Pa}^{2}-\mathrm{s}\right)$. The backward rate constants are related to the forward rate constants through the equilibrium constant as

$$
\begin{gathered}
K_{m r}^{p}=\frac{k_{m s r}^{f}}{k_{m s r}^{b}}=\frac{p_{C O}\left(p_{\mathrm{H}_{2}}\right)^{3}}{p_{\mathrm{CH}_{4}} p_{\mathrm{H}_{2} \mathrm{O}}} \\
K_{w g s}^{p}=\frac{k_{w g s}^{f}}{k_{w g s}^{b}}=\frac{p_{\mathrm{H}_{2}} p_{\mathrm{CO}_{2}}}{p_{\mathrm{H}_{2} \mathrm{O}} p_{\mathrm{CO}}}
\end{gathered}
$$

The equilibrium constants are calculated according to

$$
K_{m r}^{p}=1.003\left(1.0267 \times 10^{10}\right) \exp \left(-0.2531 Z^{4}+0.3665 Z^{3}+0.581 Z^{2}-27.134 Z+3.277\right)
$$




$$
K_{\text {wgs }}^{p}=1.049 \exp \left(-0.2935 Z^{3}+0.6351 Z^{2}+4.1788 Z+0.3169\right)
$$

The dimensionless parameter $Z$ is defined as

$$
Z=\frac{1000}{T(K)}-1
$$

The previous relations were converted to concentration basis using the following relations: for the equilibrium constants

$$
\begin{gathered}
K_{m r}^{c}=\frac{K_{m r}^{p}}{(R T)^{2}} \\
K_{w g s}^{c}=K_{w g s}^{p}
\end{gathered}
$$

where the superscripts $c$ and $p$ mean concentration and pressure basis respectively. The relation between rate constants for both reactions expressed in concentration and pressure basis are:

Forward

$$
\begin{gathered}
k_{m r, c}^{f}=(R T)^{2} k_{m r, p}^{f} \\
k_{w g s, c}^{f}=k_{w g s, p}^{f}
\end{gathered}
$$

Backward

$$
k_{m r, c}^{b}=\frac{k_{m r, c}^{f}}{K_{m r}^{c}}
$$




$$
k_{w g s, c}^{b}=\frac{k_{w g s, c}^{f}}{K_{w g s}^{c}}
$$

\subsubsection{Heterogeneous Kinetics}

Chemical kinetics calculations on surface phase conceptually have some similarities with gas phase chemistry, such as site fraction in the surface phase to mass or molar fraction in the gas phase and also surface molar concentration as volumetric molar concentration in gas phase.

Assuming reactions of the following type

$$
\sum_{k=1}^{K} v_{k i}^{\prime} X_{k} \Leftrightarrow \sum_{k=1}^{K} v_{k i}^{\prime \prime} X_{k}
$$

where $k$ represents a species from the total number of $K$ species and $i$ is a reaction of $I$ total number of reactions. Based on the previous reactions the net rate of progress for each reaction is expressed by

$$
q_{i}=k_{f i} \prod_{k=1}^{K}\left[X_{k}\right]^{v_{k i}^{\prime}}-k_{b i} \prod_{k=1}^{K}\left[X_{k}\right]^{v_{k i}^{\prime \prime}}
$$

The rate constant in the forward and backward direction are $k_{f}$ and $k_{b}$ respectively, and $\left[X_{k}\right]$ is the surface molar concentration if $k$ is surface species or volumetric molar concentration if $k$ represents a gas phase species.

The rate constant in surface reactions is expressed in Arrhenius form as in gas phase reactions and is given by

$$
k=A T^{b} \exp \left(-\frac{E_{a}}{R T}\right)
$$


where $A$ is the pre-exponential coefficient, $b$ is an exponent and $E_{a}$ is the activation energy.

The surface molar concentration (moles per unit area) is given by

$$
\left[X_{k}\right]=\frac{Z_{k}(n) \Gamma_{n}}{\sigma_{k}(n)}
$$

$Z_{k}$ is the surface species site fraction or site coverage, $\Gamma_{n}$ is the site density of phase $n$ (moles per unit area) and $\sigma_{k}$ is the number of sites that a molecule of species $k$ occupies. Similarly to mass and molar fraction on the gas phase the summation of the site fraction over all the surface species equals unity as expressed by

$$
\sum_{k=K_{s}^{f}(n)}^{K_{s}^{l}(n)} Z_{k}(n)=1
$$

The production rate (in moles per unit area per unit time) of the species $k$ in the solid phase is given by

$$
\dot{s}_{k}=\sum_{i=1}^{I} v_{k i} q_{i}
$$

and for the gas phase species the production rate in moles per unit volume per unit time is calculated as

$$
\dot{\omega}_{k}=\sum_{i=1}^{I} v_{k i} q_{i}
$$

A special case of surface reactions is when a gas phase species reacts with the metal catalyst. This reaction called "sticking reaction" represents the adsorption of the gas phase species on the surface. The rate constant for this type of reactions is calculated by 


$$
k_{f i}=\gamma_{i} \frac{\prod \sigma_{j}^{\gamma_{j i}}}{\left(\Gamma_{\text {tot }}\right)^{m}} \sqrt{\frac{R T}{2 \pi W_{k}}}
$$

where $W_{k}$ is the molecular weight of the gas phase species, $\Gamma_{t o t}$ is the total surface site concentration summed over all surface phases (site density), $m$ is the sum of all stoichiometric coefficients of reactants that are surface species, $\sigma_{j}$ is the number of sites that the surface species occupies and $v_{j i}$ is the reaction order for that species and $\mathrm{R}$ is the universal gas constant. In Eq. (4.5.8), $\gamma_{i}$ is the sticking coefficient which represents the probability that the sticking reaction occurs. The sticking coefficient is defined as

$$
\gamma_{i}=\min \left[1, a_{i} T^{b_{i}} \exp \left(-\frac{c_{i}}{R T}\right)\right]
$$

where the coefficients $a, b$ and $c$ are the parameters given for the sticking reactions which are similar to the Arrhenius parameters.

For some heterogeneous reactions the rate constant depends on surface coverage. For those surface reactions the rate constant calculated with the Arrhenius expression is modified by the coverage as follows

$$
\begin{aligned}
k_{f i}= & A_{i} T^{\beta_{i}} \exp \left(-\frac{E_{i}}{R T}\right)\left[\prod_{k=K_{s}^{f}\left(N_{s}^{f}\right)}^{K_{s}^{l}\left(N_{s}^{l}\right)} 10^{\eta_{k_{i}}\left[Z_{k}(n)\right]}\left[Z_{k}(n)\right]^{\mu_{k_{i}}} \exp \left(-\frac{\varepsilon_{k_{i}}\left[Z_{k}(n)\right]}{R T}\right)\right] \\
& {\left[\prod_{k=K_{b}^{f}\left(N_{b}^{f}\right)}^{K_{b}^{l}\left(N_{b}^{t}\right)} 10^{\eta_{k_{i}}\left[a_{k}(n)\right]}\left[a_{k}(n)\right]^{\mu_{k_{i}}} \exp \left(-\frac{\varepsilon_{k_{i}}\left[a_{k}(n)\right]}{R T}\right)\right] }
\end{aligned}
$$

where $\eta_{k_{i}}, \mu_{k_{i}}$ and $\varepsilon_{k_{i}}$ are the coverage parameters for species $k$ and reaction i. $Z_{k}$ is the surface site fraction, $a_{k}$ is the bulk activity. The product in the last equation runs only over those surface species that are specified as contributing to the coverage modification. The superscripts $l$ and $f$ mean last and first respectively, and the subscripts $s$ and $b$ mean surface and bulk species respectively. 
Similar to the reaction rates in homogeneous reactions, the progress equation for coverage of species $i$ is given by

$$
\frac{d\left[X_{i}\right]}{d t}=\sum_{r=1}^{R} k_{r}\left(v_{r i}^{\text {prod }}-v_{r i}^{r e a}\right) \prod_{s=1}^{N_{s}}\left[X_{s}\right]^{r_{r s}^{r e a}}
$$

where $R$ represents the number of reactions and $N_{s}$ the number of species present in the mechanism; $k_{\mathrm{r}}$ is the forward rate constant, $v$ is the stoichiometric coefficient and $\left[X_{\mathrm{s}}\right]$ denotes the concentration of the reactants present in reaction $r$.

For more detailed information the reader is referred to Coltrin et al. [47] and [48].

\subsection{Electrical/Electronic Conductivities}

The electrodes of the commercial button SOFCs tested at WVU are made up of two layers (see Figure 5.1). In the anode, the two layers are the anode interlayer and the anode support both consisting of a Ni-YSZ composite, with thicknesses of around $20 \mu \mathrm{m}$ and $760 \mu \mathrm{m}$ respectively. The cathode consists of a LSM-YSZ interlayer $(\sim 20 \mu \mathrm{m})$ and an LSM current collector $(\sim 180 \mu \mathrm{m})$. For these materials, the dependence of the electrical conductivity on temperature is linear and has the general form

$$
\sigma=a T+b
$$

where $\sigma$ is the electronic conductivity in $(\mathrm{S} / \mathrm{m})$ and $T$ is the temperature in $(\mathrm{K})$.

The linear trend is chosen based on the results reported by Kim et al. [49], Zhang et al. [50] and Tsai and Barnett [51] for the composite Ni-YSZ, LSM-YSZ and LSM electrodes, respectively. The constants $a$ and $b$, however, do not correspond to the values obtained from the fitting to the measured conductivities reported in [49-51]. They were scaled to represent the values reported by Zhao and Virkar [52] for cells which are similar to those tested at WVU. The constants used in this study are listed in Table 4.3. 
Table 4.3 Constants used for modeling of the temperature dependant electrical conductivities of both electrodes

\begin{tabular}{c|ccc}
\hline Constant & Ni-YSZ & LSM-YSZ & LSM \\
\hline$a$ & -0.38 & 0.0254 & 2.9058 \\
$b$ & 824.97 & -1.7542 & -1080.1 \\
\hline
\end{tabular}

The ionic conductivity of the thin $(\sim 20 \mu \mathrm{m})$ dense YSZ electrolyte has the form and activation energy as reported by Achenbach [53] and Janardhanan [12]. A small correction in the pre-exponential coefficient was performed to represent the ionic conductivity at $800^{\circ} \mathrm{C}$ reported in [52]. The modified relation is expressed by

$$
\sigma_{Y S Z}=A \exp \left(-\frac{E_{a}}{R T}\right)
$$

where the pre-exponential coefficient $A$ and the activation energy are $61456 \mathrm{~S} / \mathrm{m}$ and $85634.2 \mathrm{~J} / \mathrm{mol}$, respectively. 


\section{Chapter 5 VERIFICATION AND VALIDATION}

\subsection{Introduction}

According to the American Institute of Aeronautics and Astronautics (AIAA) [54], verification is defined as 'the process of determining that a model implementation accurately represents the developer's conceptual description of the model and the solution to the model.' Similarly, validation for the AIAA is 'the process of determining the degree to which a model is an accurate representation of the real world from the perspective of the intended uses of the model.' However, Roache [55] described these terms in a simpler way calling them 'solving the equations right' and 'solving the right equations' referring to verification and validation, respectively.

Numerical calculations performed for a button cell are used in this study unless specified otherwise. These simulations are used for verification, validation, calibration and assessment of numerical uncertainty exercises throughout this chapter, as well as to determine the effect on the cell performance by using a detailed surface mechanism to model reforming and water gas shift reaction kinetics on a Ni-YSZ anode. After the verification and validation of the computational tool DREAM-SOFC, analysis of the results obtained for the validation case operating on coal syngas is presented which later will be used as the base case in the sensitivity analysis reported in the chapter that follows.

For validation purposes the simulations presented in this study are intended to represent as closely as possible the conditions of an anode-supported commercial button cell tested [56] at West Virginia University (WVU) operating at $800^{\circ} \mathrm{C}$. The results are compared

using V-I and power curves. Other details of the simulated validation case were also analyzed though these could not be directly validated. An assessment of the numerical uncertainty is presented towards the end of the chapter. 
The computational domain includes only the anode, cathode and electrolyte as depicted in Figure 5.1.

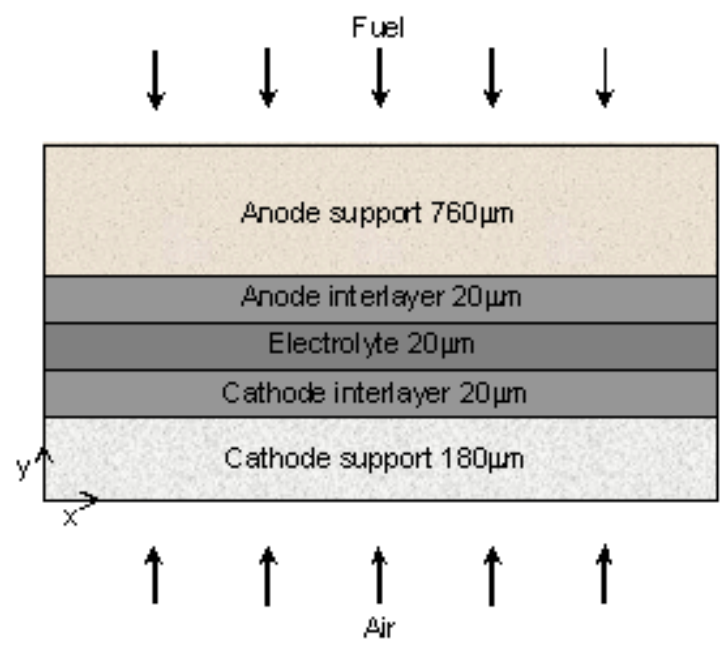

Figure 5.1 Sketch of the computational domain of the simulated button cell

Properties and physical/geometrical parameters such as electrical/ionic conductivities, porosities and thicknesses of the cell components, among others, were used as reported in [37] or estimated through experiments. The porosities and thicknesses of the components used in the simulations are shown in Table 5.1 and the tortuosity of the electrodes is set as 5 for both electrodes.

Table 5.1 Geometrical parameters of the button cell components [37]

\begin{tabular}{c|ccccc}
\hline & $\begin{array}{c}\text { anode } \\
\text { support }\end{array}$ & $\begin{array}{c}\text { anode } \\
\text { interlayer }\end{array}$ & electrolyte & $\begin{array}{c}\text { cathode } \\
\text { interlayer }\end{array}$ & $\begin{array}{c}\text { cathode current } \\
\text { collector }\end{array}$ \\
\hline$\varepsilon$ (porosity) & 0.48 & 0.23 & 0 & 0.26 & 0.45 \\
thickness $(\mu \mathrm{m})$ & 760 & 20 & 20 & 20 & 180 \\
\hline
\end{tabular}

The area specific resistance (ASR) at $800^{\circ} \mathrm{C}$ for each of the layers shown in Figure 5.1 along with their electrical conductivities and thicknesses are shown in Table 5.2. As it can be seen the electrolyte and anode support are the cell components with the higher resistances. The active area of the button cell is approximately $2 \mathrm{~cm}^{2}$ where the two 
electrodes and electrolyte are considered to have the same radius $(\sim 0.8 \mathrm{~cm})$. It is important to note that in the experimental testing the radius of the anode is about $1.2 \mathrm{~cm}$ which would lead to lower cell temperatures since there would be more area to transfer heat by convection. The domain is spatially discretized using 50 nodes in each direction in the plane of cell. In the direction normal to the cell, 10 nodes each are distributed in the cathode and in the electrolyte and 20 nodes are used in the thick anode. The grid is block uniform in each component along the cell thickness and is uniform in the other two directions. The discretization of the governing equations was performed using the control volume technique. The discretized equations were solved using DREAM-SOFC. The operating temperature of the button cell is $800^{\circ} \mathrm{C}$ and air is fed through the cathode.

Table 5.2 Area specific resistance of each layer of the button cell at $800^{\circ} \mathrm{C}$

\begin{tabular}{c|cccccc}
\hline & $\begin{array}{c}\text { Anode } \\
\text { support }\end{array}$ & $\begin{array}{c}\text { Anode } \\
\text { interlayer }\end{array}$ & Electrolyte & $\begin{array}{c}\text { Cathode } \\
\text { interlayer }\end{array}$ & $\begin{array}{c}\text { Cathode } \\
\text { curr. coll. }\end{array}$ & $\begin{array}{c}\text { Total } \\
\text { ASR }\end{array}$ \\
\hline $\operatorname{ASR}\left(\Omega-\mathrm{cm}^{2}\right)$ & 0.0226 & $3.298 \times 10^{-4}$ & 0.048 & $7.84 \times 10^{-3}$ & $4.88 \times 10^{-4}$ & 0.0793 \\
\hline
\end{tabular}

For all the scalar solutions, a zero flux boundary condition is prescribed across the lateral surrounding faces of the computational domain, i.e. edge of cathode, electrolyte and anode. For the charge conservation equation, a zero reference potential is used as the boundary condition at the cathode-air stream interface. The total current is prescribed at the anode-fuel stream interface, and thus the potential at that interface is part of the solution. For more detailed information, see [4]. The species conservation equations are only solved inside the electrodes. At the electrode-electrolyte interfaces a zero flux is prescribed for the species due to the impervious nature of the electrolyte. Though the fluid flow inside the tubes supplying the reactants to the cell is not included in the calculation domain, their effect on the cell is taken into account through appropriate boundary conditions on the faces that are exposed to the flows. The heat and mass transfer coefficients at cathode-air and anode-fuel interfaces were calculated [57] from axi-symmetric simulations of the flow inside the test furnace using the commercial CFD software FLUENT. Convective heat and mass transfer coefficients through the dimensionless Nusselt and Sherwood numbers as shown in Figure 5.2 are prescribed at anode/fuel interface and cathode/air interface 
boundaries along with the free stream conditions away from these interfaces. Internal reforming and water gas shift reactions catalyzed by $\mathrm{Ni}$, are modeled inside the Ni-YSZ anode electrode. The kinetics of these two reactions occurring in the gas phase are neglected in this study as it has been approached by other researchers [11,26]. In fact, it was shown that the kinetics in the gas phase can be neglected under typical operating conditions of SOFCs [58].

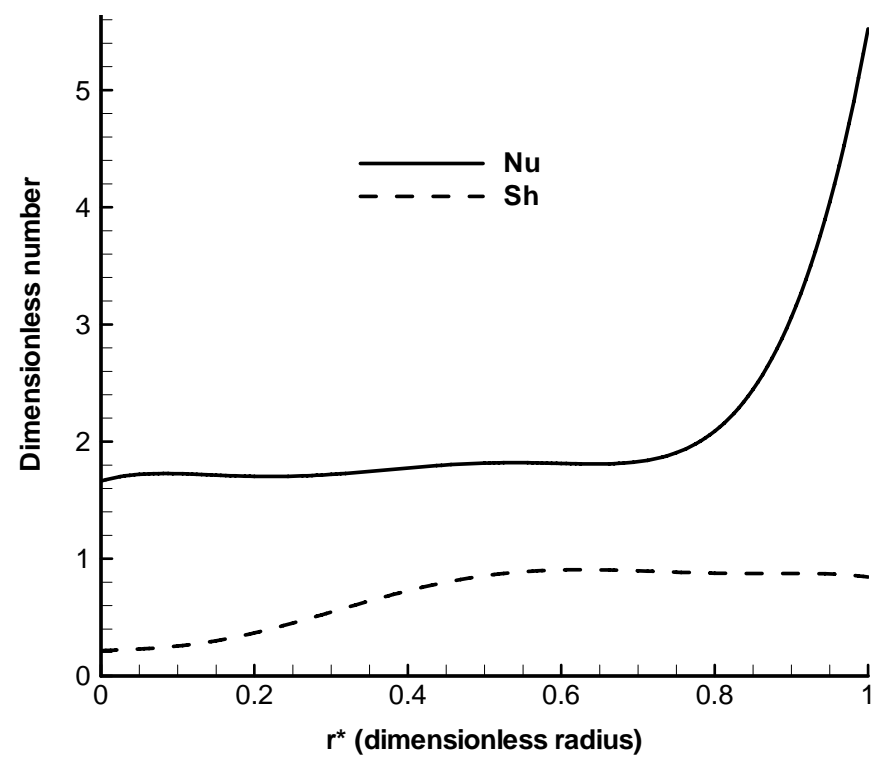

Figure 5.2 Nusselt and Sherwood dimensionless numbers used at the gas-electrode interfaces

\subsection{Verification of the Reforming Kinetics Model}

An indirect verification of the reforming kinetics model implemented in this study is done by comparing the results reported by Lehnert et al. [21] since basically the same rate constants for the methane reforming and water gas shift reactions are used in the present work. The study of Lehnert et al. [21] is based on a one-dimensional model where only the anode electrode was included in the computational domain whereas the model developed in this study and described in previous chapters, is a transient three-dimensional model. However, since it is applied to a button cell where almost negligible radial distributions are observed, it is fair to use it to verify the reforming kinetics model. In their simulations, the 2 $\mathrm{mm}$ thick anode is assumed to operate isothermally at $850^{\circ} \mathrm{C}$ supporting a current density of 
$300 \mathrm{~mA} / \mathrm{cm}^{2}$. The fuel composition supplied to the anode is considered to be that resulting from $30 \%$ pre-reformed methane as shown in Table 5.3.

Table 5.3 Fuel composition used for verification of the reforming model [21]

\begin{tabular}{l|ccccc}
\hline Component & $\mathrm{CH}_{4}$ & $\mathrm{H}_{2} \mathrm{O}$ & $\mathrm{H}_{2}$ & $\mathrm{CO}$ & $\mathrm{CO}_{2}$ \\
\hline Molar fraction & 0.171 & 0.493 & 0.263 & 0.029 & 0.044 \\
\hline
\end{tabular}

The same operating conditions were prescribed in DREAM-SOFC in order to verify the reforming kinetics model. The comparison of the predicted net molar production rates with those reported in literature [21] is shown in Figure 5.3. As it can be seen, the two models compare well along the thickness of the anode where the largest differences are observed close to the anode-electrolyte interface. These differences may arise from the fact that a different treatment is applied at that interface by the two models being compared. Therefore, it can be concluded that the reforming kinetics model implemented in DREAMSOFC has been verified.

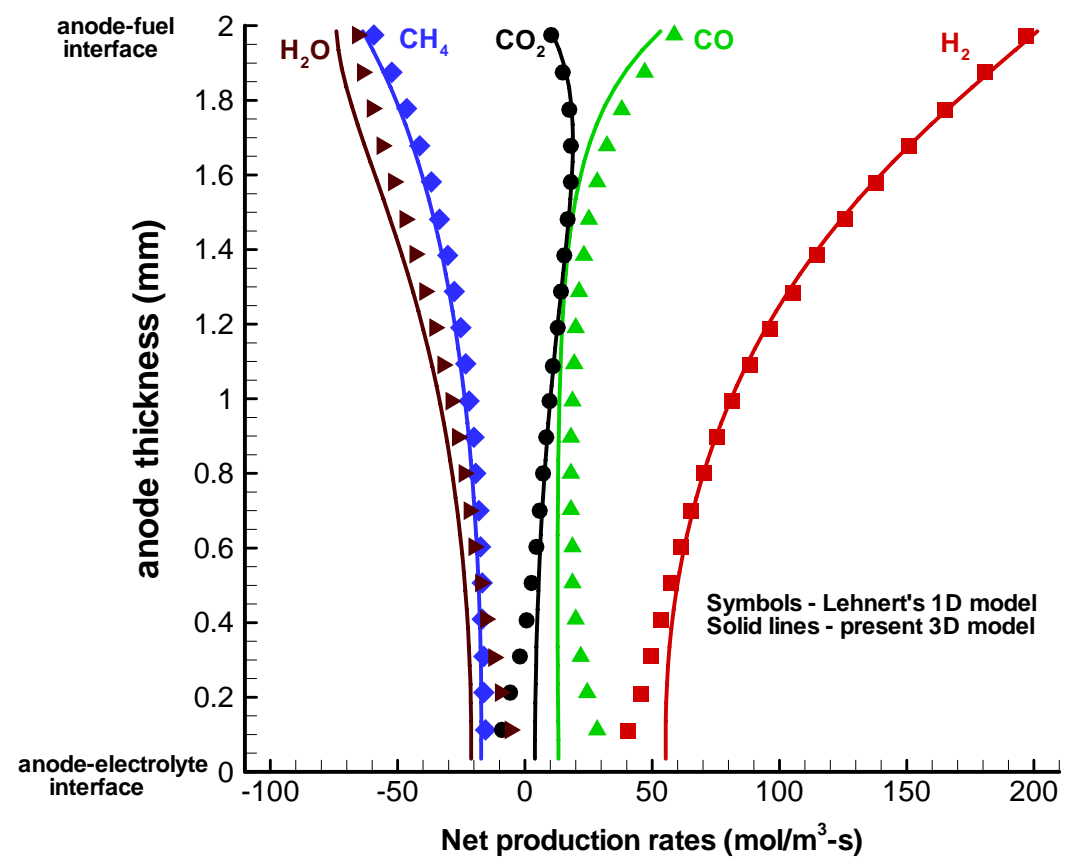

Figure 5.3 Comparison of the present model net production rates with those reported in literature 


\subsection{Calibration/Validation}

The numerical simulations performed with the computational tool DREAM-SOFC were compared with the experimental data obtained at WVU [56]. The validation case (the base case) consists of a button cell operating on simulated clean syngas, a mixture of $\mathrm{H}_{2}-\mathrm{CO}-$ $\mathrm{CO}_{2}-\mathrm{H}_{2} \mathrm{O}$ with concentrations of $30 \%-23 \%-21 \%-26 \%$ by volume, respectively. The operating cell temperature is $800^{\circ} \mathrm{C}$. More detailed description of these experiments can be found in [56, 59]. As expected, experimental uncertainty is present in the data obtained experimentally. As shown in Figure 5.4 where the cell supports a load of $0.5 \mathrm{~A} / \mathrm{cm}^{2}$, the measured cell voltage varies with time which according to the experimentalists at WVU it is mainly caused by the fluctuations of the environment since this was not kept under control. Once the cell becomes more stable (after around 20 hours) the average cell voltage is approximately $0.622 \mathrm{~V}$.

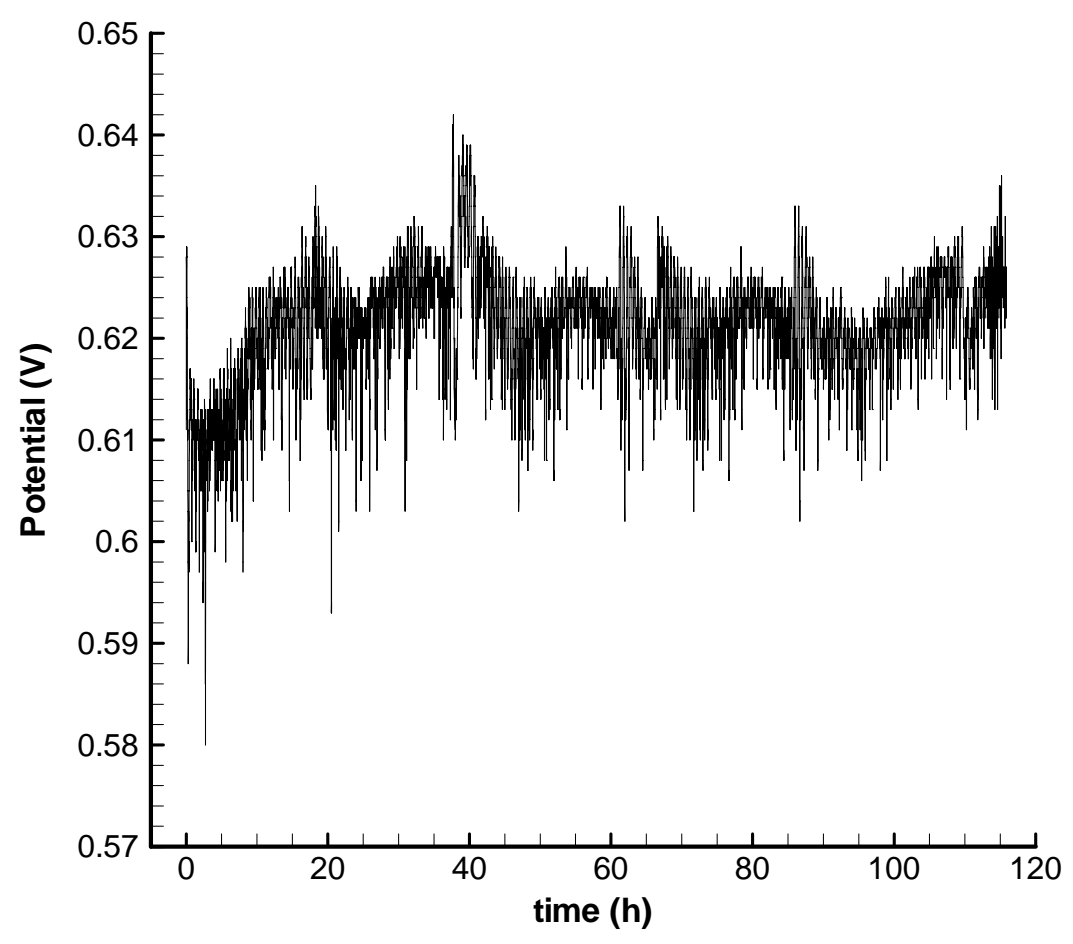

Figure 5.4 Experimentally obtained time variation of the cell voltage of a button cell running on coal syngas at $800^{\circ} \mathrm{C}$ and supporting a load of $0.5 \mathrm{~A} / \mathrm{cm}^{2}$ 
The V-I curve was obtained experimentally at $40 \mathrm{hrs}, 90 \mathrm{hrs}$ and $110 \mathrm{hrs}$ of operation. From these data, the mean at each current loaded experimentally was calculated and the uncertainty was estimated using the standard deviation of the mean given by

$$
\sigma_{m}=\sqrt{\frac{\sum_{i=1}^{N}\left(x_{i}-\bar{x}\right)^{2}}{N(N-1)}}
$$

where $x_{i}$ is the voltage measured at sample $i, \bar{x}$ is the average voltage of the $\mathrm{N}$ samples (three in this case).

The calculated experimental uncertainties varied from $1 \mathrm{mV}$ at low current densities to $9 \mathrm{mV}$ at high current densities which represent approximately $0.2 \%$ and $8 \%$ respectively. The experimental error bars are shown in Figure 5.5 along with the average experimental V-I curve.

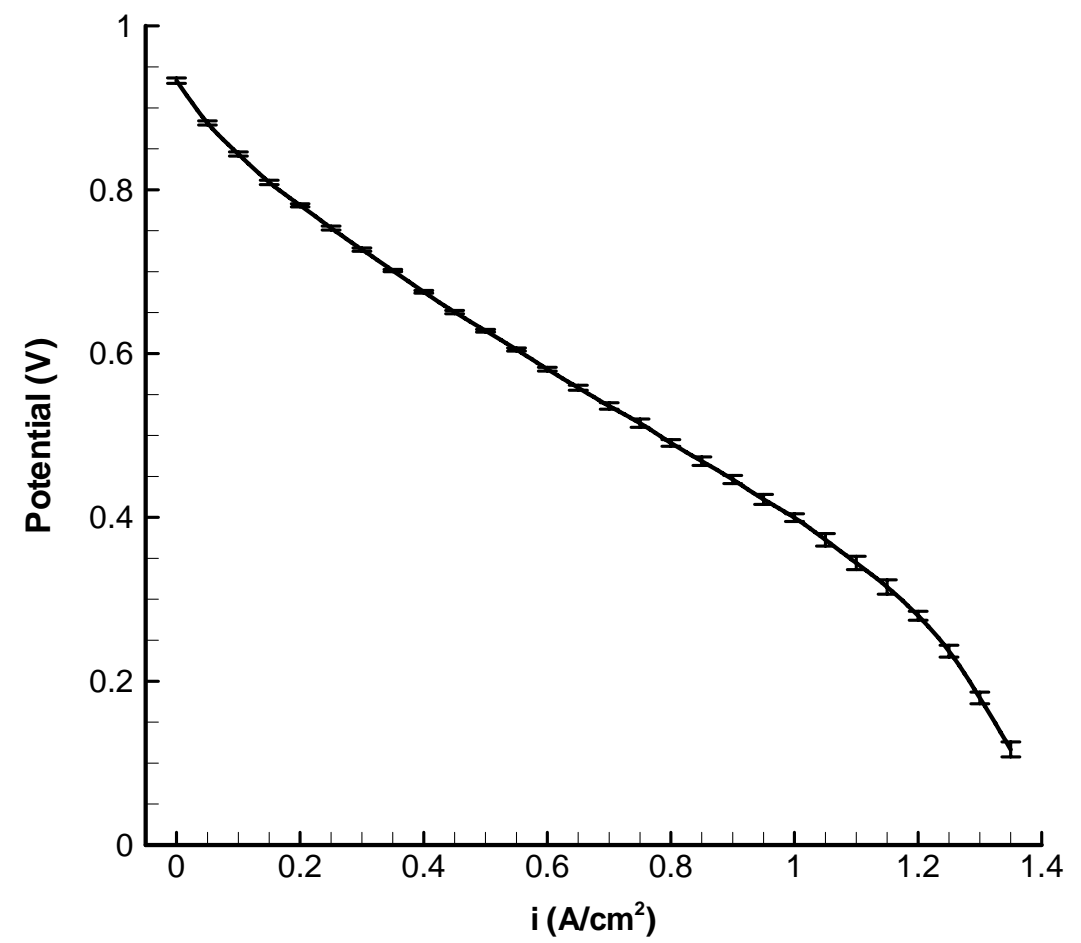

Figure 5.5 Experimental error bars of a button cell running on coal syngas at $800^{\circ} \mathrm{C}$ 
The comparison between the $\mathrm{V}-\mathrm{i}$ and power density curves from experiments and numerical predictions is shown in Figure 5.6. The predicted V-i curve for the cell operating on clean syngas compares well with the experimental V-i curve over the whole current density range and predicting closely the limiting current.

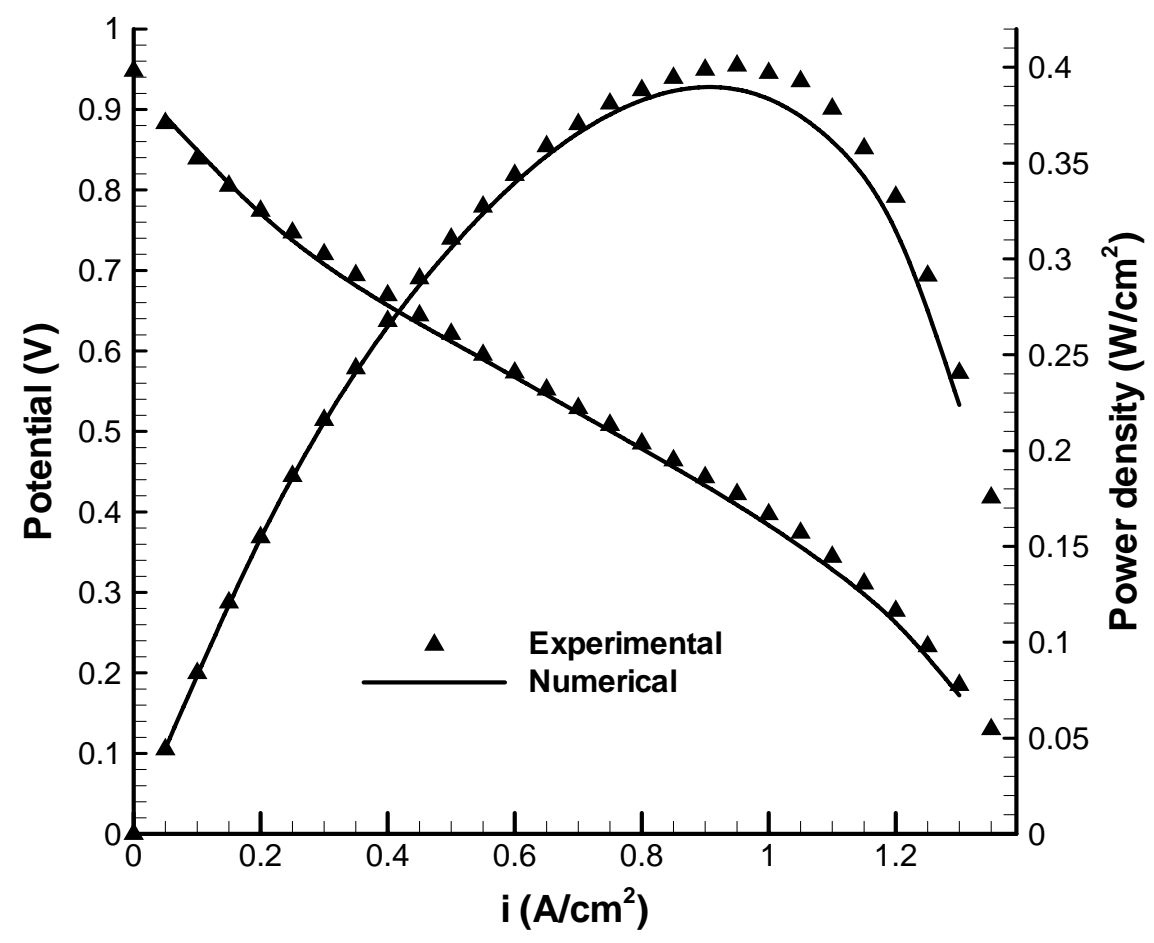

Figure 5.6 Validation of the computational model through the V-I and power density curves; cell running on syngas at $800^{\circ} \mathrm{C}$

It should be noted that similar to previous studies $[11,12,15]$, the computational model developed in this study was calibrated through the exchange current densities for hydrogen, carbon monoxide and oxygen, since these properties were not measured for the tested cells. The calibration was performed in order to predict closely the activation region of the V-I curve. The exchange currents are calculated from Eqns. (4.1.17), (4.1.18) and (4.1.24) where the pre-exponential coefficients $c_{1}, c_{2}$ and $c_{3}$ are $3.936 \times 10^{7}, 300$ and $5.874 \times 10^{9}$ $\mathrm{A} / \mathrm{m}^{2}$, respectively. The reference concentrations and activation energies are those reported in Table 4.1. It is important to note, that the activation energies and reference concentrations used in the equations for the exchange current densities were obtained from 
literature. The constants $c_{1}, c_{2}$ and $c_{3}$ reported above where used as the calibration parameters for the exchange currents.

Using the same model parameters as obtained from the calibration of DREAM SOFC against the experimental results for the cell operating on syngas at $800^{\circ} \mathrm{C}$ (as described above), the performance of the button cell running on wet hydrogen $\left(97 \% \mathrm{H}_{2}\right.$ and $\left.3 \% \mathrm{H}_{2} \mathrm{O}\right)$ at $800^{\circ} \mathrm{C}$ was simulated. Experimental data was available for this case, as well, and the comparison of the experimental and numerical V-I curves is shown in Figure 5.7.

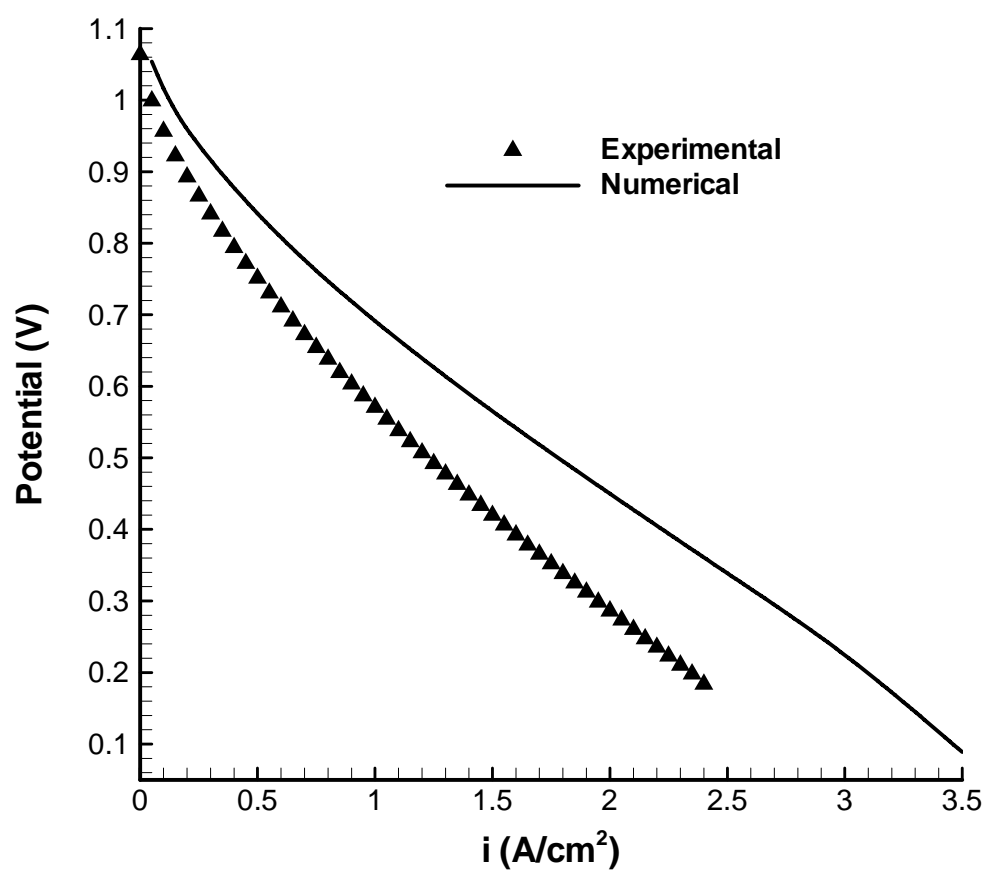

Figure 5.7 Performance of a button cell running on wet hydrogen at $800^{\circ} \mathrm{C}$

It can be seen that there is not a good agreement between the two curves over the entire range of current densities. At higher currents the disagreement is quite large and the limiting current is not predicted well, with the numerical simulation over-predicting the limiting current as well as the performance. It is important to note here that in this case, the measured open circuit voltage $(\mathrm{OCV})$ is around $30 \mathrm{mV}$ lower than the theoretical Nernst potential and DREAM-SOFC does not account for these types of losses (usually called leakage loss) and therefore some discrepancy was expected between the predictions and 
experimental data. However, a model to account for this type of loss can be devised as done by Zhu et al. [11, 60], although this model would not be appropriate for this particular case since the leakage loss approaches zero towards the limiting current according to that model, whereas in the current model the leakage loss increases as the current density increases.

The leakage loss for the case that was used for calibration was negligible. The experimental data shown in Figure 5.7 is an averaged cell potential of three different tests where the cell operates at identical conditions. In all these three tests, the measured OCV was between 20 and $60 \mathrm{mV}$ lower than the Nernst potential, which shows the repeatability of the cell performance declines when the cell operates on wet hydrogen in the experiments. In the case of the button cell running on syngas, however, the measured OCV was only a couple of mili-volts lower than the theoretical Nernst potential (within the accuracy range of the measurements), which could be the reason of predicting the cell performance very close over the whole current density range for that case.

Another reason for the discrepancy seems to be the under prediction of the activation overpotential by DREAM-SOFC when the cell operates on wet hydrogen. It can be seen from Figure 5.7 that at low currents, the slope of experimental VI curve is much larger than that of the numerical VI curve which means that the actual activations losses are higher than those computed by the electrochemistry model of DREAM-SOFC. Since the empirical parameters of the electrochemistry model are calibrated using the data for a cell operating on coal syngas, it is possible that there are synergistic effects of combined hydrogen and carbon monoxide electrochemistry which result in better $\mathrm{H}_{2}$ oxidation kinetics in syngas cell that cannot be realized in the absence of carbon monoxide. This argument, however, needs more scrutiny through experimental and numerical investigations. To summarize, some discrepancy is expected between the experiments and predictions for this case due to leakage losses. The reasons for the major differences observed are not yet well understood and currently under investigation. 


\subsection{Analysis of the Button Cell Operating on Simulated Clean Syngas}

The base case is that of the button cell running on syngas with the compositions shown in Table 5.4 and operating at $800^{\circ} \mathrm{C}$.

Table 5.4 Composition of the clean syngas fuel stream

\begin{tabular}{c|c|c|c|c}
\hline & $\mathrm{H}_{2}$ & $\mathrm{CO}$ & $\mathrm{CO}_{2}$ & $\mathrm{H}_{2} \mathrm{O}$ \\
\hline Molar fraction/mass fraction & $0.3 / 0.029$ & $0.23 / 0.307$ & $0.21 / 0.441$ & $0.26 / 0.223$ \\
\hline
\end{tabular}

The given concentrations are very close to the equilibrium concentrations of the methane reforming reaction and the water gas shift reaction. The value of the parameter $c$ in the diffusion correction equation (4.3.1) is $2.33 \times 10^{-5}$ for this case.

The mass fraction profiles of the species in the anode are shown in Figure 5.8. These profiles are along the thickness of the anode at the center of the button cell. For this composition direct electrochemical oxidation of both fuels (hydrogen and carbon monoxide) is considered and modeled numerically. The profiles in Figure 5.8 show the trends expected from the electrochemical oxidation reactions. The concentrations of hydrogen and carbon monoxide at the anode-electrolyte interface decreased as the cell current increased and for water vapor and carbon dioxide they increased. As the current increases and approaches the limiting value, the concentrations of hydrogen and carbon monoxide near the active interface tend to zero while those of water vapor and carbon dioxide are expected to be predominant. This behavior is as shown in Figure 5.9. These observations are only true if the methane reforming and water gas shift reactions are not dominant over the electrochemical reactions. This is in fact, the case here since the inlet fuel composition is close to chemical equilibrium. Almost linear (only slightly curved) profiles along the thickness of the anode shown in Figure 5.8 also indicate that there is a very small production/consumption of species due to bulk reactions. 


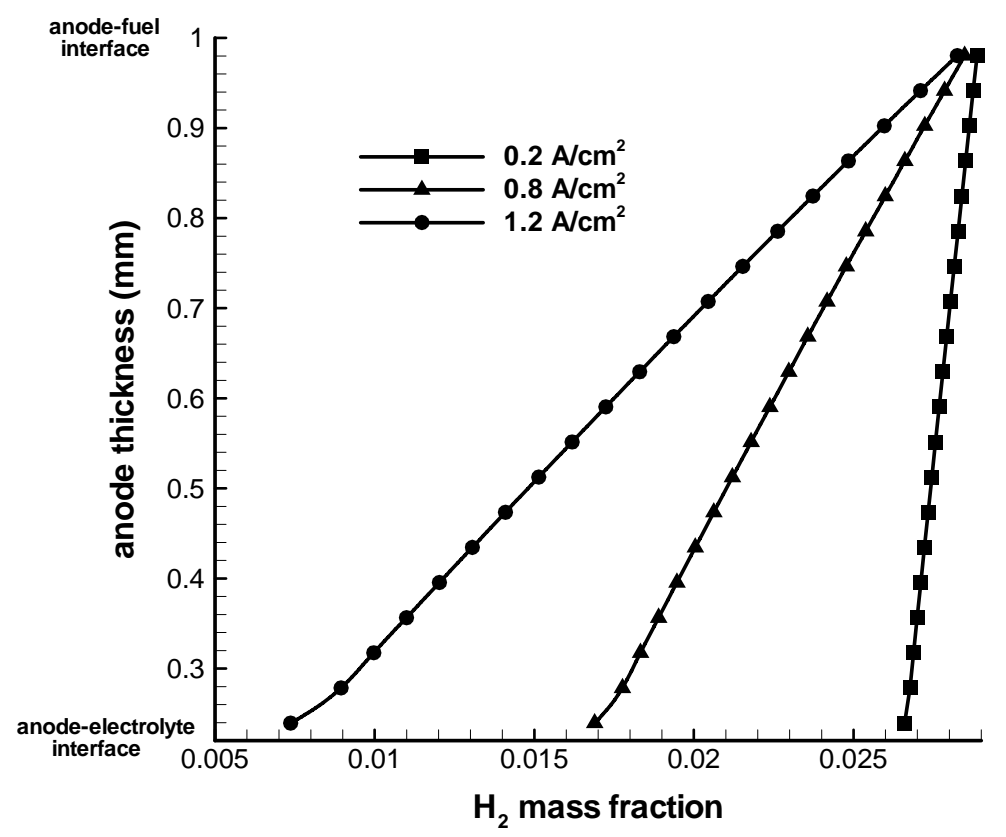

(a)

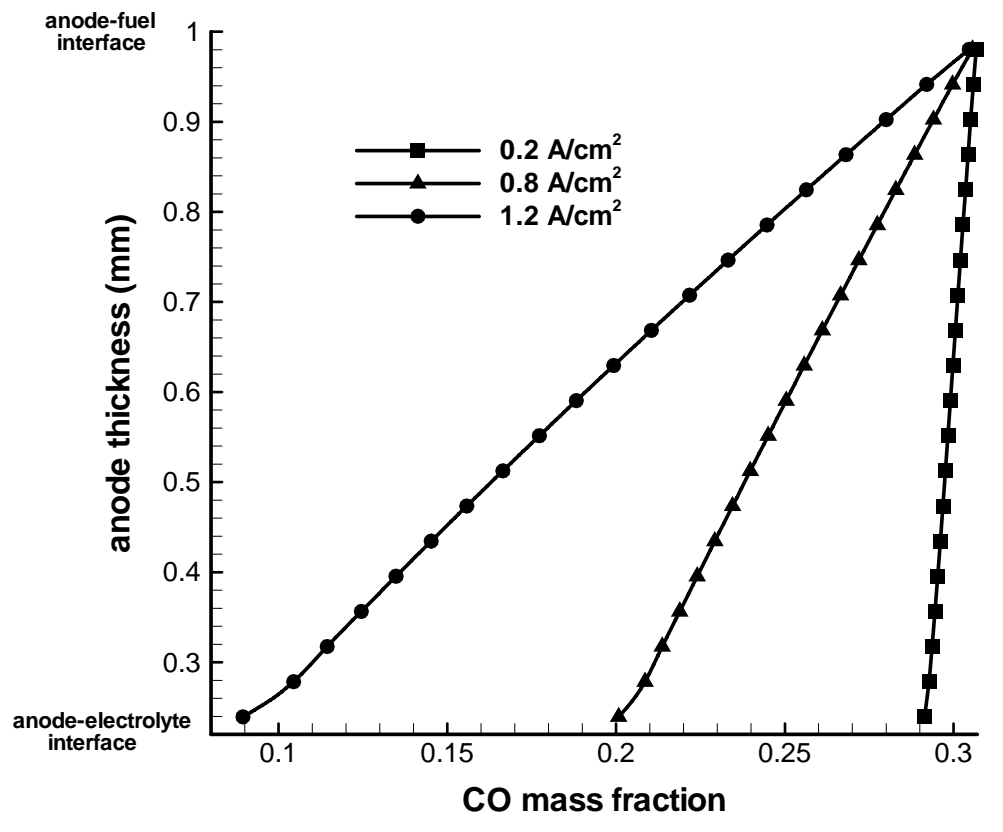

(b) 


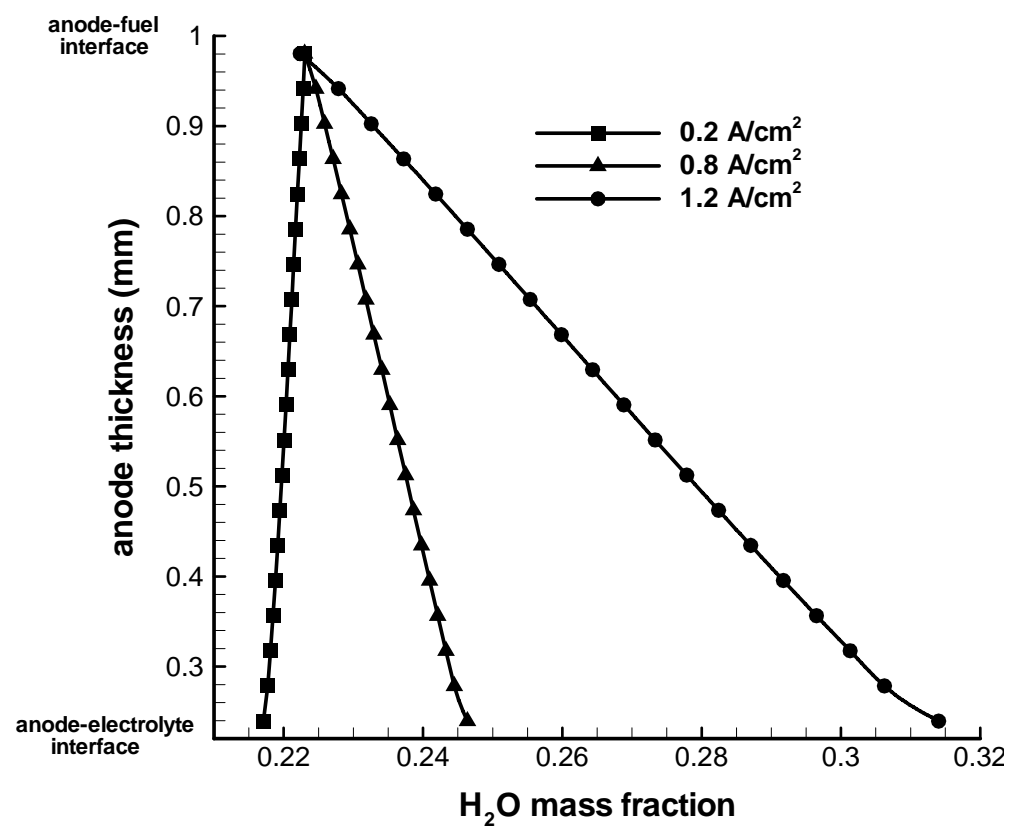

(c)

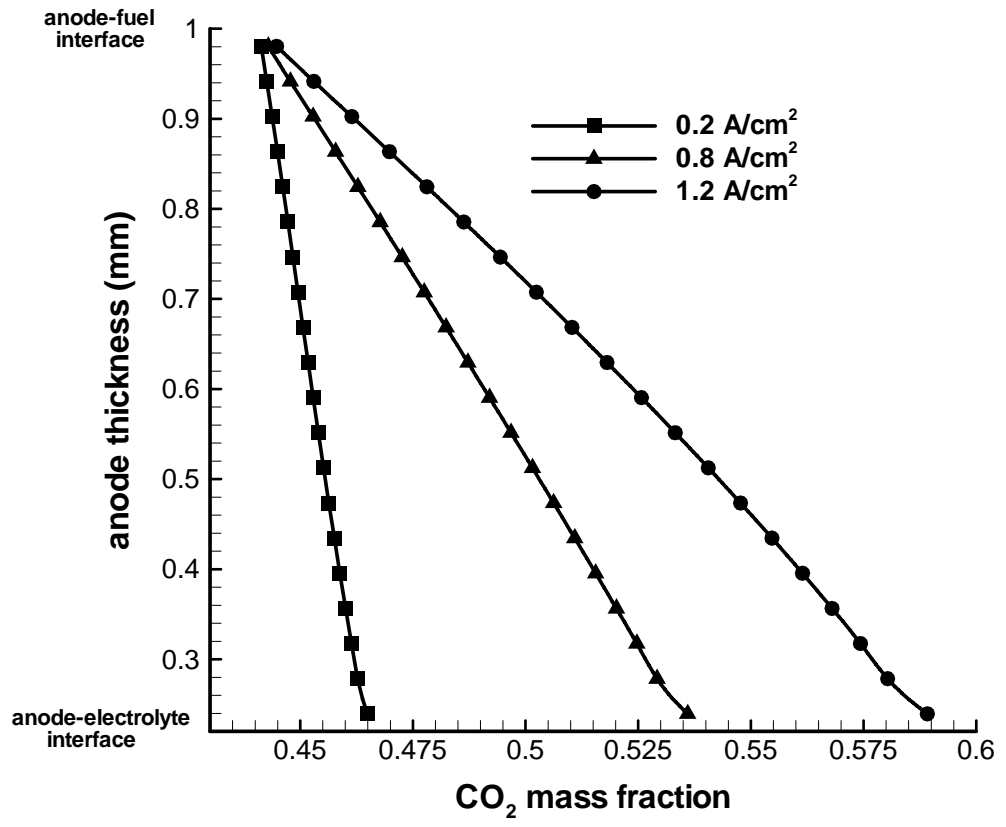

(d)

Figure 5.8 Mass fraction profile along the thickness of the anode for base case (a) $\mathrm{H}_{2}$,

(b) $\mathrm{CO}$, (c) $\mathrm{H}_{2} \mathrm{O}$ and (d) $\mathrm{CO}_{2}$ of a button cell operating on clean syngas 
The molar fractions and mass fractions of the species inside the electrodes at the electrode-electrolyte interface as a function of the current density are shown in Figure 5.9(a) and (b) respectively. The concentrations of the products of both electrochemical oxidation reactions $\left(\mathrm{H}_{2} \mathrm{O}\right.$ and $\left.\mathrm{CO}_{2}\right)$ increase as the current density increases, as expected. It is interesting to note that the hydrogen and carbon monoxide concentrations at the anodeelectrolyte interface appear to go to zero at the same current which suggests that for cells containing both of these fuels at the anode, there is only one limiting current. This behavior is presumably explained by the fact that these two fuels tend to equilibrate with each other through the water-gas shift reaction. The oxygen concentration at the cathode-electrolyte interface also decreases as the current density increases. However, the depletion of oxygen occurs at a lower rate than hydrogen and carbon monoxide, which suggests that the cell voltage is limited by the anode.

The oxygen concentration profiles (mass fraction) along the thickness of the cathode at different current densities are shown in Figure 5.10. Similar to the anode, the cathode shows the expected trends for oxygen concentration such as decrease at the cathodeelectrolyte interface as the current increases and linear profiles due to the absence of source terms inside the cathode, except at the cathode-electrolyte interface. It is interesting to note that the concentration in the first interior node close to the cathode-air interface is lower than the free stream concentration prescribed away from this interface. The concentration at this location reduces as the current density increases. The decline of the oxygen concentration is because of the prescribed mass transfer coefficient along with the free stream concentration to calculate the flux at the interface treated in this study as the boundary condition. Similar observations were noted by Goldin et al. [15]. The same kind of behavior but in a smaller degree can be seen in the anode-fuel interface in Figure 5.8. 


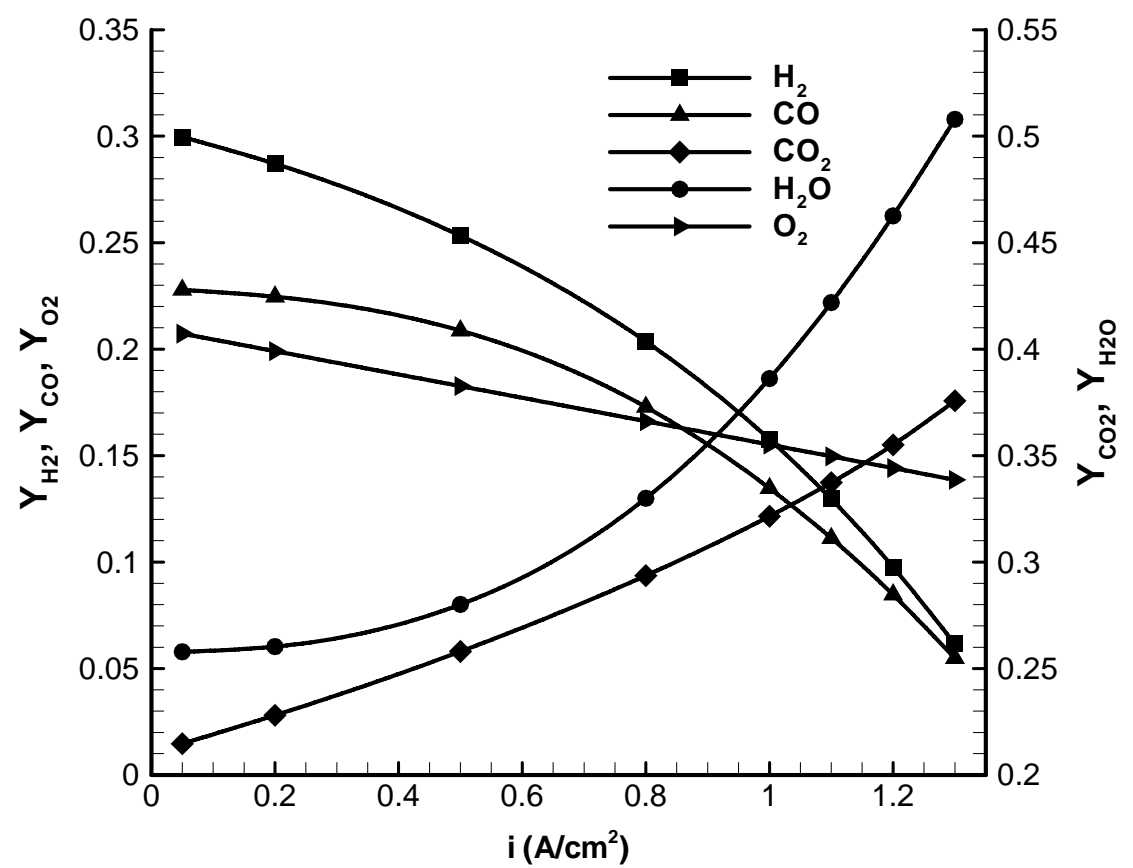

(a)

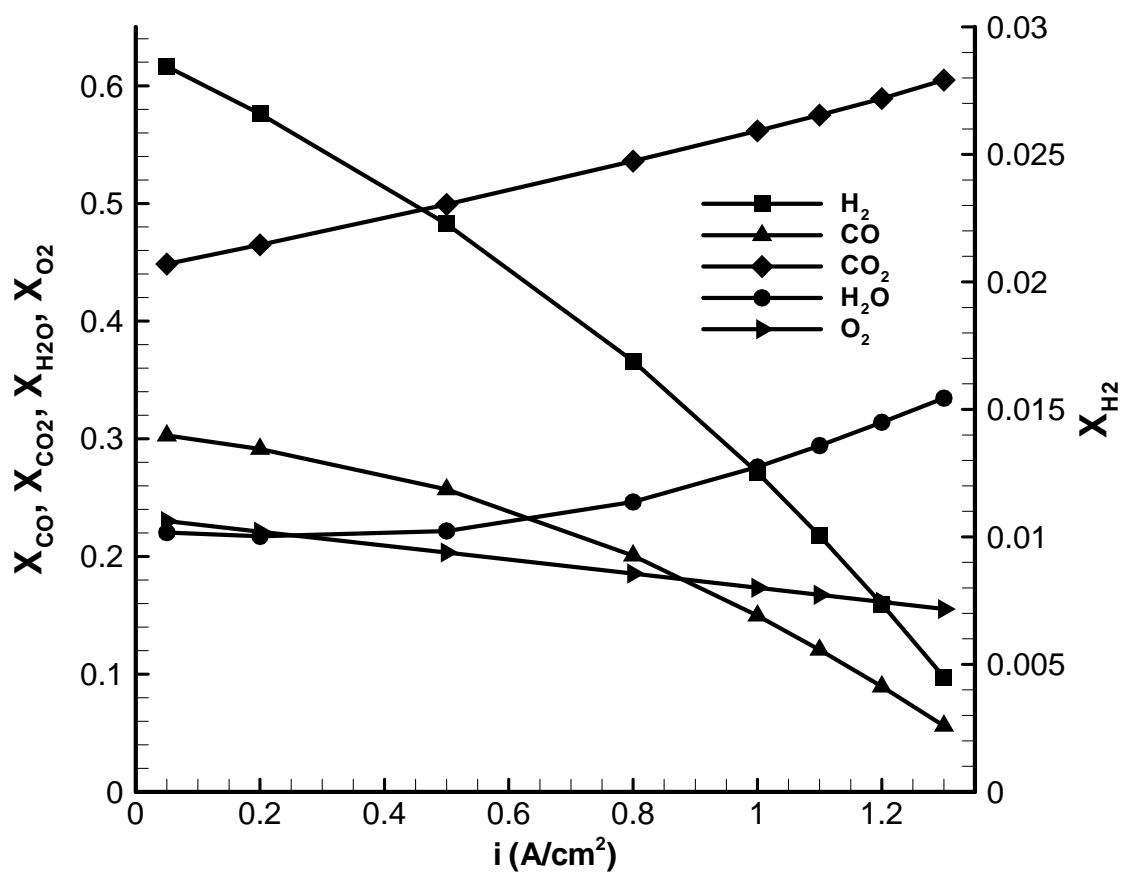

(b)

Figure 5.9 Species concentrations at the electrode-electrolyte interfaces of a button cell for the base case, (a) mole fractions and (b) mass fractions 


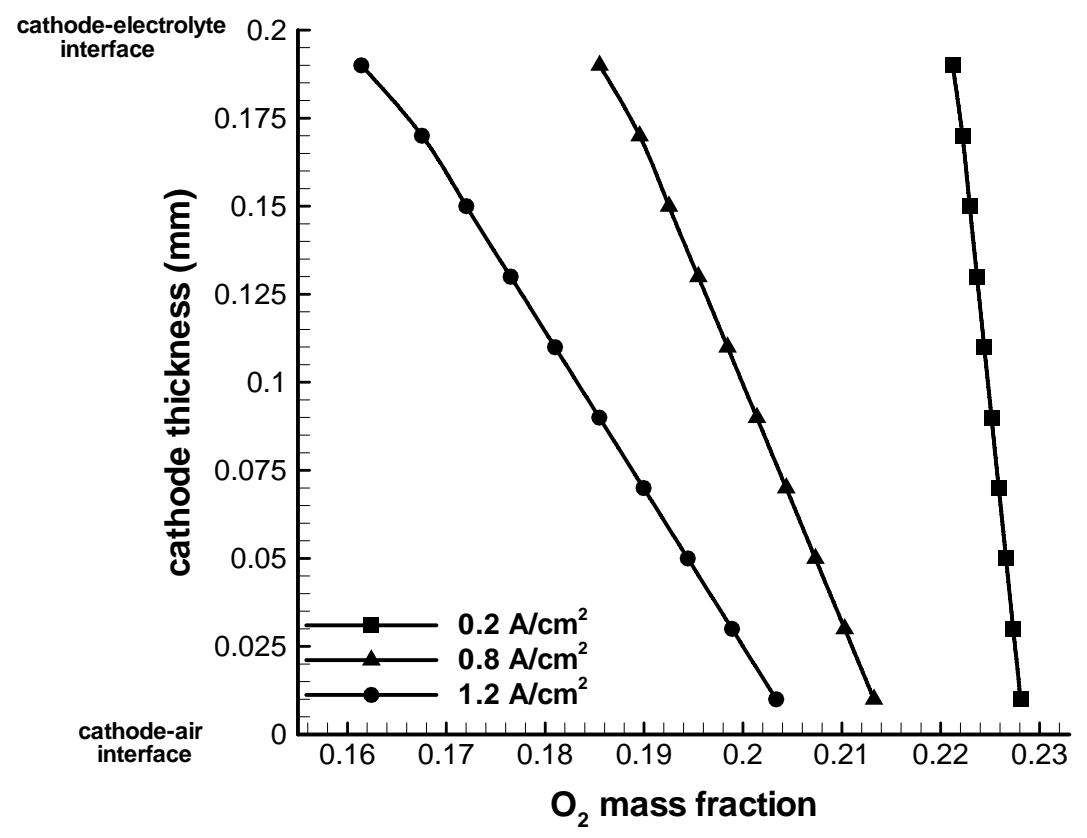

Figure 5.10 Oxygen mass fraction profiles along the thickness of the cathode of a button cell operating on syngas

The overpotentials predicted for a cell operating on a coal syngas mixture are shown in Figure 5.11. At high currents, the ohmic overpotential is the smallest overpotential while the hydrogen and carbon monoxide activation overpotentials are the largest, which confirms that the cell is limited by the anode. The hydrogen and carbon monoxide activation overpotentials are about equal over the whole current density range supported by the cell. This trend is expected according to the electrochemical model where the oxidation of hydrogen and carbon monoxide occurs in parallel and because the Nernst potentials for hydrogen and carbon monoxide are very close (since the operation is not far from chemical equilibrium.) At high currents a small difference is observed where the carbon monoxide overpotential is larger than the hydrogen activation overpotential. Even when the current supported by carbon monoxide is smaller than the current driven by hydrogen, its exchange current is lower than that for hydrogen, resulting in a higher overpotential. This is consistent with results from several other works in the literature, where it was observed that the activation overpotential of carbon monoxide is higher than hydrogen activation overpotential $[32,38]$ or that the exchange current for hydrogen is larger than that for carbon monoxide [6,32], resulting in a higher carbon monoxide overpotential. The 
concentration overpotential shows an expected trend as it increases rapidly at high currents. The faster decrease in the cell potential at high currents is attributed mainly to anode activation overpotentials as well as to the concentration overpotential to some extent.

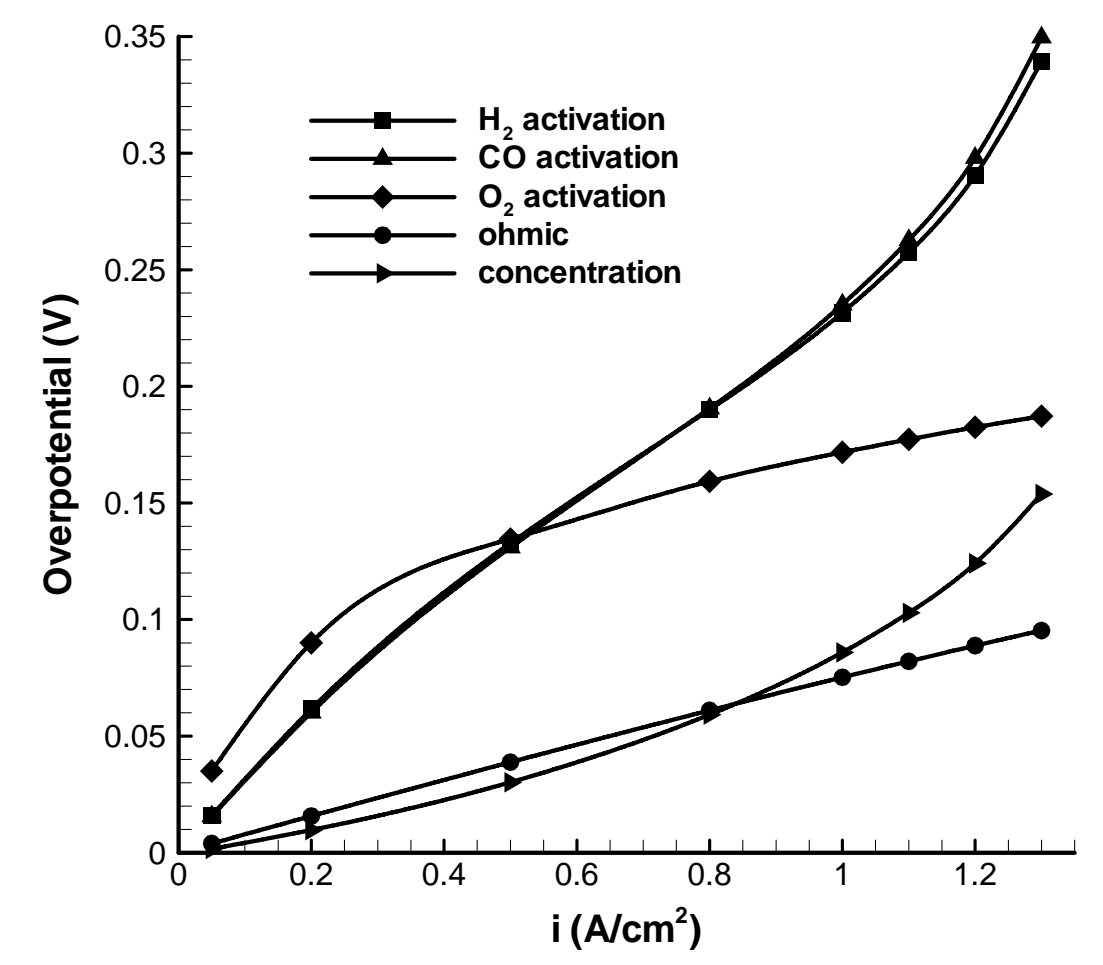

Figure 5.11 Overpotentials of a cell operating on clean syngas

The net production rates of the four species involved in the electrochemical oxidation of hydrogen and carbon monoxide are presented in Figure 5.12. The net production rate is positive if the species are being produced and negative if they are consumed. From these production rates it can be seen that, for the most part, the net production rates for carbon monoxide and water vapor are positive at low currents and those of carbon dioxide and hydrogen are negative which indicate that net water gas shift reaction is proceeding backwards inside the anode at low currents. However, at high currents this reaction proceeds in the forward direction producing hydrogen and carbon dioxide as can be seen in Figure 5.12. It is also observed that on the top part of the electrode (anode-fuel stream interface, $\mathrm{y} \approx 1 \mathrm{~mm}$ ) from medium to high currents, the water gas shift reaction proceeds in the reverse direction. The opposite trend happens in the bottom part of the anode (anode- 
electrolyte interface, $y \approx 0.22 \mathrm{~mm}$ ) in the same range of current densities. This can be explained by the fact that as the current increases, the water vapor concentration at the anode-electrolyte interface increases while the hydrogen concentration decreases at the same time, resulting in net forward water gas-shift reaction. With the increase of the current, the magnitude of the net production rates increases. This can be attributed to the temperature increase (see Figure 5.15a) i.e. the higher the temperature the faster the reactions and higher utilization, as well as to the concentration distribution.

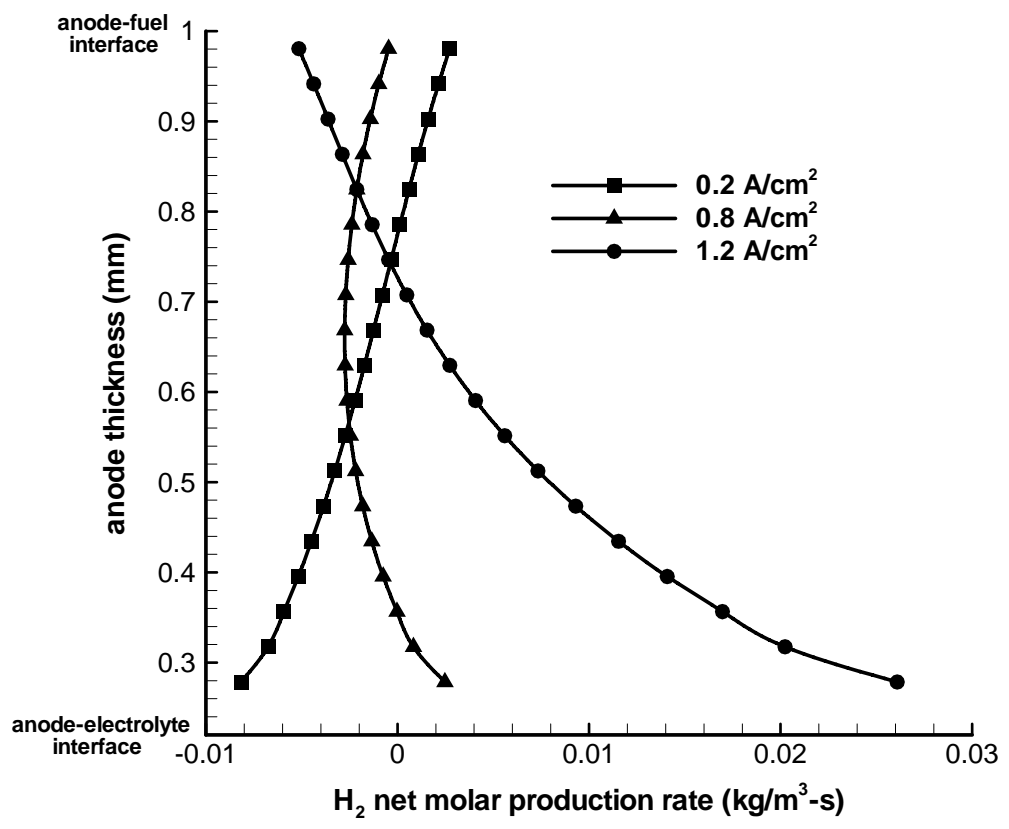

(a) 


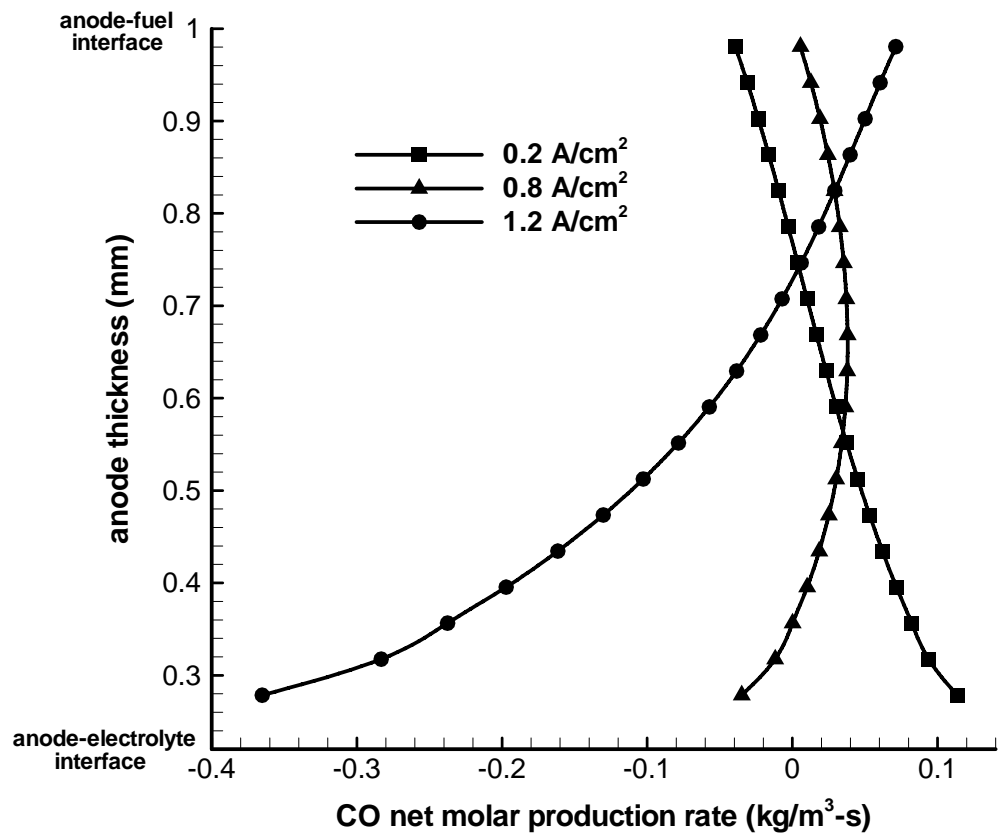

(b)

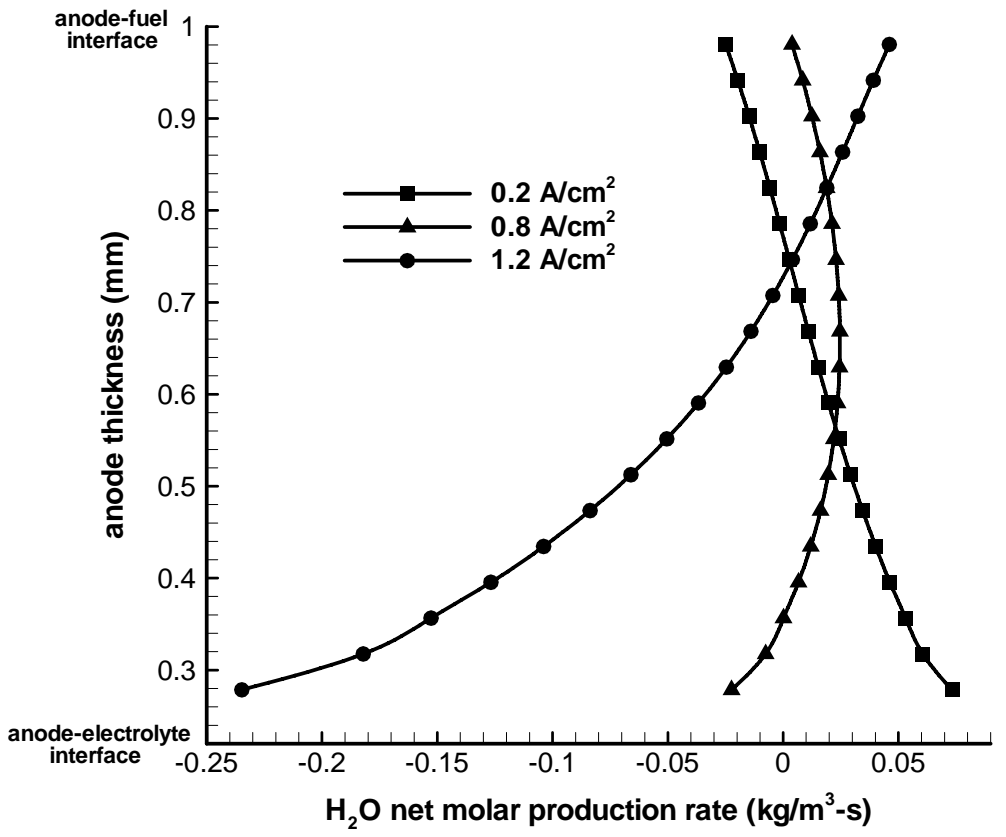

(c) 


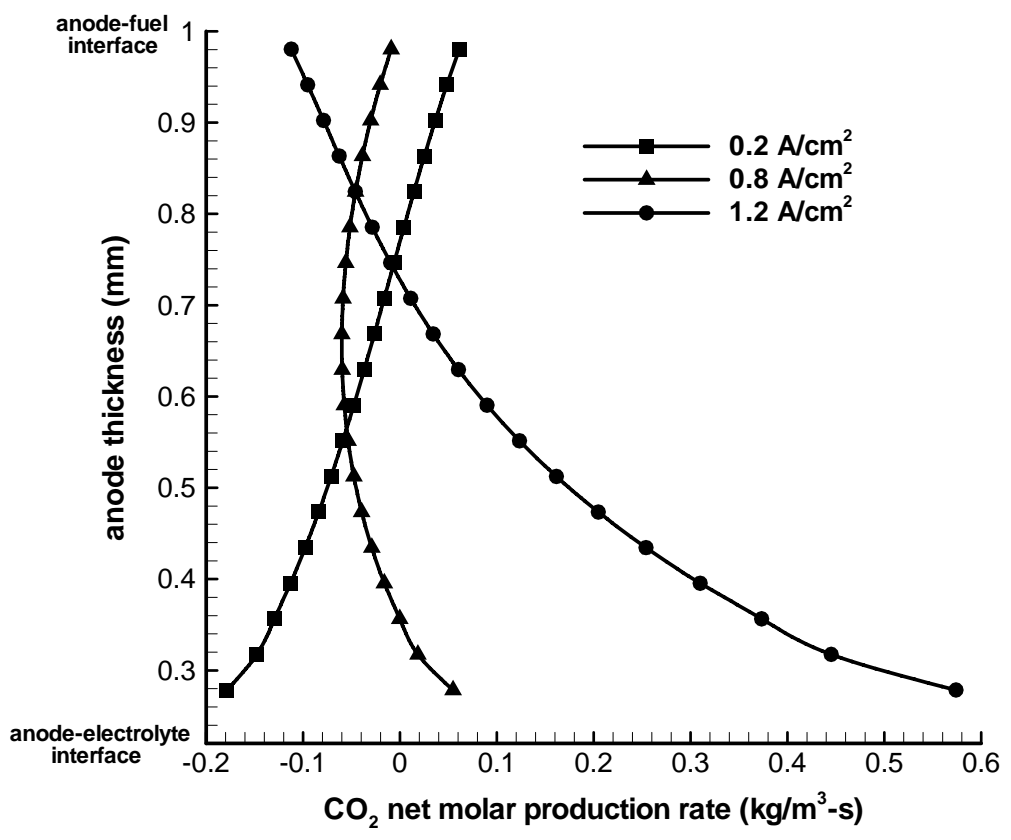

(d)

Figure 5.12 Net molar production rates inside the anode for (a) $\mathrm{H}_{2}$, (b) $\mathrm{CO}$, (c) $\mathrm{H}_{2} \mathrm{O}$ and (d) $\mathrm{CO}_{2}$ of a button cell operating on coal syngas

The net production rate for methane is shown in Figure 5.13. As it can be seen, methane is produced in the anode electrode, which implies that methane reforming reaction proceeds in the reverse direction. It is important to note that the net production rate for methane is small since the reverse reaction rate is slow. As the current density is increased, the production rate of methane decreases because less hydrogen and carbon monoxide are available as they are depleted by the electrochemical reactions. 


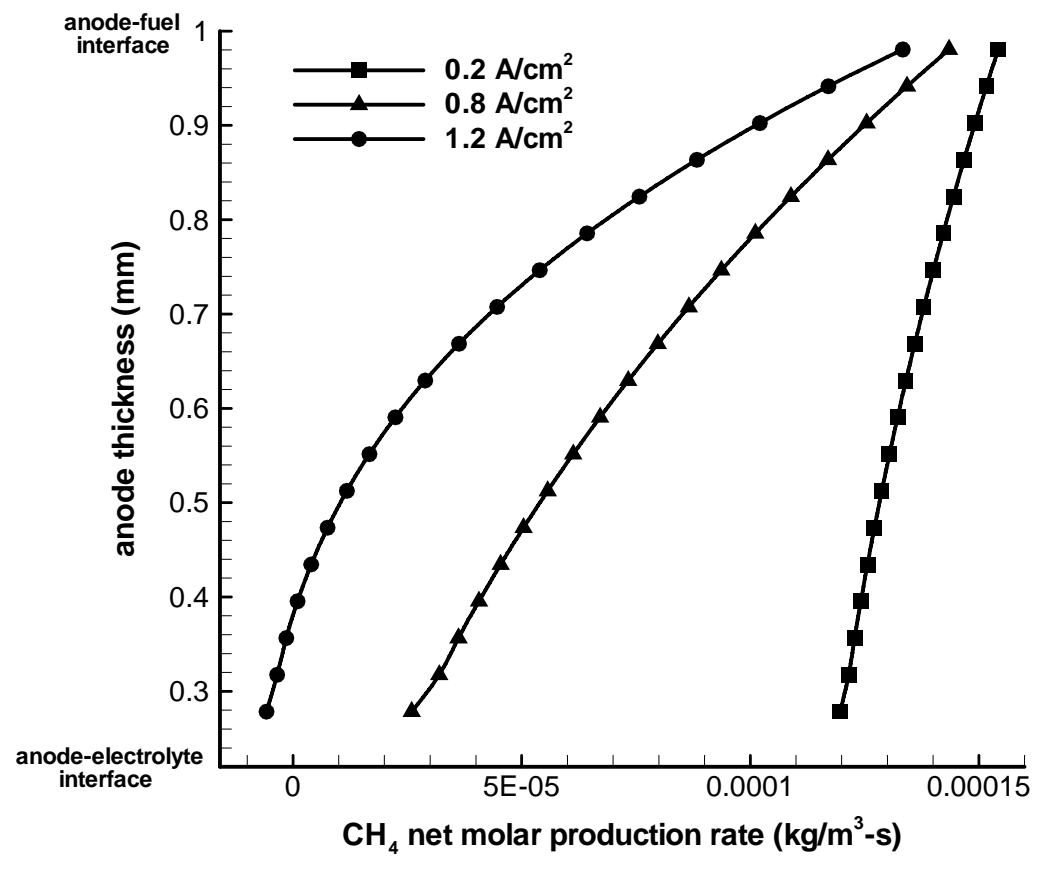

\section{Figure 5.13 Net molar production rate of methane inside the anode of a button cell operating on coal syngas}

For coal syngas composition, simultaneous electrochemical oxidation of hydrogen and carbon monoxide occurs at the anode-electrolyte interface. The numerical model predicts quantitatively the splitting of the total current between current produced from separate oxidation of hydrogen and carbon monoxide. The splitting of the total current is shown in Figure 5.14. As it can be seen from Figure 5.14, the current supported by hydrogen oxidation is always larger than that produced from carbon monoxide oxidation. The ratio of hydrogen current and carbon monoxide current is dependent on the total current. As can be seen from Figure 5.14(b) this ratio varies between around 6.2 at low currents and 5.2 at high currents. The ratio predicted by the electrochemistry model employed here is larger than the ratio of 2.5 proposed by Suwanwarangkul [6], the ratio of 4.0 used by Gemmen and Trembly [5] and, the ratios of 1.9 to 2.3 and 2.3 to 3.1 at $1023 \mathrm{~K}$ and $1073 \mathrm{~K}$ respectively, determined experimentally by Matsuzaki and Yasuda [32]. However, when the percentage of the current supported by hydrogen is calculated (see Figure 5.14(b)), it is observed that it varies only slightly around $85 \%$ with respect to the total current density. Nishino et al. [27] found that at high currents, the ratio of hydrogen current to carbon 
monoxide current is approximately one. This behavior was not observed in this study, even though the ratio decreases as the total current increases.

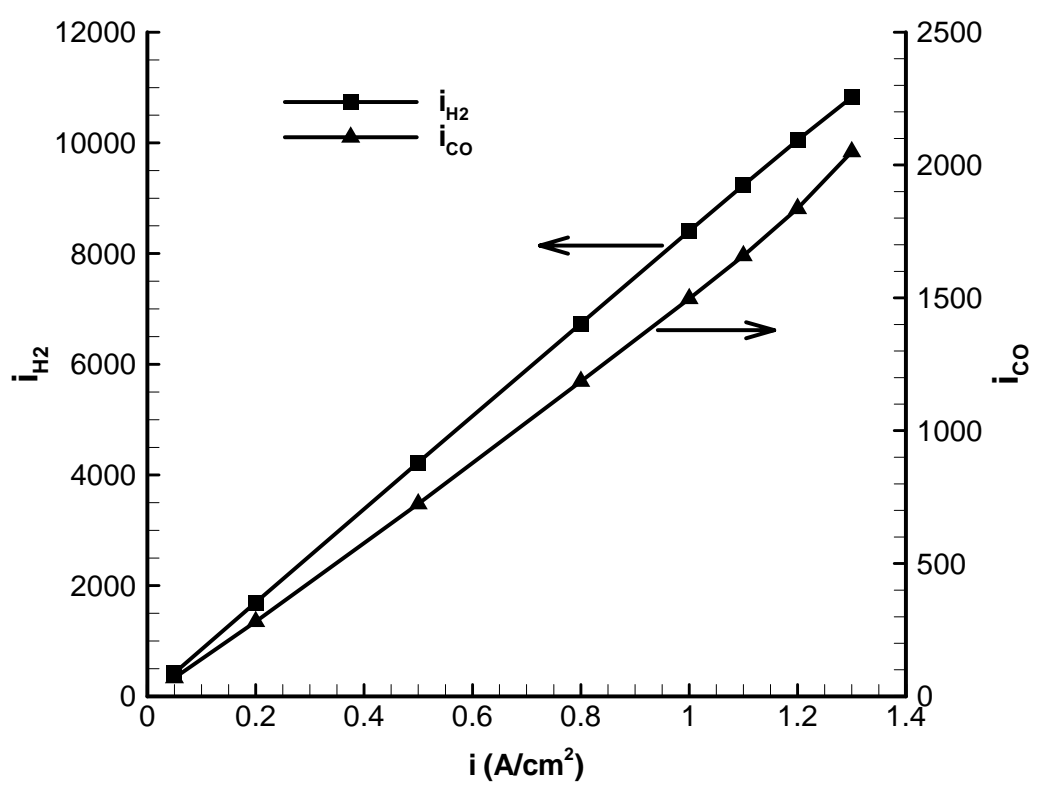

(a)

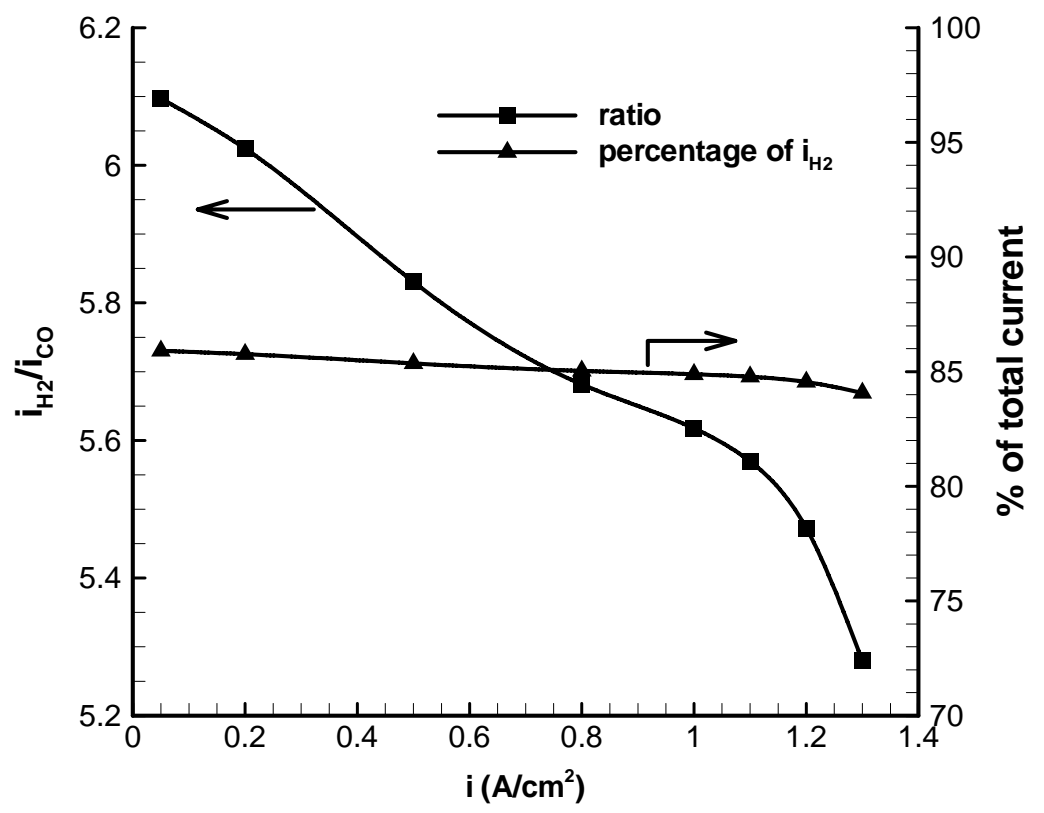

(b)

Figure 5.14 Predicted $\mathrm{H}_{2}$ and $\mathrm{CO}$ currents in a button cell operating on syngas (a) splitting of the total current and (b) ratio between $\mathrm{H}_{2}$ and $\mathrm{CO}$ current 
The maximum temperature inside the button cell is found to be occurring in the electrolyte layer. This maximum cell temperature expressed as change in temperature with respect to the operating temperature of $800^{\circ} \mathrm{C}$, is plotted against the cell current in Figure 5.15(a). As expected the cell temperature increases with the current. When the cell is fed with clean syngas the maximum temperature of the button cell is about 16 degrees higher than the surroundings when the cell supports a high current i.e. close to limiting current. The different sources of heat in the fuel cell are shown in Figure 5.15(b). It is important to note that the entropic heat is always larger than the ohmic heat. From the same figure it can be seen that the overall heat of reaction from the methane reforming and water gas shift reactions (i.e. surface reactions, scale on the right y-axis) is negligible compared with entropic and ohmic heat. Also, it is interesting to note that the net heat production due to surface reactions from the water gas shift reaction is negative in the range from low to medium current densities whereas it is positive at high current densities. Therefore, it can be concluded that the net water gas shift reaction proceeds forward at high current densities. On the other hand, the heat from the methane reforming reaction is negligible compared with that from the water gas shift reaction as a consequence of the rate of both reactions, being faster that of the water gas shift reaction. However, it can be seen in Figure 5.15(b) that the methane reforming reaction proceeds mainly in the reverse direction producing methane and water vapor over the whole cell current density range. 


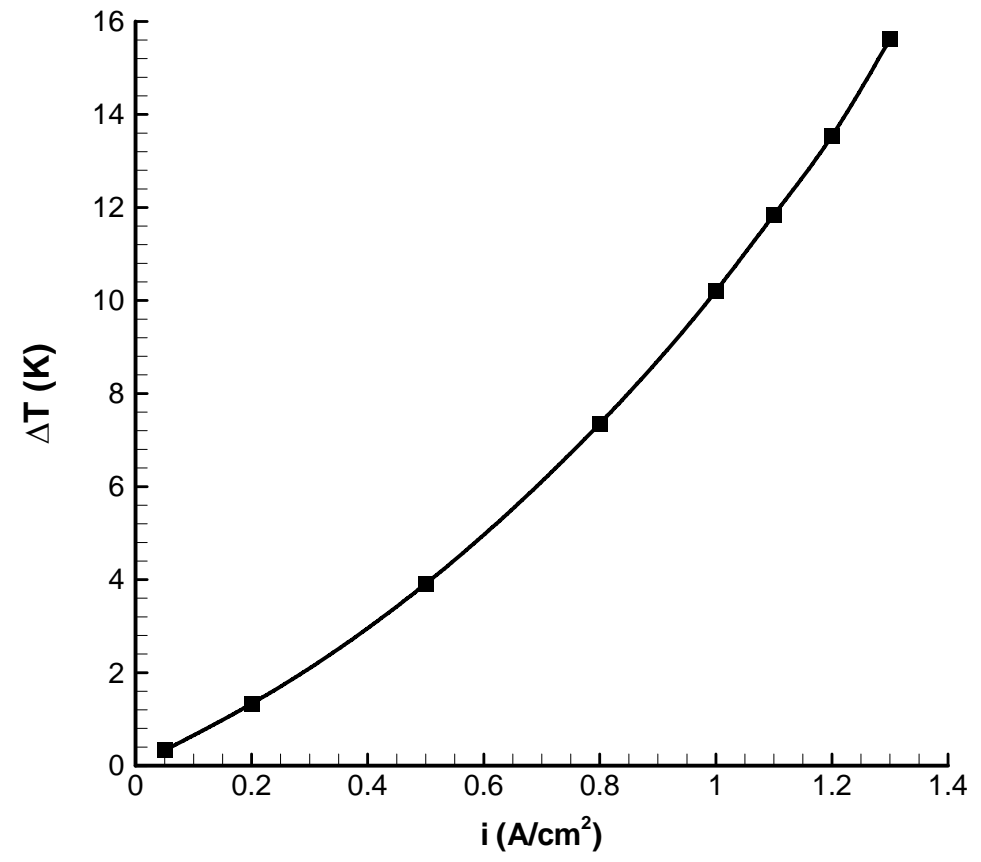

(a)

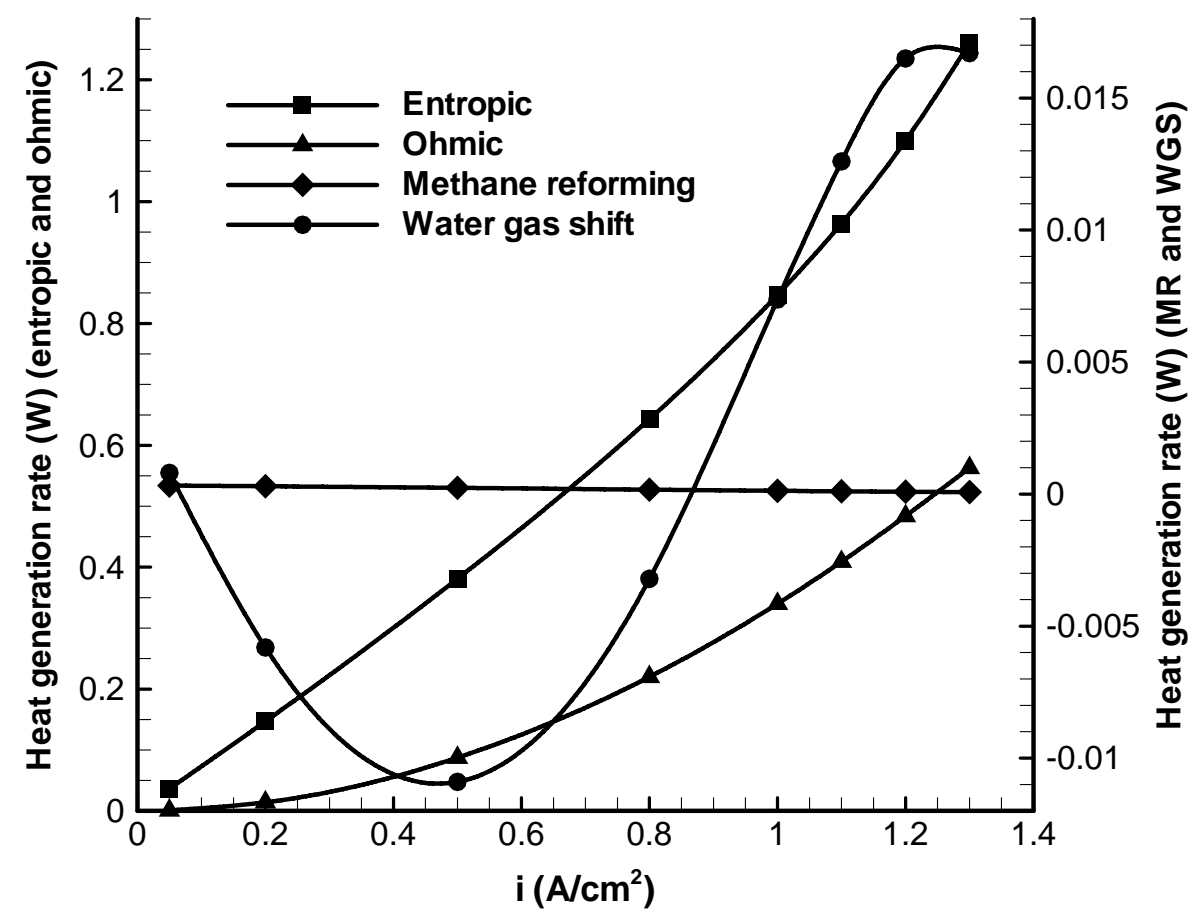

(b)

Figure 5.15 Variation of the (a) maximum change in cell temperature and (b) heat sources for a cell operating on clean syngas 


\subsection{Assessment of Numerical Uncertainty}

In this section, the numerical uncertainty for the case of the button cell operating at $800^{\circ} \mathrm{C}$ and running on wet hydrogen is assessed. This case was selected because of the fact that the numerical prediction on the performance of this cell did not compare well with the results obtained experimentally as shown in Figure 5.7.

In order to assess the uncertainty with the method applied in this study (described in the following section), numerical simulations on three different grids are needed. Thus, the grid described at the beginning of this chapter is used as one of those three grids (triplet), the refining and coarsening of that grid yielded the other two grids required. The original grid was refined by doubling the grid in each direction and coarsened by halving the grid density in each direction. The details of the three grids used for the assessment of the numerical uncertainty are described in Table 5.5.

Table 5.5 Number of computational cells used in the three grids to assess numerical uncertainty

\begin{tabular}{l|cccc}
\hline \multicolumn{1}{c|}{ Grid } & x-direction & y-direction & z-direction & Total \\
\hline Fine $\left(\mathrm{G}_{1}\right)$ & 100 & 80 & 100 & 800000 \\
Medium $\left(\mathrm{G}_{2}\right)$ & 50 & 40 & 50 & 100000 \\
Coarse $\left(\mathrm{G}_{3}\right)$ & 25 & 20 & 25 & 12500 \\
\hline
\end{tabular}

The method used to assess the numerical uncertainty was proposed and developed by Celik et al. [61, 62] to predict the true error. It is a variant of the extrapolation method proposed by Celik et al. [63, 64] named Approximate Error Scaling method (AES). The method is briefly described below. 


\subsubsection{Error Estimation Method}

This method is based on the idea that assumes that the true error, $E_{t}$ is proportional to the approximate error, $E_{a}$, that is

$$
E_{t}^{h}=c E_{a}^{h}
$$

where $c$ represents the global proportionality constant.

The true error is defined by

$$
E_{t}^{h}=\phi-\phi_{h}
$$

where ' $\phi$ ' is the true solution and ' $\phi_{h}$ ' is the approximate solution obtained using grid of average size ' $h$ '. The approximate error given by

$$
E_{a}^{h}=\phi_{h}-\phi_{\alpha h}
$$

In Eqn. (5.5.3), $\alpha$ is the grid refinement or coarsening factor i.e. $\alpha_{1}=h_{2} / h_{1}, \alpha_{2}=h_{3} / h_{2}$, etc., where $h_{i}$ represents the average grid size, also $h_{1}<h_{2}<h_{3}$ which means that subscript " 1 " denotes the smallest grid size (finest grid) and subscript " 3 " the coarsest grid.

In order to apply Eqn. (5.5.1) three grid calculations (triplet) are needed. The postprocessing of the numerical solutions on three different grids $\left(\phi_{1}, \phi_{2}, \phi_{3}\right)$ and the use of Eqn. (5.5.1) enable determination of the local proportionality constant $c_{i, j, k}$ given by

$$
\begin{aligned}
& c_{i, j, k}^{1}=\frac{\phi_{2}^{i, j, k}-\phi_{1}^{i, j, k}}{\phi_{3}^{i, j, k}-2 \phi_{2}^{i, j, k}+\phi_{1}^{i, j, k}} \\
& c_{i, j, k}^{2}=\frac{\phi_{3}^{i, j, k}-\phi_{2}^{i, j, k}}{\phi_{3}^{i, j, k}-2 \phi_{2}^{i, j, k}+\phi_{1}^{i, j, k}}
\end{aligned}
$$

The global proportionality constant $c$ is calculated from the local constants as follows 


$$
c=\frac{1}{2} \frac{\left\|c_{i, j, k}^{1}\right\|_{\infty}+\left\|c_{i, j, k}^{2}\right\|_{\infty}}{N}
$$

and the operator

$$
\left\|c_{i, j, k}\right\|_{\infty}=\sum_{m=1}^{N}\left|c_{i, j, k}\right|
$$

$N$ in Eqns. (5.5.6) and (5.5.7) represents the total number of computational cells in the coarse grid. It is important to note that $\phi_{h}$ in Eqns. (5.5.4) and (5.5.5) represents each of the variables solved by the numerical calculations i.e. potential, cell temperature, species concentrations, etc., on the grid size $h$, therefore, there is a global proportionality constant for each variable being solved. This methodology although written in this section for applications in 3D (indices $i, j, k$ ), it can also be applied in two and one-dimensional problems as well as in integral quantities.

\subsubsection{Uncertainty Estimation Method}

Once the global proportionality constant has been calculated as shown by Eqn. (5.5.6) and making use of the relationship between the true error and the approximate error as given by Eqn. (5.5.1) the uncertainty can be calculated using the Grid Converging Index (GCI) uncertainty estimator. The calculation of the uncertainty is based on the use of the fine and medium grids from the same triplet used to calculate the global proportionality constant. Re-writing Eqn. (5.5.1) for the grids mentioned above

$$
E_{t}^{f m}=c E_{a}^{f m}
$$

where the superscript $f m$ means that interpolation was performed from the fine grid to the medium grid. The definitions of the true and approximate errors shown in Eqn. (5.5.8) are given by

$$
E_{t}^{f m}=\phi_{e x t}^{f m}-\phi_{f m}^{n u m}
$$




$$
E_{a}^{f m}=\phi_{f m}^{n u m}-\phi_{m}^{n u m}
$$

where $\phi_{e x t}^{f m}$ represents the extrapolated value at zero grid size which is an estimate of the analytical value. Substituting Eqns. (5.5.9) and (5.5.10) in Eqn. (5.5.8) and solving for $\phi_{e x t}^{f m}$ we get

$$
\phi_{e x t}^{f m}=\phi_{f m}^{n u m}+c\left(\phi_{f m}^{n u m}-\phi_{m}^{n u m}\right)
$$

Then the uncertainty is calculated using the GCI which is given by

$$
G C I=1.25\left|\frac{\phi_{e x t}^{f m}-\tilde{\phi}_{f}}{\tilde{\phi}_{f}}\right|
$$

where $\tilde{\phi}_{f}$ is the interpolated value from the numerical solution on the fine grid.

The methodology described previously for the calculation of the proportionality constant as well as for the uncertainty is the same when applied to local or integral quantities.

\subsubsection{Results}

The methodology to assess the numerical uncertainty described above was applied to the button cell running on wet hydrogen $\left(97 \% \mathrm{H}_{2}-3 \% \mathrm{H}_{2} \mathrm{O}\right)$ at $800^{\circ} \mathrm{C}$. The numerical simulations on the three grids needed by the method were performed for four different total currents supported by the cell: 1, 2, 3 and 4 A. Therefore 12 cases were simulated using DREAM-SOFC to assess the numerical uncertainties at different current densities smaller than the experimentally determined limiting current. Special attention was given to some of the solved variables such as cell potential, maximum cell temperature, mass fraction of the species $\mathrm{H}_{2}, \mathrm{H}_{2} \mathrm{O}$ and $\mathrm{O}_{2}$ at the electrode-electrolyte interface, hydrogen and oxygen activation overpotentials and, ohmic and entropic heat. The error bars for some of these variables are shown in Figure 5.16. The smallest error bars were calculated for the cell 
potential and entropic heat, whereas the ohmic heat was the parameter that showed the largest error bars. The rest of the variables show considerably low numerical errors. It was observed in all the variables for which the numerical error was assessed, that the numerical error increases as the current supported by the cell increases. This fact suggests that only at high currents (where the dynamics are faster) finer grids may be needed to discretize the computational domain, especially in the direction normal to the cell surface. This observation is also supported by the fact that the numerical error in the ohmic heating is the largest, since it is a function of the gradient of the electric potential in the direction normal to the cell.

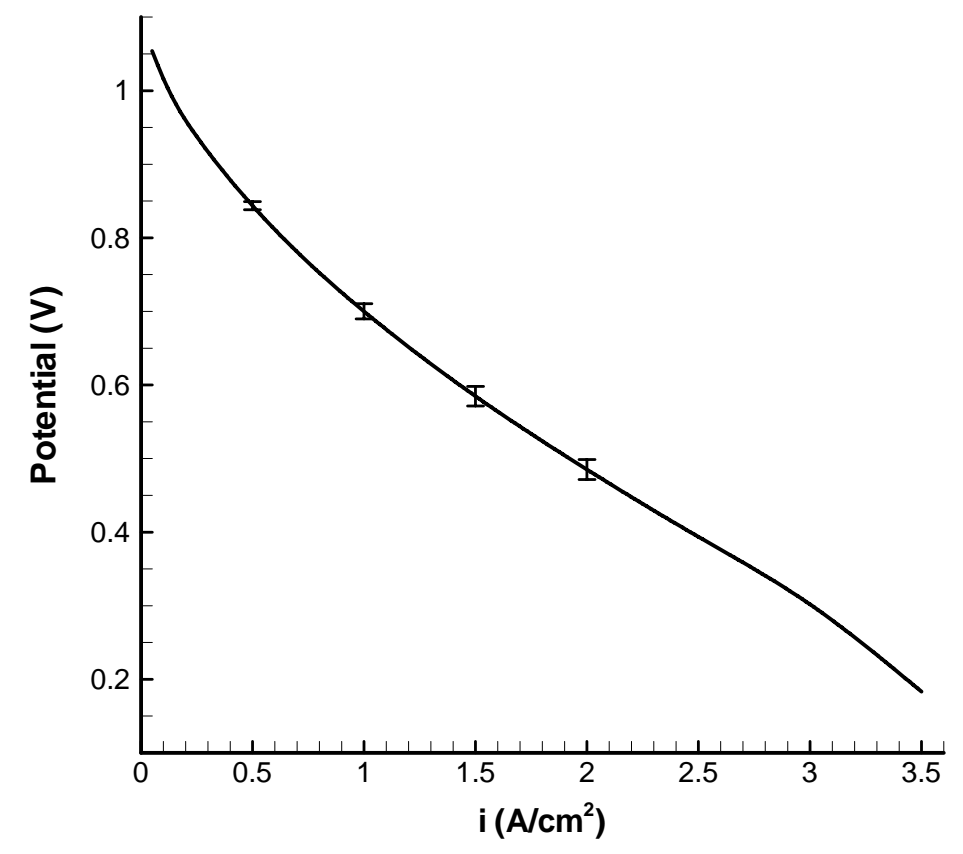

(a) 


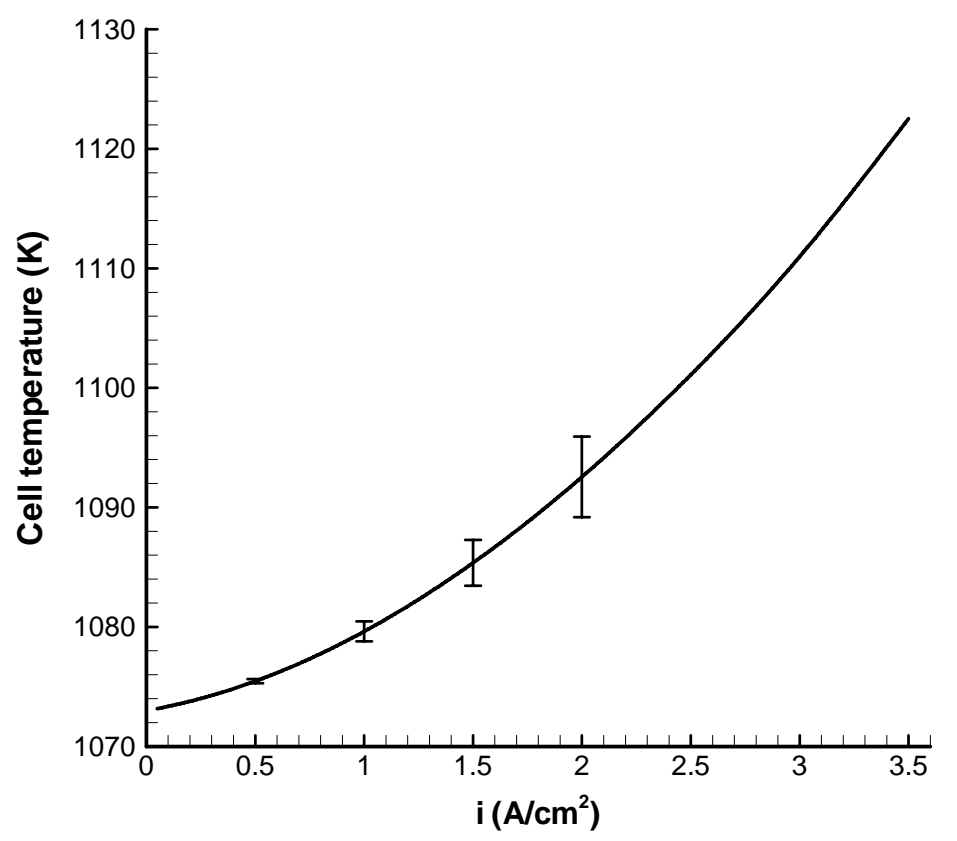

(b)

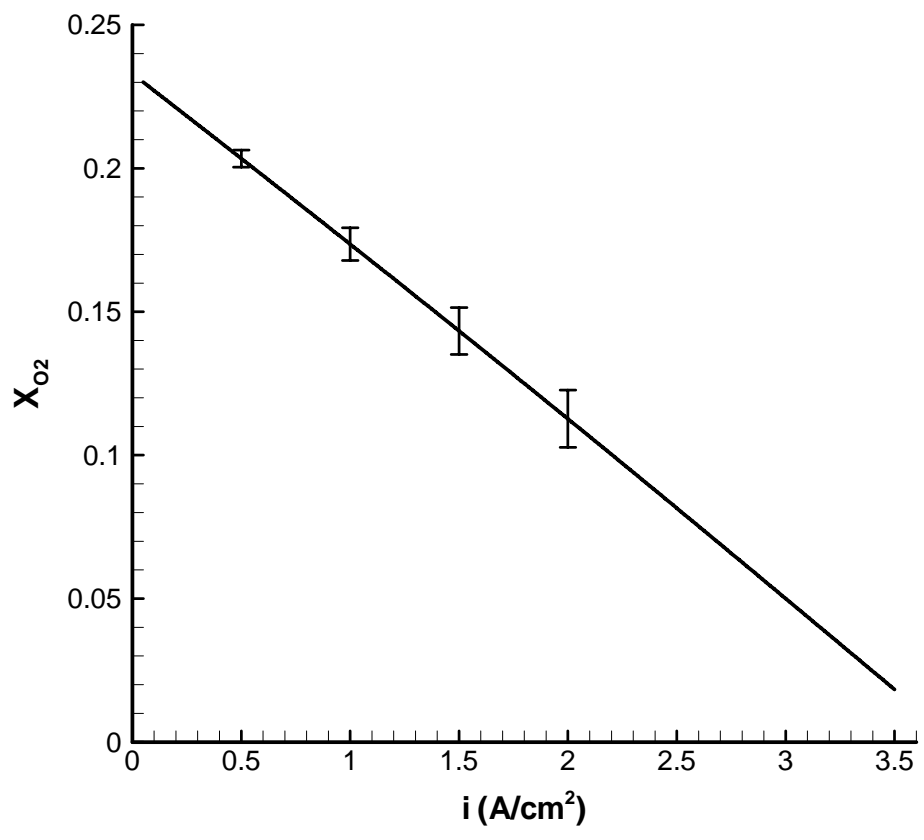

(c) 


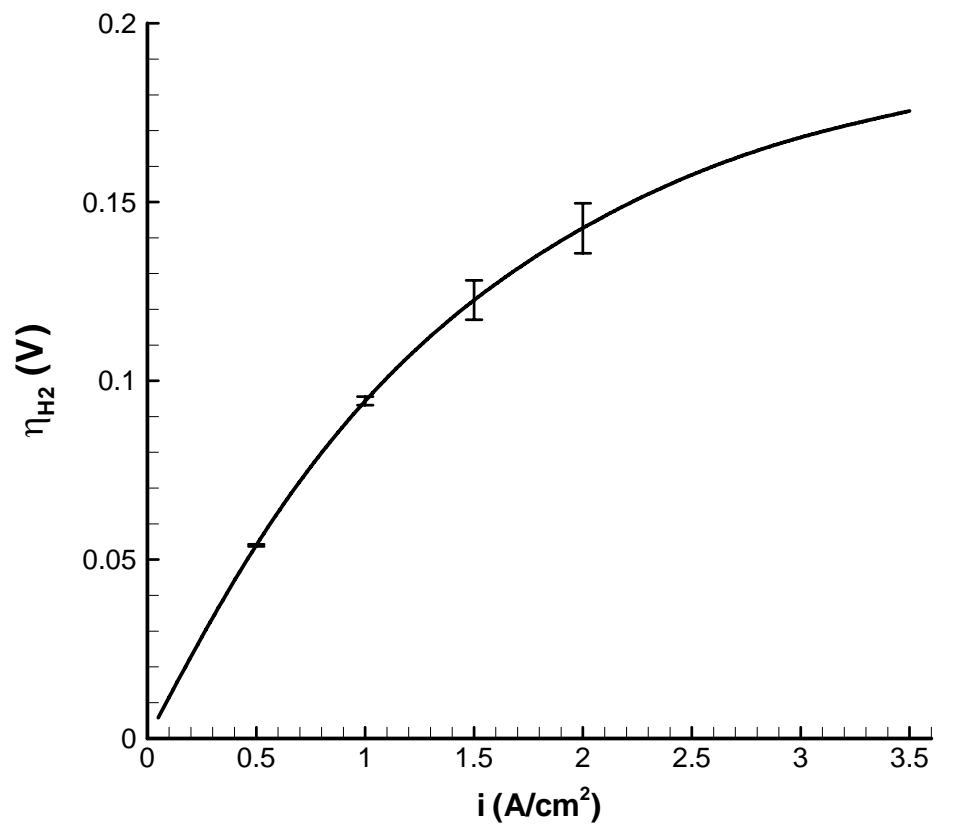

(d)

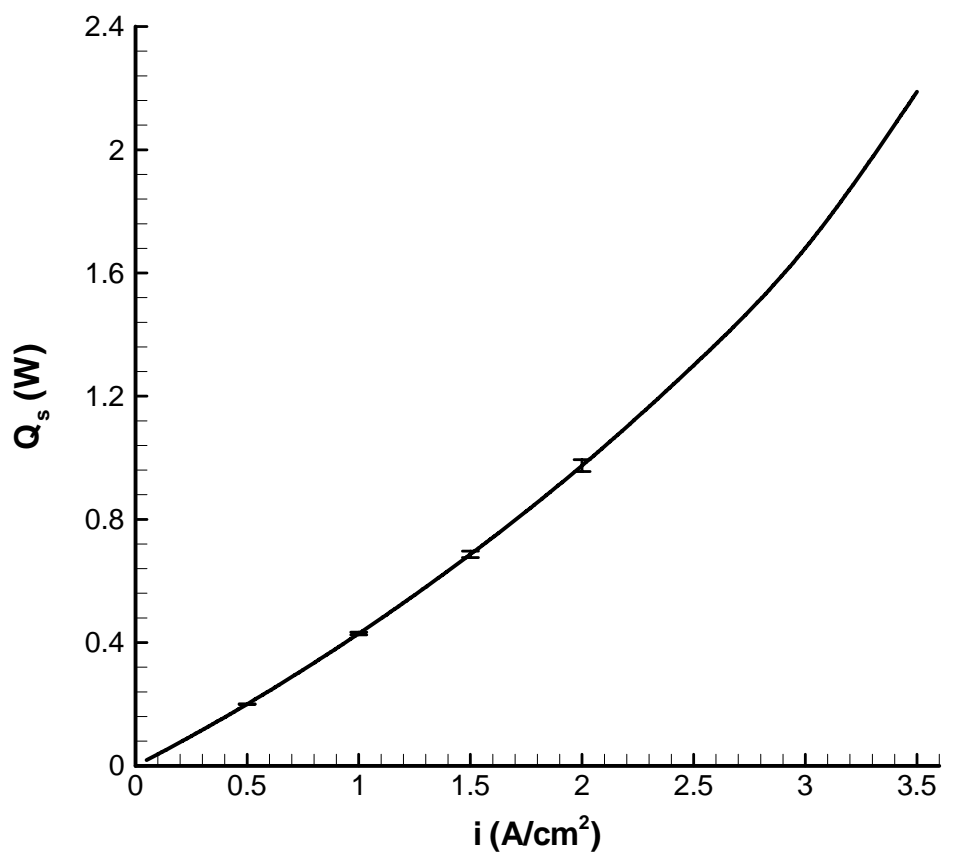

(e) 


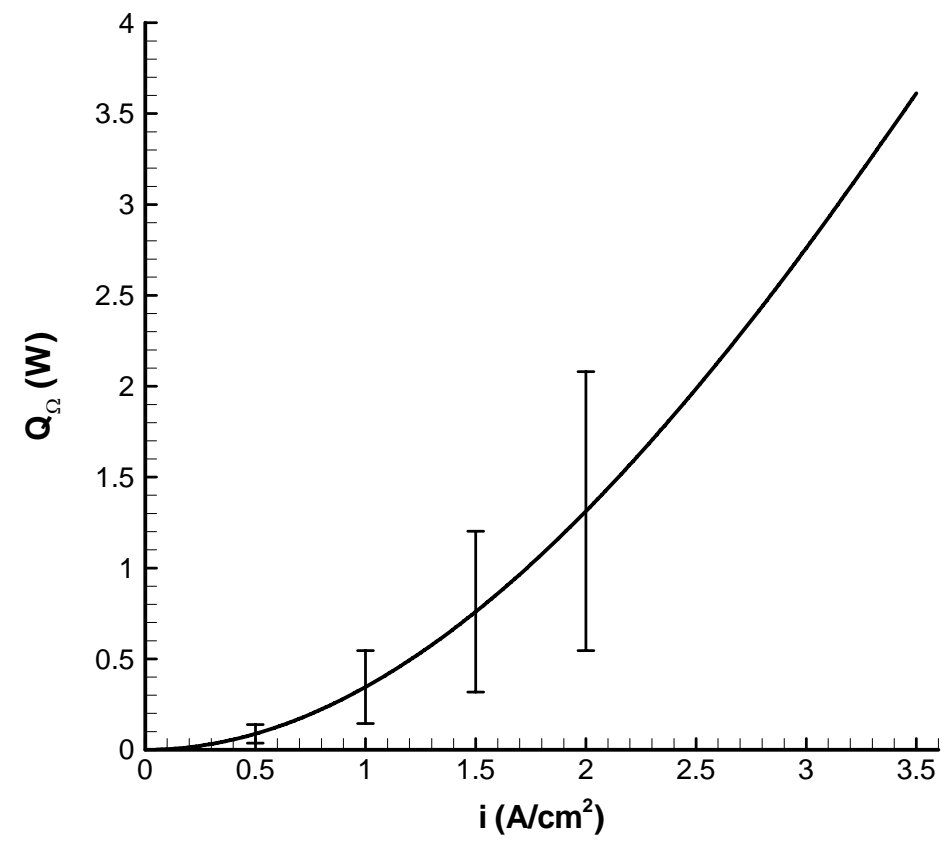

(f)

Figure 5.16 Estimated error bars using AES method for (a) cell potential, (b) cell maximum temperature, (c) oxygen mass fraction at the cathode-electrolyte interface, (d) hydrogen activation overpotential, (e) entropic heat, and (f) ohmic heat

The numerical uncertainties for the variables mentioned above at the four different current densities are reported in Table 5.6 as percentages. As it can be seen and expected according to the error bars discussed above, the numerical uncertainty increases as the current density increases. Excluding the ohmic heating whose numerical uncertainty is around 58\%, for most of the variables shown in Table 5.6, the uncertainty is less than about $2 \%$ at current densities less than $1 \mathrm{~A} / \mathrm{cm}^{2}$, and less than $5 \%$ at higher currents, which are acceptable numerical uncertainties. 
Table 5.6 Estimated numerical uncertainty of a button cell operating on wet hydrogen at different current densities

\begin{tabular}{|c|ccccccccc|}
\hline & \multicolumn{8}{|c|}{ Uncertainty (\%) } \\
\hline $\mathrm{i}\left(\mathrm{A} / \mathrm{cm}^{2}\right)$ & $\mathrm{V}$ & $T_{\text {cell }}$ & $X_{\mathrm{O}_{2} \text {,int }}$ & $X_{\mathrm{H}_{2} \text {,int }}$ & $X_{\mathrm{H}_{2} \mathrm{O} \text {,int }}$ & $\eta_{\mathrm{O}_{2}}$ & $\eta_{H_{2}}$ & $Q_{s}$ & $Q_{\Omega}$ \\
\hline 0.5 & 0.64 & 0.02 & 1.47 & 0.17 & 0.48 & 0.40 & 0.62 & 0.44 & 57.77 \\
1 & 1.49 & 0.08 & 3.31 & 0.35 & 0.85 & 1.88 & 1.28 & 0.97 & 57.98 \\
1.5 & 2.29 & 0.18 & 5.75 & 0.61 & 1.13 & 3.31 & 4.46 & 1.49 & 58.21 \\
2 & 2.83 & 0.31 & 8.86 & 0.86 & 1.36 & 5.41 & 4.90 & 1.99 & 58.46 \\
\hline
\end{tabular}

Even with a high numerical uncertainty in the overall ohmic heating, the cell temperature which is dependent on the ohmic heating showed the lowest numerical uncertainty, less than $0.5 \%$. For the cell potential which depends not only on the cell temperature (ohmic heating) but also on species concentrations, overpotentials, etc., a low assessed numerical uncertainty, less than $3 \%$ at $4 \mathrm{~A}$, was calculated. Therefore, it can be concluded that the estimated numerical uncertainties, especially those for the main variables such as cell potential, temperature and species concentrations, are reasonably low showing that the incurred numerical errors do not considerably affect the numerical calculations. 


\section{Chapter 6}

\section{PARAMETRIC ANALYSIS}

In this chapter the validated/calibrated code DREAM-SOFC is used to predict the performance of a button cell operating under several different conditions. The effect of these operating conditions which include: operating temperature, operating fuel stream composition, supplied fuel stream to the anode not at equilibrium, activation energy in the exchange current for carbon monoxide, and electrochemical oxidation of carbon monoxide is studied.

\subsection{Temperature Effect}

Numerical simulations of a button cell operating at $750^{\circ} \mathrm{C}$ and $850^{\circ} \mathrm{C}$ were performed. The fuel composition is the same as that used in the baseline case (syngas) and reported in Table 5.4. From numerical simulations it was observed (as expected) that the higher the operating temperature the better the performance of the cell, as shown in Figure 6.1. The

maximum power densities were about $0.33,0.38$ and $0.43 \mathrm{~W} / \mathrm{cm}^{2}$ at $750^{\circ} \mathrm{C}, 800^{\circ} \mathrm{C}$ and $850^{\circ} \mathrm{C}$, respectively. 


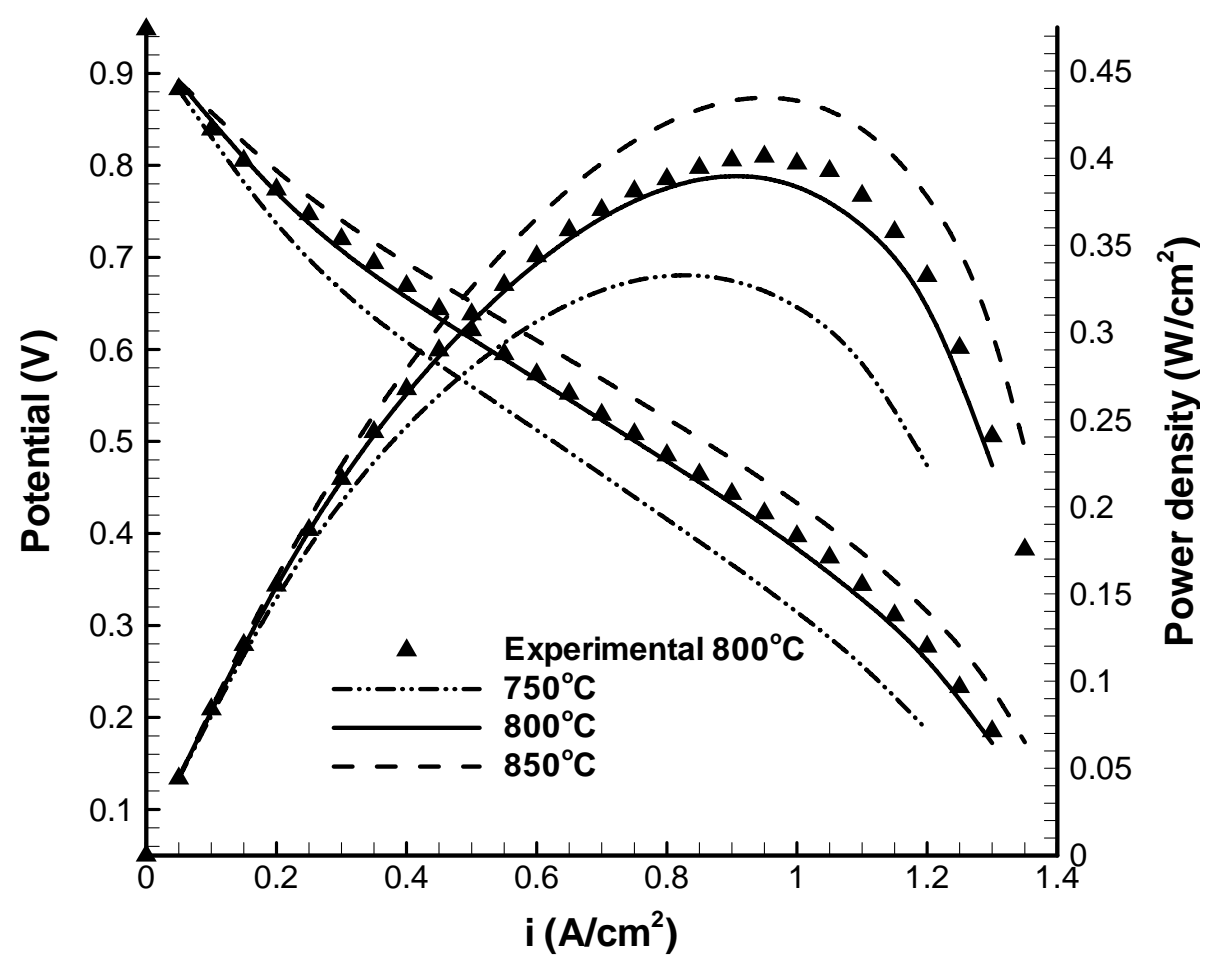

Figure 6.1 Predicted performance of a button cell running on syngas at different operating temperatures

The improvement in the performance of the cell as the temperature increases is due to the fact that all the overpotentials are lower at higher temperatures as shown in Figure 6.2. In general, all the overpotentials showed the same trend at different operating temperatures where the ohmic overpotential remains the lowest at high current densities even at $750^{\circ} \mathrm{C}$. The largest loss of potential is caused by the anode activation overpotential which is approximately twice the oxygen overpotential at high currents. Therefore it is evident that the cell potential is limited by the anode at the three operating temperatures. The carbon monoxide activation overpotential (not shown here) is similar qualitatively and quantitatively to the hydrogen activation overpotential at the three operating temperatures. 


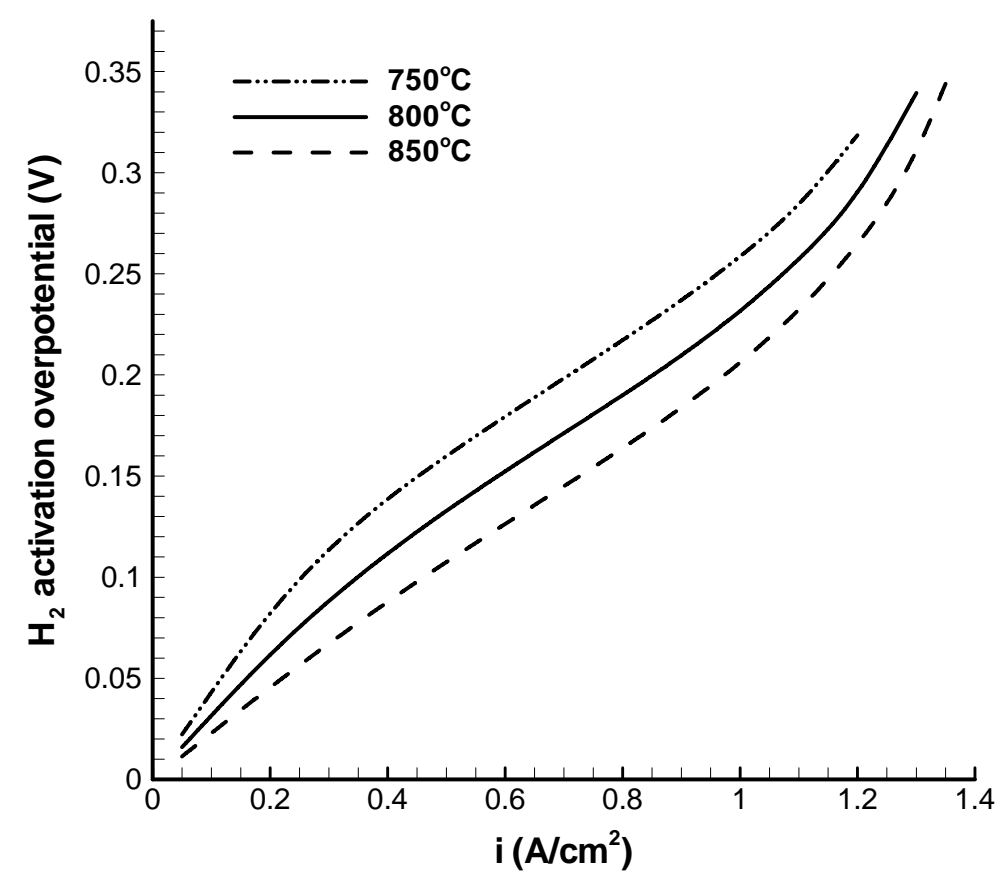

(a)

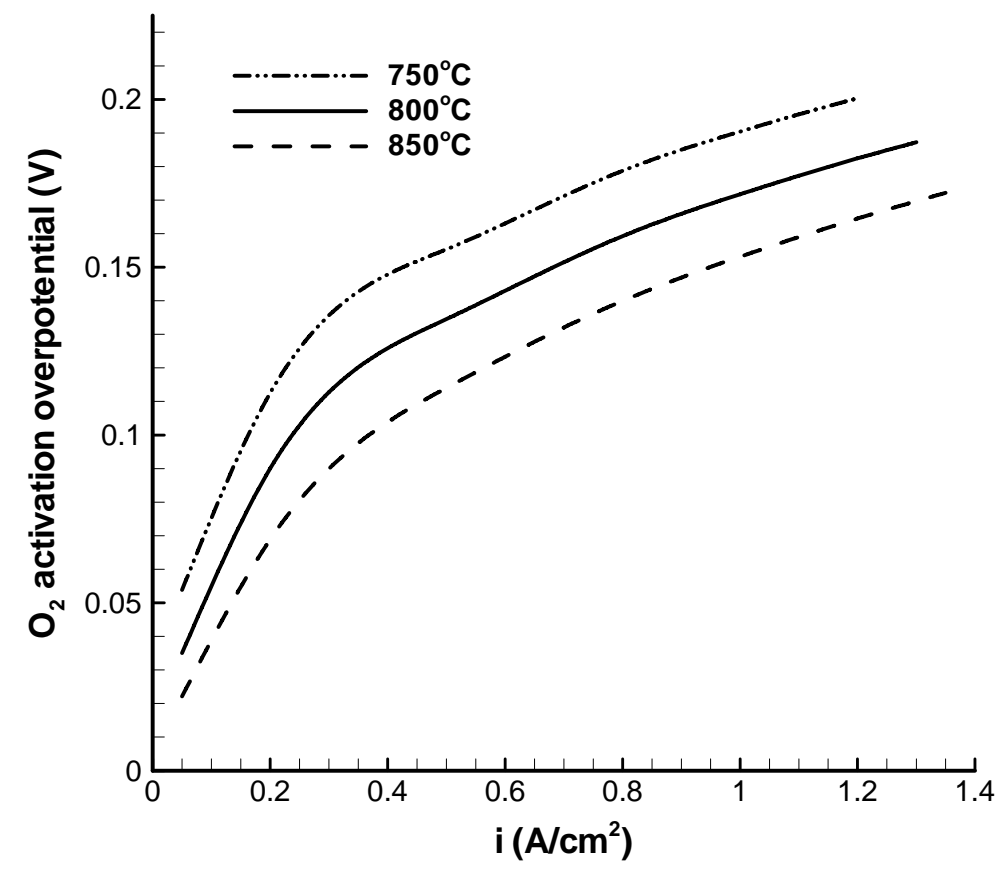

(b) 


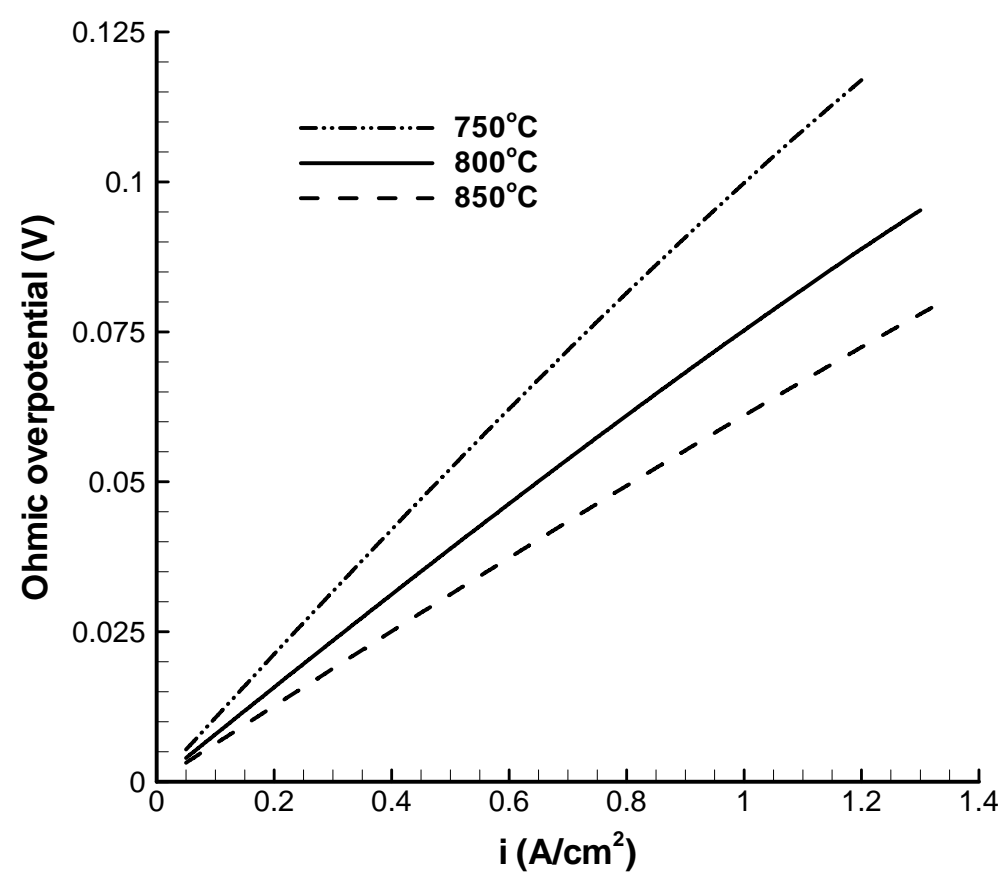

(c)

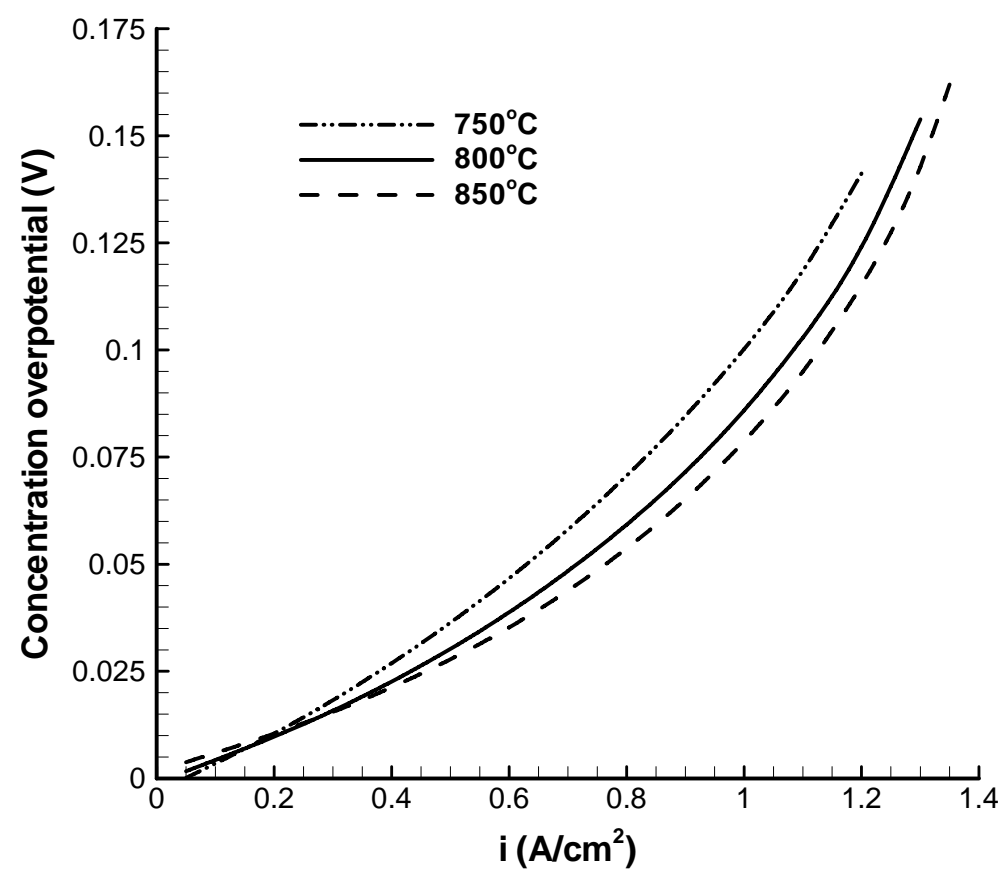

(d)

Figure 6.2 Overpotentials of a button cell operating at different temperatures; (a) hydrogen activation, (b) oxygen activation, (c) ohmic and (d) concentration 
The electrochemistry model considers simultaneous oxidation of $\mathrm{H}_{2}$ and $\mathrm{CO}$. The cell operating temperature showed a considerable effect on relative dominance of these two reactions as can be seen in Figure 6.3, where the ratio of the current produced from $\mathrm{H}_{2}$ to the current supported by $\mathrm{CO}$ is shown. The higher the operating temperature, the higher the fraction of the current produced from hydrogen oxidation. At $850^{\circ} \mathrm{C}$ the ratio varies from around 10 at low currents to 5 at high currents. The ratio varies slightly from 6 to 5 at $800^{\circ} \mathrm{C}$ and increases from 3.5 to 5 from low to high currents, at $750^{\circ} \mathrm{C}$.

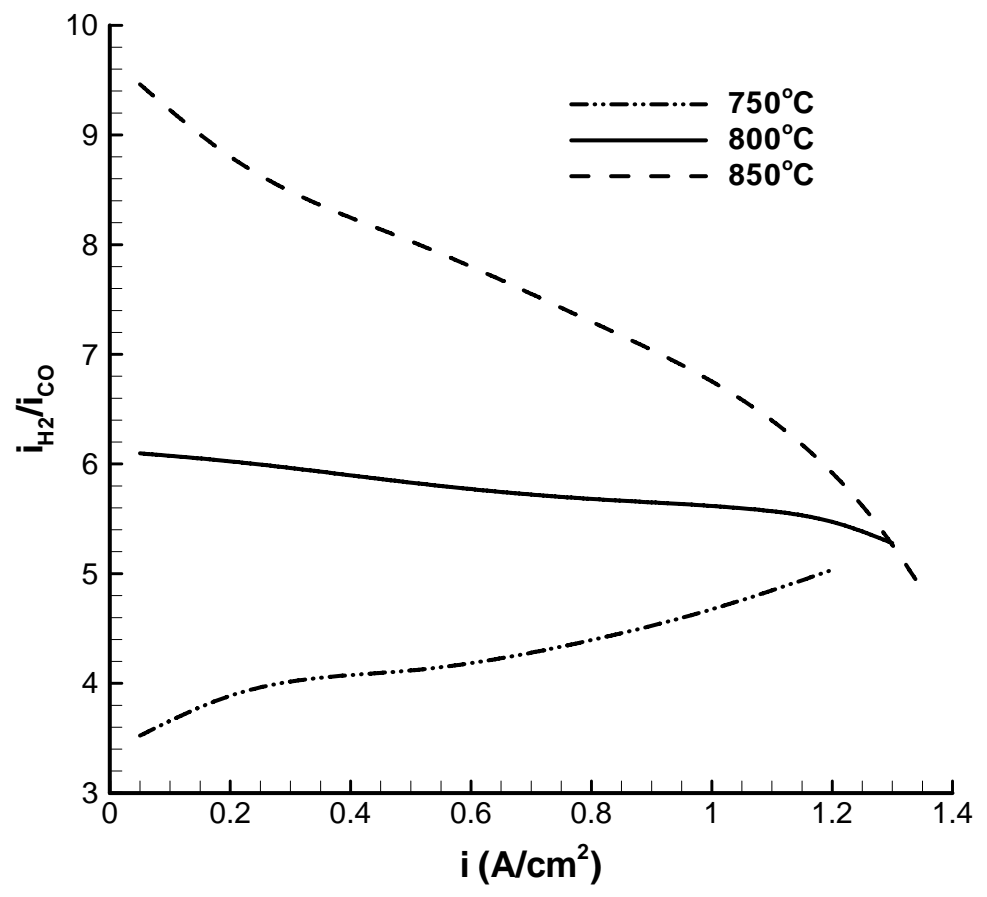

Figure 6.3 Ratio between the current supported by $\mathrm{H}_{2}$ and $\mathrm{CO}$ at different operating temperatures

The heat generation rate due to the water-gas shift reaction (WGSR) also showed a dependence on the operating temperature (see Figure 6.4). The overall (in the whole anode) heat generation due to WGSR was positive, (heat was released from this bulk reaction) which means that the WGSR proceeded forward producing $\mathrm{H}_{2}$ at $750^{\circ} \mathrm{C}$. The opposite behaviour was observed at $850^{\circ} \mathrm{C}$ where the WGSR proceeded in the reverse direction, producing $\mathrm{CO}$. At $800^{\circ} \mathrm{C}$ this reaction produced $\mathrm{H}_{2}$ only at high currents. The overall heat from the methane reforming reaction (not shown here) was negligible (two orders of 
magnitude smaller) compared to the water gas shift reaction and it proceeded always in the reverse direction producing methane.

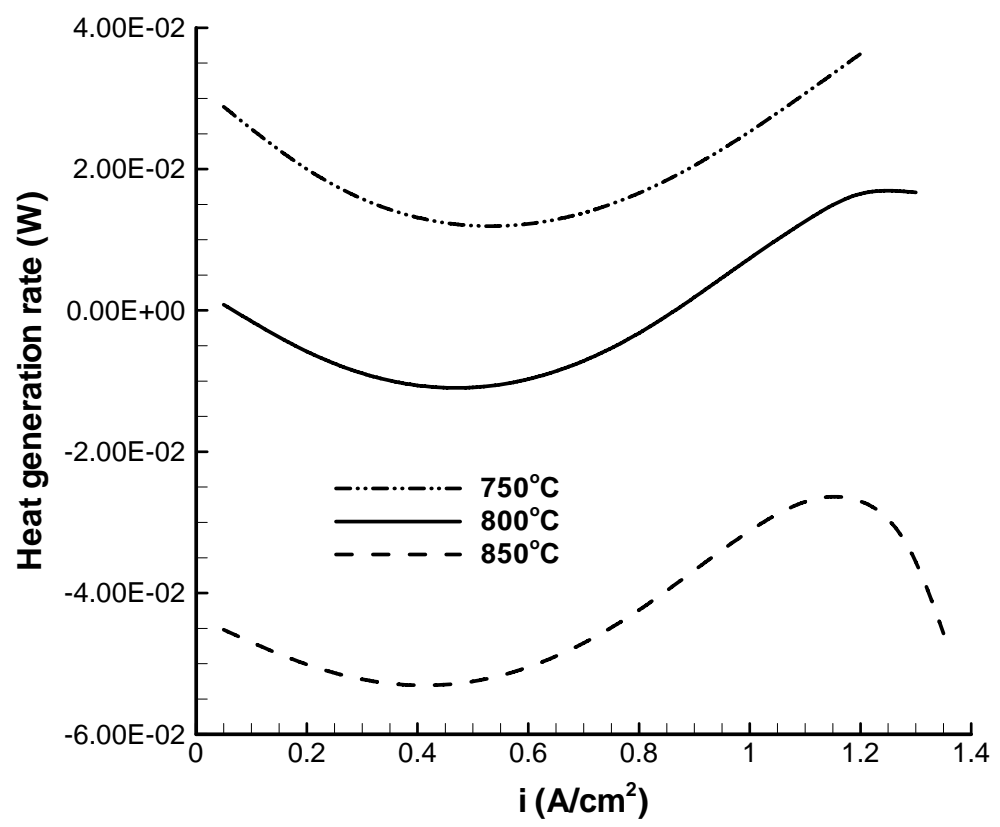

Figure 6.4 Overall heat generation from WGSR at different operating temperatures

The ohmic heat presented in Figure 6.5a decreased when the operating temperature increased due to an increase in the ionic conductivity of the electrolyte with temperature. At the three different operating temperatures, the ohmic heat showed the expected parabolic dependence on current density. The entropic heat (see Figure 6.5b) only showed a slight change with respect to the operating temperature, increasing with an increase in the operating temperature. A faster increase in entropic heat is observed at high currents with respect to the linear increase at low currents whose trend is the same observed for the entropy change for the overall reaction of a SOFC as a function of temperature, the higher the temperature the larger the entropy change. 


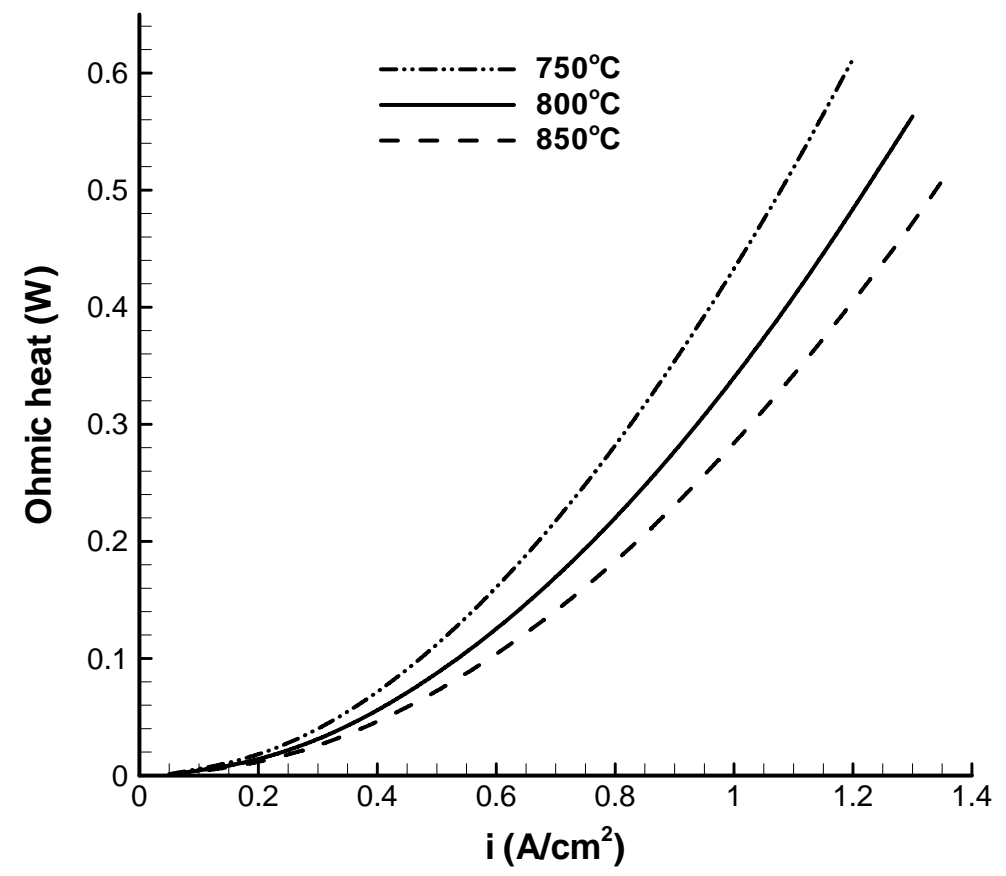

(a)

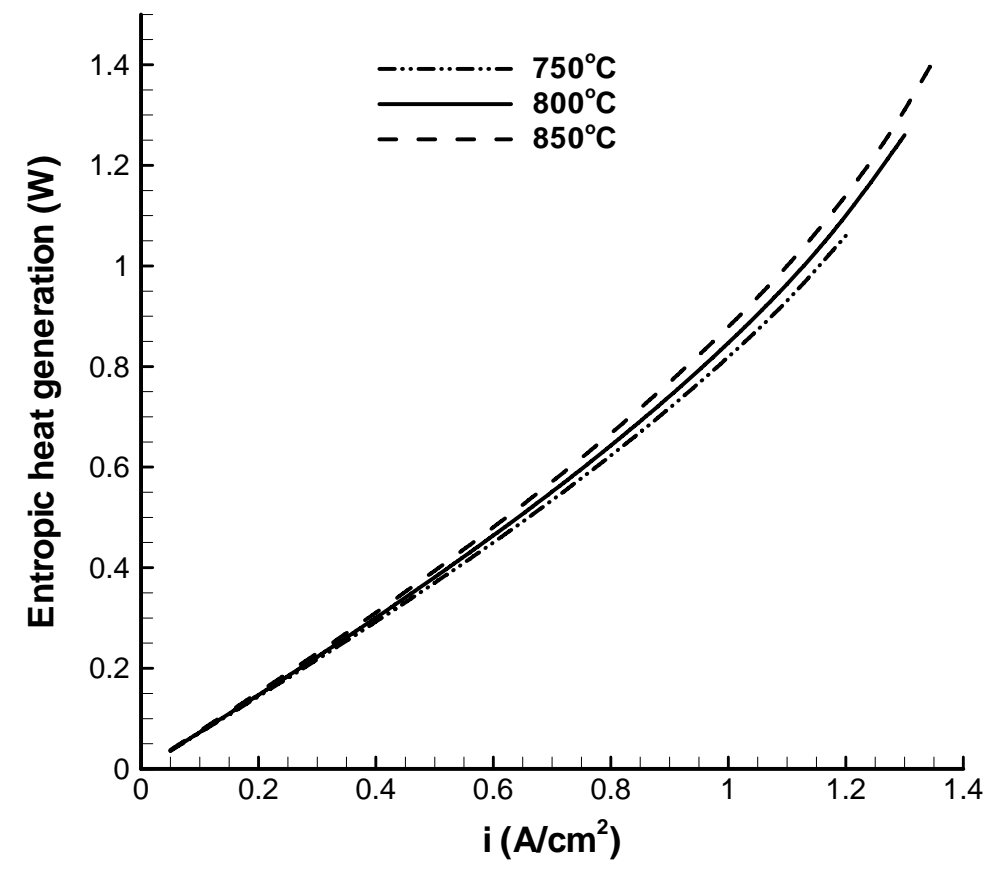

(b)

Figure 6.5 Heat generation at different operating temperatures; (a) ohmic heat and (b) entropic heat 
As an overall trend, it was observed that the change in cell temperature (defined as the difference between the cell temperature and the operating temperature) with respect to the operating temperature was larger at lower operating temperatures as shown in Figure 6.6. When operating at $800^{\circ} \mathrm{C}$ the button cell heats up by around $16^{\circ} \mathrm{C}$ near the limiting current (around $1.3 \mathrm{~A} / \mathrm{cm}^{2}$ ). Goldin et al. [15] in a three-dimensional study of a button cell using a commercial code predicted that the cell operating at $800^{\circ} \mathrm{C}$ and running on wet hydrogen heats up by around $40^{\circ} \mathrm{C}$ at high currents $\left(\sim 3 \mathrm{~A} / \mathrm{cm}^{2}\right)$ when radiation is not considered as is the case in the present study. This compares reasonably well with the predicted cell temperature by DREAM-SOFC although the button cells operate at different concentrations and currents. As in the present study, Goldin et al. [15] observed that the maximum cell temperature is located in the electrolyte.

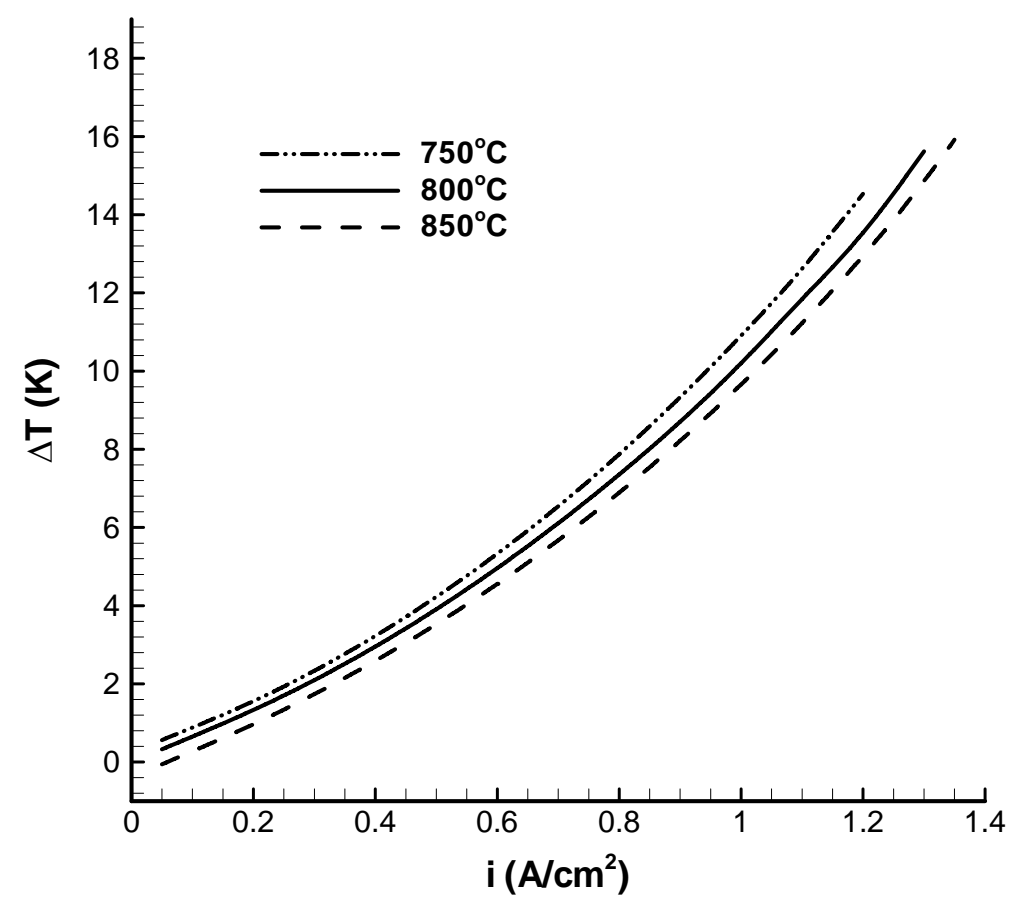

Figure 6.6 Cell temperature change $\left(T_{\text {cell }}-T_{\text {op }}\right)$ at different operating temperatures

The species concentration distributions were also affected by the operating temperature mainly because of the reaction rate of the water gas shift reaction. The molar and mass fractions at the anode-electrolyte interface for hydrogen and carbon monoxide are shown in Figure 6.7 and Figure 6.8, respectively. As it can be seen, the hydrogen concentration at the 
anode-electrolyte interface is higher at low temperatures whereas the carbon dioxide concentration is higher at high temperatures. This behavior can be explained by the fact that the water gas shift reaction proceeds forward producing hydrogen at $700^{\circ} \mathrm{C}$ and it proceeds in the reverse direction at $850^{\circ} \mathrm{C}$ producing carbon monoxide (see Figure 6.4).

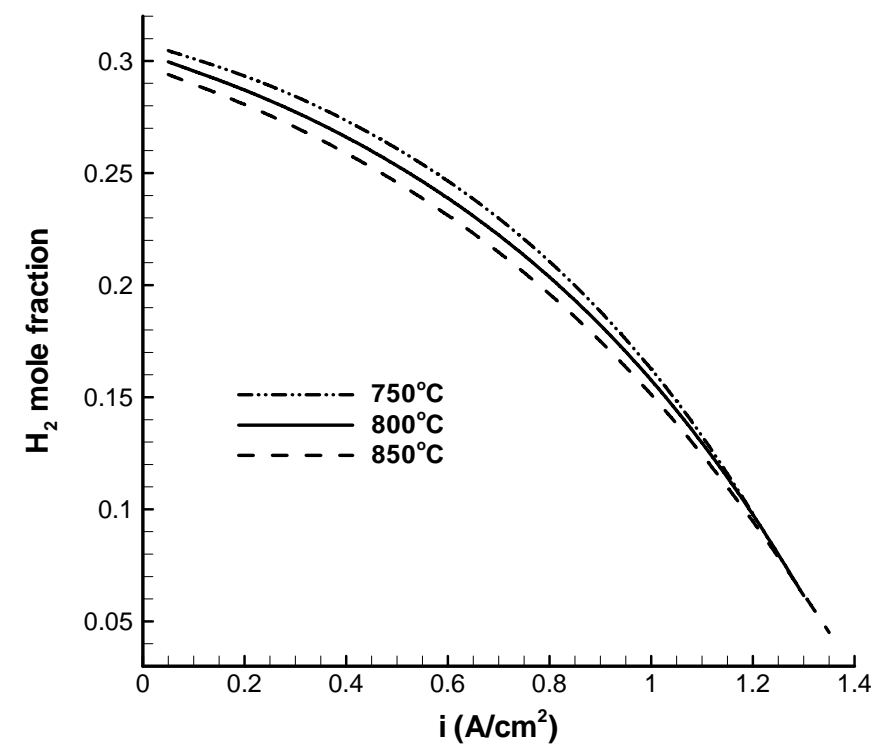

(a)

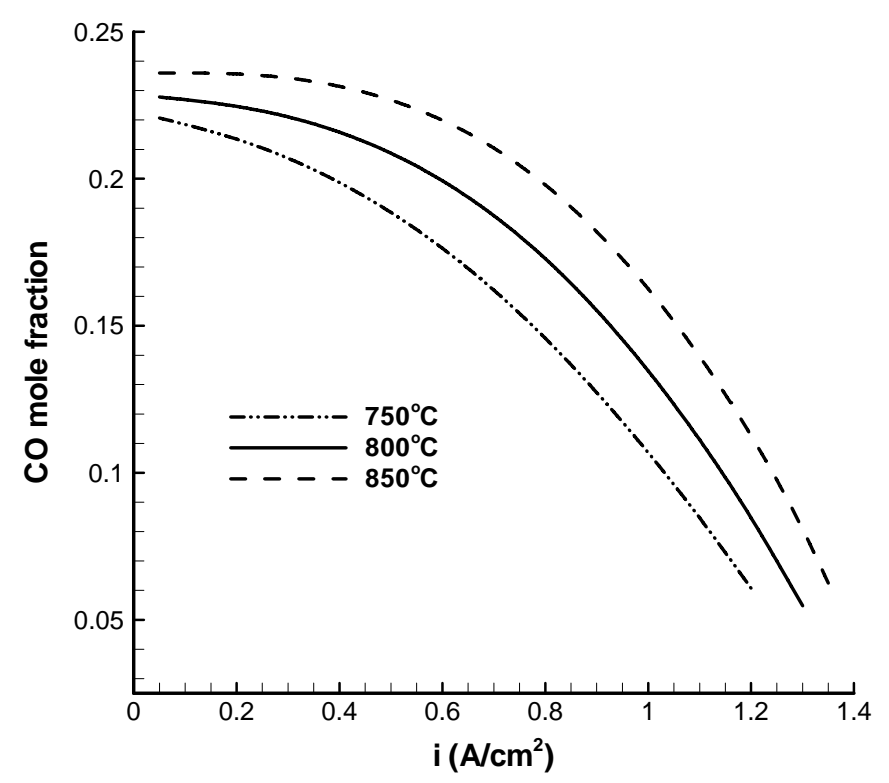

(b)

Figure 6.7 Molar fractions at the anode-electrolyte interface for (a) hydrogen and (b) carbon monoxide 


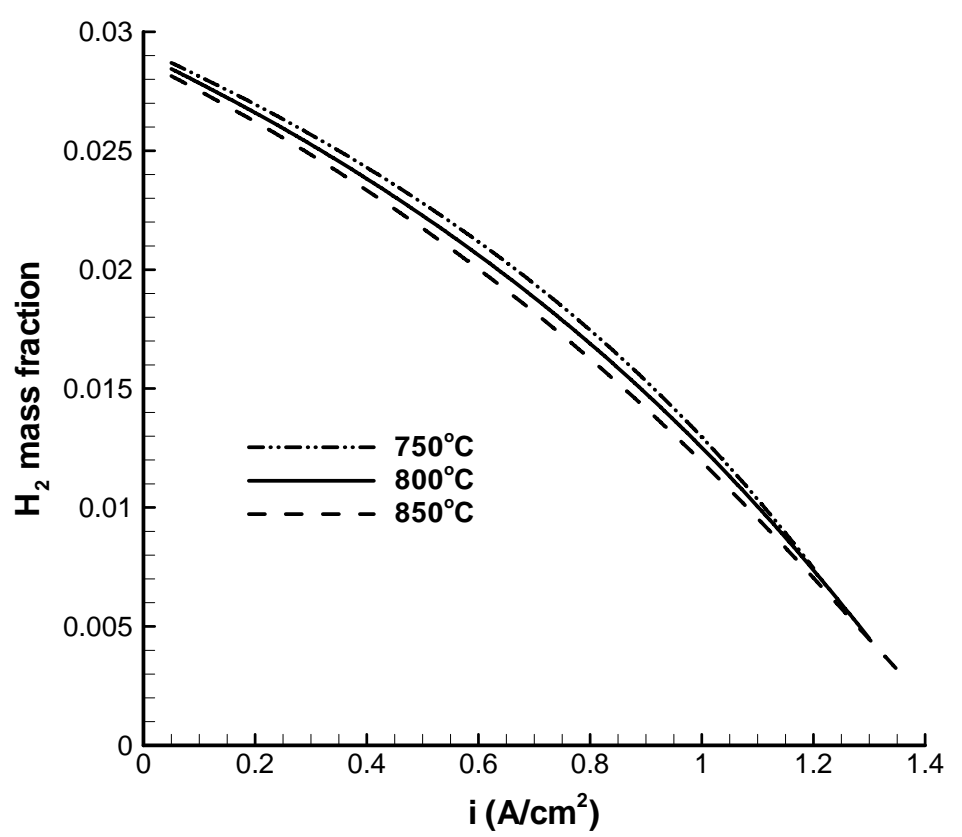

(a)

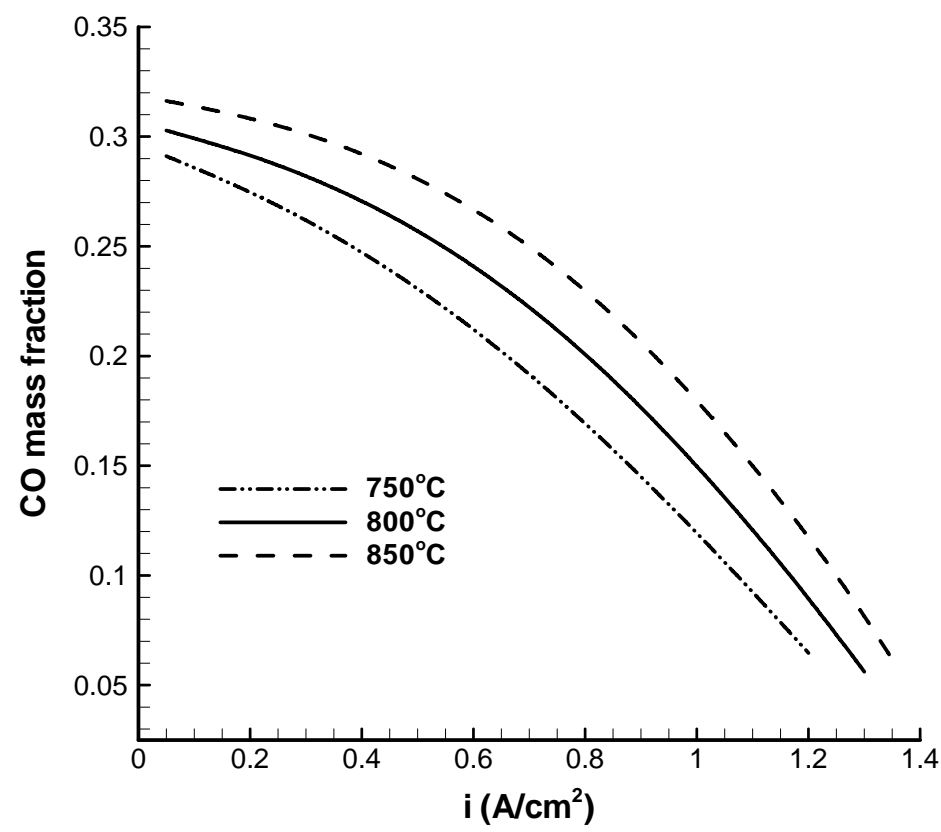

(b)

Figure 6.8 Mass fractions at the anode-electrolyte interface for (a) hydrogen and (b) carbon monoxide 


\subsection{Concentration Effect}

The effect of the fuel composition on the performance of a button cell operating at $800^{\circ} \mathrm{C}$ was also investigated. Three cases different from the baseline case were studied. The three cases consider the same species $\left(\mathrm{H}_{2}, \mathrm{CO}, \mathrm{CO}_{2}, \mathrm{H}_{2} \mathrm{O}\right)$ but with different concentrations. In one case, the total amount of fuel $\left(\mathrm{H}_{2}\right.$ and $\left.\mathrm{CO}\right)$ is $75 \%$, in the other case it is $25 \%$, and in the baseline it is $53 \%$. In these three cases considered, the ratio of hydrogen concentration to carbon monoxide concentration was kept constant. In the fourth case the fuel obtained after $30 \%$ of pre-reformed methane with the concentrations used for the verification of the code and shown in Table 5.3 is used.The total amount of fuel for this case is around $46.3 \%$ $\left(\mathrm{H}_{2}, \mathrm{CO}\right.$ and $\left.\mathrm{CH}_{4}\right)$. The value of the parameter $c$ in the diffusion correction equation (4.3.1) is $4.88 \times 10^{-5}$ for this case. The performance of the cell operating with different syngas compositions is shown in Figure 6.9. The higher the fuel concentration $\left(\mathrm{H}_{2}+\mathrm{CO}\right)$ better the performance and higher the limiting current. The limiting current is higher when the fuel concentration is higher since more fuel $\left(\mathrm{H}_{2}\right.$ and $\left.\mathrm{CO}\right)$ is available to be electrochemically oxidized.

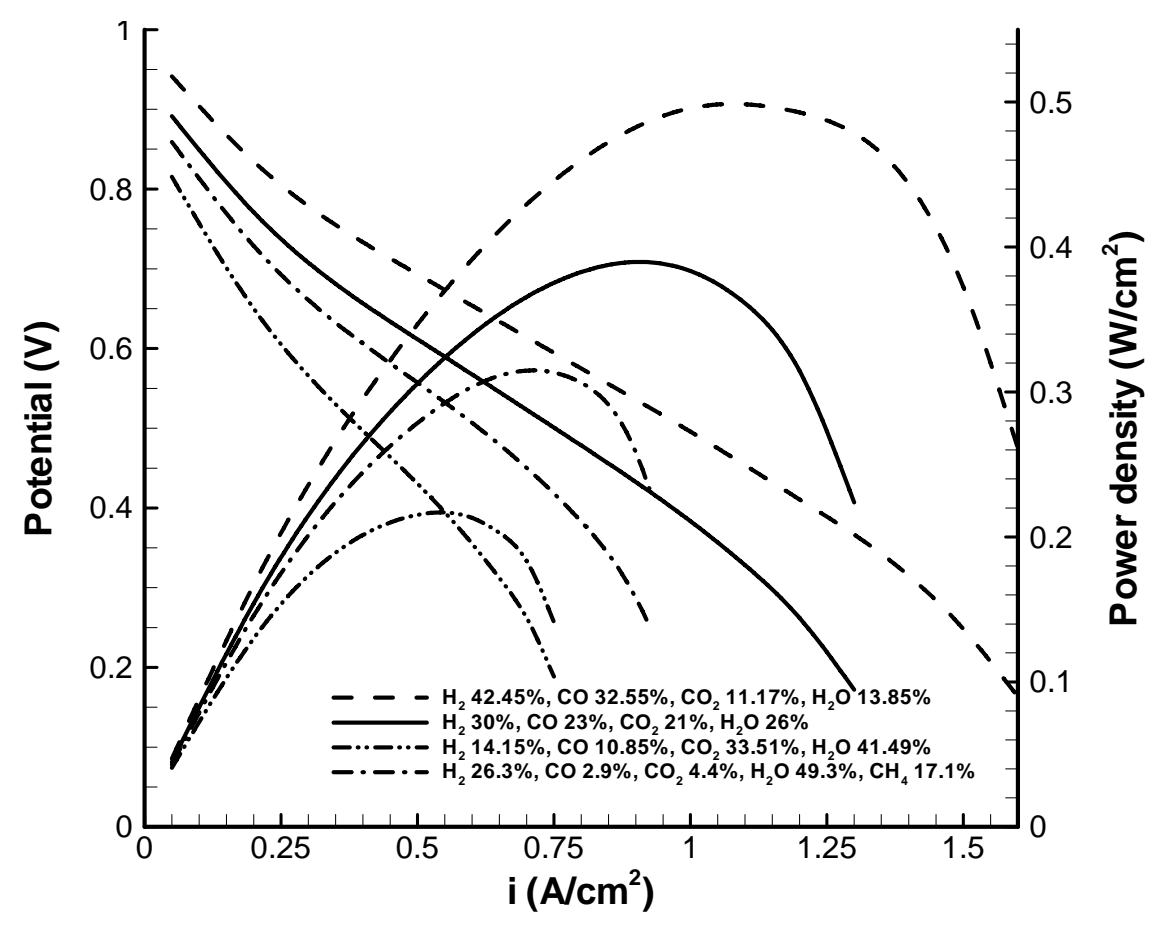

Figure 6.9 Predicted performance of a button cell at different fuel compositions;

$$
\mathrm{T}_{\mathrm{op}}=\mathbf{8 0 0}{ }^{\circ} \mathrm{C}
$$


A better performance at higher fuel concentration is observed as a consequence of a decrease mainly in the activation overpotentials of $\mathrm{H}_{2}$ and $\mathrm{CO}$, and in the concentration overpotential as shown in Figure 6.10. The ohmic overpotential for all three cases that do not include methane in the fuel stream is practically the same. A small difference can be seen in the pre-reformed methane fuel case where the ohmic overpotential increases slightly. The reason for this increase in ohmic overpotential can be explained by the fact that the cell temperature may decrease due to the endothermic methane reforming reaction which translates into a decrease in the electrolyte ionic conductivity. Similarly, the cathode activation overpotential increases slightly as a consequence of the cooling effect of the reforming reaction.

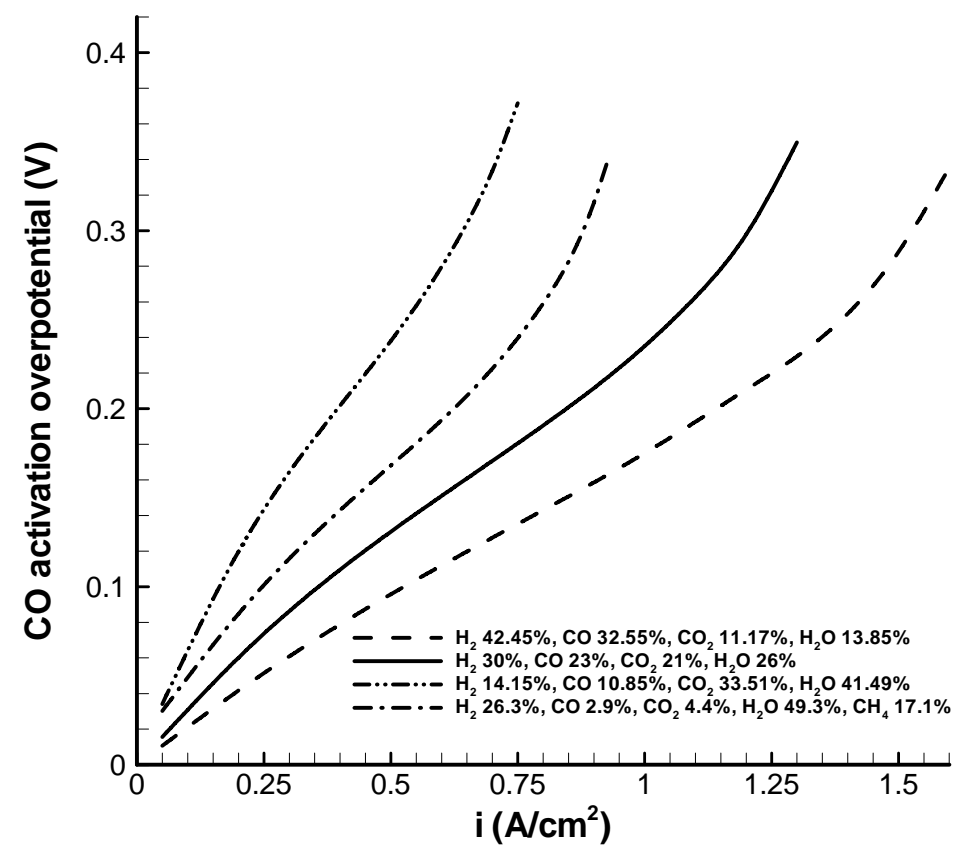

(a) 


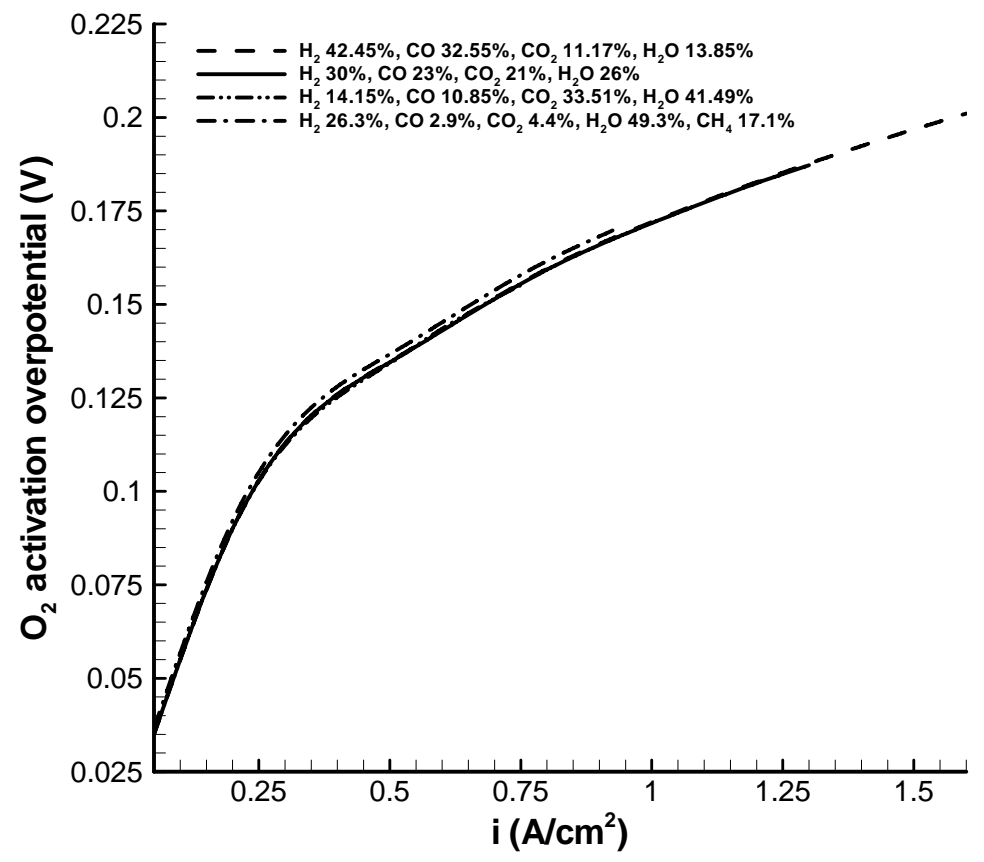

(b)

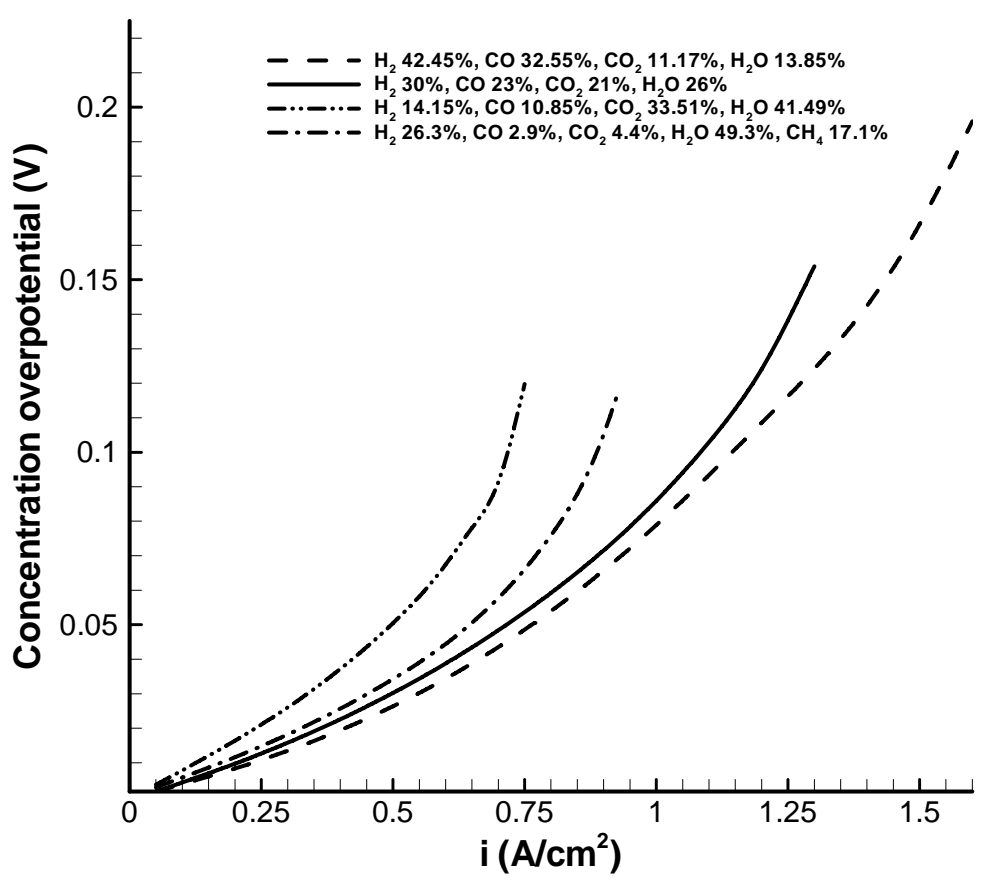

(c) 


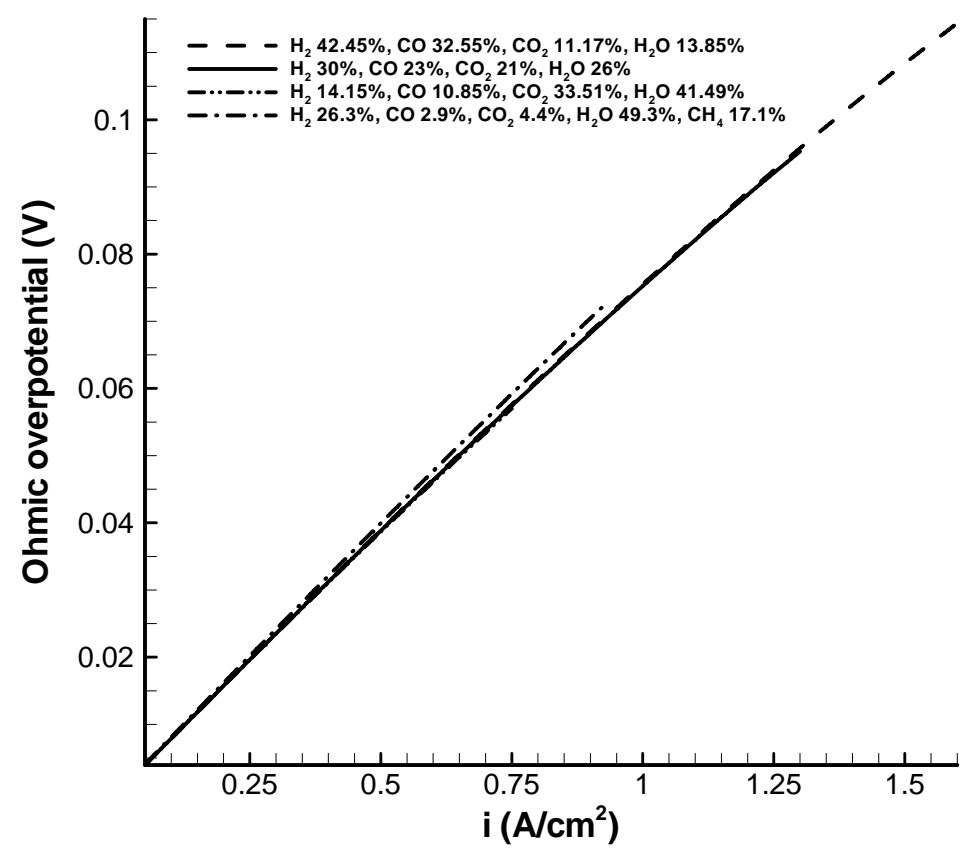

(d)

Figure 6.10 Overpotentials of a button cell operating at different fuel compositions; (a) CO activation, (b) oxygen activation, (c) concentration and (d) ohmic

The splitting of the total current between $\mathrm{H}_{2}$ and $\mathrm{CO}$ currents did not change considerably among the three cases that did not consider methane as shown in Figure 6.11. When the total amount of fuel $\left(\mathrm{H}_{2}\right.$ and $\left.\mathrm{CO}\right)$ was $25 \%$ and $53 \%$, the ratio of the hydrogen current to the carbon monoxide current changed only from about 6 to 4.5 and from about 6 to 5.4 , respectively. This ratio varied from around 6 to 7 when $75 \%$ of the anode stream was fuel. Therefore, even when the ratio of the hydrogen concentration to carbon monoxide concentration was kept constant, a difference in the splitting of the current is observed. For the case considering methane this ratio becomes large starting at around 18 at low currents, increasing up to 25 at a current density of about $0.30 \mathrm{~A} / \mathrm{cm}^{2}$ and decreasing again to 16 close to the limiting current. According to these results, the splitting of the total current between the current supported by hydrogen and carbon monoxide is greatly dependent on the fuel concentration and to some extent on the total current. Therefore, neglecting carbon monoxide electrochemical oxidation or assuming a ratio between these two currents does not seem to be a good approach though these assumptions are commonly used in literature. 


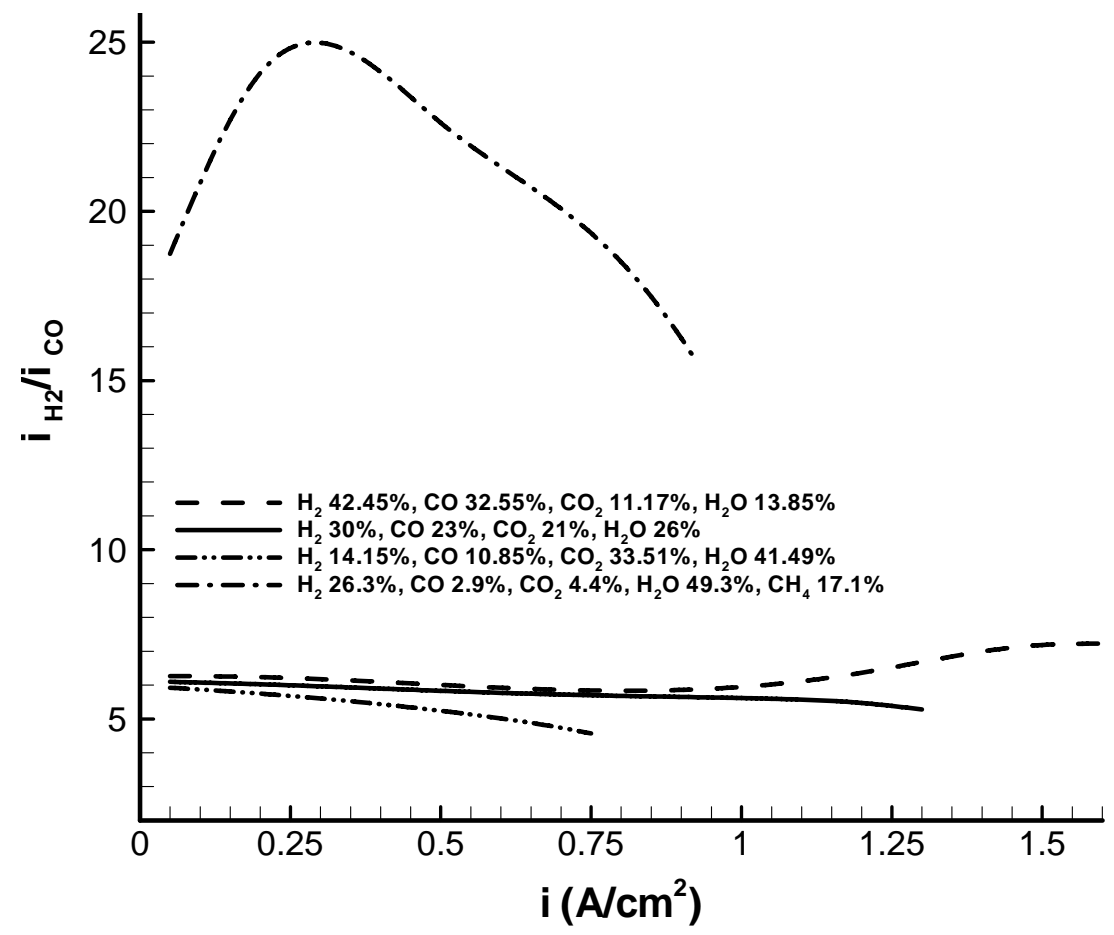

Figure 6.11 Ratio of $\mathrm{H}_{2}$ current to $\mathrm{CO}$ current at different syngas compositions; $\mathbf{T}_{\mathrm{op}}=800^{\circ} \mathrm{C}$

The overall heat from the WGSR is positive (releases heat) over the whole current density range when the fuel composition includes methane, which means that the WGSR proceeds forward as shown in Figure 6.12a. For the 25\% fuel concentration case the heat production is relatively small but positive for most of current density range. For the other two cases (53\% and $75 \%$ fuel) at current densities below $0.75 \mathrm{~A} / \mathrm{cm}^{2}$ the reaction consumes hydrogen to produce carbon monoxide, and at larger currents, the reaction proceeds in the other direction. At high concentrations $(75 \%$ fuel) the rate of this reaction is around one order of magnitude larger than that for $53 \%$ fuel in the anodic stream. The overall heat from the methane reforming reaction presented in Figure $6.12 \mathrm{~b}$ is negligible for the cases that do not contain methane, however for the pre-reformed methane fuel case, this heat is highly endothermic and an order of magnitude larger than that released from the water gas shift reaction. Therefore it is expected to observe a decrease in the cell temperature when the cell is running on a $30 \%$ pre-reformed fuel. 


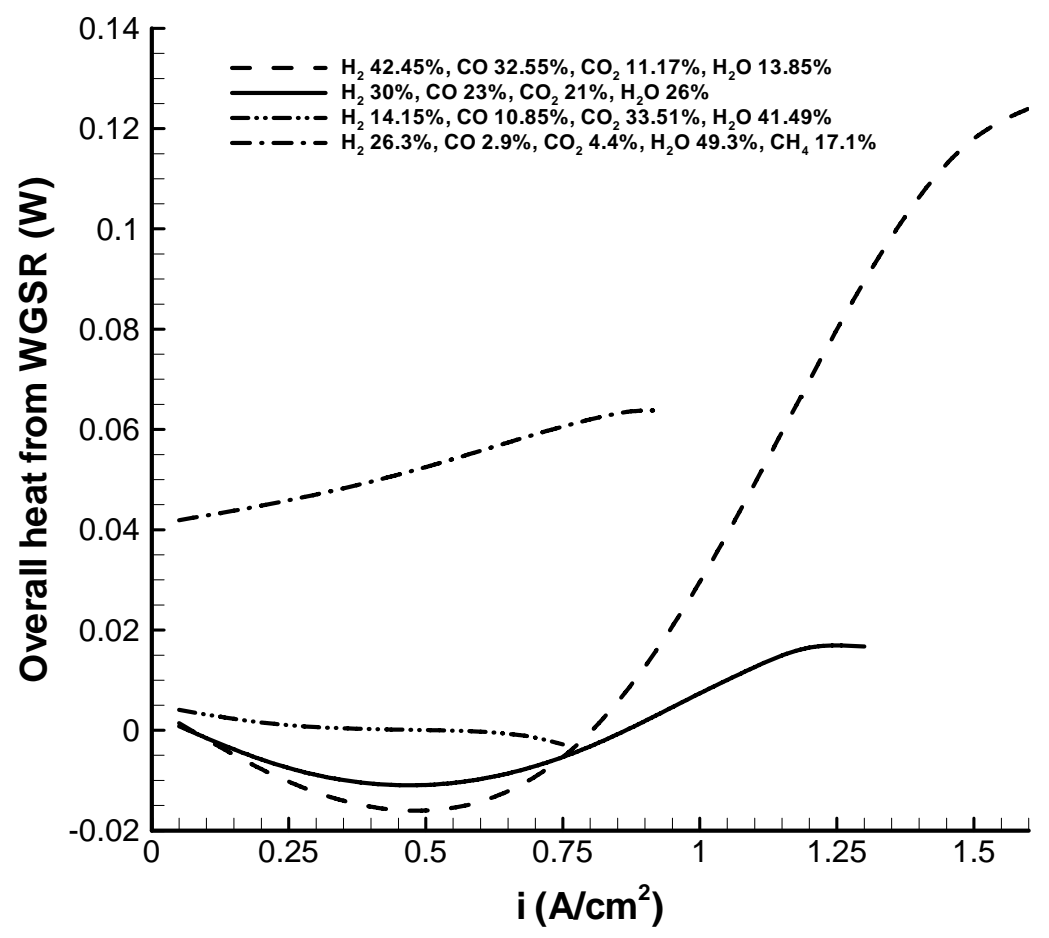

(a)

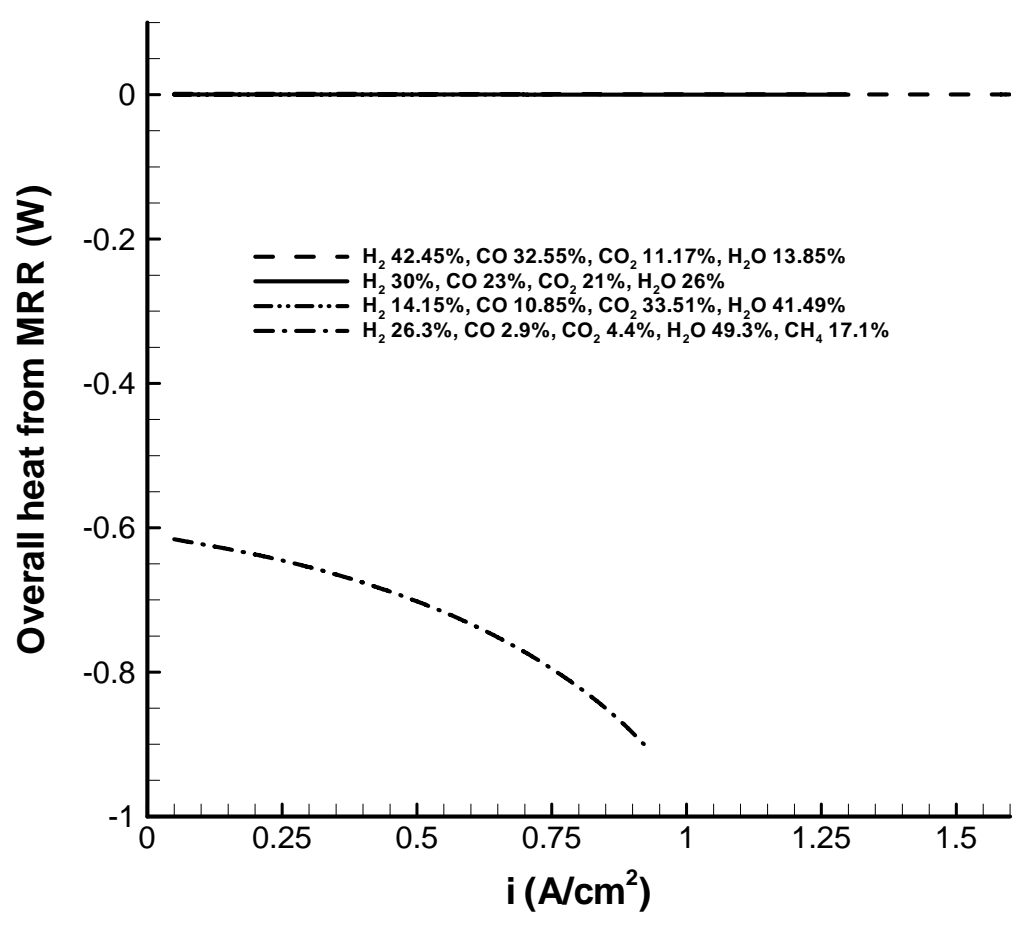

(b)

Figure 6.12 Overall heat generation from (a) WGSR and (b) MRR at different syngas compositions 
The entropic heat increases as the total amount of fuel $\left(\mathrm{H}_{2}, \mathrm{CO}\right.$ and $\left.\mathrm{CH}_{4}\right)$ decreases as shown in Figure 6.13a. The ohmic heat is almost the same for the four cases studied since the electrical/ionic conductivities do not change with the concentration of the fuel stream, but with the cell temperature. A small increase in ohmic heat can be seen for the case of pre-reformed fuel since the cell cools down a few degrees causing a decrease in the electrolyte ionic conductivity (see Figure 6.13b)

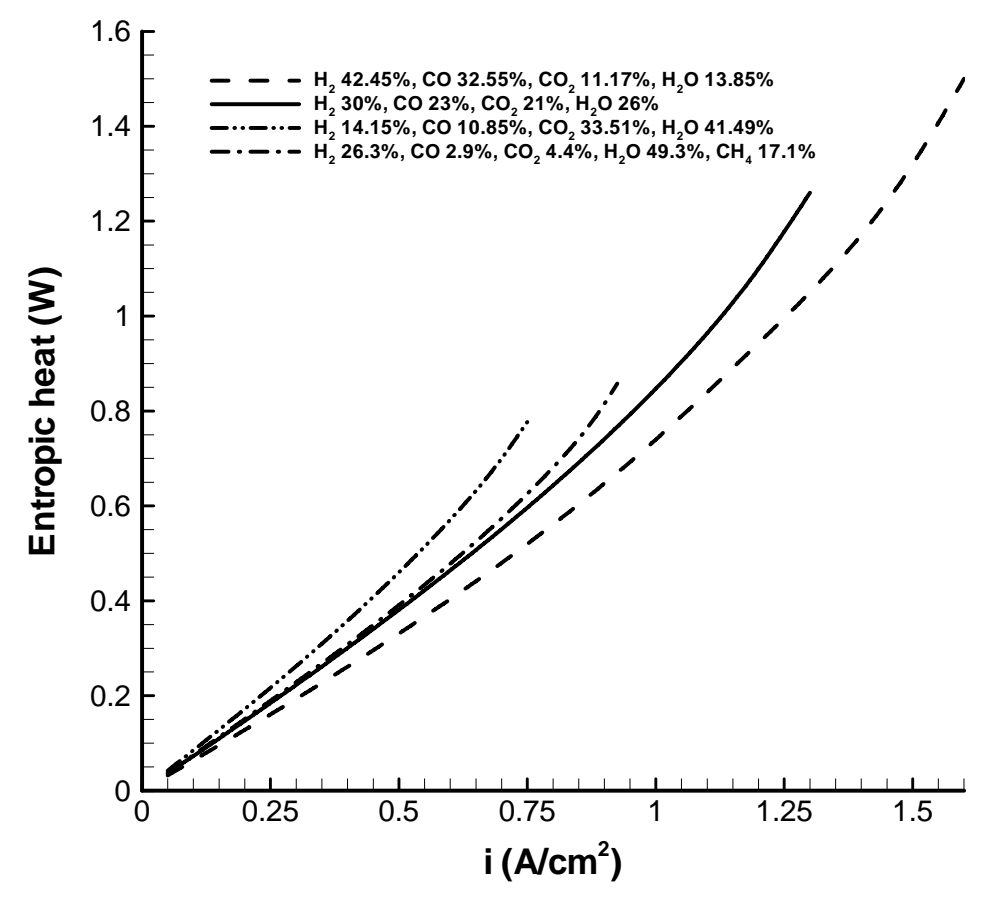

(a) 


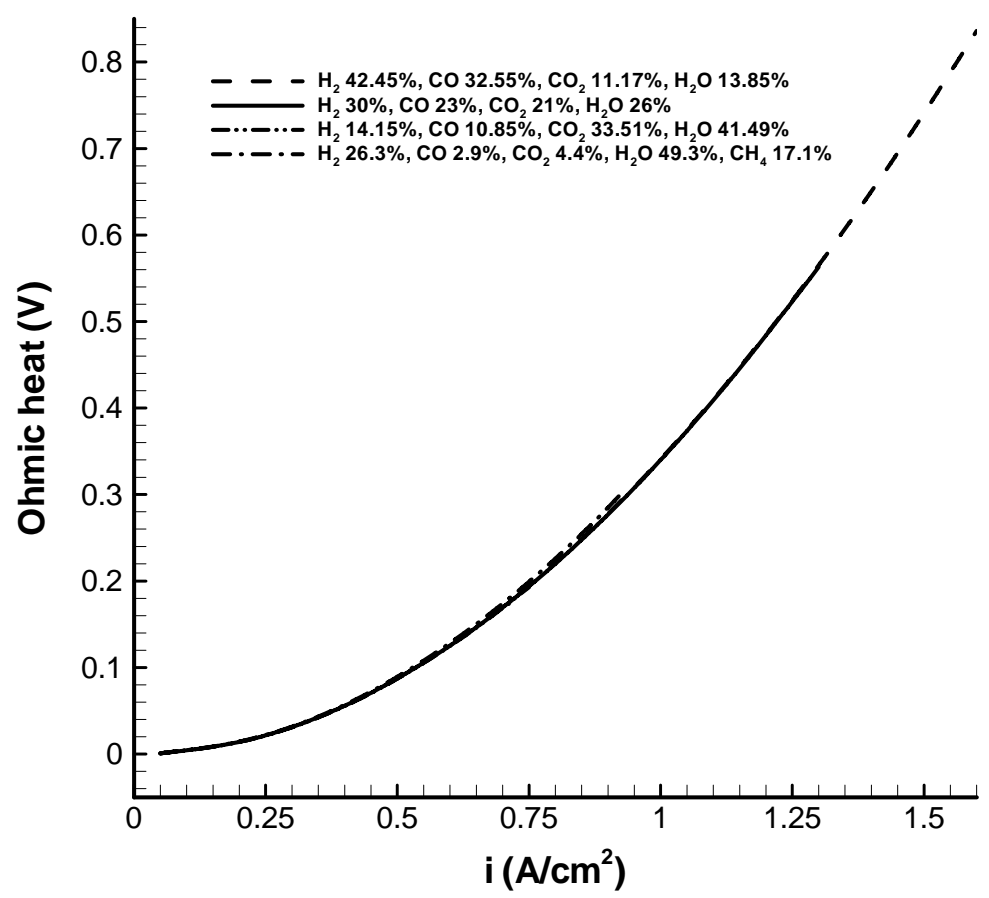

(b)

\section{Figure 6.13 Overall heat generation in a button cell operating at different fuel compositions; (a) entropic heat and (b) ohmic heat}

From all heat sources, the entropic heat is the dominant source of heat followed by the heat absorbed by the methane reforming reaction and the heat source from ohmic heating. Therefore, for the cases not including methane in the fuel stream, the cell heats up over the whole range of current density since the net heat is a source, however, at low currents, for the case of pre-reformed fuel, the net heat is a sink causing the cell to cool down by about 5 $\mathrm{K}$ as shown in Figure 6.14. As the current density increases, the net heat becomes a source increasing the cell temperature. Similarly, Goldin et al. [15] predicted with a threedimensional model using a commercial code that a button cell running on a mixture of $75 \%$ $\mathrm{CH} 4$ and $25 \% \mathrm{CO} 2$ operating at $1073 \mathrm{~K}$ cools down by about $7 \mathrm{~K}$ at low currents which shows a good agreement with the predicted temperature in the present study using the developed in-house code DREAM-SOFC. 


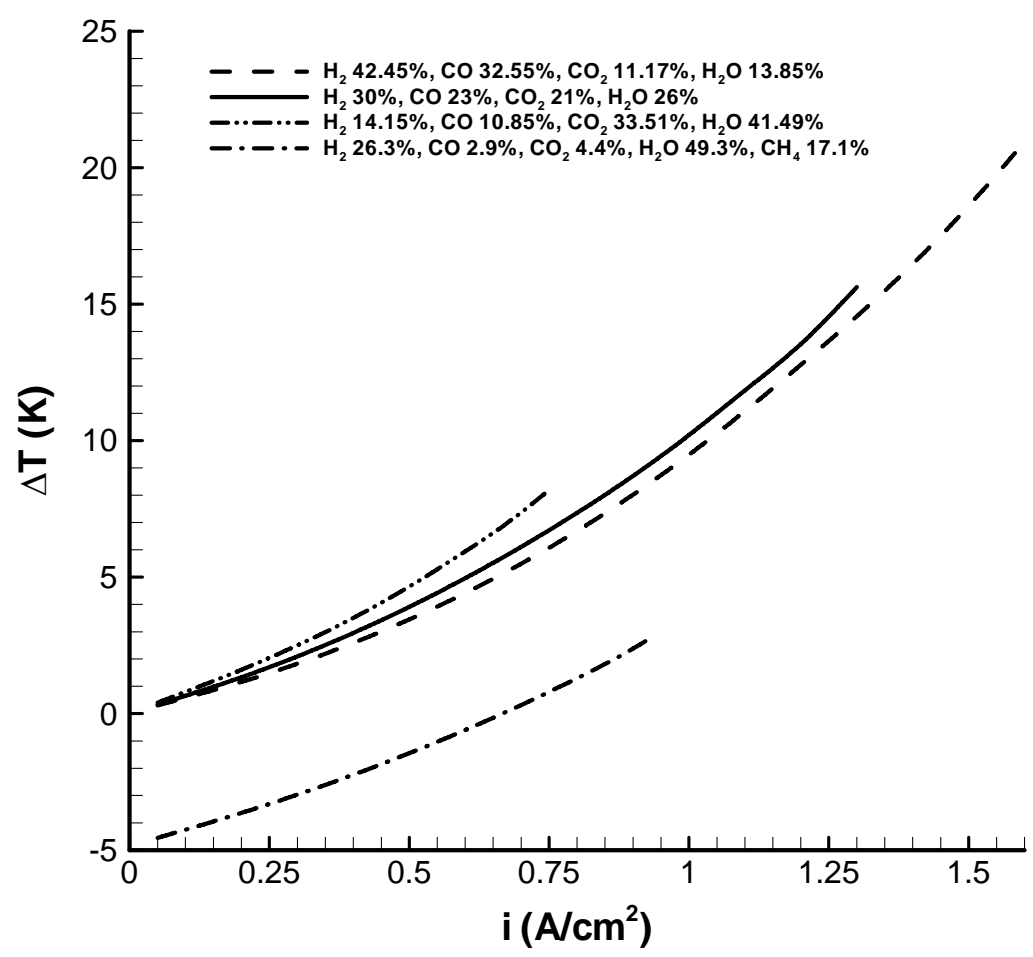

Figure 6.14 Cell temperature change $\left(T_{\text {cell }}-T_{o p}\right)$ at different syngas compositions

For the case of the button cell running on pre-reformed methane with the composition shown in Table 5.3, the fuel stream is not at equilibrium unlike the base case; therefore, the methane reforming and water gas shift reactions are occurring at a considerable rate. When the rate of the methane reforming and water gas shift reactions dominate (are faster) over the oxidation reaction rates, the concentration distribution of the species participating in those reactions is not expected to be linear inside the anode as it was shown in Figure 5.8. For the fuel stream of $30 \%$ pre-reformed methane, the mass fraction profiles along the thickness of the anode are shown in Figure 6.15. It can be seen that these profiles show a curvature indicating that species are being transformed through the methane reforming and water gas shift reactions inside the anode. At these operating conditions, both reactions proceed in the forward direction producing hydrogen as shown in Figure 6.15a where the hydrogen concentration inside the anode is higher than that in the free stream concentration at low currents. As the current supported by the cell increases, the rate of the electrochemical reactions becomes faster and therefore the concentration inside the electrodes starts decreasing. In a similar trend but in the opposite direction, the methane concentration inside the anode decreases at low currents in a faster rate (see Figure 6.15c). 
From the carbon monoxide concentration profile (see Figure 6.15b) it can be inferred that the reforming reaction is proceeding faster than the water gas shift reaction since the net production is positive for this species. Although the rate constant for the water gas shift reaction is larger than that for the methane reforming reaction, the carbon monoxide concentration is very low in this case, which slows the reaction rate for the water gas shift reaction.

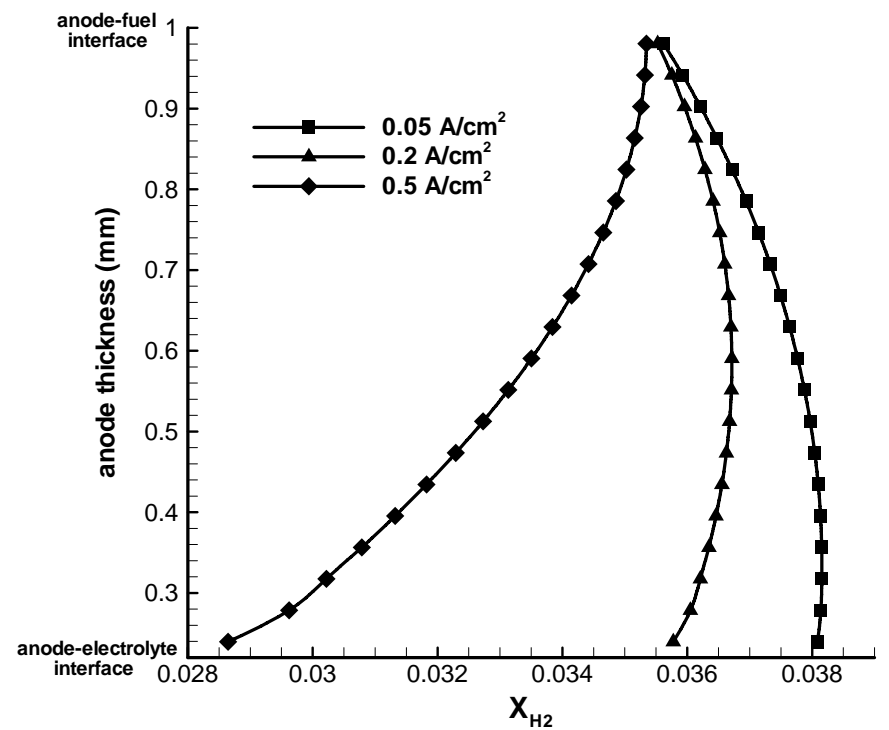

(a)

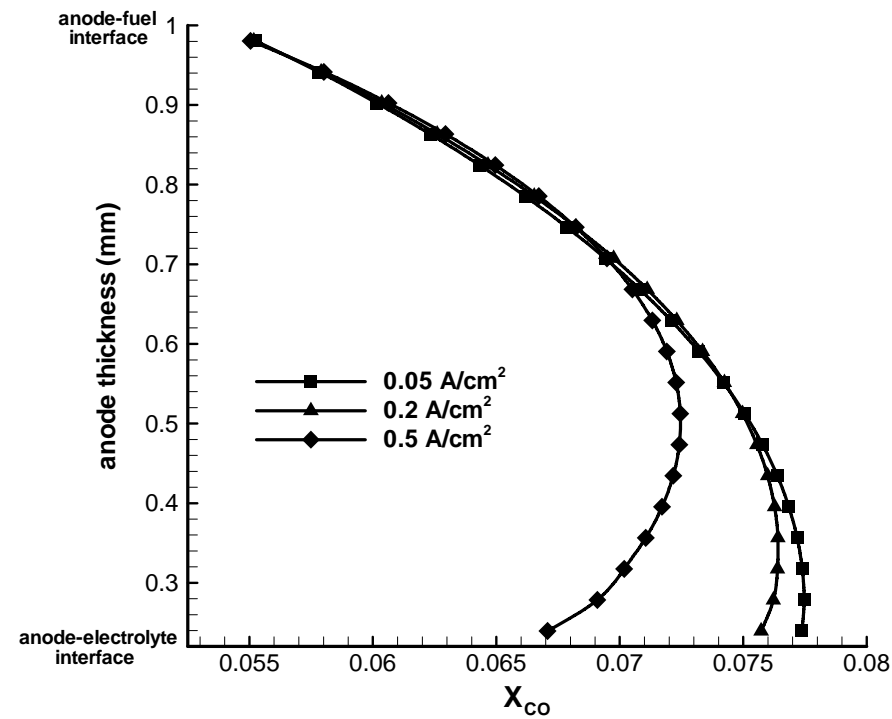

(b) 


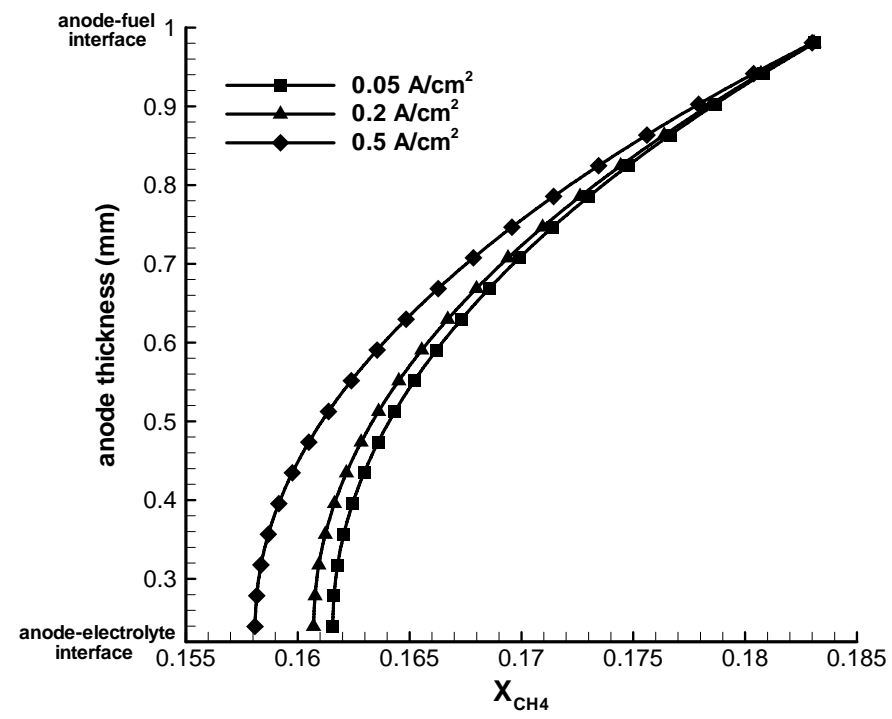

(c)

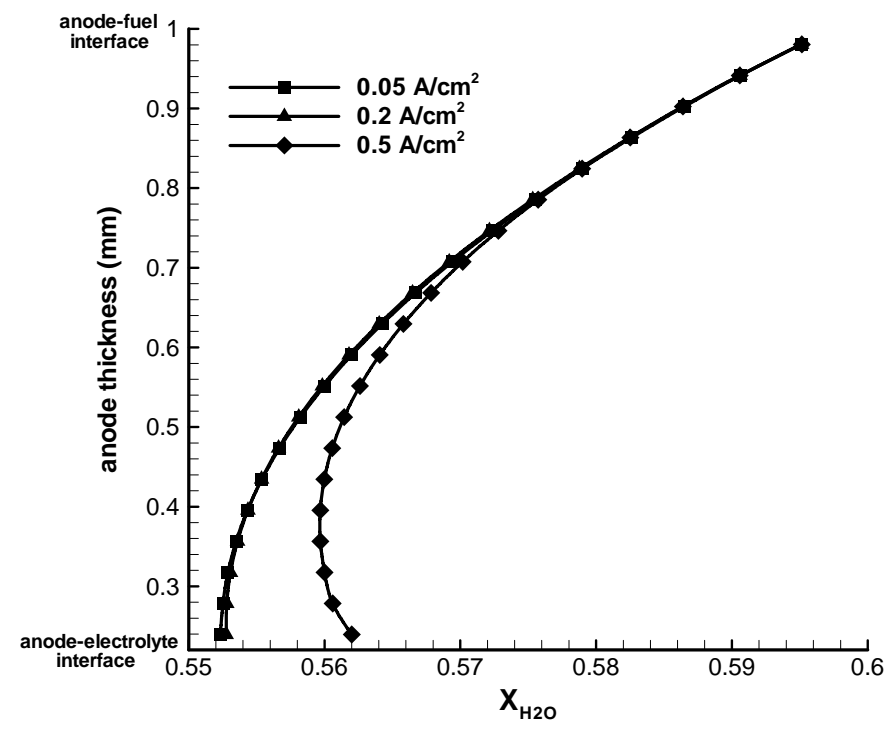

(d)

Figure 6.15 Mass fraction profiles along the thickness of the anode for a button cell operating on $30 \%$ pre-reformed methane (a) $\mathrm{H}_{2}$, (b) $\mathrm{CO}$, (c) $\mathrm{CH}_{4}$ and (d) $\mathrm{H}_{2} \mathrm{O}$

\subsection{Syngas Composition High in CO}

In this section, a button cell operating at $800^{\circ} \mathrm{C}$ on clean syngas whose fuel concentration is high in carbon monoxide is simulated using DREAM-SOFC and its predicted performance is compared to that of the base case cell. Besides having higher concentration of carbon monoxide the altered syngas composition is not at equilibrium. The syngas composition used in this study is as presented in Table 6.1. 
Table 6.1 Composition the clean syngas fuel stream with high CO concentration

\begin{tabular}{c|c|c|c|c}
\hline & $\mathrm{H}_{2}$ & $\mathrm{CO}$ & $\mathrm{CO}_{2}$ & $\mathrm{H}_{2} \mathrm{O}$ \\
\hline Molar fraction/mass fraction & $0.05 / 0.0042$ & $0.48 / 0.57$ & $0.06 / 0.112$ & $0.41 / 0.313$ \\
\hline
\end{tabular}

Comparing this case with the base case, it can be seen that the total amount of fuel $\left(\mathrm{H}_{2}\right.$ and $\mathrm{CO}$ ) is the same in both fuel streams fed to the anode. The predicted performance of the button cell at these operating conditions is shown in Figure 6.16. As it can be observed, the cell operating on syngas at equilibrium delivers a higher performance and a higher limiting current than the syngas composition which is not at equilibrium.

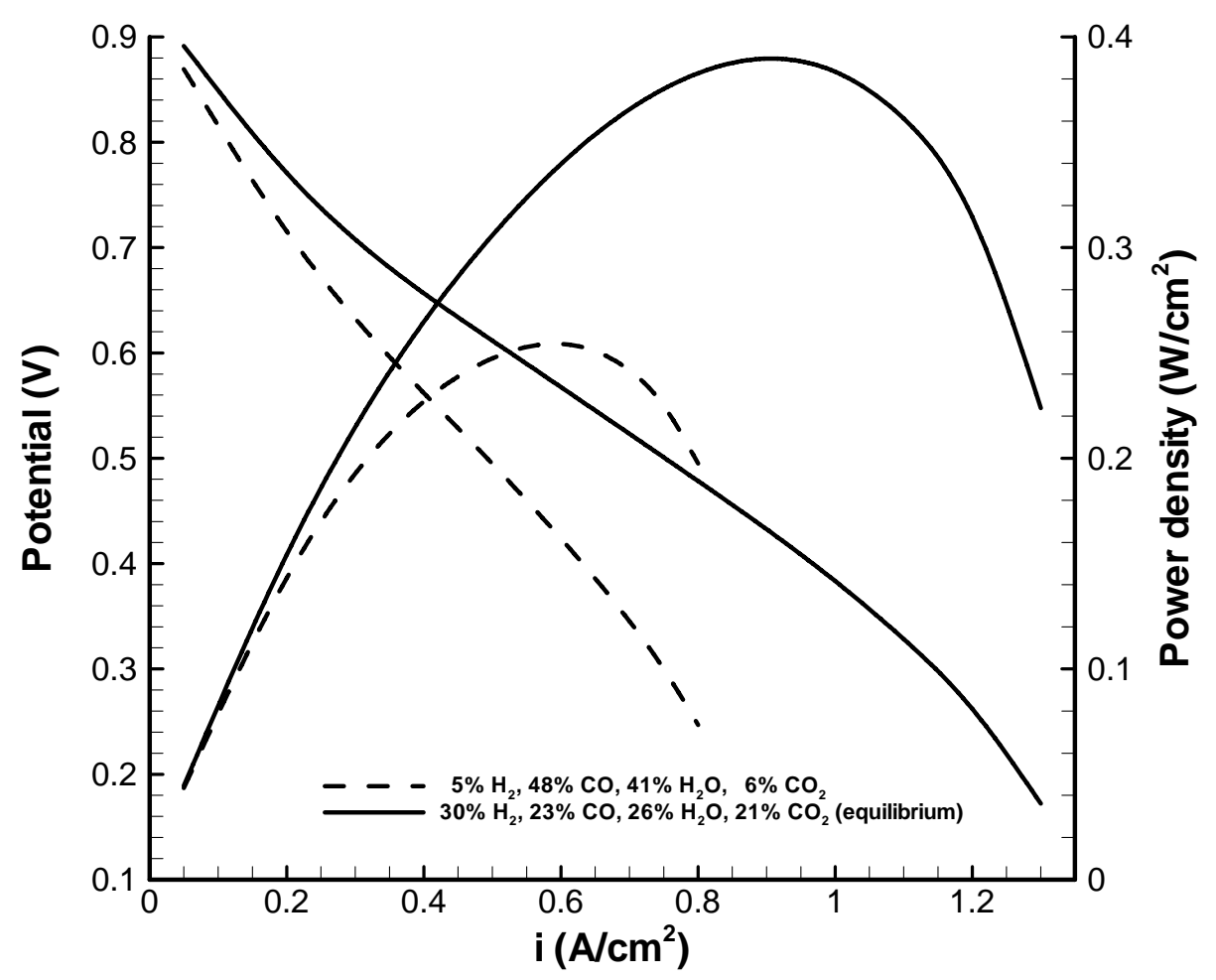

Figure 6.16 Predicted V-I and power density curves for the button cell running on equilibrium and non-equlibrium syngas concentrations

It was found that the major losses of potential in both cases (equilibrium and nonequilibrium fuel concentrations) were caused by hydrogen and carbon monoxide activation 
overpotentials followed by oxygen activation, concentration and ohmic overpotentials. Comparing the non-equilibrium case with the equilibrium concentration case, the cause of decline in the cell performance is attributed to a considerable increase in the anode activation ovepotentials (hydrogen and carbon monoxide) and concentration overpotential as shown in Figure 6.17. Ohmic and oxygen activation overpotentials remained basically the same with a small decrease in the case of non-equilibrium fuel concentration due, presumably, to an increase in the cell temperature. Thus it can be concluded that though the total fuel concentration (sum of $\mathrm{H}_{2}$ and $\mathrm{CO}$ concentration) is the same for the two cases, the one with more hydrogen and less carbon monoxide shows better performance due to relatively lower activation and concentration losses associated with hydrogen oxidation.

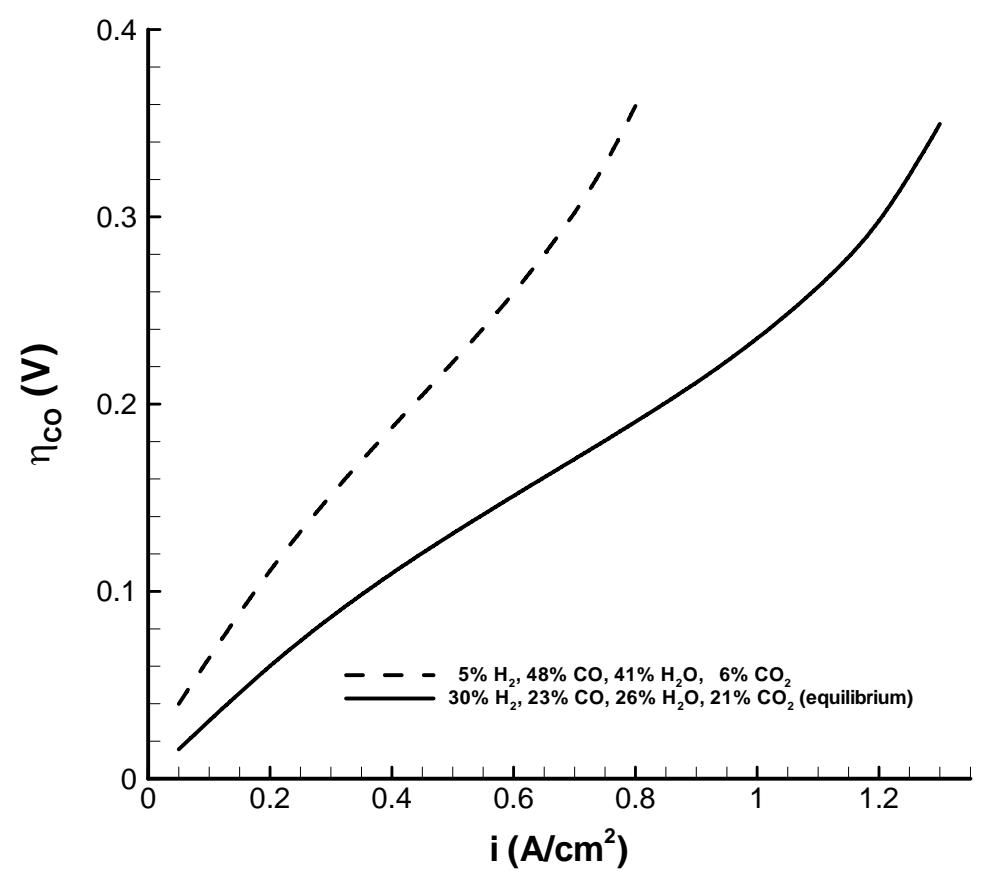

(a) 


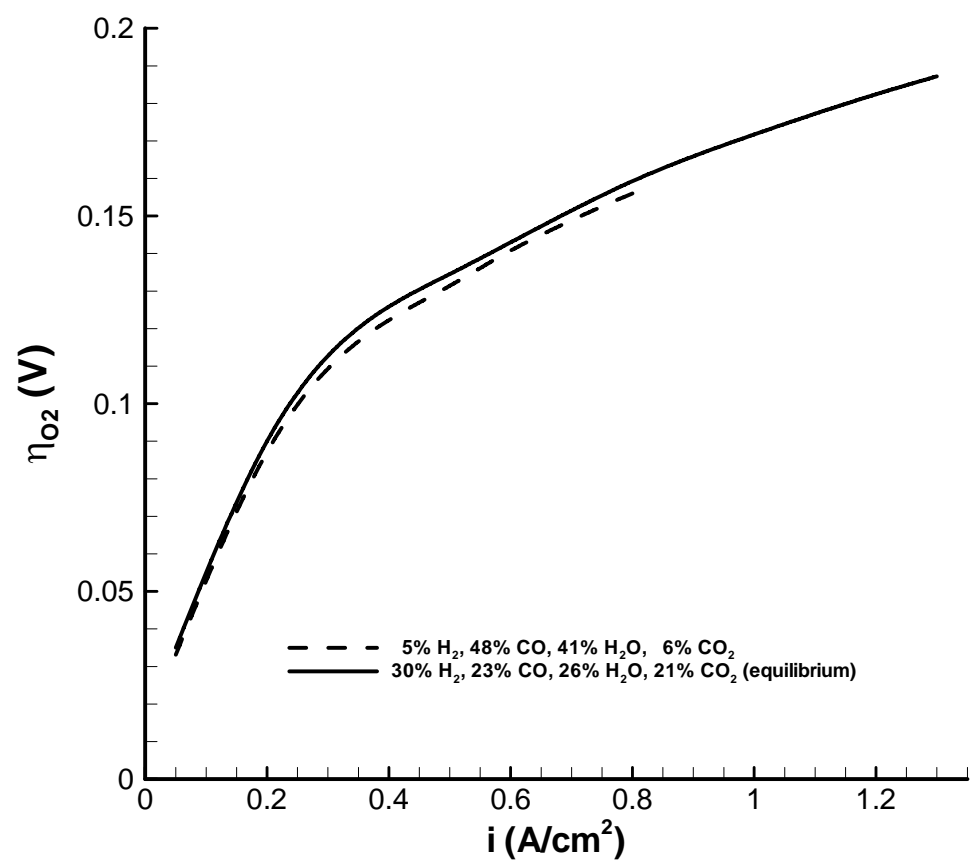

(b)

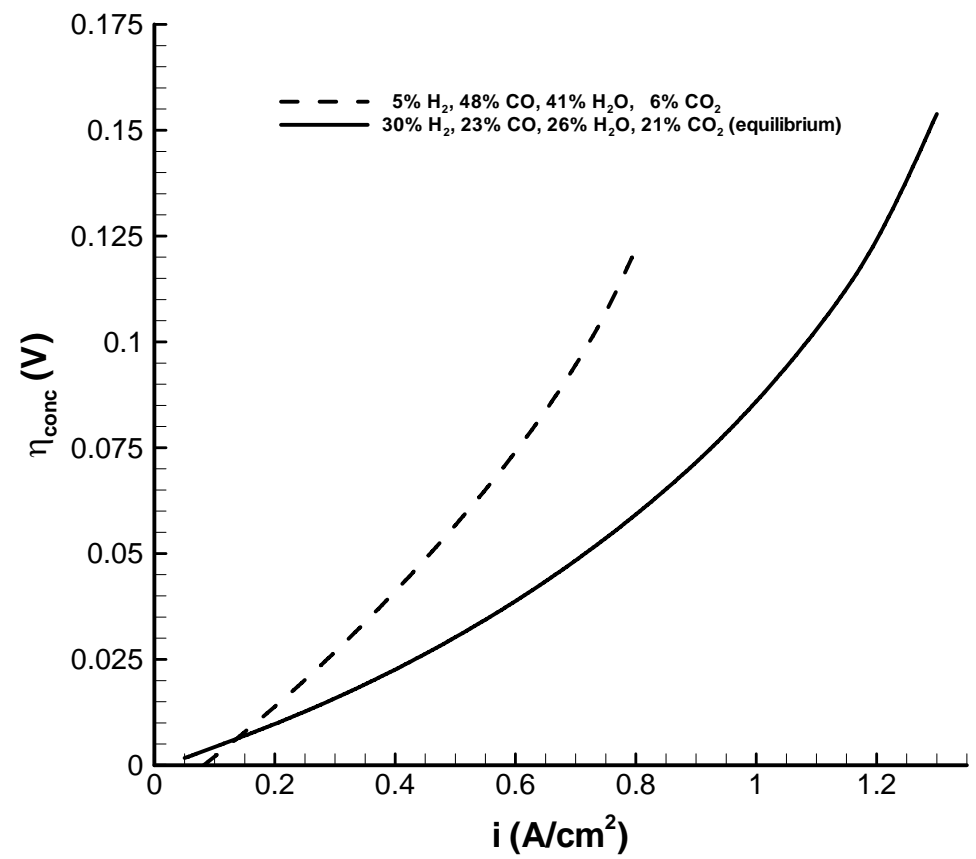

(c) 


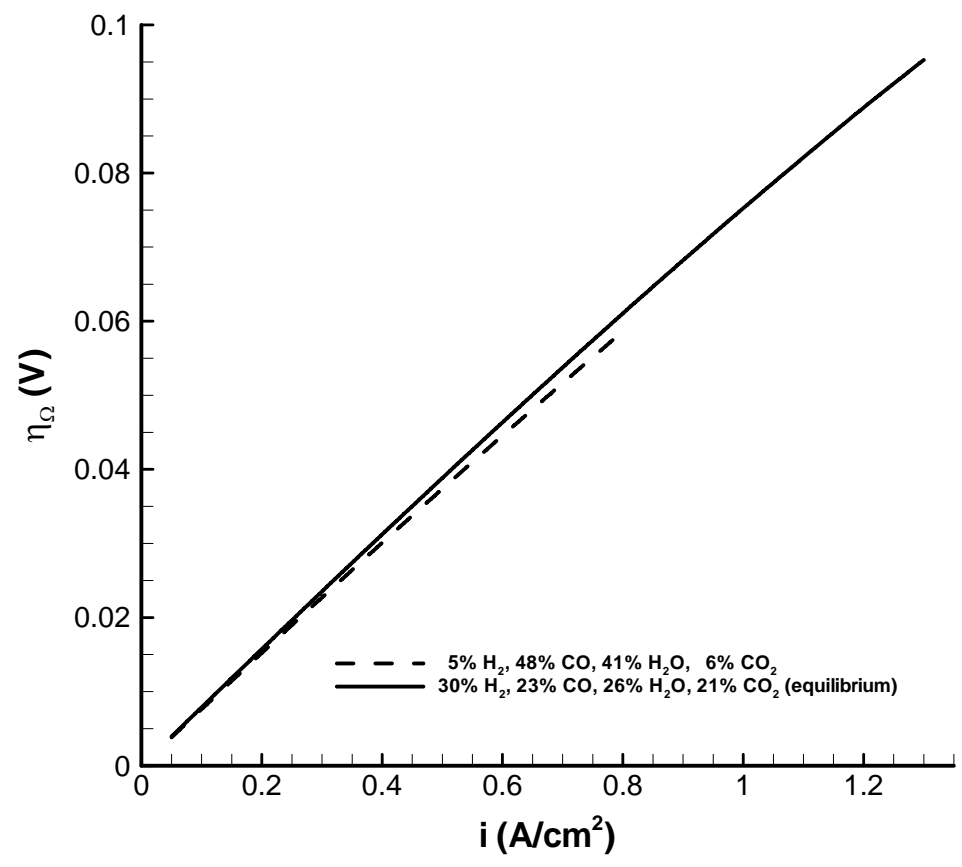

(d)

Figure 6.17 Overpotentials of a button cell operating on equilibrium and nonequilibrium syngas compositions; (a) carbon monoxide activation, (b) oxygen activation, (c) concentration and (d) ohmic

The change in cell temperature $\left(\mathrm{T}_{\text {cell }}-\mathrm{T}_{\mathrm{op}}\right)$ is larger in the case of operation under nonequilibrium syngas concentration as can be seen in Figure 6.18. The cell running on nonequilibrium fuel concentration heats up more as a consequence of a higher rate of the exothermic water gas shift reaction as shown by the overall heat from this reaction in Figure 6.19a. It can also be seen that heat is produced by water gas shift reaction even at open circuit condition and as a result cell temperature increases by about $6^{\circ} \mathrm{C}$ even when the cell is not producing any current. 


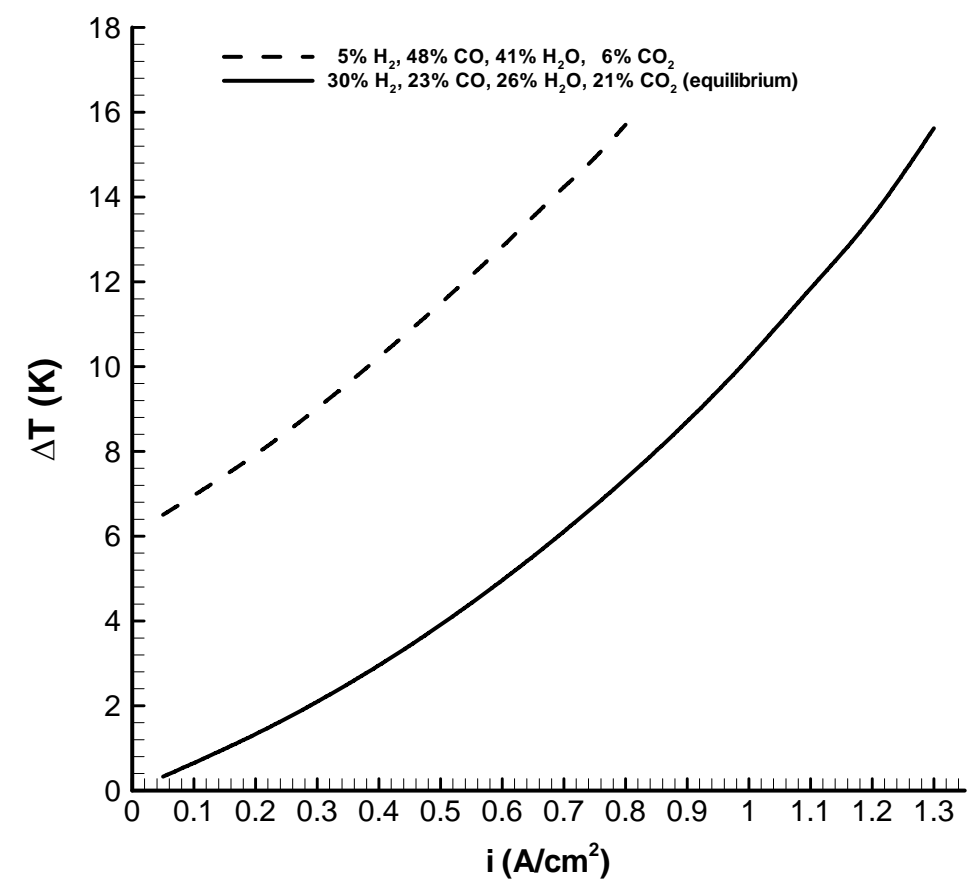

Figure 6.18 Cell temperature change during cell operation on syngas at equilibrium and non-equilibrium concentrations

For the non-equilibrium composition case, the water gas shift reaction proceeds forward over the whole current density range whereas the case with equilibrium composition proceeds forward only at high currents as shown in Figure 6.19a. The methane reforming reaction proceeds in the reverse direction in both cases although the heat generated by this reaction is negligible when compared with heat from the water gas shift reaction (see Figure $6.19 b)$. From Figure $6.19 \mathrm{c}$, it can be seen that the entropic heat is higher for the nonequilibrium case as a consequence of a higher cell temperature. The ohmic heat is lower in the non-equilibrium case also due to a higher cell temperature which decreases the cell ohmic resistance (see Figure 6.19d). 


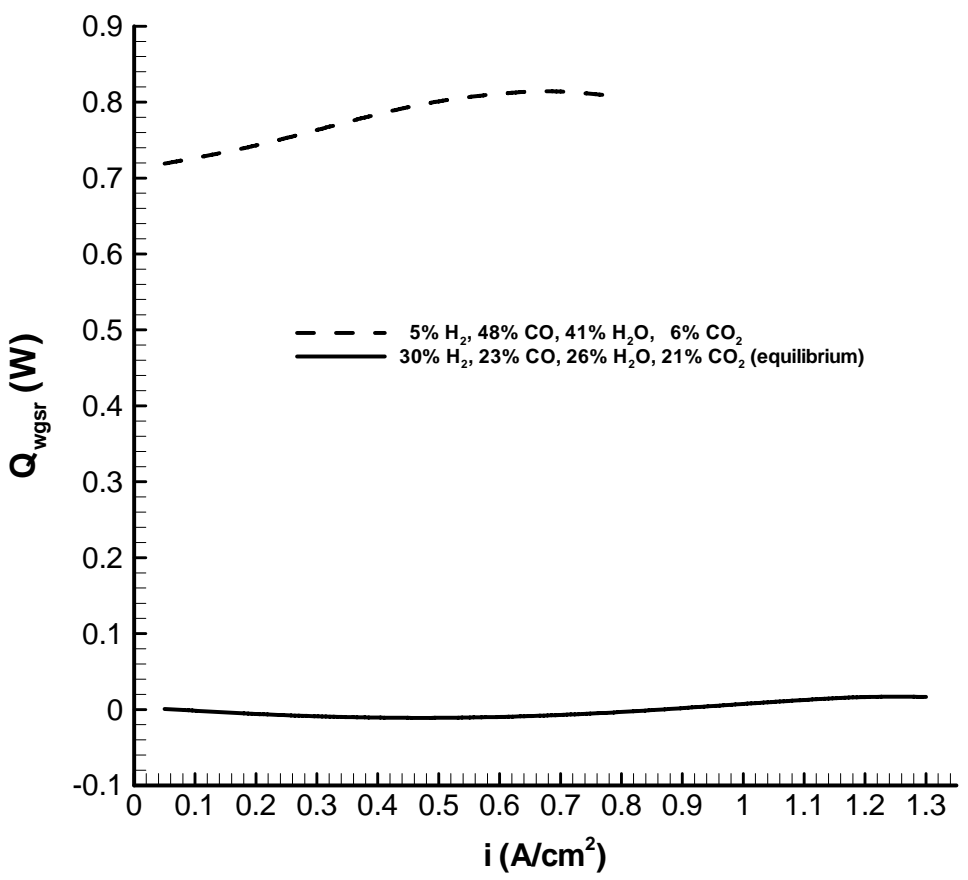

(a)

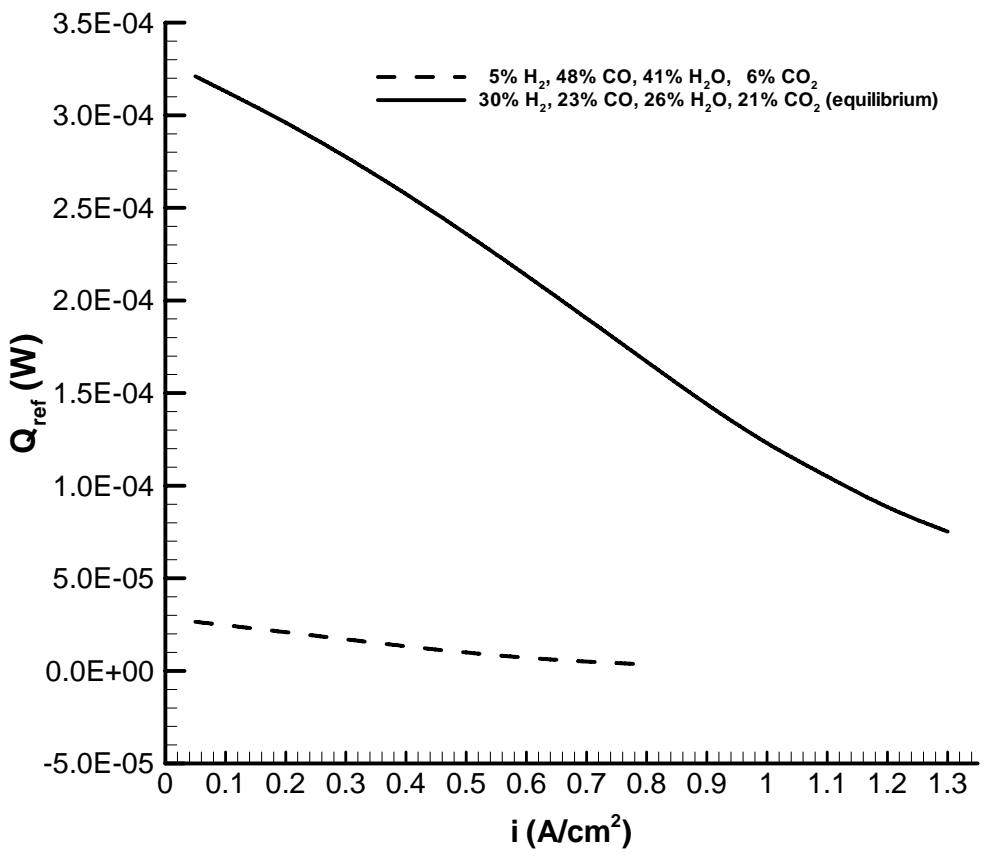

(b) 


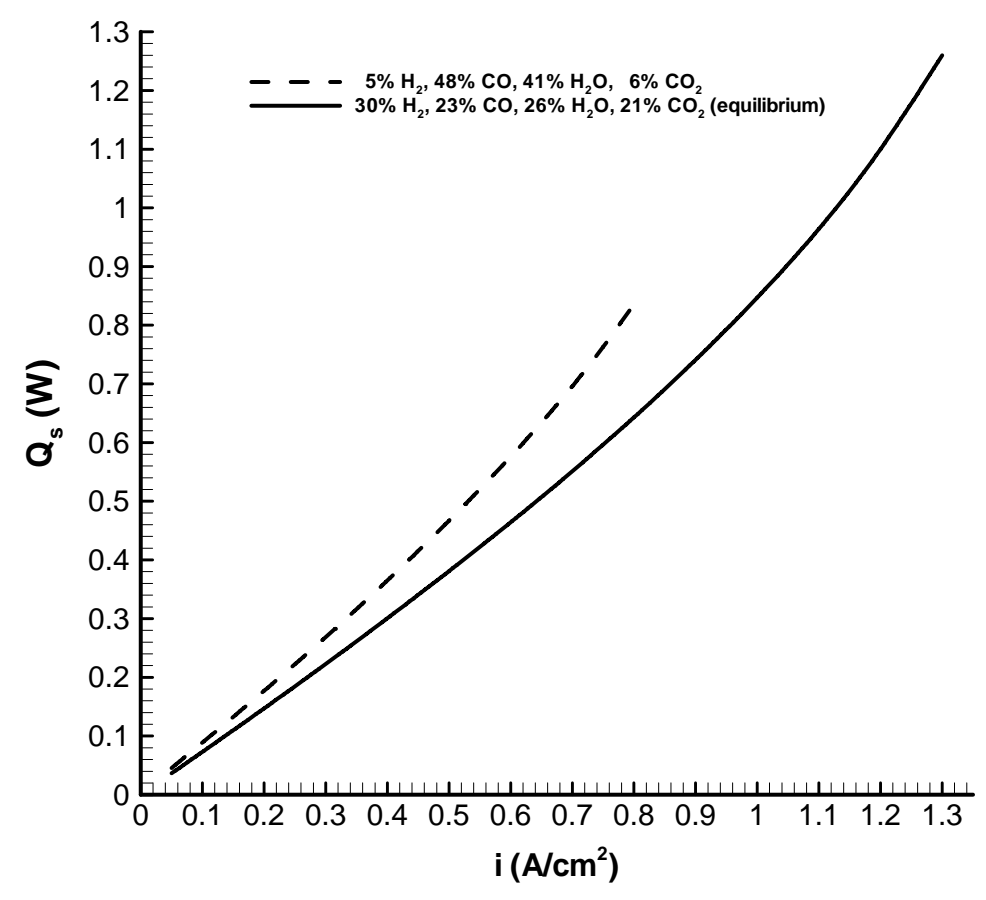

(c)

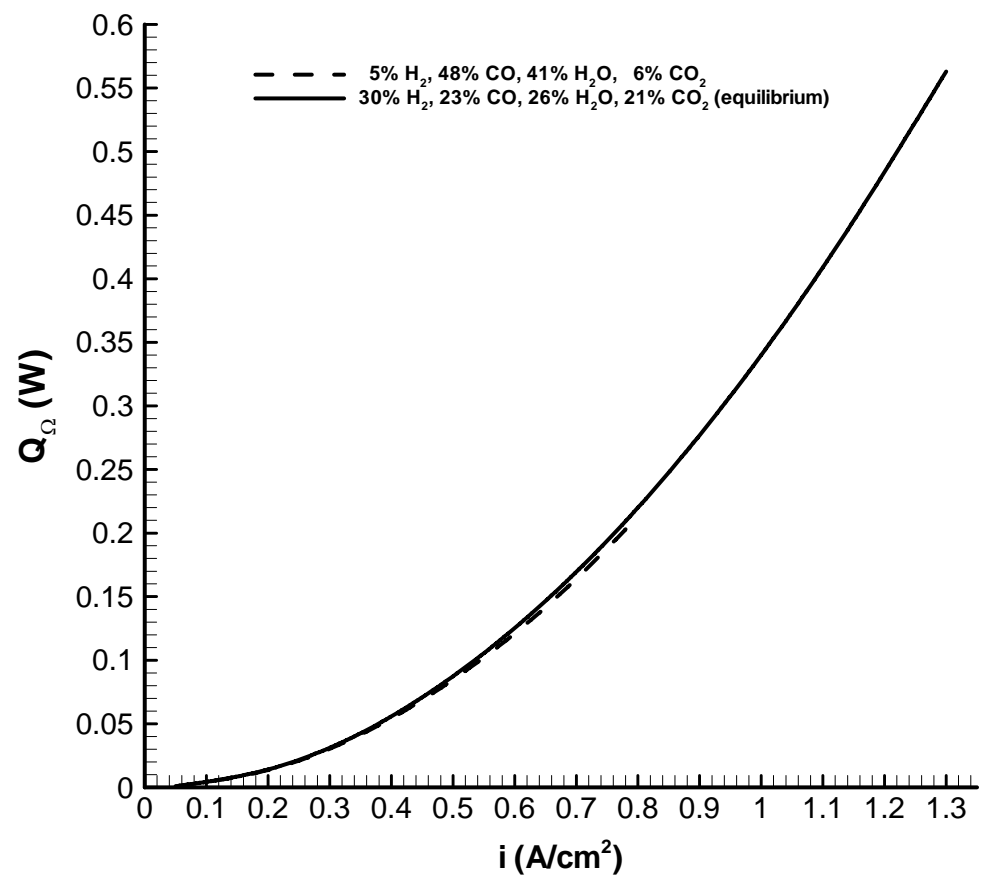

(d)

Figure 6.19 Overall heat sources in a button cell operating at equilibrium and nonequilibrium syngas composition; (a) WGSR, (b) MRR, (c) entropic and (d) ohmic 
The splitting of the total current supported by hydrogen and carbon monoxide is shown in Figure 6.20 where the ratio of the two is presented as a function of the current density. For the non-equilibrium case, the ratio increases from around 0.6 to 2.2 for low currents to high currents whereas in the equilibrium composition case, it decreases for low to high currents from 6 to 5.2 approximately. Once more, it is shown that the partition of the current between hydrogen and carbon monoxide is dependent on the fuel concentrations.

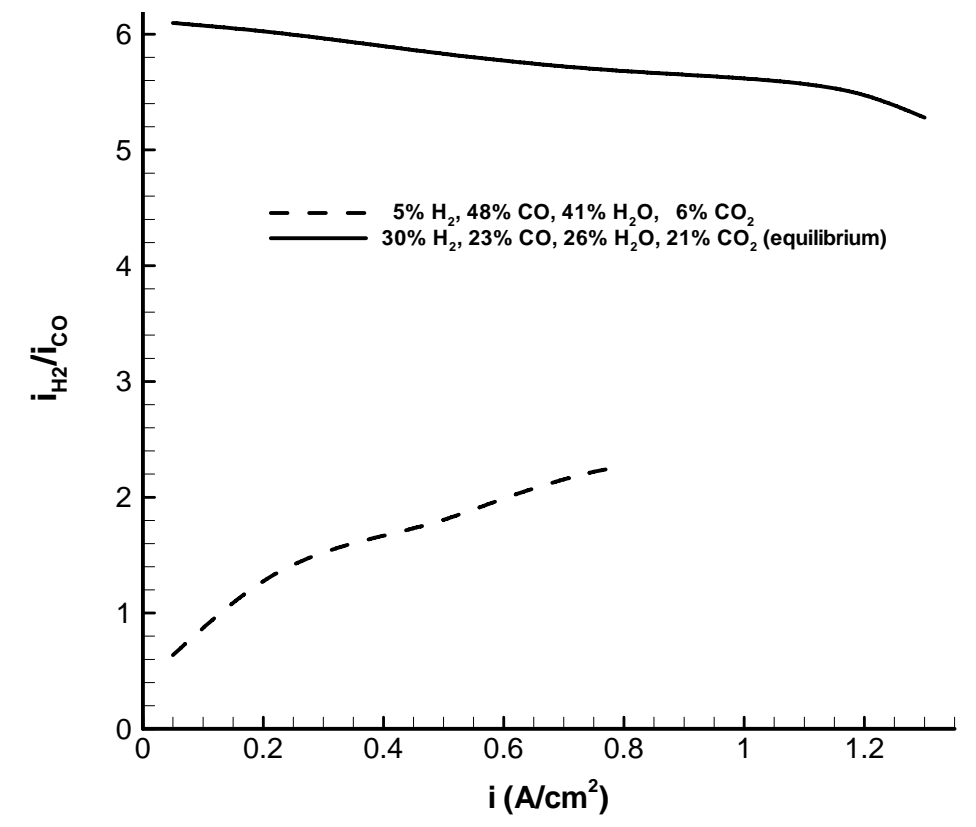

Figure 6.20 Ratio of the current supported by hydrogen to the current supported by carbon monoxide at equilibrium and non-equilibrium syngas composition

From previous calculations (base case with syngas composition at equilibrium), it was observed that there was only one limiting current even though two fuels can be oxidized simultaneously. The existence of one limiting current was explained by the fact that the concentrations equilibrate through the water gas shift reaction. It is interesting to note that this still holds true for operation of the cell on inlet fuel concentrations which are far from equilibrium, as the one shown in Table 6.1. This can be seen from Figure 6.21 which shows that even for the non-equilibrium syngas case, the concentration of hydrogen and carbon monoxide at the active interface tend to zero at around same cell current. This suggests that 
the water gas shift reaction is fast enough to equilibrate the concentrations even when the inlet syngas fuel concentration is far from equilibrium.
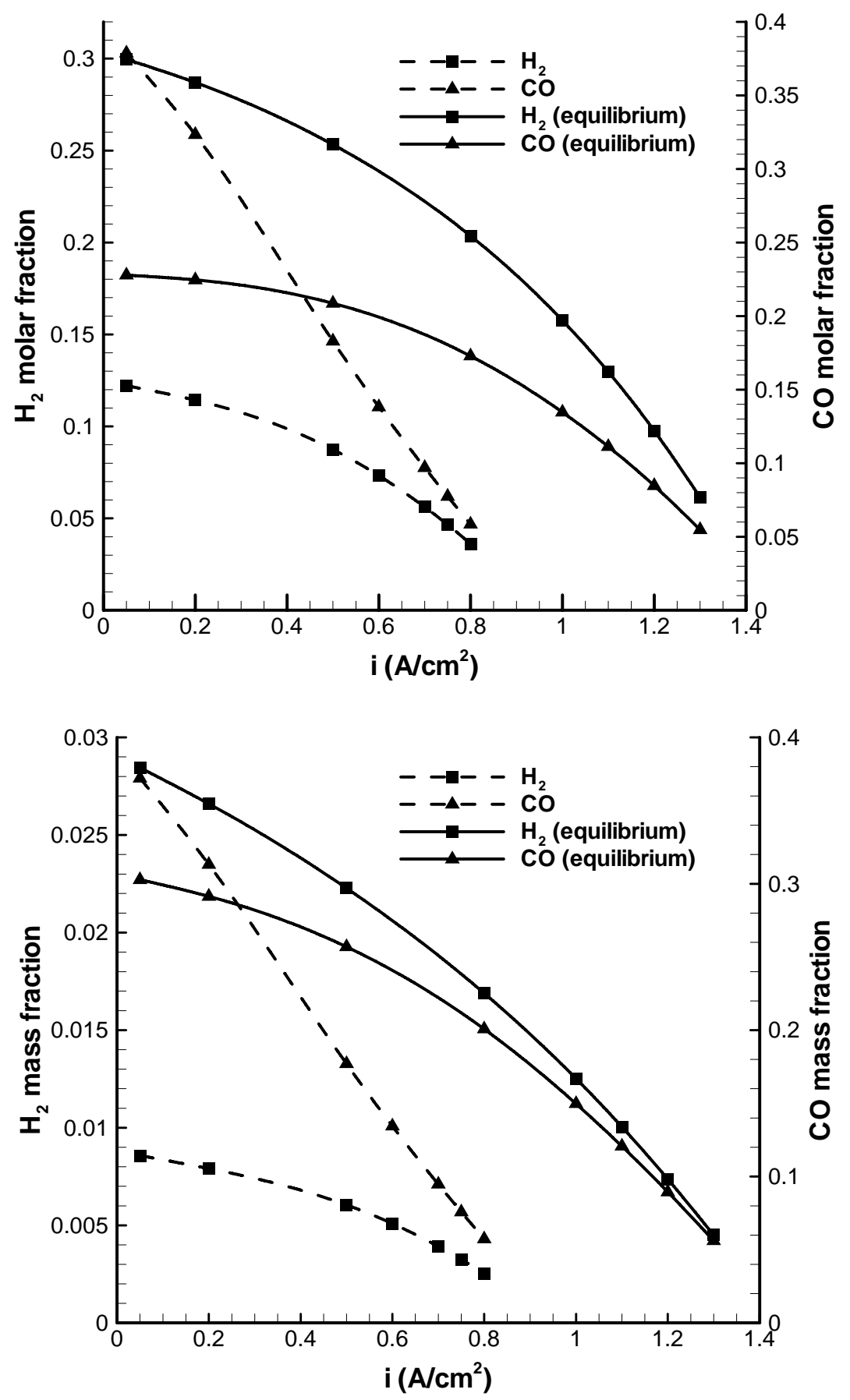

Figure 6.21 Concentration of hydrogen and carbon monoxide at the anode-electrolyte interface of a button cell opearting at equilibrium and non-equilibrium syngas composition; (a) mole fractions and (b) mass fractions 
As in the case of the fuel stream whose composition was that of pre-reformed methane, the concentration profiles along the thickness of the anode are not expected to be linear since the fuel composition is not at equilibrium. However, the difference of this case with respect to the pre-reformed case is that the carbon monoxide concentration decreases along the thickness of the anode as shown in Figure 6.22 since the water gas shift reaction proceeds in the forward direction and also the methane concentration is negligible.

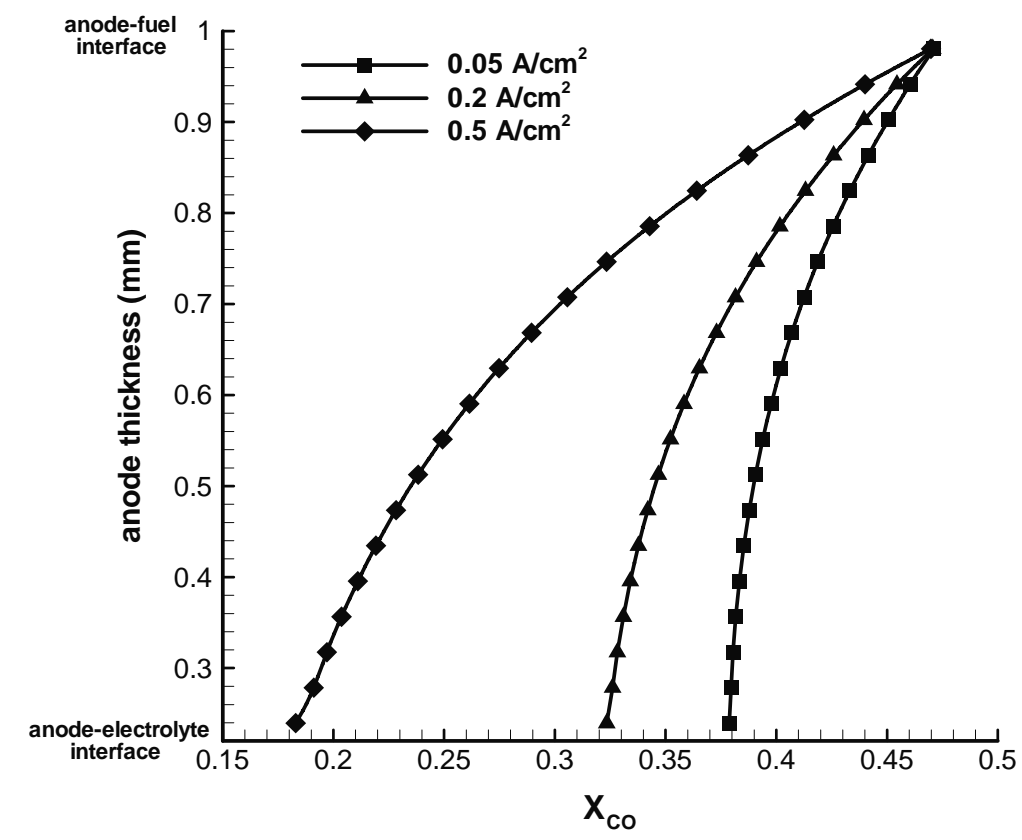

Figure 6.22 Carbon monoxide mass fraction profile along the thickness of the anode on a button cell operating at $800^{\circ} \mathrm{C}$ on syngas with high $\mathrm{CO}$ concentration

\subsection{Effect of CO electrochemical oxidation}

To investigate the effect of carbon monoxide electrochemistry on the cell performance, another simulation is performed for a cell operating on coal syngas at the same conditions as the base case but with carbon monoxide electrochemistry artificially disabled. The results from this simulation are compared with those from the base case which considered carbon monoxide electrochemistry. Figure 6.23 shows the predicted V-I and power density curves for these two cases. It can be seen from Figure 6.23 that though the fuel is same for the two cases, the cell voltage is lower when $\mathrm{CO}$ electrochemistry is neglected. Limiting current, however, is about the same for the two cases. The small decline in performance 
when carbon monoxide electrochemistry is neglected is caused by an increase in the hydrogen activation overpotential since the total current is supported only by hydrogen and also by the decrease of hydrogen concentration at the anode-electrolyte interface which reduces the hydrogen exchange current.

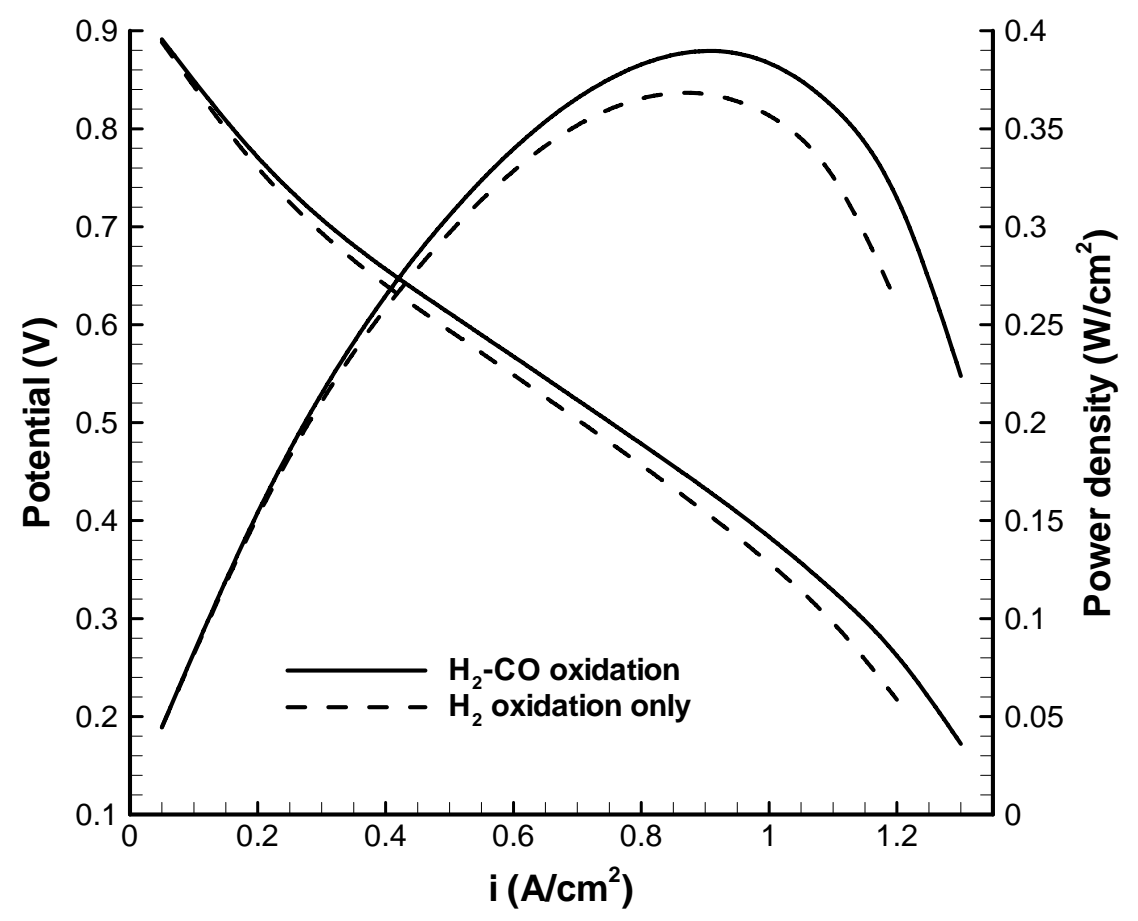

Figure 6.23 Predicted V-I and power density curves for the button cell operating on coal syngas with and without $\mathrm{CO}$ oxidation

The overall heat produced from the water gas shift reaction plotted in Figure 6.24 shows that the net water gas shift reaction always proceeds in forward direction for the case where carbon monoxide oxidation is neglected whereas it proceeds in the backward direction at low currents for the other case. Therefore, as expected, a small increase in the cell temperature is observed when carbon monoxide oxidation is not considered. Also, the water gas shift reaction rate is much higher when carbon monoxide electrochemistry is neglected. This implies that though carbon monoxide is not directly supporting the current production, it is indirectly contributing by augmenting the hydrogen supply through the water gas shift reaction. 


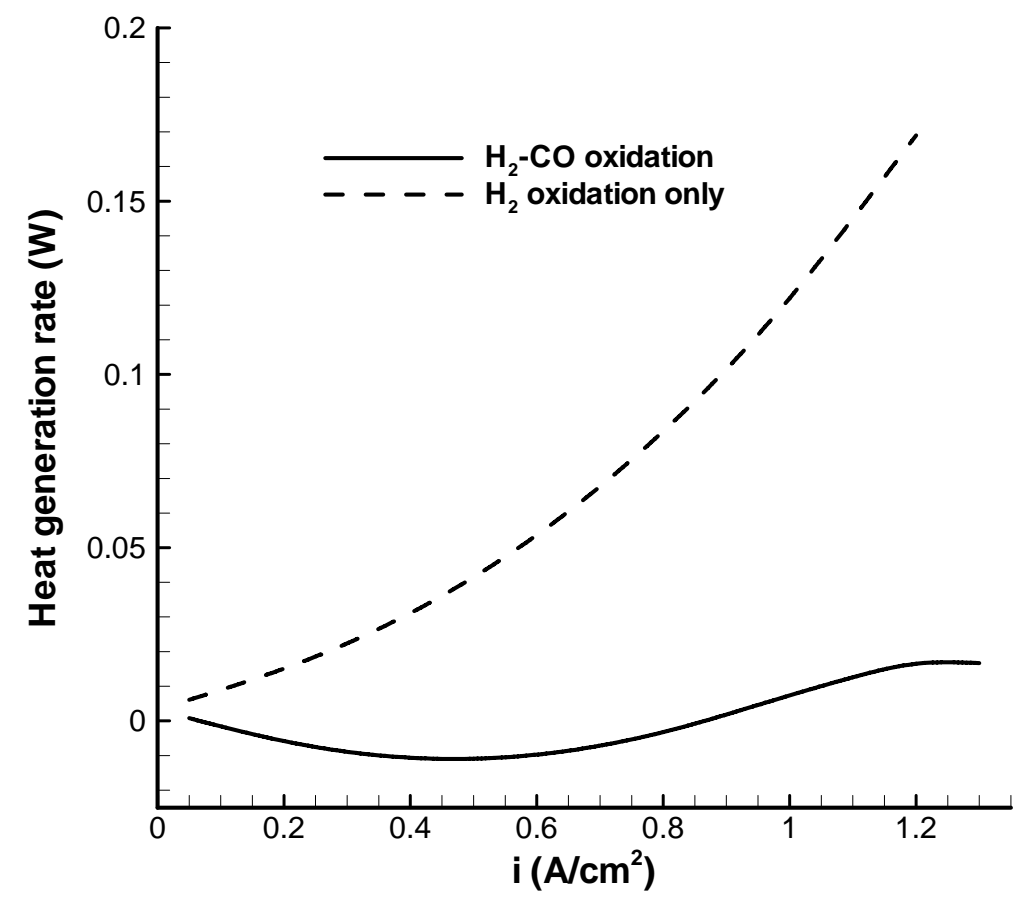

Figure 6.24 Overall heat from the water gas shift reaction when carbon monoxide oxidation is neglected

The plot of local carbon monoxide concentration at the anode/electrolyte interface presented in Figure 6.25 shows that carbon monoxide concentration decreases fast near the limiting current even though it is not involved in the electrochemistry. To summarize, if carbon monoxide electrochemistry is not taken into account as done by some researchers $[8$, $10,11]$ the computations will incur errors due to over prediction of water gas shift reaction rates and resulting heat generation. Moreover incorrect prediction of carbon monoxide concentration distribution may lead to wrong conclusions with respect to carbon deposition and similar phenomenon. 


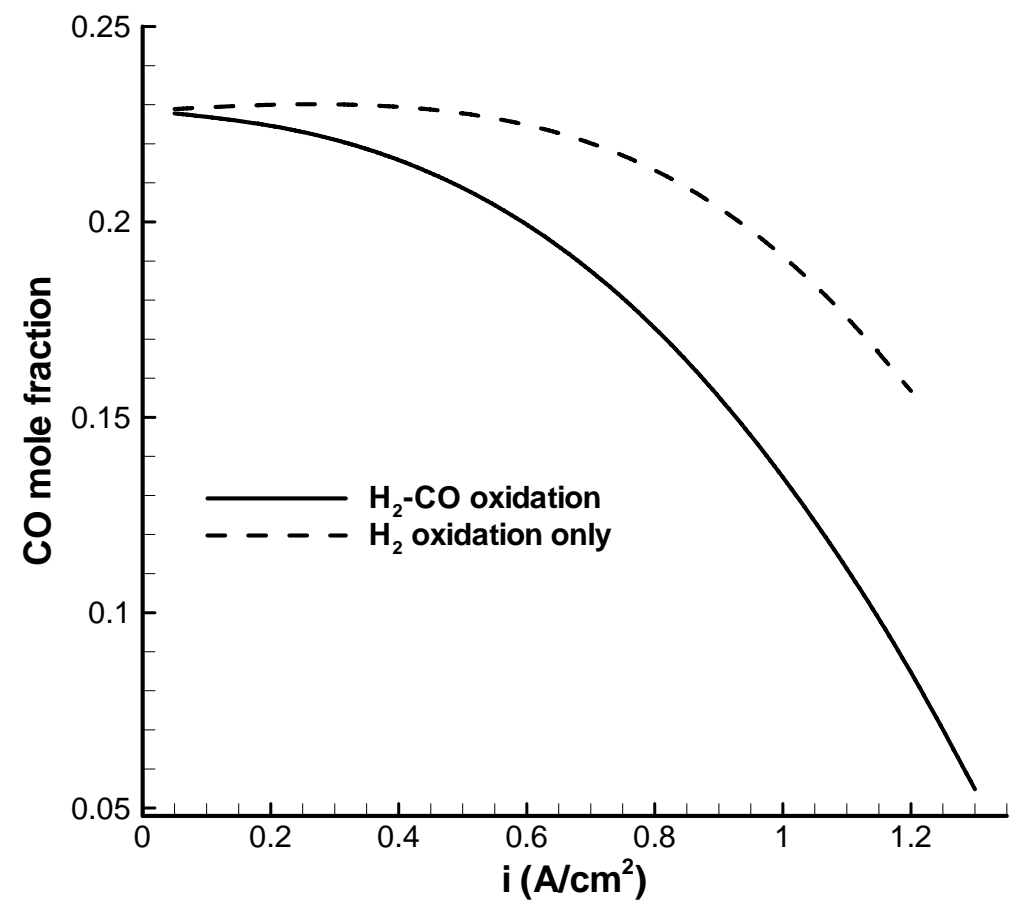

(a)

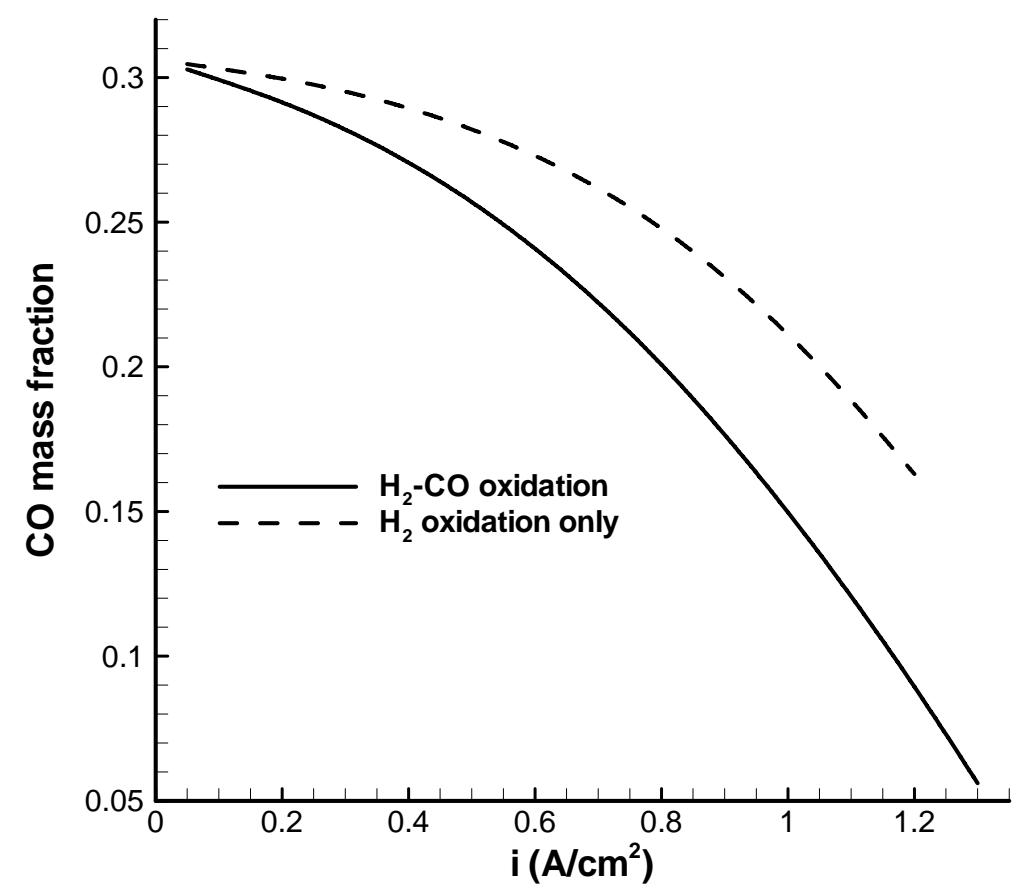

(b)

Figure 6.25 Carbon monoxide concentration at the center of the anode/electrolyte interface when electrochemical oxidation of $\mathrm{CO}$ is considered and neglected; (a) mole fraction and (b) mass fraction 


\subsection{Effect of Activation Energy in the Exchange Current of CO}

As the last parametric exercise, the effect of including an activation energy (and therefore temperature dependence) in the carbon monoxide exchange current equation is studied. The empirically proposed relation for this exchange current has the form

$$
i_{0, C O}^{*}=c_{2}^{\prime}\left(\frac{Y_{C O}}{Y_{C O, \text { ref }}}\right) \exp \left(-\frac{E_{a c t, C O}}{R T}\right)
$$

where the proposed carbon monoxide activation energy is $100 \mathrm{~kJ} / \mathrm{mol}$, a value that falls in between the activation energy for hydrogen oxidation (92 kJ/mol [38]) and oxygen reduction $(120 \mathrm{~kJ} / \mathrm{mol}[42])$. The new parameter $c_{2}^{\prime}$ is calculated in such a way that Eqn. (6.5.1) will match with the already calibrated Eqn. (4.1.18), when both are evaluated at $800^{\circ} \mathrm{C}$. Therefore, the parameter $c_{2}^{\prime}$ takes the value of $2.215 \times 10^{7} \mathrm{~A} / \mathrm{m}^{2}$.

It is important to note that the value of $100 \mathrm{~kJ} / \mathrm{mol}$ which was assigned to the activation energy for carbon monoxide oxidation is completely arbitrary and it contradicts the observed weak dependence of carbon monoxide exchange current density on temperature [38] which suggest low activation energy of carbon monoxide electrochemistry. The purpose of this exercise is to simply analyze a hypothetical case when the carbon monoxide electrochemistry shows temperature dependence similar to hydrogen and oxygen.

Numerical simulations of the button cell with the exchange current for carbon monoxide as shown in Eqn. (6.5.1) were performed at $750^{\circ} \mathrm{C}, 800^{\circ} \mathrm{C}$ and $850^{\circ} \mathrm{C}$ in order to compare these results with those shown in section 6.1 devoted to sensitivity analysis where the effect of operating temperature was analyzed. At $800^{\circ} \mathrm{C}$, a considerable difference in the cell performance with and without the activation energy in the carbon monoxide exchange current is not expected, since the exchange current value at $800^{\circ} \mathrm{C}$ is the same and the increase in cell temperature is only about $16^{\circ} \mathrm{C}$ when the cell supports a current close to the limiting current. The comparison on the cell performance with and without the activation 
energy for carbon monoxide exchange current for the three temperatures mentioned above is shown in Figure 6.26.

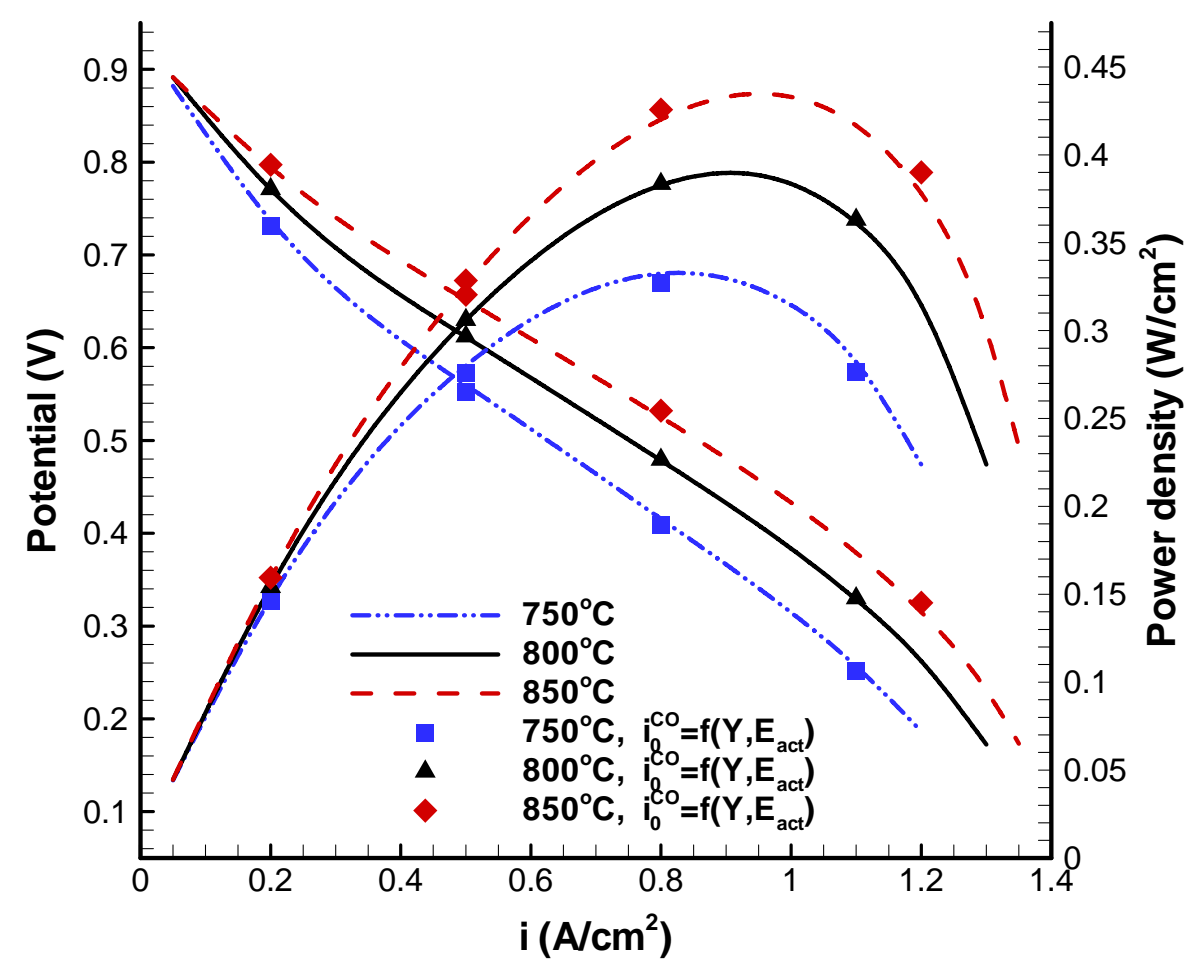

Figure 6.26 Effect on cell performance of activation energy in carbon monoxide exchange current at different operating temperatures

The difference between the two cases being compared is less than $2 \mathrm{mV}$ at high currents and even smaller at lower currents when the operating temperature is $800^{\circ} \mathrm{C}$. At cell operating temperatures of $750^{\circ} \mathrm{C}$ and $850^{\circ} \mathrm{C}$ the maximum difference in cell potential is about $7 \mathrm{mV}$ and $10 \mathrm{mV}$ respectively.

The difference in carbon monoxide activation overpotential between the two cases is negligible at $800^{\circ} \mathrm{C}(\sim 3 \mathrm{mV})$ as expected and shown in Figure 6.27. Relatively larger changes of up to $12 \mathrm{mV}$ can be seen in the carbon monoxide activation overpotential at $750^{\circ} \mathrm{C}$ and up to $19 \mathrm{mV}$ at $850^{\circ} \mathrm{C}$. The changes in hydrogen activation overpotential (not shown here) were qualitatively and quantitatively similar to the changes observed in carbon monoxide activation overpotential. The rest of the overpotentials such as oxygen activation, 
ohmic and concentration basically remained the same showing the weak effect of the carbon monoxide activation overpotential for oxidation on the cell performance.

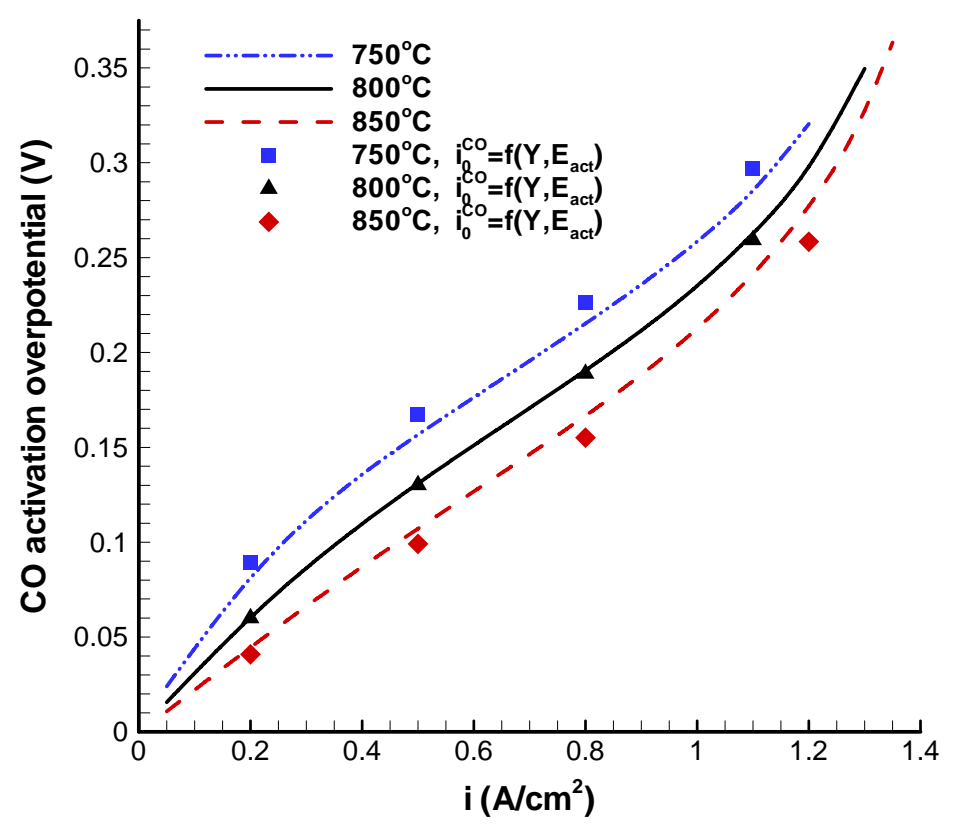

Figure 6.27 Change in carbon monoxide activation overpotential by considering activation energy in its exchange current

Similarly, the heat sources during the operation of the button cell such as entropic, ohmic and that generated from the methane reforming reaction remained basically the same except the heat released from the water gas shift reaction which showed differences especially at high currents at the three different operating cell temperatures studied here. It can be seen in Figure 6.28 that the changes increase as the current density increases at the three operating temperatures. Also the major difference is observed at the highest operating temperature $\left(850^{\circ} \mathrm{C}\right)$ and the lowest, as expected, at $800^{\circ} \mathrm{C}$ (the calibration temperature). From the fact that the only considerable observed change in energy sources was that from the water gas shift reaction, a small increase in the cell temperature, especially at high currents, is expected when the operating temperature is $750^{\circ} \mathrm{C}$ compared with base case (no activation energy in carbon monoxide exchange current included), whereas the cell should cool down slightly with respect to the base case at the operating temperature of $850^{\circ} \mathrm{C}$. The expected cell temperature trends mentioned above can be seen in Figure 6.29 


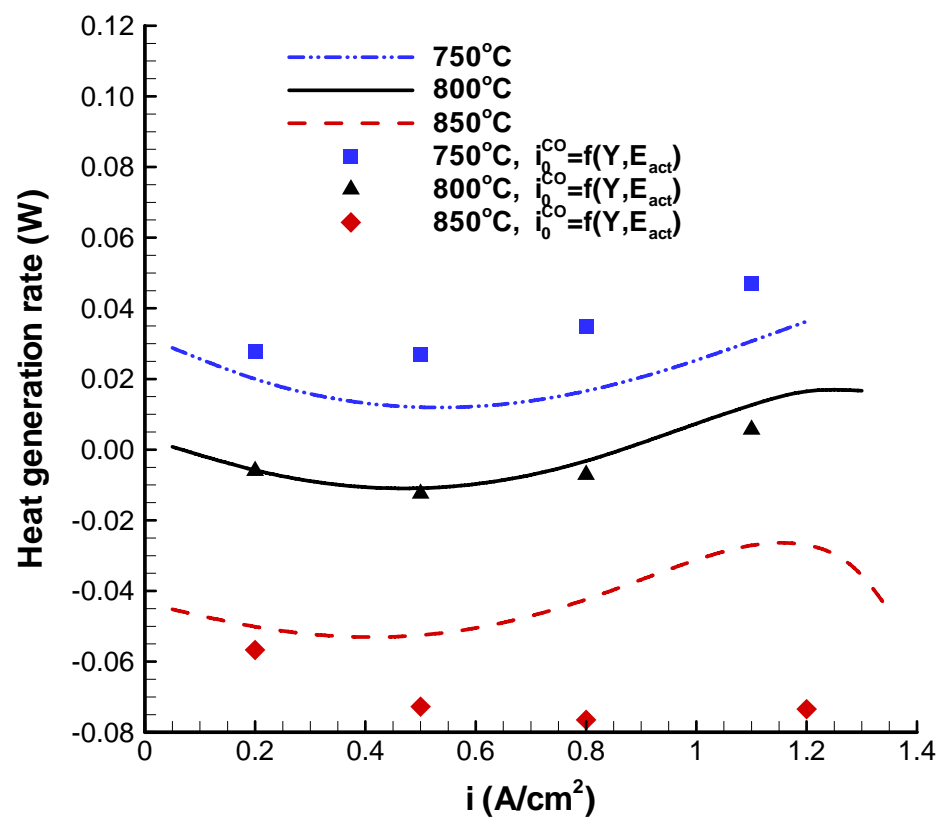

Figure 6.28 Change in heat generation rate from WGSR by considering activation energy in carbon monoxide exchange current

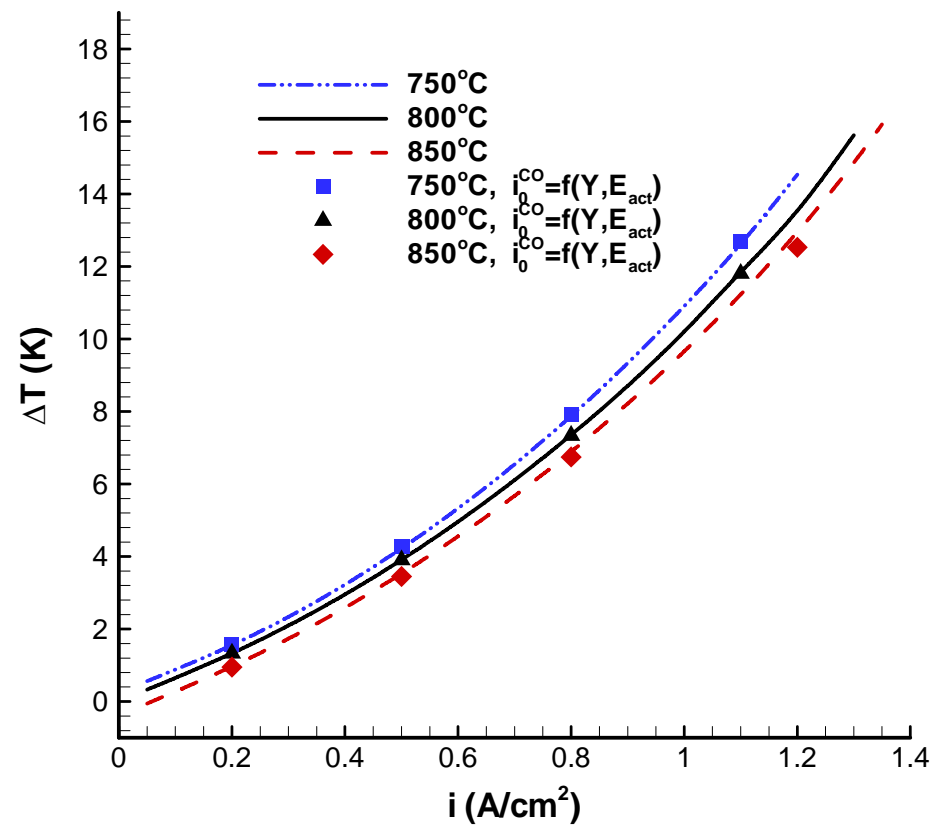

Figure 6.29 Change in cell temperature increase by considering activation energy in carbon monoxide exchange current 
The major difference between the two cases compared here was observed in the splitting of the total current between the current supported by hydrogen and carbon monoxide. As it can be seen in Figure 6.30 a considerable difference not only qualitative but also quantitative is observed in the ratio of hydrogen current to carbon monoxide current at the operating temperatures of $750^{\circ} \mathrm{C}$ and $850^{\circ} \mathrm{C}$. At $800^{\circ} \mathrm{C}$ the change is not much since at this temperature the carbon monoxide exchange current including the activation energy was re-calibrated. When the carbon monoxide exchange current includes activation energy, the ratio between the current supported by hydrogen to the current driven by carbon monoxide varies between 4 and 6.5 for the three operating temperatures considered in this analysis, whereas if the activation energy is not included, the ratio varies from around 3.5 to 9.5, therefore, the activation energy of the carbon monoxide exchange current shrinks the range of this ratio.

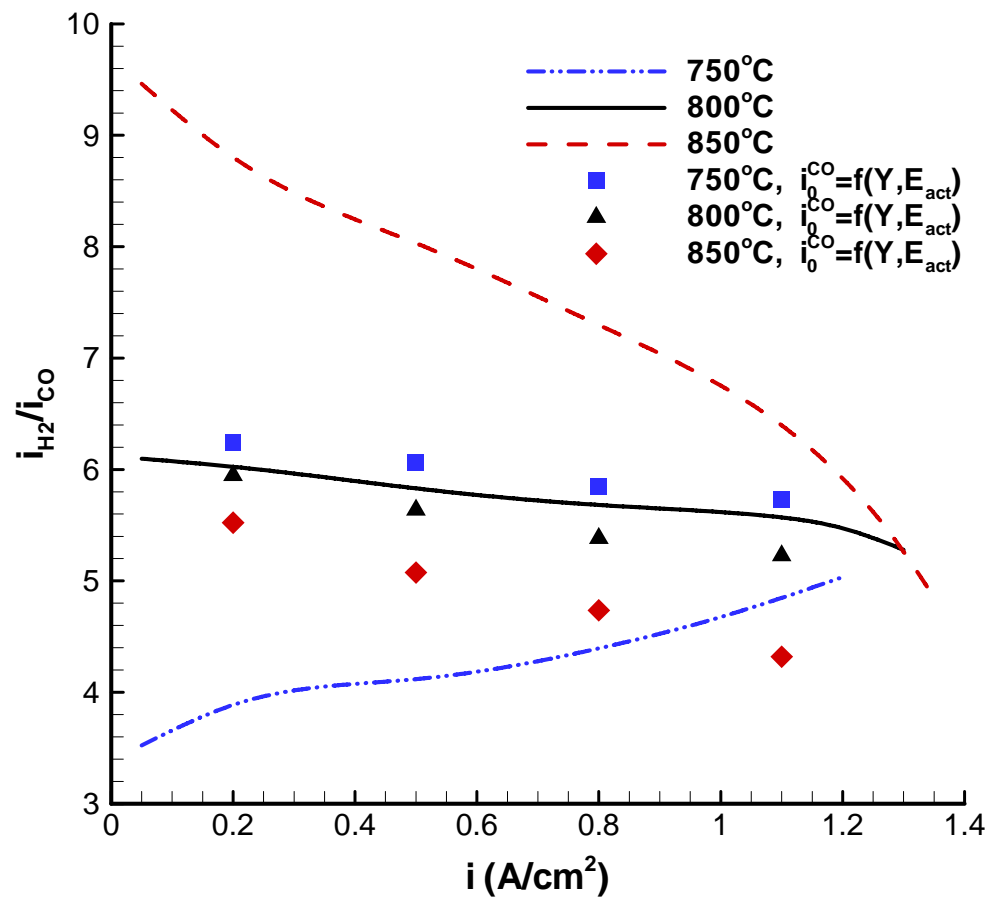

Figure 6.30 Change in the hydrogen current to carbon monoxide current ratio by considering activation energy in carbon monoxide exchange current

Another major difference is that, with respect to the ratio of the currents (hydrogen and carbon monoxide) the ratio increases at lower temperatures and decreases at higher 
temperatures for the case with carbon monoxide activation energy, which is the opposite trend observed in the base case when no activation energy is included in the carbon monoxide exchange current. When the activation energy is included in the carbon monoxide exchange current this also becomes dependent/sensitive to the cell temperature (see Eqn. (6.5.1)), therefore an increase in temperature causes an increase in exchange current. So, at higher temperatures more carbon monoxide would be oxidized than at lower temperatures and, according to the electrochemistry model, less current will be supported by hydrogen since the total current is the sum of hydrogen and carbon monoxide currents. Therefore the ratio between these two currents would decrease as the temperature increases assuming that the hydrogen and carbon monoxide concentrations are nearly the same, because of the concentration dependence of the exchange current. When no activation energy is included in the carbon monoxide exchange current, this exchange current remains the same irrespective of the cell temperature, therefore the resistance to oxidize carbon monoxide is the same, whereas if the cell temperature changes, the exchange current for hydrogen changes in the same direction as temperature and the resistance to oxidize hydrogen in opposite direction, hence the higher the temperature the higher the current supported by hydrogen, resulting in a higher ratio between the hydrogen current to carbon monoxide current. The opposite behavior would be observed if the cell temperature decreases i.e. the hydrogen current to carbon monoxide current decreases.

Increasing the current density increases the cell temperature but also decreases the concentration of the fuel species at the anode-electrolyte interface through the oxidation reactions. The concentration of the fuel species (hydrogen and carbon monoxide) can also increase or decrease through the methane reforming and water gas shift reactions. An increase in the hydrogen current to carbon monoxide current ratio would be expected if, for hydrogen, the temperature effect is stronger than the concentration effect in case the concentration of the fuel decreases, resulting in a net increase of the exchange current, which then should result in higher hydrogen current to carbon monoxide current ratio as shown in Figure 6.30 by the case where the cell operates at $750^{\circ} \mathrm{C}$ without activation energy in the carbon monoxide exchange current. However, this trend is not shown by the other cases suggesting that the concentration effect is stronger than temperature effect on the 
hydrogen exchange currents. This observation is in accordance with the conclusion reached by Nagel et al [22] where it is established that the fuel composition (concentration effect) is more important than the parameters of the activation overpotential such as activation energy and pre-exponential coefficient, geometry (porosity and tortuosity) and material properties such as heat transfer coefficient.

It is also noticed that the ratio decreases faster as the current density increases when the cell operating temperature is $850^{\circ} \mathrm{C}$ caused by the fact that the water gas shift reaction proceeds in the reverse direction at that operating temperature as shown in Figure 6.28

In can be concluded that the activation energy of carbon monoxide oxidation does not affect the cell performance but it affects considerably the current produced by the two fuels that can be oxidized directly. 


\section{Chapter 7}

\section{PLANAR CELL OPERATING \\ ON METHANE}

\subsection{Introduction}

In this chapter, as an application, the developed computational tool is used to predict the performance of a planar cell running on pre-reformed methane. All the capabilities of the code described in the previous chapters are used in this application which include; internal reforming and water gas shift reaction inside the Ni-YSZ anode, simultaneous electrochemical oxidation of hydrogen and carbon monoxide, detailed effective diffusivity for multi-component fuel mixtures.

The main difference between the simulation of the planar cell and the button cell is that in the former, a one-dimensional model is used to solve the continuity, momentum and energy equations inside the gas channels (anode and cathode). Therefore, additional boundary conditions are needed in this application case compared to the button cell simulations. For the gas channels, species concentrations, temperature and mass flow rates of the fuel and air streams are prescribed at the inlet of the gas channels. For details about this one-dimensional model please see [4].

\subsection{Operating conditions}

The planar cell studied here operates at $800^{\circ} \mathrm{C}$ running on $30 \%$ pre-reformed methane with the composition described in Table 5.3. The cell supports a total current of $30 \mathrm{~A}$ and according to the prescribed inlet mass flow rate of the fuel channels, it operates at around $50 \%$ utilization. The considered flow arrangement for the planar cell is co-flow. The geometrical parameters of the PEN structure are the same as reported in Table 5.1 and the bipolar plates have the dimensions reported in [53] where the total length and width of the 
cell are $10 \mathrm{~cm}$ each. The bipolar plates include 18 channels on each side where the width and height of the channels are $3 \mathrm{~mm}$ and $1 \mathrm{~mm}$ respectively. The distance between two adjacent channels (rib width) is $2.42 \mathrm{~mm}$ and the thickness of the current collector is 1.5 $\mathrm{mm}$. The total cell thickness is about $6 \mathrm{~mm}$. For a rough sketch of the cross-section of the planar cell showing three channels see Figure 7.1.

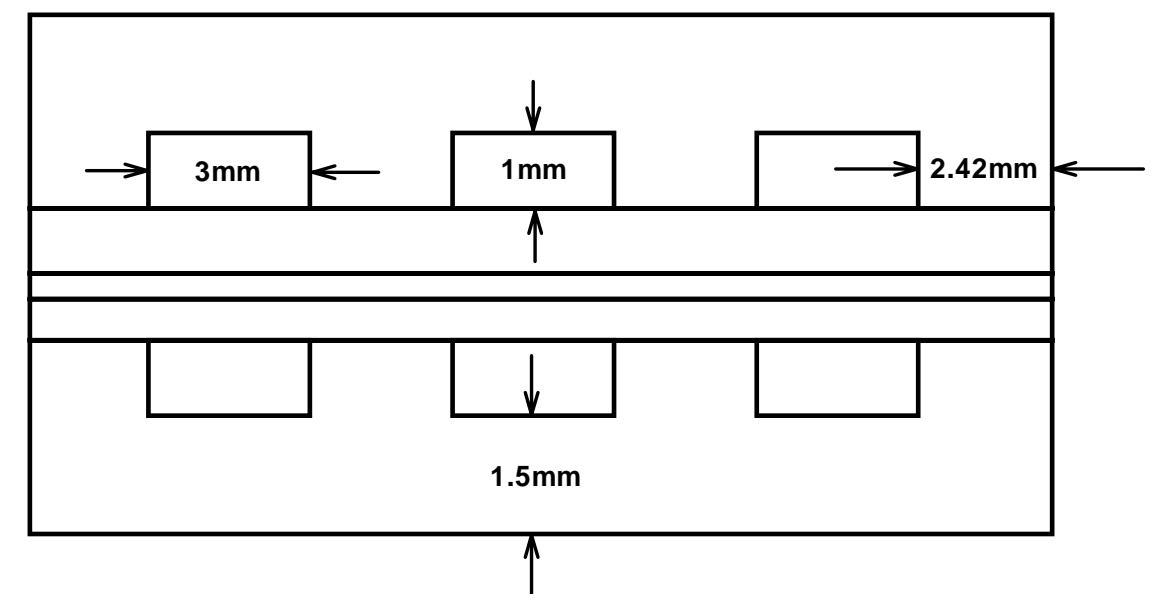

Figure 7.1 Sketch of the planar cell showing only three channels

\subsection{Results}

Under the operating conditions described above, the current planar cell delivers approximately $18 \mathrm{~W}$ of power. The mass fraction contours at the anode-electrolyte interface for hydrogen, carbon monoxide and methane are shown in Figure 7.2. The inlet of the gases is at cell length equals zero. It can be seen that the mass fraction for hydrogen and methane decreases along the flow direction (cell length) while the carbon monoxide concentration increases. In the fuel channels, a slight increase in hydrogen concentration is observed near the entrance of the fuel gasses (not shown here).

The oxygen mass fraction at the cathode-electrolyte interface is shown in Figure 7.3. As expected the oxygen concentration decreases along the flow direction and it is always lower under the ribs than under the channels. 


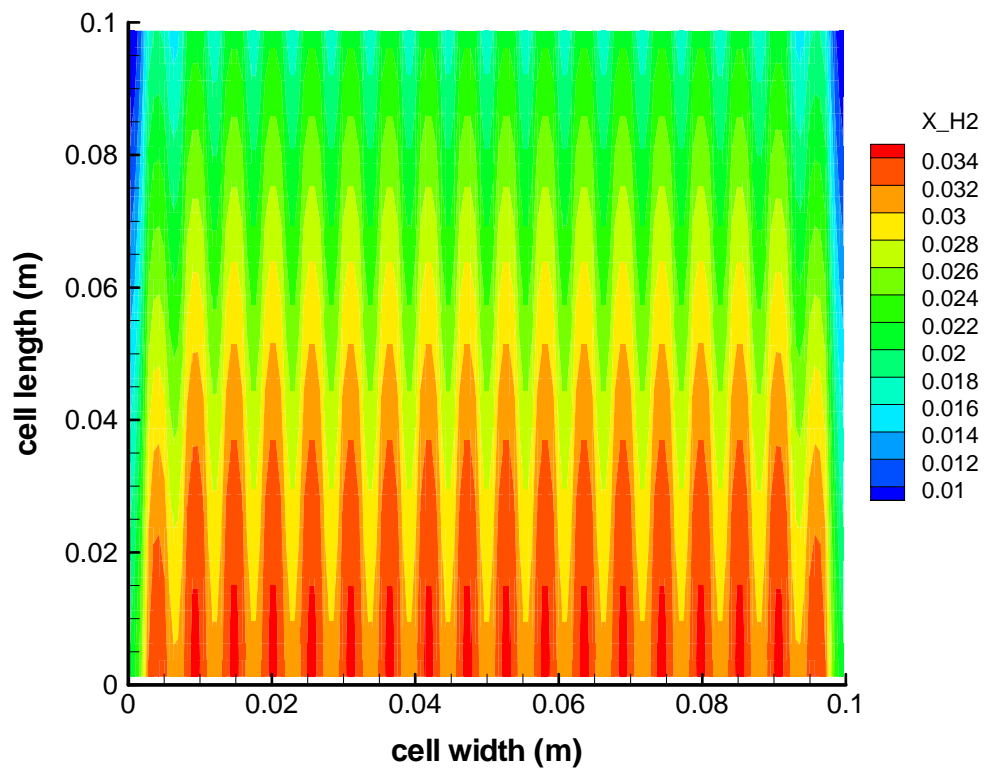

(a)

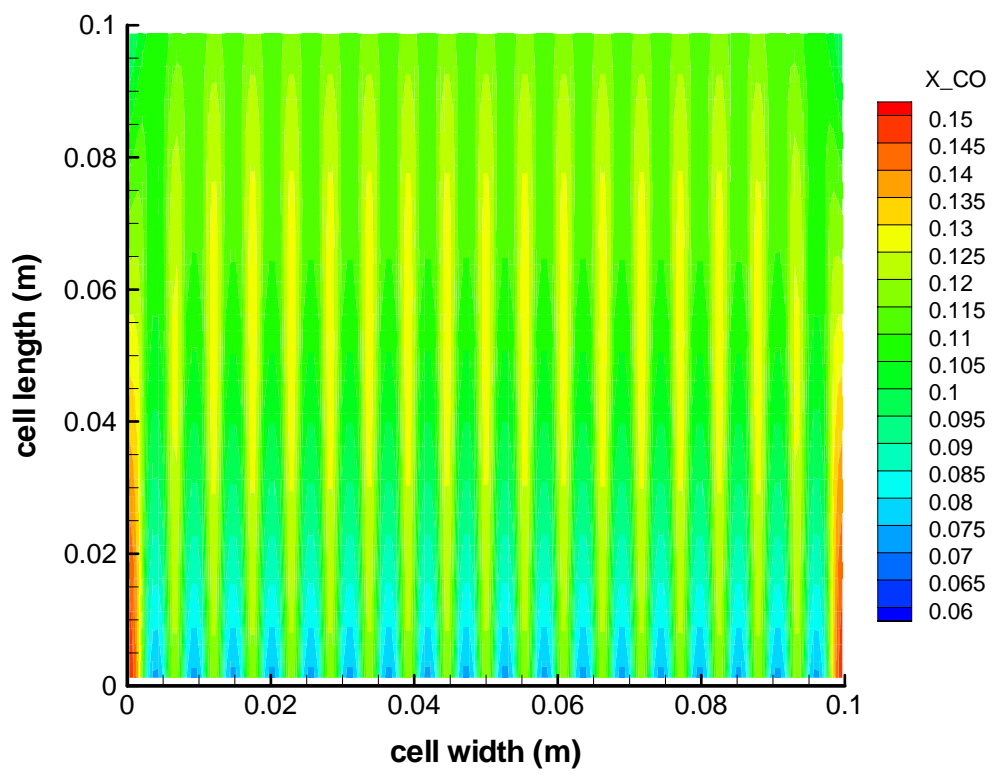

(b) 


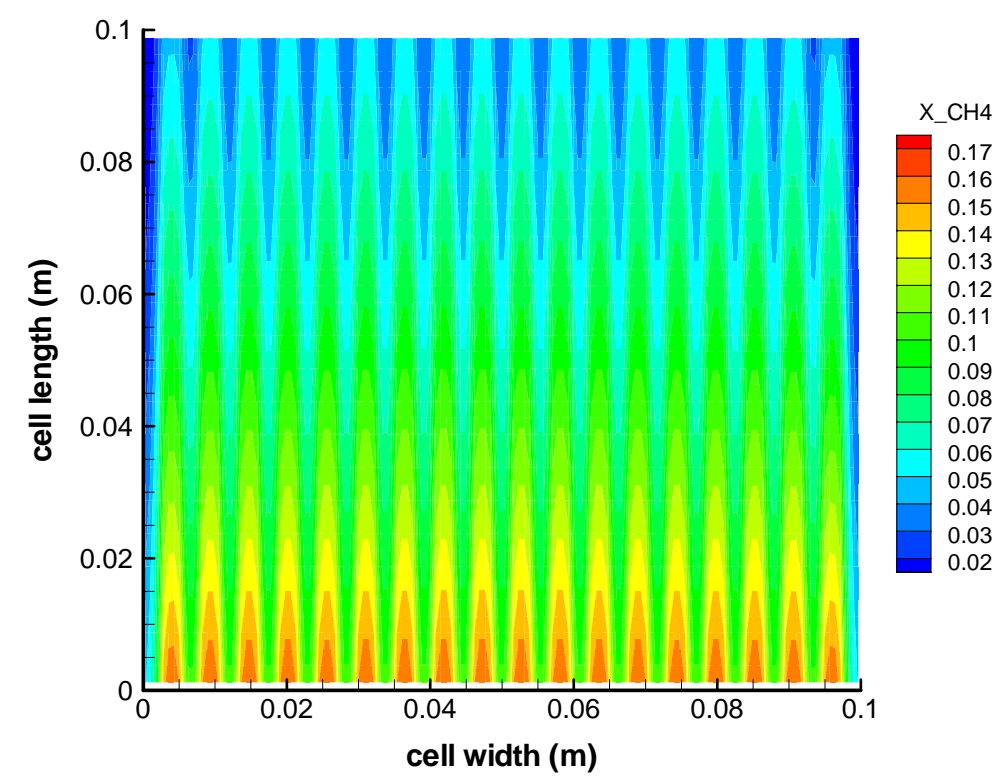

(c)

Figure 7.2 Mass fraction contours at the anode-electrolyte interface for (a) hydrogen, (b) carbon monoxide and (c) methane

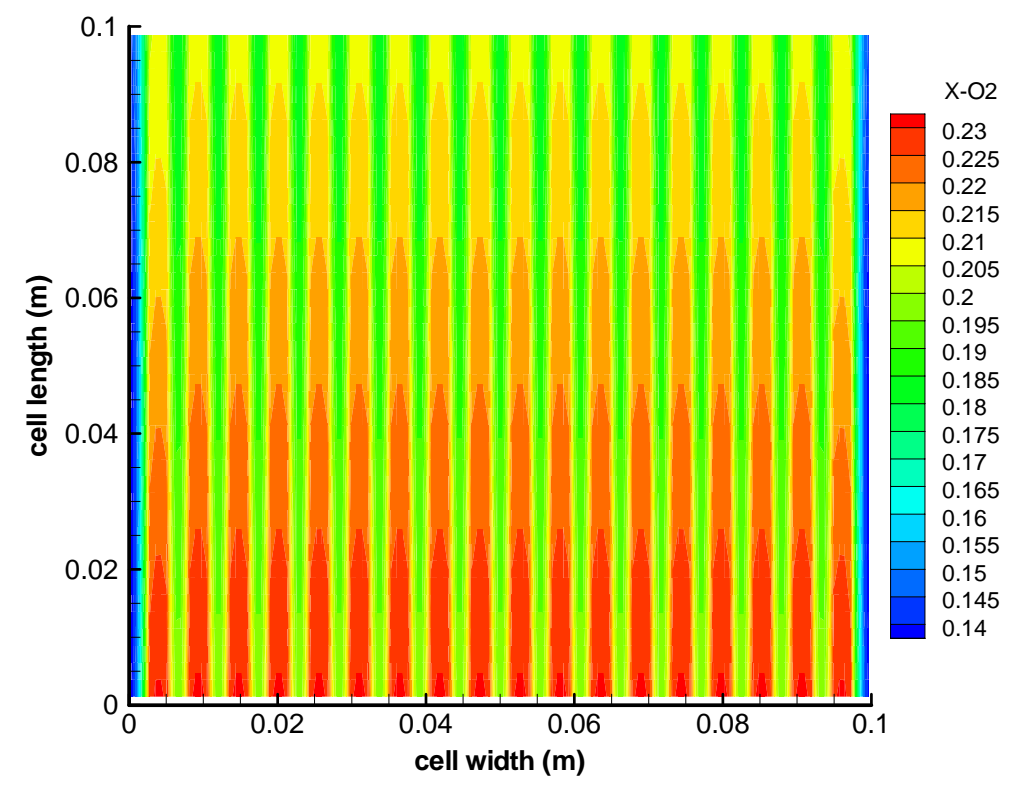

Figure 7.3 Mass fraction contours of oxygen at the cathode-electrolyte interface 
The activation overpotentials for hydrogen, carbon monoxide and oxygen at their respective electrode-electrolyte interface are shown in Figure 7.4. At the anode-electrolyte interface, the overpotentials for hydrogen (see Figure 7.5) and carbon monoxide are larger under the ribs than under the channels. The distributions of these two overpotentials are very similar because of the nature of the electrochemistry model. The higher overpotentials under the ribs may be a consequence of lower concentration under the ribs than under the channels since the activation overpotential is proportional to the exchange current density which depends on the concentration at the active interface. The activation overpotentials for hydrogen and carbon monoxide decrease along the flow direction and they increase towards the outlet. The opposite trend is observed in the oxygen activation overpotential where it starts increasing from the inlet and decreases towards the outlet. This is caused by the temperature increase which has a more dominant effect on the exchange current for oxygen than the concentration. For the three activation overpotentials the magnitudes are comparable although oxygen activation overpotential presents a slightly larger overpotential. It is important to mention that activation overpotentials are also proportional to the current, therefore their distribution is also influenced by the current distribution (see Figure 7.9)

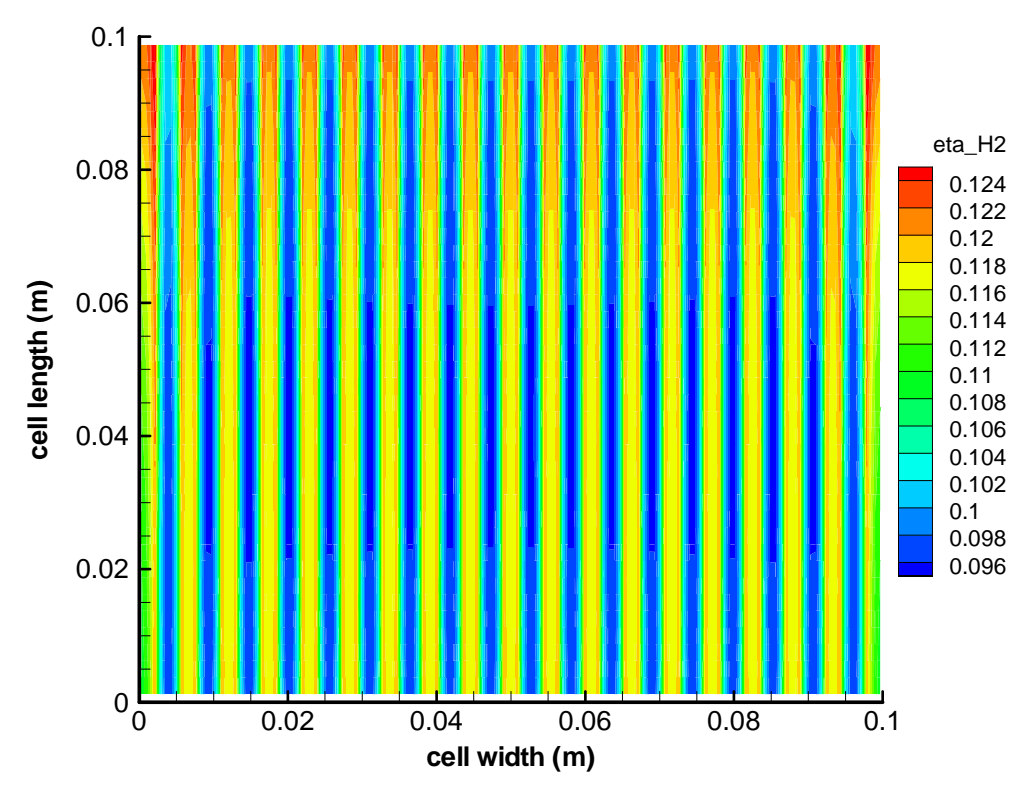

(a) 


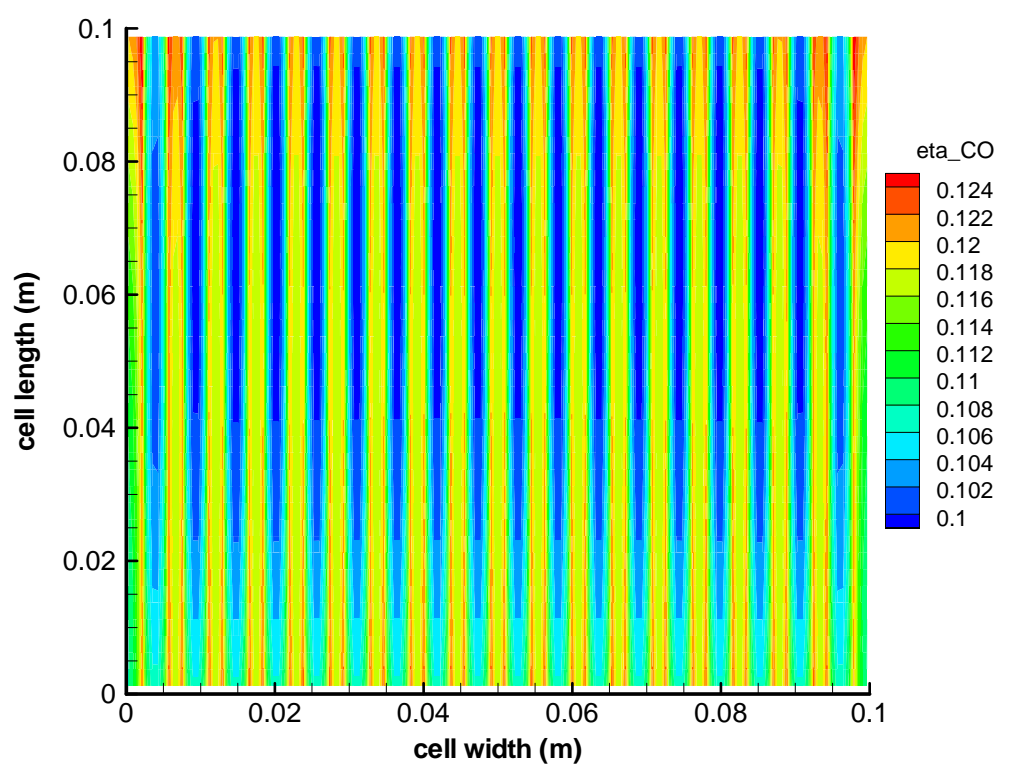

(b)

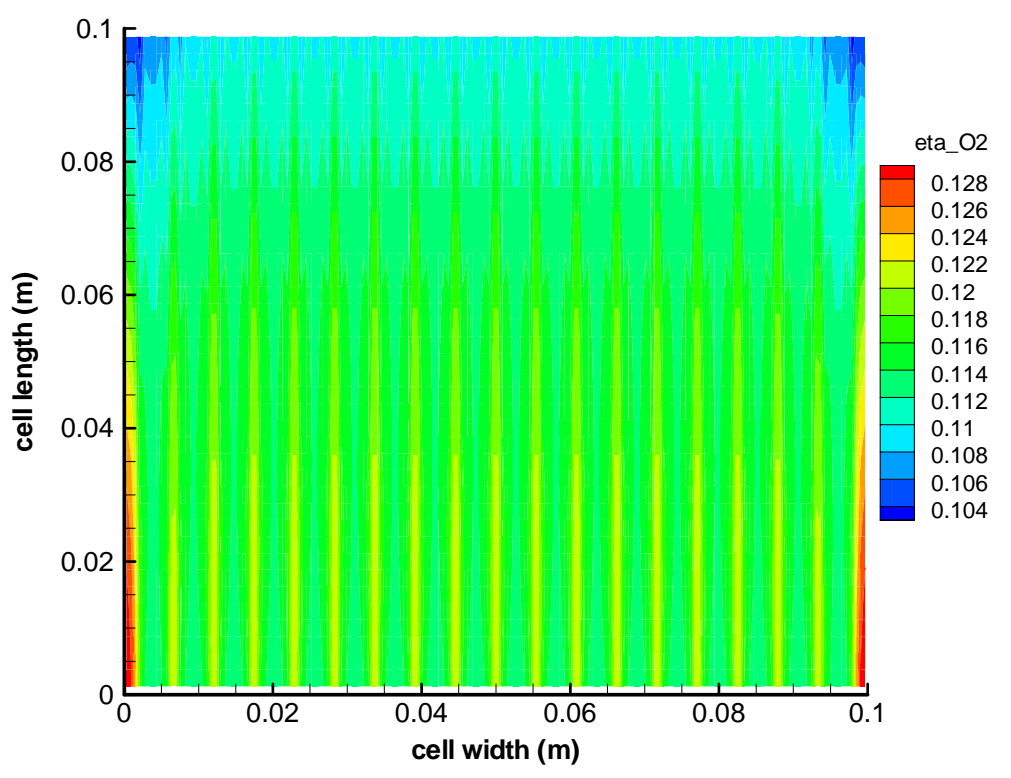

(c)

Figure 7.4 Contours of activation overpotentials at the electrode-electrolyte interface for (a) hydrogen oxidation, (b) carbon monoxide oxidation and (c) oxygen reduction 


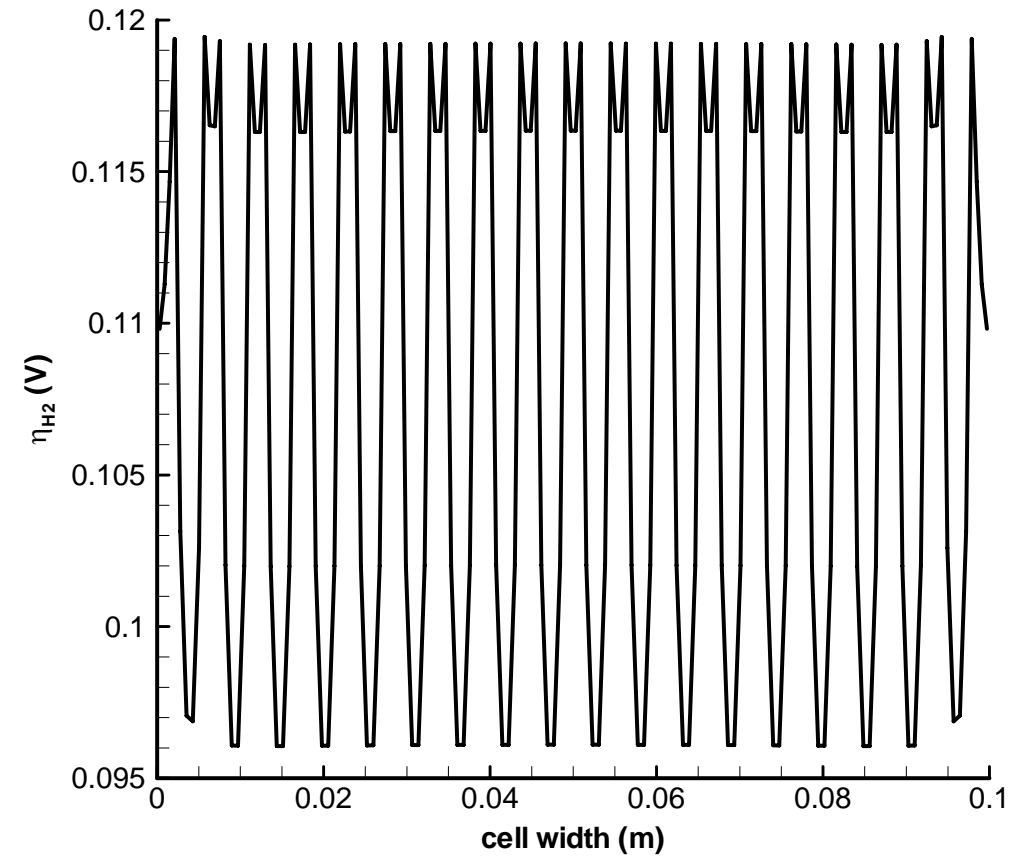

Figure 7.5 Hydrogen activation overpotential along the width of the cell at the middle of the cell

In Figure 7.6, the temperature contours at the anode-electrolyte interface are shown, where clearly it can be seen that the cell temperature in most part of the cell is lower than the operating temperature which shows that the endothermic methane reforming reaction proceeds fast enough to cool down the cell by about $7 \mathrm{~K}$ in the inlet section. As the gases flow along the cell length, the cell heats up slowly, which is a result of the ohmic heating and the exothermic water gas shift reaction. Only in about the last $20 \%$ of the cell length, the cell temperature is higher than the operating temperature. 


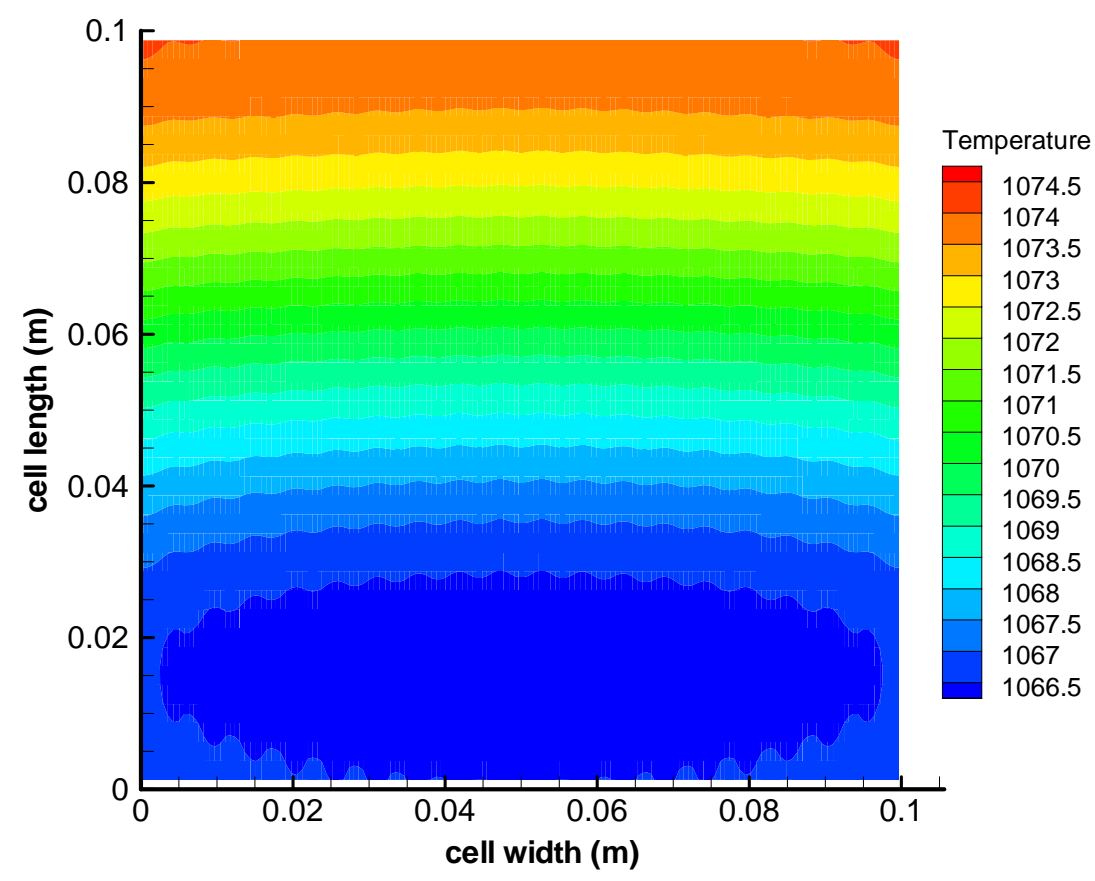

Figure 7.6 Temperatures contours at the anode electrolyte interface of a planar cell running on $30 \%$ pre-reformed methane at $1073 \mathrm{~K}\left(800^{\circ} \mathrm{C}\right)$

The temperature variation along the flow direction inside different layers of the cell at a location near the center of the cell are shown in Figure 7.7 where a temperature decrease is observed in all of the components near the inlet section of the gases. The hotter components near the inlet are the air channel, fuel channel, and cathode and anode current collectors. The cathode, electrolyte and anode are the colder components near the inlet because the endothermic methane reforming reaction proceeds fast in the anode electrode causing the cell to cool down. The similar temperature in the PEN structure is due to the fact that the electrolyte and cathode are thinner than the anode and close to the latter. Near to the outlet, all the components, except the air channel, have basically the same temperature and no more than one degree higher than the operating temperature which shows that the cell operation can be sustained itself without external heating of the exhausted fuel stream allowing direct recycling. The temperature increase close to the outlet is a consequence of a larger net ohmic and entropic heat than the net reforming heat. These results show a qualitative agreement with the data reported by Nikooyeh et al. [14] and Wang et al. [31]. 


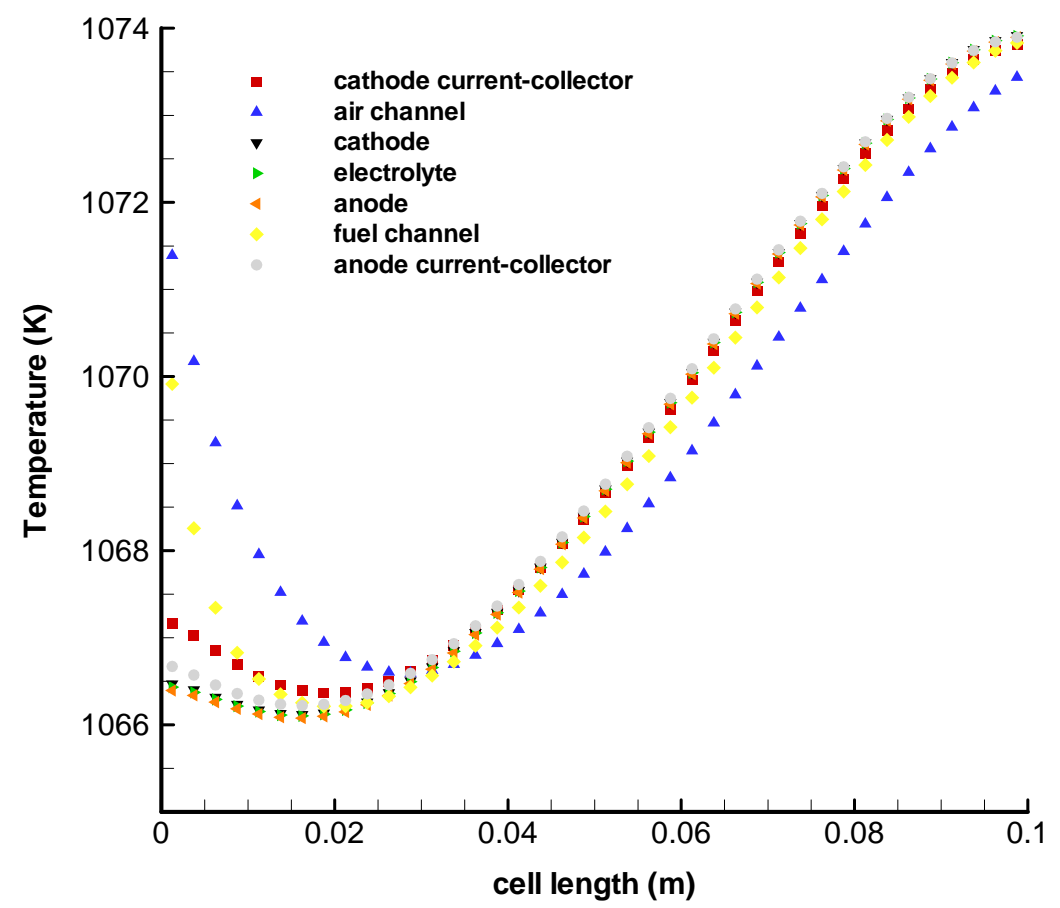

Figure 7.7 Temperature of the cell components in a plane that passes through one of the center channels along the cell flow direction

The temperature contours in planes along the cell length and thickness directions, cutting through a center channel and a center rib are shown in Figure 7.8. It can be seen that the temperature inside the channels is lower after about the first half of the cell length than the other cell components due to convection of the gas streams.

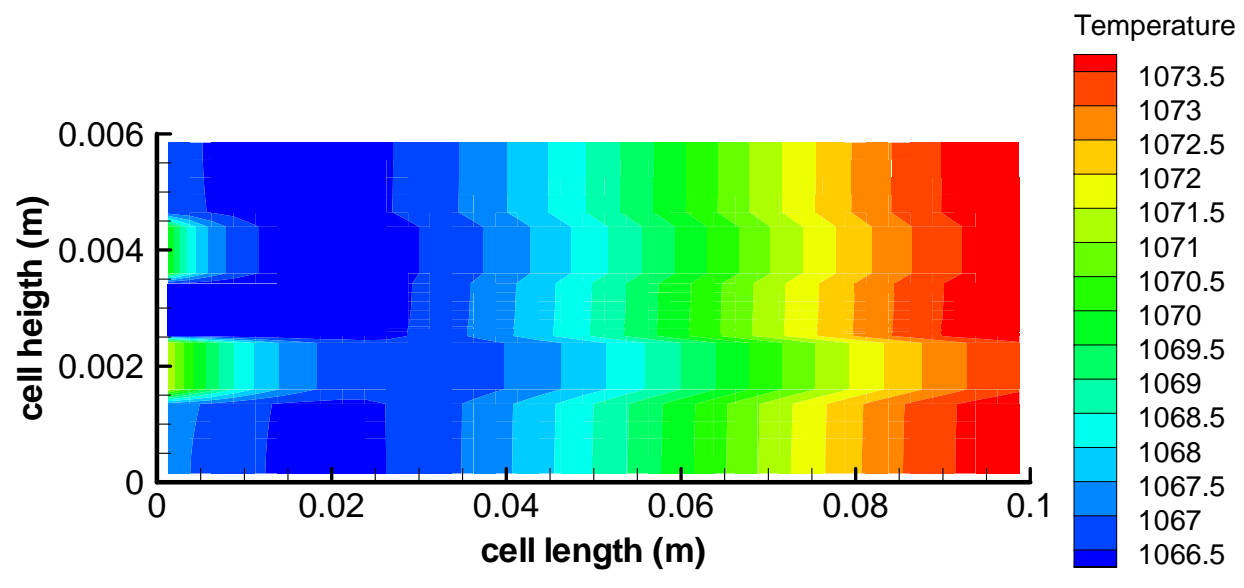

(a) 


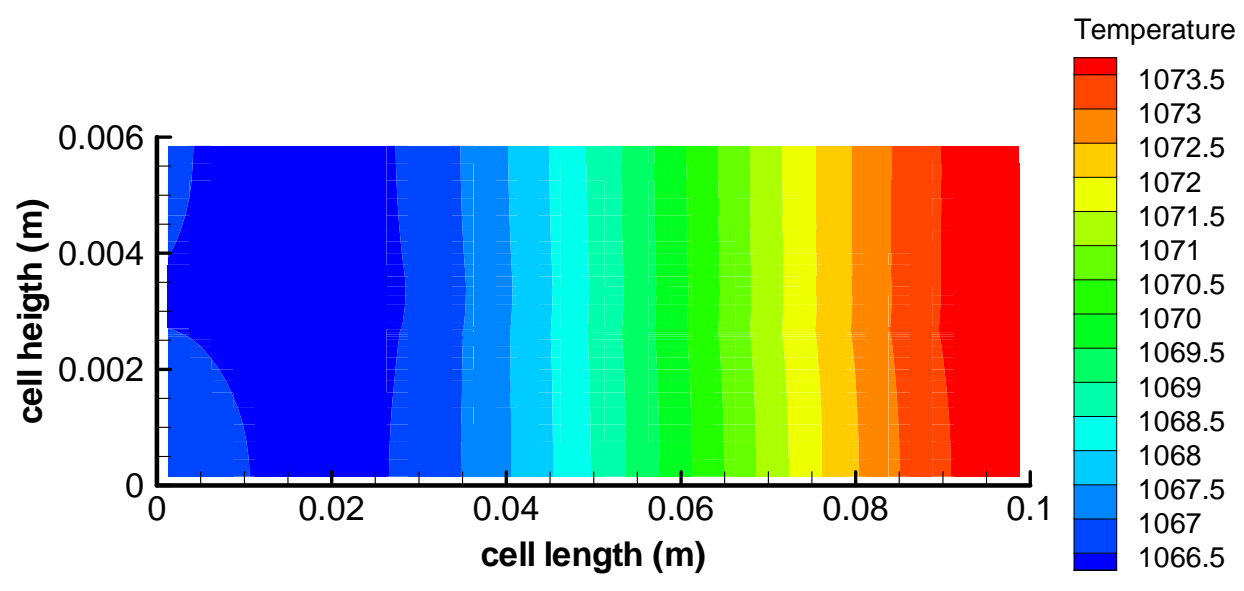

(b)

Figure 7.8 Temperature contours along the flow direction and thickness of the cell (a) in a plane through a center channel and (b) in a plane through the center rib

The distributions of the current density supported by hydrogen and carbon monoxide at the anode-electrolyte interface are shown in Figure 7.9. It is evident that the current density produced from hydrogen oxidation is larger than that supported by carbon monoxide. The current driven by hydrogen decreases along the cell length whereas that produced from carbon monoxide oxidation increases slightly, however, the hydrogen current is always larger than the carbon monoxide current over the whole anode-electrolyte interface as shown in Figure 7.9. The ratio of the hydrogen current to the carbon monoxide current varies from about 24 to 6 from inlet to outlet as shown in Figure 7.10. 


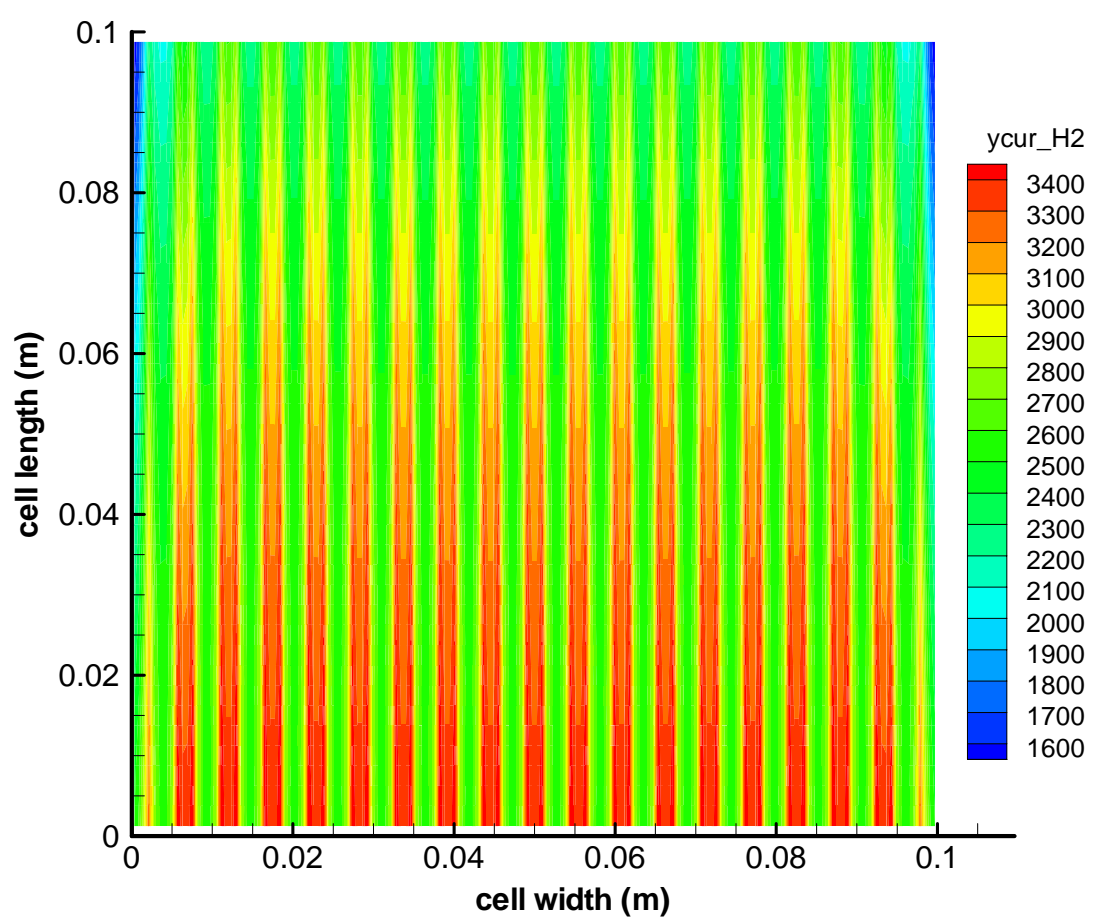

(a)

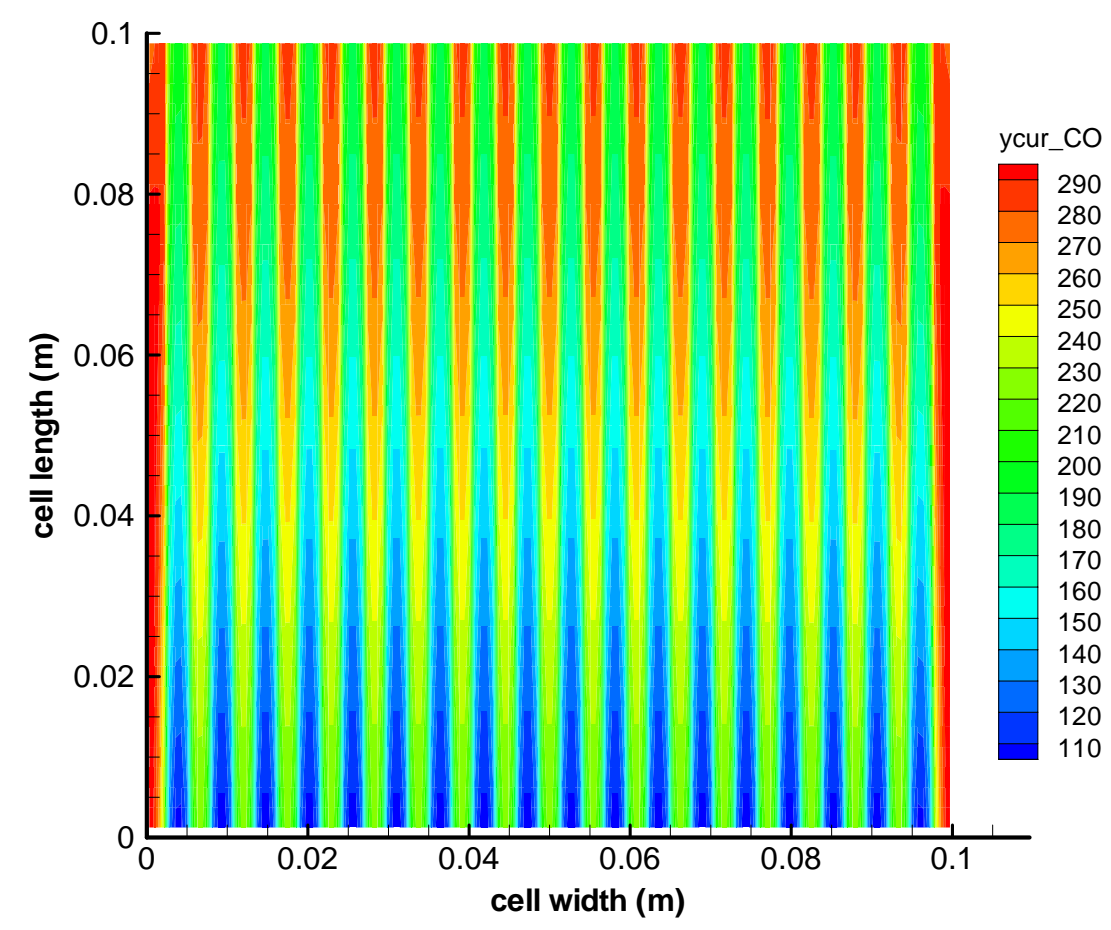

(b)

Figure 7.9 Current density $\left(\mathrm{A} / \mathrm{cm}^{2}\right)$ distributions at the anode-electrolyte interface supported by (a) hydrogen and (b) carbon monoxide 


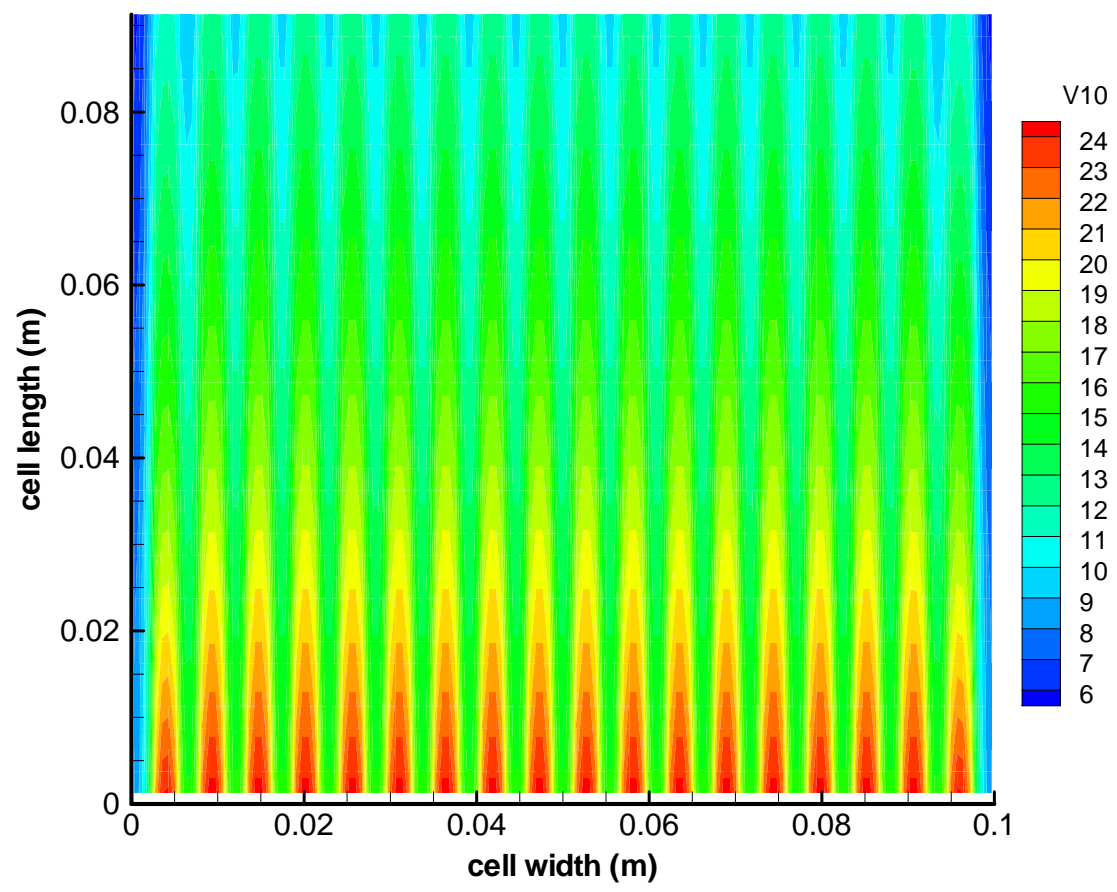

Figure 7.10 Ratio of the hydrogen current to the carbon monoxide current at the anode-electrolyte interface 


\section{Chapter 8}

\section{CONCLUSIONS AND FUTURE WORK}

\subsection{Conclusions}

An existing code developed in-house, DREAM-SOFC, capable of simulating the performance of SOFCs operating on wet hydrogen was enhanced by extending its capabilities to model the performance of SOFCs running on variety of fuel mixtures such as coal syngas, natural gas, etc. For this, several models were developed for phenomena specific to multi-component fuel mixtures such as transport, chemistry and chemical kinetics inside a Ni-YSZ anode, and the models were implemented in the computational frame work.

Some the issues solved in this study include the implementation of an electrochemistry model that considers simultaneous electrochemical oxidation of hydrogen and carbon monoxide. Besides, this model is capable to predict the splitting of the total current between current supported by hydrogen and carbon monoxide as part of the solution and not prescribed a priori. The electrochemistry model was also used along with a detailed surface reaction mechanism and not only with a global reaction mechanism as commonly found in the literature.

Direct electrochemical oxidation of methane was not considered in this study but internal reforming and water gas shift reactions inside the Ni-YSZ anode during the operation of the SOFC were taken into account, where $\mathrm{Ni}$ is an active catalyst for these two reactions. These catalyzed reactions were modeled through two different mechanisms; a global mechanism consisting of two reversible reactions, the methane reforming and the water gas shift reactions and a detailed surface reaction mechanism consisting of 42 reactions, 6 gas species and 12 surface species. 
The chemical kinetics model of the global mechanism consisting of the methane reforming and water gas shift reactions was verified by comparing the three-dimensional calculations of the present study with one-dimensional results published in the literature.

The multi-component diffusion process inside the porous anode electrode was accurately modeled including the Knudsen diffusivity, molecular diffusivity, binary diffusivity, porosity and tortuosity of the porous media. The transport of the species was modeled inside composite two-layered electrodes which consist of the support layer and the interlayer or active layer. The anode electrode was a composite Ni-YSZ electrode whereas the cathode was a composite of LSM-YSZ in the interlayer and the current collector was composed of LSM.

The extended model was calibrated/validated by adjusting the pre-exponential coefficient of the exchange current densities for hydrogen, carbon monoxide and oxygen in order to closely predict numerically the activation region of the V-I curve obtained experimentally at West Virginia University for a button cell running on simulated clean syngas operating at $800^{\circ} \mathrm{C}$. The prediction of a similar cell operating on wet hydrogen was not satisfactory when compared with the experiments because of an evident leakage loss observed during the experimental testing. In the developed computational tool, a model to account for leakage losses was not considered.

The numerical uncertainty for the cell operating on wet hydrogen was assessed using a grid convergence study resulting in small errors on the cell potential as well as on the overpotentials. Although the ohmic heating showed a considerably large uncertainty, its effect on the other variables such as cell voltage, overpotentials, and species concentrations was negligible.

A parametric analysis of the computational model was performed in which the effect of: operating temperature, fuel stream composition, activation energy of the carbon monoxide exchange current density and neglecting the carbon monoxide electrochemical oxidation were analyzed. 
The enhancement of the cell performance with increasing temperature was due to a reduction in the overpotentials. Other than that, it was observed that the operating temperature has an important effect on the splitting of the total current between hydrogen and carbon monoxide currents. Also the direction of the water-gas shift reaction was strongly influenced by the operating temperature thus affecting the balance of hydrogen versus carbon monoxide.

On the other hand increasing the fuel concentration (sum of hydrogen and carbon monoxide) increased the cell performance as well as the limiting current. The syngas fuel concentration did not show any significant effect on the splitting of the total current between hydrogen and carbon monoxide when the ratio of hydrogen concentration to carbon monoxide concentration is kept constant, however the direction of the water-gas shift reaction was influenced strongly by the syngas composition. Under other operating fuel compositions, the splitting of the total current shows a strong dependence on fuel concentration. Also, the model predicts only one limiting current when the cell runs on coal syngas even though simultaneous electrochemical oxidation of hydrogen and carbon monoxide is considered. The same is true irrespective of whether the inlet fuel stream composition is close to equilibrium or not. Apparently, the water gas shift reaction is fast enough that equilibrates these two fuels.

It was found that, for a button cell operating on coal syngas fuel, the predicted cell performance decreased about $5 \%$ at the maximum power density conditions when $\mathrm{CO}$ electrochemistry is neglected. In addition, the dynamics of the water gas shift reaction are quite different for cases with and without carbon monoxide electrochemistry. The results allude to the possibility that neglecting carbon monoxide electrochemistry may introduce errors in the predictions of concentration fields, heat generation inside the cell and its distribution.

When an arbitrary activation energy of $100 \mathrm{~kJ} / \mathrm{mol}$ for the carbon monoxide oxidation reaction as opposed to a negligible small activation energy is used, the predicted performance of the cell is affected negligibly, however, the predicted splitting of the total 
current between the current supported by hydrogen and the current driven by carbon monoxide changes considerably qualitatively and quantitatively.

Finally, operation of a planar cell running on $30 \%$ pre-reformed methane was demonstrated. The simulated anode-supported planar cell consisted of eighteen gas flow channels on both anode and cathode sides. Under co-flow arrangement, operation of the planar cell at $800^{\circ} \mathrm{C}$ on pre-reformed methane showed that cell cools down about 7 degrees near the inlet of the gases and at the outlet the gasses only heat up about 2 degrees with respect to the operating temperature. The major part of the total current was supported by hydrogen over the whole active surface area. The ratio between the current driven by hydrogen and carbon monoxide varied from 24 near the inlet section of the gasses to 6 towards the outlet of the planar cell.

\subsection{Future Work}

Following are some of the recommended activities that could be undertaken in future to further enhance the capabilities of DREAM-SOFC and/or use it as an effective research tool.

- Modeling the transport of fuel contaminants inside the SOFC which could eventually lead to the development of a model to predict cell performance degradation

- Development of an empirical-physical model based on experimental data to predict the performance degradation of SOFCs due to fuel contaminants

- Implementation of a kinetic model for electrochemistry with detailed reaction mechanisms to model the electrochemical oxidation of hydrogen and electrochemical reduction of oxygen at the active interfaces 
- Modeling of SOFC performance operating on other alternative fuels such as, biogas, methanol, biomass, etc.

- Parallelization of the computational tool DREAM-SOFC in order to simulate cell stacks of planar SOFCs which are used in real life for energy conversion

- Inclusion of heat transfer processes by radiation since the importance of this phenomenon on the performance of SOFCs has not been well established though SOFCs operate at high temperature for radiation to be a significant mode of heat transfer

- Devise a numerical scheme to accelerate convergence when solving stiff equations particularly when detailed reaction mechanisms are used in order to obtain detailed information inside the electrodes. This will allow fast enough calculations that would be needed for cell performance degradation predictions

- Consideration of convection inside the porous electrodes especially when accurate and detailed species concentration distributions may be needed 


\section{REFERENCES}

[1] EG\&G Technical Services, I., Fuel Cell Handbook. 7th. ed. U.S. Department of Energy, Office of Fossil Energy, National Energy Technology Laboratory, 2004.

[2] I. Celik, S.R.P., A Modular Approach to SOFC Modeling. Final report submitted to Oak Ridge Associated Universities (ORAU), Oak Ridge, TN, 2003.

[3] Pakalapati, S.R., Numerical Study of Current Distribution Inside the Cathode and Electrolyte on a Solid Oxide Fuel Cell. Masters Thesis, Mechanical and Aerospace Engineering Department, West Virginia Univeristy, Morgantown, WV, USA, 2003.

[4] Pakalapati, S.R., A new reduced order model for solid oxide fuel cells, in Mechanical and Aerospace Engineering Department, Ph.D. Thesis, West Virginia University: Morgantown, WV, 2006.

[5] R. S. Gemmen, J.T., On the mechanism and behavior of coal syngas transport and reaction within the anode of a solid oxide fuel cell. Journal of Power Sources, 2006. 161: p. 1084-1095.

[6] R. Suwanwarangkul, E.C., E. Entchev, S. Charojrochkul, M. D. Pritzker, M. W. Fowler, P. L. Douglas, S., Experimental and modeling study of solid oxide fuel cell operating with syngas fuel. Journal of Power Sources, 2006. 161: p. 308-322.

[7] Y. Patcharavorachot. A. Arpornwichanop, A.C., Electrochemical study of a planar solid oxide fuel cell: Role of support structures. Jounal of Power Sources, 2008. 177: p. 254-261.

[8] P. Aguiar, C.S.A., N. P. Brandon, Anode-supported intermediate temperature direct internal reforming solid oxide fuel cell. I: model-based steady-state performance. Jounal of Power Sources, 2004. 138: p. 120-136.

[9] M. M. Hussain, X.L., I. Dincer, Mathematical modeling of planar solid oxide fuel cells. Journal of Power Sources, 2006. 161: p. 1012-1022.

[10] M. Ni, D.Y.C.L., M. K. H. Leung, Modeling of methane fed solid oxide fuel cells: Comparison between proton conducting electrolyte and oxygen ion conducting electrolyte. Jounal of Power Sources, 2008. 183: p. 133-142.

[11] H. Zhu, R.J.K., V. M. Janardhanan, O. Deutschmann, D. G. Goodwin, Modeling Elementary Heterogeneous Chemistry and Electrochemistry in Solid-Oxide Fuel Cells. Journal of the Electrochemical Society, 2005. 152: p. A2427-A2440. 
[12] V. M. Janardhanan, O.D., CFD analysis of a solid oxide fuel cell with internal reforming: Coupled interactions of transport, heterogeneous catalysis and electrochemical processes. Journal of Power Sources, 2006. 162: p. 1192-1202.

[13] B. A. Haberman, J.B.Y., Three-dimensional simulation of chemically reacting gas flows in the porous support structure of an integrated-planar solid oxide fuel cell. International Journal of Heat and Mass Transfer, 2004. 47: p. 3617-3629.

[14] K. Nikooyeh, A.A.J., J. M. Hill, 3D modeling of anode-supported planar SOFC with internal reforming. Jounal of Power Sources, 2007. 171: p. 601-609.

[15] G. Goldin, H.Z., R. J. Kee, D. Bierschenk, S. A. Barnett, Multidimensional flow, thermal, and chemical behavior in solid-oxide fuel cell button cells. Jounal of Power Sources, 2009. 187: p. 123-135.

[16] J. Larminie, A.D., Fuel Cell Systems Explained. 2nd ed. 2003, England: John Wiley \& Sons.

[17] R. O'Hayre, S.C., W. Colella, F. B. Prinz, Fuel Cell Fundamentals. 1st. ed. 2006, NJ: John Wiley \& Sons.

[18] http://science.nasa.gov.

[19] M. Ni, M.K.H.L., D. Y. C. Leung, A modeling study on concentration overpotentials of a reversible solid oxide fuel cell. Jounal of Power Sources, 2006. 163: p. $460-466$.

[20] S. H. Chan, K.A.K., Z. T. Xia, A complete polarization model of a solid oxide fuel cell and its sensitivity to the change of cell component thickness. Jounal of Power Sources, 2001. 93: p. 130-140.

[21] W. Lehnert, J.M., F. Thom, Modelling of gas transport phenomena in SOFC anodes. Journal of Power Sources, 2000. 87: p. 57-63.

[22] F. P. Nagel, T.J.S., S. M. A. Biollaz, S. Stucki, Charge, mass and heat transfer interactions in solid oxide fuel cells operated with different fuel gases-A sensitivity analysis. Jounal of Power Sources, 2008. 184: p. 129-142.

[23] F. P. Nagel, T.J.S., S. M. A. Biollaz, A. Wokaun, Performance comparison of planar, tubular and Delta8 solid oxide fuel cells using a generalized finite volume model. Jounal of Power Sources, 2008. 184: p. 143-164.

[24] S. Nagata, A.M., T. Kato, Y. Kasuga, Numerical analysis of output characteristics of tubular SOFC with internal reformer. Journal of Power Sources, 2001. 101: p. 60-71. 
[25] S. Lee, J.B., S. Lim, J. Park, Improved configuration of supported nickel catalysts in a steam reformer for effective hydrogen production from methane. Journal of Power Sources, 2008. 180: p. 506-515.

[26] E. S. Hecht, G.K.G., H. Zhu, A. M. Dean, R. J. Kee, L. Maier, O. Deutschmann, Methane reforming kinetics within a Ni-YSZ SOFC anode support. Applied Catalysis A: General, 2005. 295: p. 40-51.

[27] T. Nishino, H.I., K. Suzuki, Comprehensive Numerical Modeling and Analysis of a Cell-Based Indirect Internal Reforming Tubular SOFC. Journal of Fuel Cell Science and Technology, 2006. 3: p. 33-44.

[28] F. Arpino, N.M., Numerical simulation of mass and energy transport phenomena in solid oxide fuel cells. Energy (2008), doi:10.1016/j.energy.2008.08.025, 2008.

[29] F. J. Gardner, M.J.D., M. P. Brandon, M. N. Pashley, M. Cassidy, SOFC technology development at Rolls-Royce. Jounal of Power Sources, 2000. 86: p. 122-129.

[30] G. Wang, Y.Y., H. Zhang, W. Xia, 3-D model of thermo-fluid and electrochemical for planar SOFC. Jounal of Power Sources, 2007. 167: p. 398-405.

[31] Q. Wang, L.L., C. Wang, Numerical study of thermoelectric characteristics of a planar solid oxide fuel cell with direct internal reforming of methane. Journal of Power Sources, 2008.

[32] Y. Matsuzaki, I.Y., Electrochemical Oxidation of H2-H2O-CO-CO2 System at the Interface of a Ni-YSZ Cermet Electrode and YSZ Electrolyte. Journal of the Electrochemical Society, 2000. 147: p. 1630-1635.

[33] A. L. Dicks, K.D.P., A. Siddle, Intrinsic reaction kinetics of methane steam reforming on a nickel/zirconia anode. Journal of Power Sources, 2000. 86: p. 523530.

[34] A. Weber, B.S., A. C. Müller, D. Herbstritt, E. Ivers-Tiffée, Oxidation of H2, CO and methane in SOFCs with Ni/YSZ-cermet anodes. Solid State Ionics, 2002. 152153: p. 543-550.

[35] K. Sasaki, Y.H., R. Kikuchi, K. Eguchi, A. Ueno, H. Takeuchi, M. Aizawa, K. Tsujimoto, H. Tajiri, H. Nishikawa, Y. Uchida, Current-Voltage Characteristics and Impedance Analysis of Solid Oxide Fuel Cells for Mixed H2 and CO Gases. Journal of The Electrochemical Society, 2002. 149: p. A227-A233.

[36] Y. Jiang, A.V.V., Fuel Composition and Diluent Effect on Gas Transport and Performance of Anode-Supported SOFCs. Journal of the Electrochemical Society, 2003. 150: p. A942-A951.

[37] F. Zhao, A.V.V., Dependence of polarization in anode-supported solid oxide fuel cells on various cell parameters. Journal of Power Sources, 2005. 141: p. 79-95. 
[38] A. M. Sukeshini, B.H., B. P. Becker, C. A. Stoltz, B. W. Eichhorn, G. S. Jackson, Electrochemical Oxidation of $\mathrm{H} 2, \mathrm{CO}$ and $\mathrm{CO} / \mathrm{H} 2$ Mixtures on Patterned Ni Anodes on YSZ Electrolytes. Journal of the Electrochemical Society, 2006. 153: p. A705A715.

[39] Patankar, S.V., Numerical Heat Transfer and Fluid Flow. Hemisphere Publishing Corporation. 1980.

[40] J. Li, G.C., X. Zhu, H. Tu, Two-dimensional dynamic simulation of a direct internal reforming solid oxide fuel cell. Journal of Power Sources, 2007. 171: p. 585-600.

[41] Achenbach, E., Three-dimensional and time-dependent simulation of a planar solid oxide fuel cell stack. Journal of Power Sources, 1994. 49: p. 333-348.

[42] A. C. Co, S.J.X., V. I. Birss, A Kinetic Study of the Oxygen Reduction Reaction at LaSrMnO3-YSZ Composite Electrodes. Journal of The Electrochemical Society, 2005. 152(3): p. A570-A576.

[43] H. Yakabe, M.H., M. Uratani, Y. Matsuzaki, I. Yasuda, Evaluation and modeling of performance on anode-supported solid oxide fuel cell. Journal of Power Sources, 2000. 86: p. 423-431.

[44] R. B. Bird, W.E.S., E. N. Lightfoot, Transport Phenomena. 2nd ed. John Wiley \& Sons. 2002, NY.

[45] R. C. Reid, J.M.P., T. K. Sherwood, The Properties of Gases and Liquids. 2nd ed. 1987, New York: McGraw-Hill.

[46] F. N. Cayan, S.R.P., F. Elizalde-Blancas, I. B. Celik, On Modeling Multi-component Diffusion Inside the Porous Anode of Solid Oxide Fuel Cells Using Fick'sModel. Journal of Power Sources, 2009. doi:10.1016/j.powsour.2009.03.026.

[47] M. E. Coltrin, R.J.K., F. M. Rupley, E. Meeks, SURFACE CHEMKIN-III: A FORTRAN PACKAGE FOR ANALYZING HETEROGENEOUS CHEMICAL KINETICS AT A SOLID-SURFACE - GAS-PHASE INTERFACE. Report SAND96$8217,1996$.

[48] http://www.cantera.org.

[49] S. Kim, H.M., S. Hyun, J. Moon, J. Kim, H. Lee, Performance and durability of Nicoated YSZ anodes for intermediate temperature solid oxide fuel cells. Solid State Ionics, 2006. 177: p. 931-938.

[50] C. Zhang, W.L., H. Liao, C. Li, C. Coddet, Microstructure and Electrical Conductivity of Atmospheric Plasma-Sprayed LSM/YSZ Composite Cathode Materials. Journal of Thermal Spray Technology, 2007. 16: p. 1005-1010. 
[51] T. Tsai, S.A.B., Effect of LSM-YSZ cathode on thin-electrolyte solid oxide fuel cell performance. Solid State Ionics, 1997. 93: p. 207-217.

[52] Feng Zhao, A.V.V., Dependence of polarization in anode-supported solid oxide fuel cells on various cell parameters. Journal of Power Sources, 2005. 141: p. 79-95.

[53] Achenbach, E., Status of the IEA Benchmark Test I on Stack Modeling. IEAWorkshop, Rome, Italy, 1995.

[54] AIAA, Guide for the Verification and Validation of Computational Fluid Dynamics Simulations. American Institute of Aeronautics and Astronautics, AIAA-G-0771998, Reston, VA, 1998.

[55] Roache, P., Verification and Validation in Computational Science and Engineering. Hermosa, Albuquerque, NM, 1998.

[56] C. Xu, J.W.Z., H. O. Finklea, O. Demircan, M. Gong, X. Liu, The effect of phosphine in syngas on Ni-YSZ anode-supported solid oxide fuel cells. Journal of Power Sources, 2009. doi:10.1016/j.jpowsour.2009.04.044.

[57] Personal communication with Jose A. Escobar-Vargas. 2008.

[58] F. Elizalde-Blancas, S.R.P., J. A. Escobar-Vargas, I. B. Celik, Numerical Evaluation and Comparison of Different Reduced Mechanisms for Predicting the Performance of a SOFFC Operating on Coal Syngas. Proceedings of the 2008 ASME Fluids Engineering Division Summer Conference, Jacksonville, FL, August 10-14, 2008, 2008.

[59] F. Elizalde-Blancas, S.R.P., F. N. Cayan, C. Xu, I. B. Celik, H. O. Finklea, J. W. Zondlo, A Full 3D Computational Model for SOFC Running on Syngas. Submitted to Journal of Fuel Cells Science and Technology, 2009.

[60] H. Zhu, R.J.K., A general mathematical model for analyzing the performance of fuel-cell membrane-electrode assemblies. Journal of Power Sources, 2003. 117: p. $61-74$.

[61] I. Celik, E.K., D. Parsons, A Reliable Error Estimation Technique for CFD Application. Proceedings of the AVT-147 Symposium on Computational Uncertainty in Military Vehicle Design, December 3-6, 2007 Athens, Greece.

[62] F. Elizalde-Blancas, E.K., I. Celik, Application of Error Scaling Method in Conjunction with GCI. Proceedings of the 3rd Workshop on CFD Uncertainty Analysis, October 23-24, 2008, Lisbon, Portugal, 2008.

[63] I. Celik, J.L., Assessment of numerical uncertainty for the calculations of turbulent flow over a backward facing step. International Journal for Numerical Methods in Fluids, 2005. 49: p. 1015-1031. 
[64] I. Celik, J.L., G. Hu, C. Shaffer, Limitations of Richardson extrapolation and some possible remedies. ASME Journal of Fluids Engineering, 2005. 127: p. 795-805.

[65] M. A. R. Sharif, Z.G., A smoothing algorithm for the higher-order derivative terms in a non-linear $\kappa-\varepsilon$ turbulence model. Progress in Computational Fluid Dynamics, 2002. 2: p. 45-57. 


\section{APpendix A}

\section{DETAILED SURFACE REACTION MECHANISM}

As another demonstration of the capabilities of the developed code, a detailed surface mechanism is implemented for chemical kinetics inside the anode and preliminary results were obtained. The detailed surface reaction mechanism consisting of 42 reactions, 6 gas species and 12 surface species proposed by Hecht et al. [26] is a mechanism which was developed to emulate the methane reforming and water gas shift reaction kinetics in a NiYSZ solid oxide fuel cell. This mechanism is presented in Table A.1 along with its kinetic information. The parameters provided in Table A.1 are the Arrhenius parameters. Reactions 1, 3, 5, 7, 9 and 11 represent the interaction between the gas phase species and the Ni. These reactions are called adsorption reactions and also known as sticking reactions. Reactions 2, 4, 6, 8, 10 and 12 are the reverse reactions of the adsorption reactions; these reactions represent the desorption of the gas phase species from the surface. The total surface site density considered for this heterogeneous mechanism is $2.6 \times 10^{-9} \mathrm{~mol} / \mathrm{cm}^{2}$ [26].

The case studied with the detailed surface mechanism is of a button cell operating at $800^{\circ} \mathrm{C}$ and supporting a current of $2.2 \mathrm{~A}$. The composition of the fuel supplied to the button cell is that of simulated clean syngas reported in Table 5.4. The value of the parameter 'specific catalyst area' was set as $1 \times 10^{5} \mathrm{~m}^{-1}$ similar in magnitude to that used in [26]. The boundary conditions are exactly the same as used and reported in Chapter 5.

Small time step of $10^{-4} \mathrm{~s}$ compared to time steps of $10^{-3} \mathrm{~s}$ used in the global mechanism was required to obtain stable solutions using this detailed heterogeneous reaction mechanism. Besides, smoothing of the oxygen concentration in the anode was required to get converged solutions. The smoothing on oxygen concentration was performed using the smoothing algorithm proposed by Sharif and Ghu [65]. 
Table A.1 Heterogeneous reaction mechanism for methane reforming and water gas shift reactions on Ni-YSZ electrodes [26]

\begin{tabular}{|c|c|c|c|c|}
\hline & Reaction & A & $\mathrm{n}$ & $E$ \\
\hline 1 & $H_{2}+N i(s)+N i(s) \rightarrow H(s)+H(s)$ & $1.000 \times 10^{-2}$ & 0.0 & 0.00 \\
\hline 2 & $H(s)+H(s) \rightarrow \mathrm{Ni}(s)+\mathrm{Ni}(s)+\mathrm{H}_{2}$ & $5.593 \times 10^{+19}$ & 0.0 & 88.12 \\
\hline 3 & $\mathrm{O}_{2}+\mathrm{Ni}(s)+\mathrm{Ni}(s) \rightarrow O(s)+O(s)$ & $1.000 \times 10^{-2}$ & 0.0 & 0.00 \\
\hline 4 & $\mathrm{O}(s)+\mathrm{O}(s) \rightarrow \mathrm{Ni}(s)+\mathrm{Ni}(s)+\mathrm{O}_{2}$ & $2.508 \times 10^{+23}$ & 0.0 & 470.39 \\
\hline 5 & $\mathrm{CH}_{4}+\mathrm{Ni}(s) \rightarrow \mathrm{CH}_{4}(s)$ & $8.000 \times 10^{-3}$ & 0.0 & 0.00 \\
\hline 6 & $\mathrm{CH}_{4}(\mathrm{~s}) \rightarrow \mathrm{Ni}(\mathrm{s})+\mathrm{CH}_{4}$ & $5.302 \times 10^{+15}$ & 0.0 & 33.15 \\
\hline 7 & $\mathrm{H}_{2} \mathrm{O}+\mathrm{Ni}(s) \rightarrow \mathrm{H}_{2} \mathrm{O}(s)$ & $1.000 \times 10^{-1}$ & 0.0 & 0.00 \\
\hline 8 & $\mathrm{H}_{2} \mathrm{O}(s) \rightarrow \mathrm{Ni}(s)+\mathrm{H}_{2} \mathrm{O}$ & $4.579 \times 10^{+12}$ & 0.0 & 62.68 \\
\hline 9 & $\mathrm{CO}_{2}+\mathrm{Ni}(s) \rightarrow \mathrm{CO}_{2}(s)$ & $1.000 \times 10^{-5}$ & 0.0 & 0.00 \\
\hline 10 & $\mathrm{CO}_{2}(s) \rightarrow \mathrm{Ni}(s)+\mathrm{CO}_{2}$ & $9.334 \times 10^{+7}$ & 0.0 & 28.80 \\
\hline 11 & $\mathrm{CO}+\mathrm{Ni}(s) \rightarrow \mathrm{CO}(s)$ & $5.000 \times 10^{-1}$ & 0.0 & 0.00 \\
\hline 12 & $\mathrm{CO}(s) \rightarrow \mathrm{Ni}(s)+\mathrm{CO}$ & $4.041 \times 10^{+11}$ & 0.0 & 112.85 \\
\hline 13 & $O(s)+H(s) \rightarrow O H(s)+N i(s)$ & $5.000 \times 10^{+22}$ & 0.0 & 97.90 \\
\hline 14 & $O H(s)+N i(s) \rightarrow O(s)+H(s)$ & $2.005 \times 10^{+21}$ & 0.0 & 37.19 \\
\hline 15 & $\mathrm{OH}(s)+\mathrm{H}(s) \rightarrow \mathrm{H}_{2} \mathrm{O}(s)+\mathrm{Ni}(s)$ & $3.000 \times 10^{+20}$ & 0.0 & 42.70 \\
\hline 16 & $\mathrm{H}_{2} \mathrm{O}(s)+\mathrm{Ni}(s) \rightarrow \mathrm{OH}(s)+H(s)$ & $2.175 \times 10^{+21}$ & 0.0 & 91.36 \\
\hline 17 & $\mathrm{OH}(s)+\mathrm{OH}(s) \rightarrow \mathrm{O}(s)+\mathrm{H}_{2} \mathrm{O}(s)$ & $3.000 \times 10^{+21}$ & 0.0 & 100.0 \\
\hline 18 & $\mathrm{O}(s)+\mathrm{H}_{2} \mathrm{O}(s) \rightarrow \mathrm{OH}(s)+\mathrm{OH}(s)$ & $5.423 \times 10^{+23}$ & 0.0 & 209.37 \\
\hline 19 & $O(s)+C(s) \rightarrow C O(s)+N i(s)$ & $5.200 \times 10^{+23}$ & 0.0 & 148.10 \\
\hline 20 & $\mathrm{CO}(s)+\mathrm{Ni}(s) \rightarrow O(s)+C(s)$ & $1.418 \times 10^{+22}$ & -3.0 & 115.97 \\
\hline 21 & $\mathrm{O}(s)+\mathrm{CO}(s) \rightarrow \mathrm{CO}_{2}(s)+\mathrm{Ni}(s)$ & $2.000 \times 10^{+19}$ & 0.0 & 123.60 \\
\hline 22 & $\mathrm{CO}_{2}(s)+\mathrm{Ni}(s) \rightarrow \mathrm{O}(s)+\mathrm{CO}(s)$ & $3.214 \times 10^{+23}$ & -1.0 & 86.50 \\
\hline 23 & $\mathrm{HCO}(s)+\mathrm{Ni}(s) \rightarrow \mathrm{CO}(s)+H(s)$ & $3.700 \times 10^{+21}$ & 0.0 & 0.0 \\
\hline 24 & $\mathrm{CO}(s)+H(s) \rightarrow H C O(s)+\mathrm{Ni}(s)$ & $2.338 \times 10^{+20}$ & -1.0 & 127.98 \\
\hline 25 & $\mathrm{HCO}(s)+\mathrm{Ni}(s) \rightarrow \mathrm{O}(s)+\mathrm{CH}(s)$ & $3.700 \times 10^{+24}$ & -3.0 & 95.80 \\
\hline 26 & $\mathrm{O}(s)+\mathrm{CH}(s) \rightarrow \mathrm{HCO}(s)+\mathrm{Ni}(s)$ & $7.914 \times 10^{+20}$ & 0.0 & 114.22 \\
\hline 27 & $\mathrm{CH}_{4}+\mathrm{Ni}(s) \rightarrow \mathrm{CH}_{3}(s)+\mathrm{H}(s)$ & $3.700 \times 10^{+21}$ & 0.0 & 57.70 \\
\hline 28 & $\mathrm{CH}_{3}(s)+\mathrm{H}(s) \rightarrow \mathrm{CH}_{4}+\mathrm{Ni}(s)$ & $4.438 \times 10^{+21}$ & 0.0 & 58.83 \\
\hline 29 & $\mathrm{CH}_{3}(s)+\mathrm{Ni}(s) \rightarrow \mathrm{CH}_{2}(s)+\mathrm{H}(s)$ & $3.700 \times 10^{+24}$ & 0.0 & 100.0 \\
\hline 30 & $\mathrm{CH}_{2}(\mathrm{~s})+\mathrm{H}(\mathrm{s}) \rightarrow \mathrm{CH}_{3}(\mathrm{~s})+\mathrm{Ni}(\mathrm{s})$ & $9.513 \times 10^{+22}$ & 0.0 & 52.58 \\
\hline 31 & $\mathrm{CH}_{2}(s)+\mathrm{Ni}(s) \rightarrow \mathrm{CH}(s)+\mathrm{H}(s)$ & $3.700 \times 10^{+24}$ & 0.0 & 97.1 \\
\hline 32 & $\mathrm{CH}(s)+\mathrm{H}(s) \rightarrow \mathrm{CH}_{2}(s)+\mathrm{Ni}(s)$ & $3.008 \times 10^{+24}$ & 0.0 & 76.43 \\
\hline 33 & $\mathrm{CH}(s)+\mathrm{Ni}(s) \rightarrow \mathrm{C}(s)+H(s)$ & $3.700 \times 10^{+21}$ & 0.0 & 18.80 \\
\hline 34 & $C(s)+H(s) \rightarrow C H(s)+N i(s)$ & $4.400 \times 10^{+22}$ & 0.0 & 160.49 \\
\hline 35 & $\mathrm{O}(s)+\mathrm{CH}_{4}(s) \rightarrow \mathrm{CH}_{3}(s)+\mathrm{OH}(s)$ & $1.700 \times 10^{+24}$ & 0.0 & 88.30 \\
\hline 36 & $\mathrm{CH}_{3}(s)+\mathrm{OH}(s) \rightarrow \mathrm{O}(s)+\mathrm{CH}_{4}(s)$ & $8.178 \times 10^{+22}$ & 0.0 & 28.72 \\
\hline 37 & $\mathrm{O}(s)+\mathrm{CH}_{3}(s) \rightarrow \mathrm{CH}_{2}(s)+\mathrm{OH}(s)$ & $3.700 \times 10^{+24}$ & 0.0 & 130.10 \\
\hline 38 & $\mathrm{CH}_{2}(s)+\mathrm{OH}(s) \rightarrow \mathrm{O}(s)+\mathrm{CH}_{3}(s)$ & $3.815 \times 10^{+21}$ & 0.0 & 21.97 \\
\hline 39 & $\mathrm{O}(s)+\mathrm{CH}_{2}(s) \rightarrow \mathrm{CH}(s)+\mathrm{OH}(s)$ & $3.700 \times 10^{+24}$ & 0.0 & 126.80 \\
\hline 40 & $\mathrm{CH}(s)+\mathrm{OH}(s) \rightarrow \mathrm{O}(s)+\mathrm{CH}_{2}(s)$ & $1.206 \times 10^{+23}$ & 0.0 & 45.42 \\
\hline 41 & $\mathrm{O}(s)+\mathrm{CH}(s) \rightarrow \mathrm{C}(s)+\mathrm{OH}(s)$ & $3.700 \times 10^{+21}$ & 0.0 & 48.10 \\
\hline 42 & $\mathrm{C}(s)+\mathrm{OH}(s) \rightarrow \mathrm{O}(s)+\mathrm{CH}(s)$ & $1.764 \times 10^{+21}$ & 0.0 & 129.08 \\
\hline
\end{tabular}

For reactions $12,20,21$ and 23 whose reaction constant dependent on the coverage the parameter $\varepsilon_{C O(s)}$ is -50.0 
It is important to note that the results shown in this Appendix are not steady state solutions as shown in Figure A. 1 Time where it can be seen that the Ni coverage in the center of the cell along its thickness changes when the time is $0.5 \mathrm{~s}$ and $1.0 \mathrm{~s}$. Also the cell temperature along the thickness of the cell increases about one degree from $0.75 \mathrm{~s}$ to $1.0 \mathrm{~s}$.

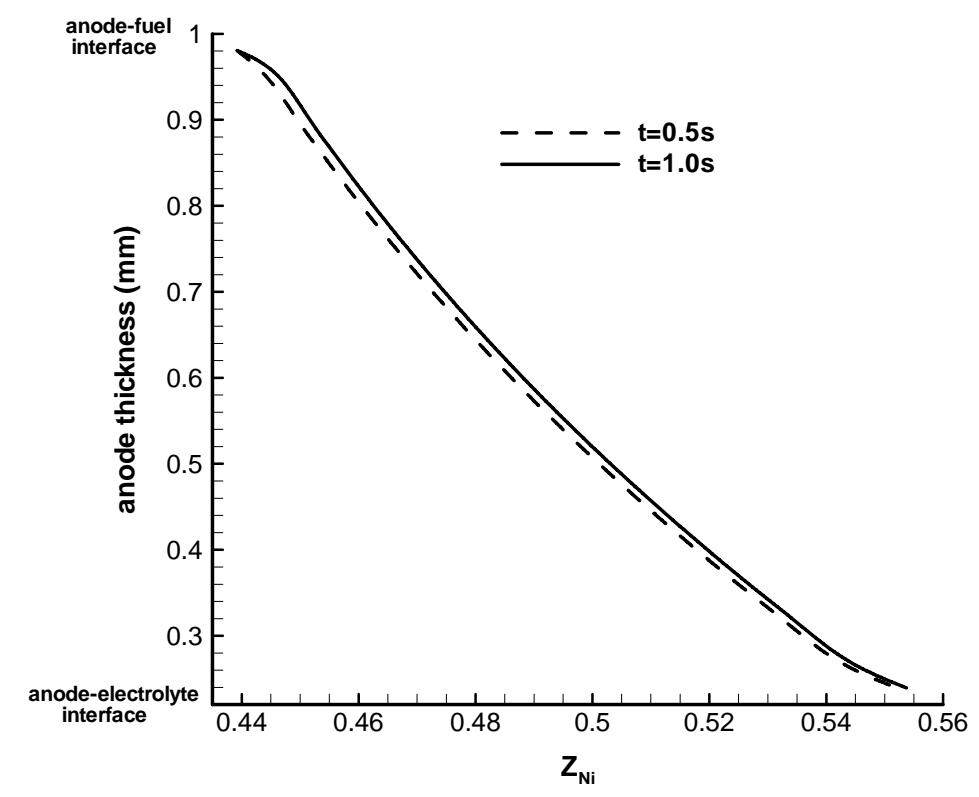

(a)

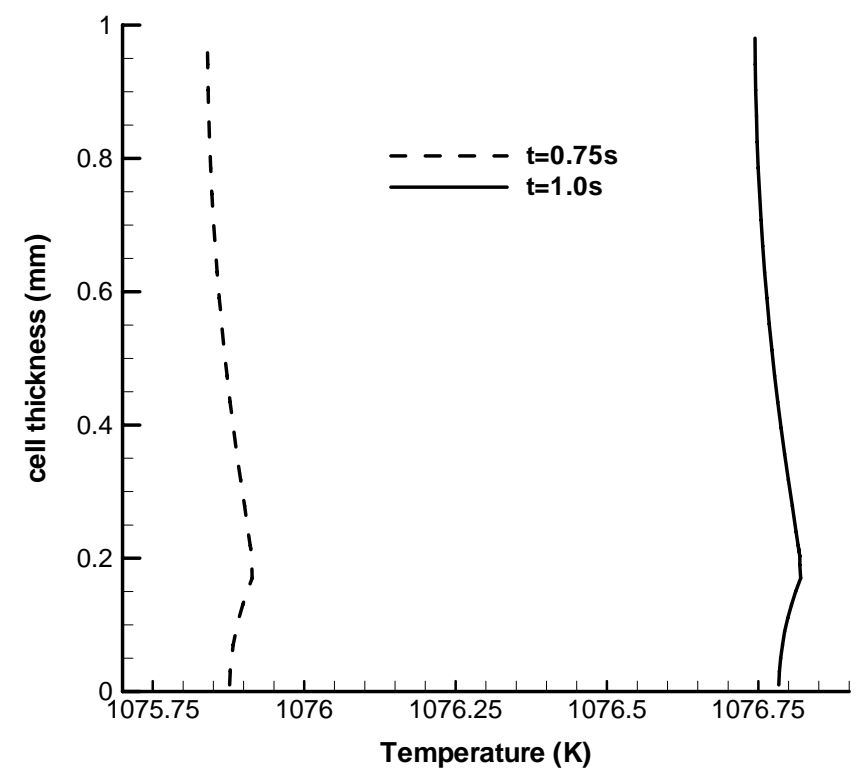

(b)

Figure A. 1 Time variation along the thickness of the anode of (a) Ni coverage and (b) cell temperature 
The coverage for the most abundant surface species at the center of the cell along its longitudinal axis at $\mathrm{t}=1 \mathrm{~s}$ are shown in Figure A.2. The qualitative behavior shown in Figure A.2 is in agreement with the results reported by Hetch et al. [26] and Zhu et al. [11]. Also, a good quantitative agreement is observed when the data reported in Figure A.2 is compared with the data presented by Janardhanan and Deutschmann [12] where it is stated that the most abundant surface species were $\mathrm{CO}$ and $\mathrm{H}$ and that the surface coverage of $\mathrm{H}$ is about $45 \%$ of $\mathrm{CO}$.

In Figure A.3, the two dimensional distributions of coverage for $\mathrm{Ni}$ and the three most abundant surface species are presented. As it can be seen there is basically no gradient in the radial direction.

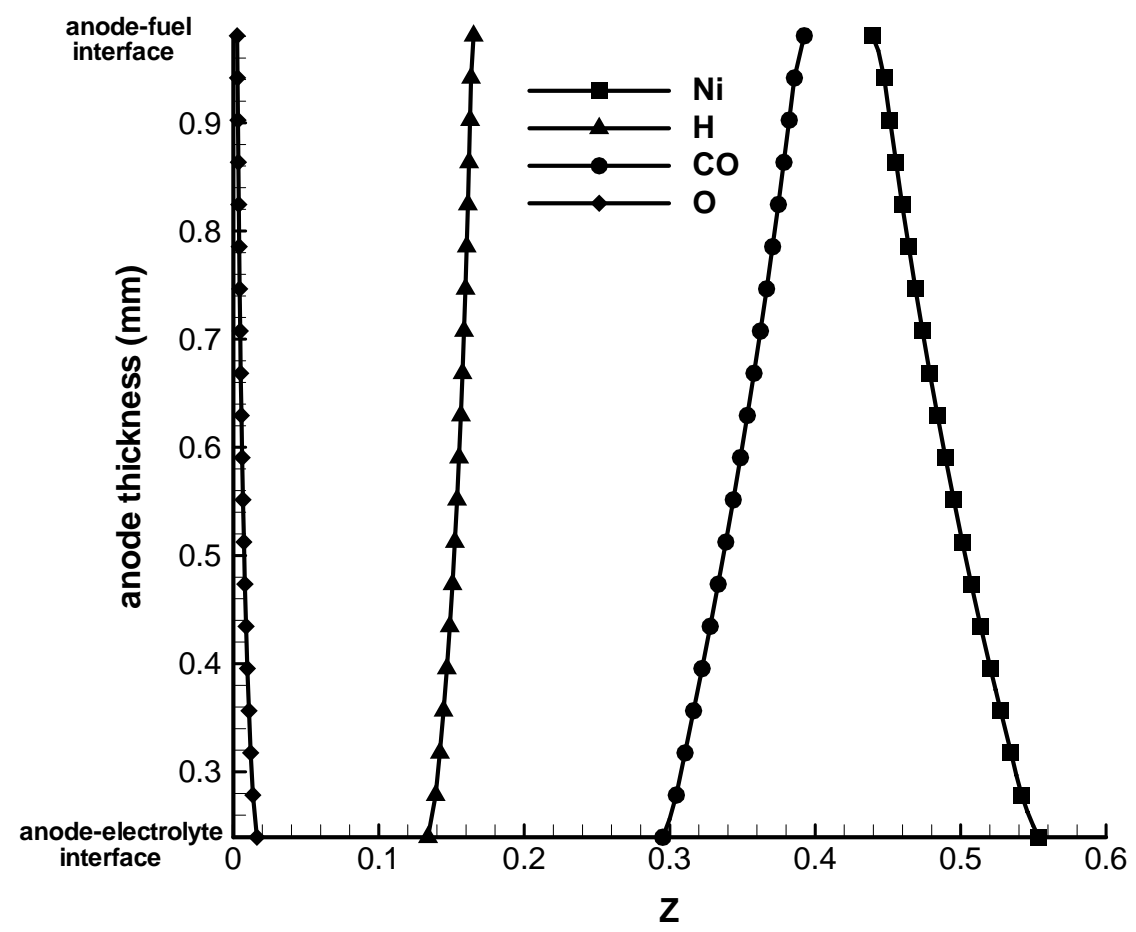

Figure A.2 Coverages of the main surface species along the thickness of the anode of a button cell operating on simulated clean syngas at $\mathrm{t}=1.0 \mathrm{~s}$ 


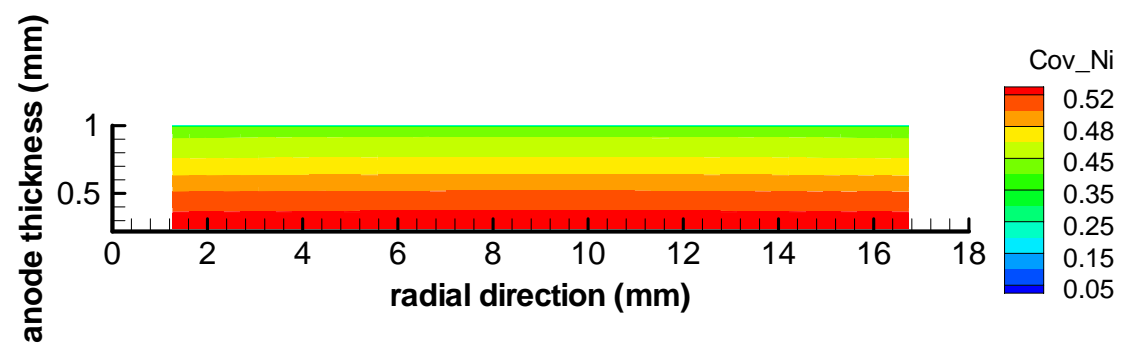

(a)

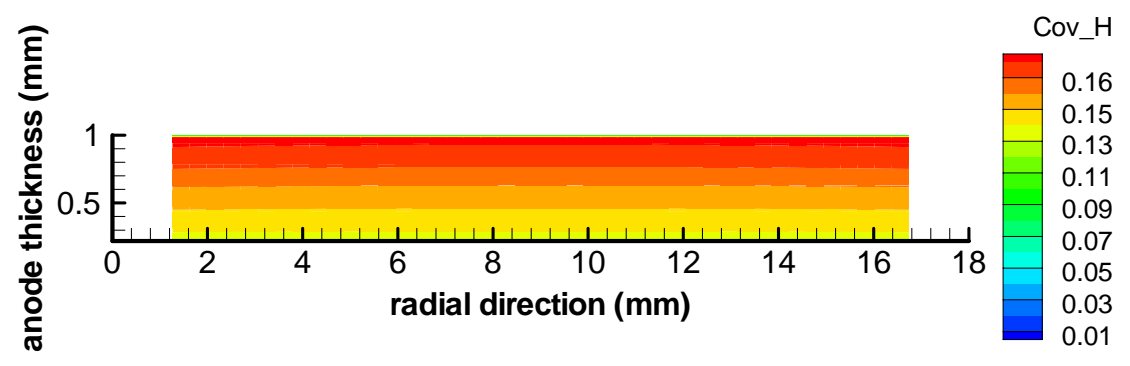

(b)

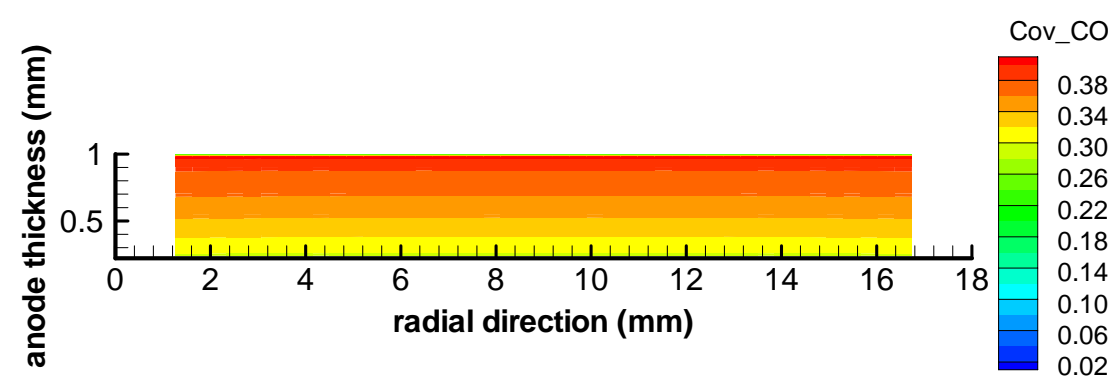

(c)

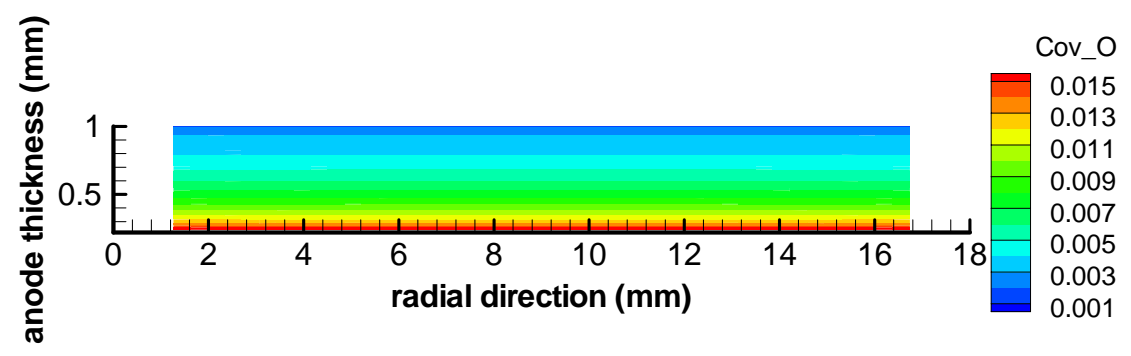

(d)

Figure A.3 Two-dimensional distributions of surface coverages at $t=1.0 \mathrm{~s}$ for (a) $\mathrm{Ni}$, (b) $\mathrm{H}$, (c) CO and (d) $\mathrm{O}$

What is unique in these simulations using the detailed surface reaction mechanism is that the computational model considers simultaneous electrochemical oxidation of hydrogen and carbon monoxide. Besides, the model predicts the splitting of the total current 
between current supported by hydrogen and carbon monoxide. In Figure A.4 the current densities supported by hydrogen and carbon monoxide are plotted in the radial direction of the button cell at $\mathrm{t}=1.0 \mathrm{~s}$, when the cell operates on coal syngas at $800^{\circ} \mathrm{C}$ and supports a total load of $2.2 \mathrm{~A}$. As it can be seen, the current driven by hydrogen is always larger than that supported by carbon monoxide where the ratio between these two currents is about 6.7 (compared to $\sim 5.5$ in the case of the global mechanism) and mostly constant over the anode-electrolyte interface.

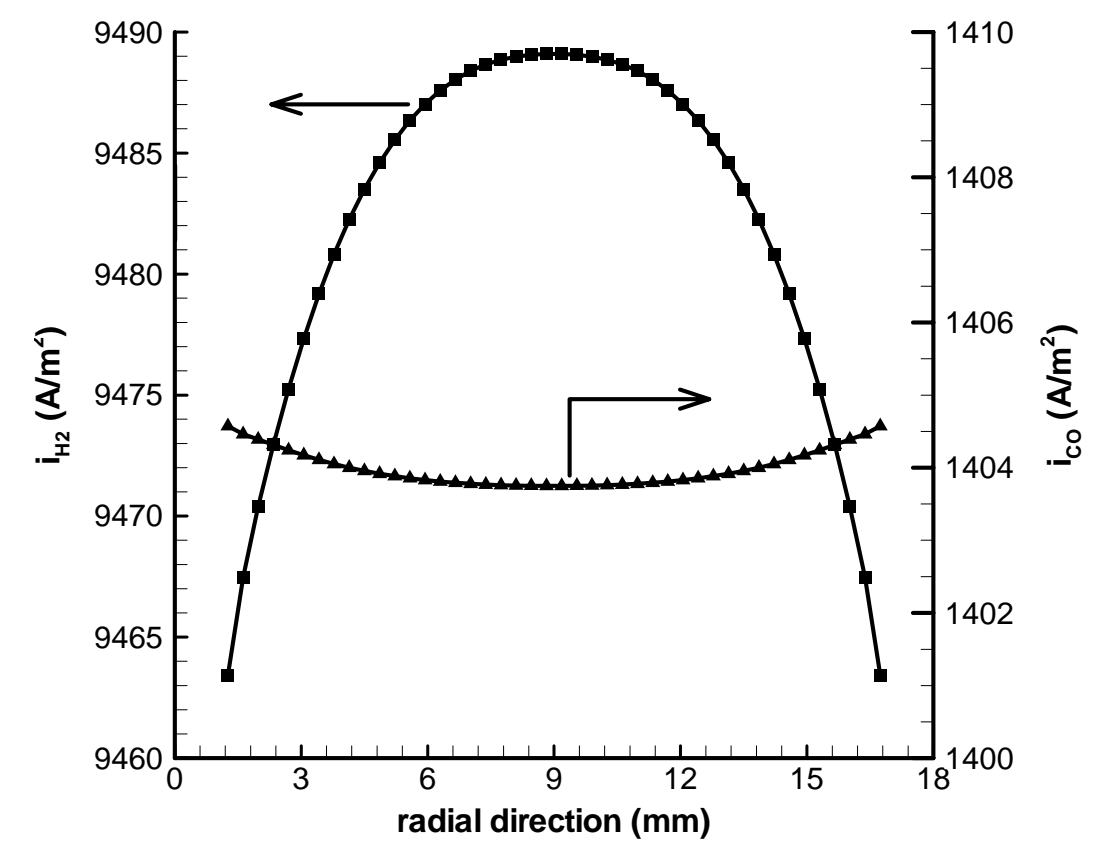

Figure A.4 Splitting of the total current between current supported by hydrogen and carbon monoxide using a detailed surface reaction mechanism

Finally, the performance of the button cell using the detailed surface mechanism is shown in Figure A.5. It is important to note that the V-I curve for the case using the detailed surface mechanism does not represent the steady state solution. The V-I curve shown represents the solution at $\mathrm{t}=0.5 \mathrm{~s}$. As it can clearly be seen, the performance is underestimated at high currents. However, by analyzing the transient behavior, it was found that the cell potential increases slightly as the solution approaches to steady state. Therefore, it is expected to have a better agreement with respect to the experimental performance when the solution reaches steady state. For the case shown in Figure A.5, the 
largest difference in the cell potential at high currents is about $58 \mathrm{mV}$ with respect to the experimental data.

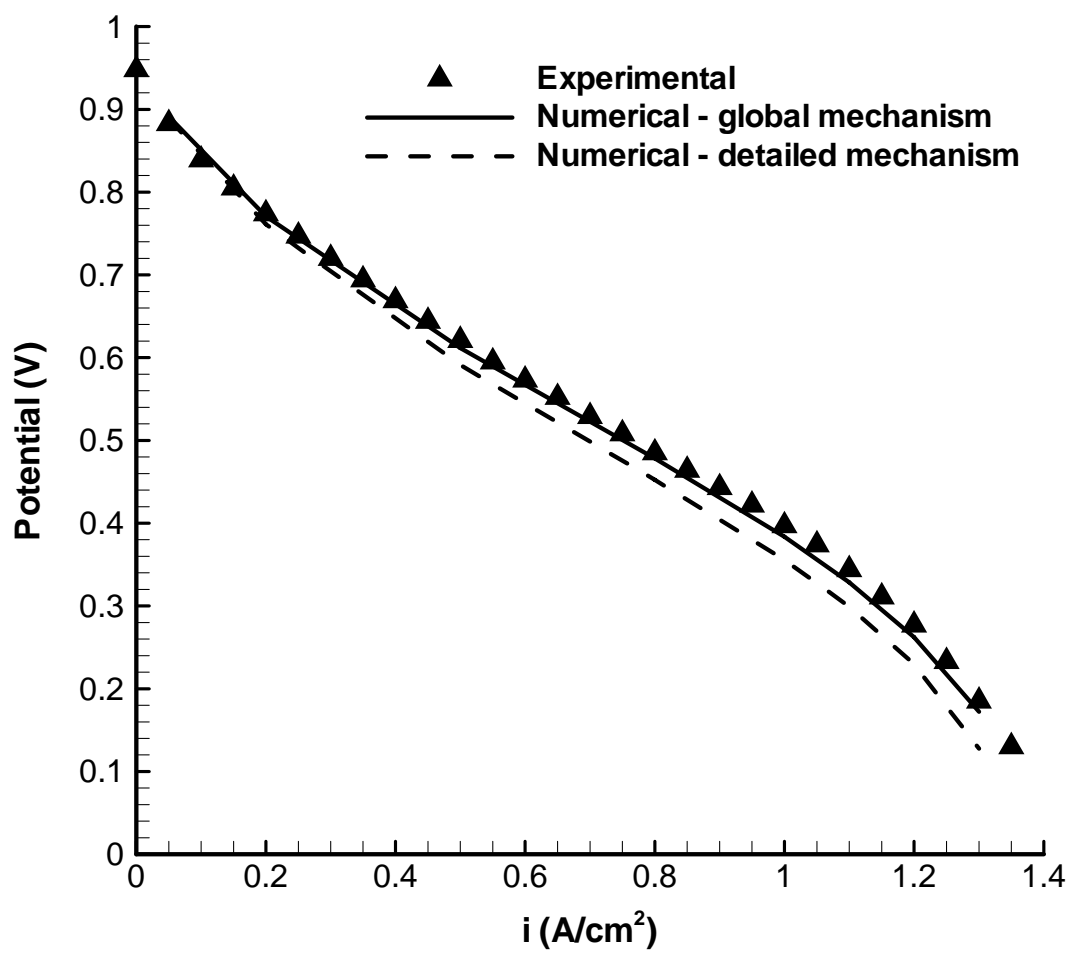

Figure A.5 Predicted performance of a button cell operating on coal syngas at $800^{\circ} \mathrm{C}$ using a detailed surface reaction mechanism 